$$
\begin{aligned}
& 581.947 \\
& \text { k25d } \\
& p t .2-6
\end{aligned}
$$

REGAL

DESCRIPTIONES PLANTARUIV NOVARUN ET WINUS COGNITARUNi

BIDIOGY 


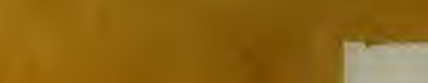

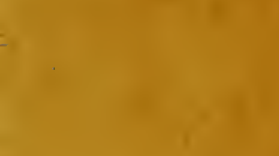
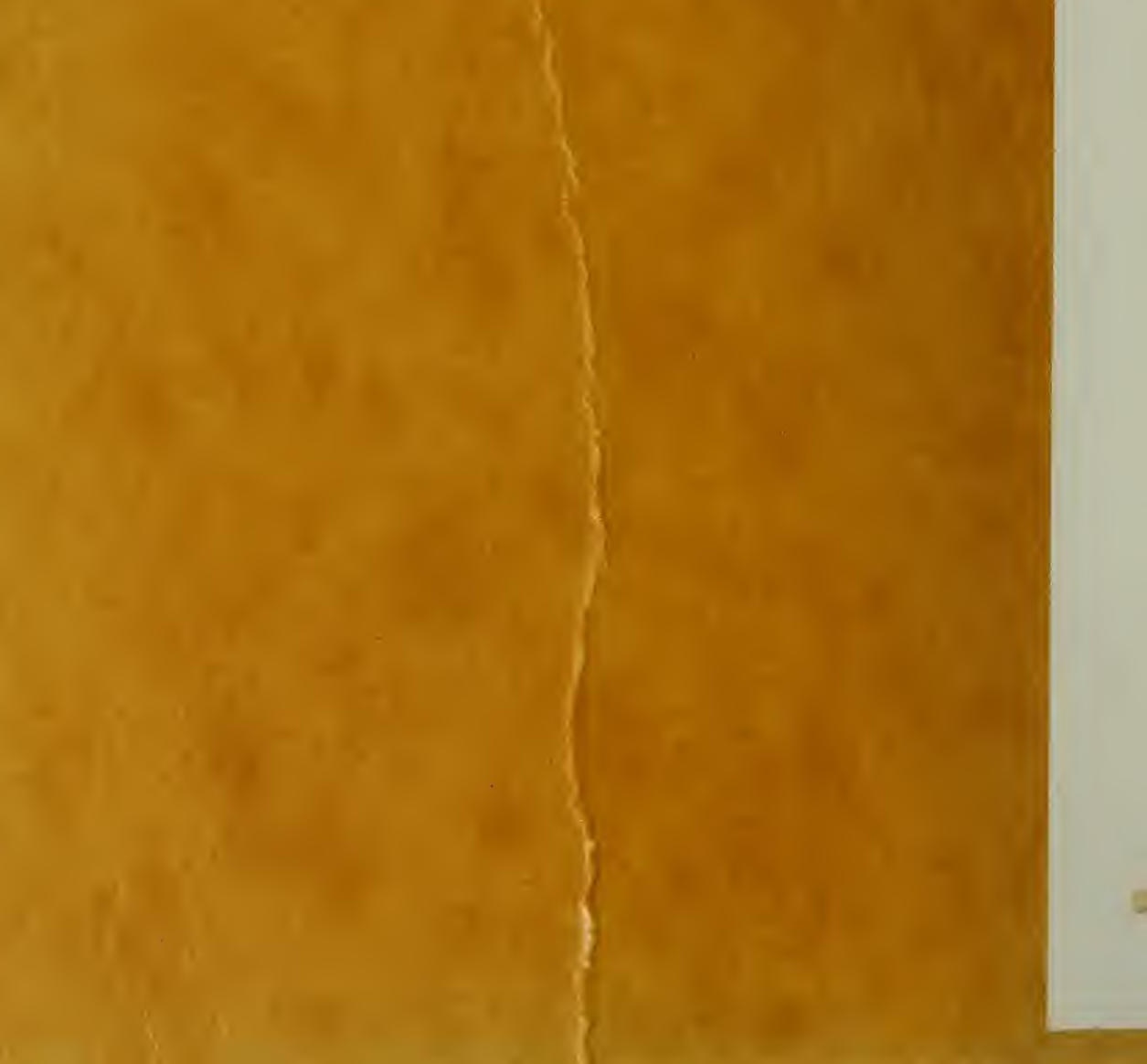
MA: \& an: ne? 


\section{DESCRIPTIONES}

PLANTARUM NOVARUII ET MINUS COGNITARUM IN REGIONIBUS TURKESTANICIS A CL. P. ET 0. FEDSCHENK 0, K 0 R $0 \mathrm{LK} 0 \mathrm{~W}$, KUSCHAKEWICZ ET KRAUSE COLLECTIS.

CUM

adnotationibus ad plantas vivas in horto Imperiali botanico Petropolitano cultas.

FASCICULUS II.

AUCTORE

E. Regel. 
Ізъ сТрудовъ Имтераторскаго С.-Петербургскаго Ботаническаг Садах T. III.

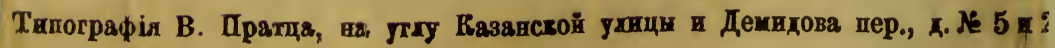




\subsection{7 \\ R2 2 bd \\ PE. 2. - 6}

Descriptiones plantarum novarum et minus cognitarum in regionibus turkestanicis a Cl. P. ot 0. Fedschenko, Korolkow, Kuschakewicz et Krause collectis. Cum adnotationibus ad plantas vivas in horto Imperiali botanico Petropolitano cultas.

Fasciculus II. Auctore E. Regel.

\section{Acantholimon k0Kandense Bge (mss.) *).}

A. (Staticopsis, androsaceum) laete-virens, totum hispidulum; foliis omnibus subulatis undique hispidulis, scapis folio duplo longioribus monostachyis patulo-hispidis, spicis confertis $5-6$ - spiculatis, rhachi pubescente, bracteis glabris interioribus obtusis tubum calycis ( 5 "' longi) subsuperantibus.

In descensu inter Isfairam et Alei leg. 0. Fedschenko. A. alatavico proximum, foliis et indumento distinctum.

\section{Acantholimonertitraeum Bge (mss.).}

A.(Tragacanthina, Erythrostoma) viride, glaberrimum, confertifolium, scapis monostachyis folio brevioribus, spicis confertis secundis sub-5-spiculatis, rhachi glaberrima, bractea exteriore late ovata dimidio breviore interioribus obtusis muticis glaberrimis tubum calycis $\left(5^{1} / 2^{\prime \prime \prime}\right.$ Iongi) superantibus, tubo superne hispido, limbo rubello mutico.

Prope Kech, incolis Kampyr murusch. Leg. 0. Fedschenko.

3. Acanthophylum SQARrosum Boiss. $\beta$. glaberrimum Borss.

A. squarrosum Boiss. habitu robustiore, caulium internodiis longioribus, foliis rigidioribus, calycis dentibus lanceolatis in spinam brevem excurrentibus ab A. spinoso dignoscitur.

a. typicum, crispulo-pubescens, calycibus dense pubescentibus.

*) Die mit Bge (mss.) bezeichneten Arten sind von $A$. von Bunge aufgestellt und die Beschreibungen uns vom Autor mitgetheilt. 
A. squarrosum Boiss. diagn. ser. II. I. pag. 81.-Boiss. et Buhse pl. transc. pag. 39.-Boiss. fl. or. I. pag. 562.

3. glaberrimum; caule foliis calycibusque glaberrimis. Boiss. fl. or. 1. c.

4. Agave pUBESCENS RGL. ET ORTG.

Amaryllideae.

A. pubescens; humilis, acaulis; foliis lorato-lanceolatis, undulatis, coriaceis, recurvo-patentibus et deinde dependentibus, integerrimis, utrinque dense pubescentibus, supra opaco-viridibus, subtus pallidioribus, utrinque fusco-maculatis; scapo erecto, tripedali et ultra, bracteato; bracteis lanceolato-subulatis, erecto-patentibus; spica simplici, laxiflora; floribus sessilibus; bracteolis parvis, subulatis; perianthii tubo recto, subaequilato, ovarium duplo superante, limbi laciniis revolutis, tubo brevioribus; staminibus corollam plus duplo superantibus, stylum circiter aequantibus; stigmate breviter trilobo. - Flores virides. Perigonium incluso ovario circ. $35 \mathrm{~m}$. m. longum. - Plantas vivas cl. Roezl e Mexico misit. -A. pubescens Rgl. Grtf. tab. 804.

Agave maculosa Hook. (Bot. Mag. tab. 5122) foliis lanceolato-subulatis denticulatis glabris, staminibus perigonii laciniis erecto-patentes circiter aequantibus, $A$. maculata $R g l$. (Grtfl. 1857 pag. 158) foliis planiusculis (nec undulatis) glabris, perigonii tubo supra ovarium coarctato infundibuliformi apicem versus ampliato, ovarium circiter aequante, limbi laciniis erecto-patentibus tubum circiter aequantibus, facile dignoscuntur. A caeteris speciebus hujus sectionis, species nostra foliis utrinque dense pubescentibus integerrimis maculatis florumque structura longe distat.

5. AyARYlis (HipPea Strum) ROEZLi RgL. Amaryllideae.

A. Roezli; spatha tetraphylla, phyllis exterioribus oppositis anguste lanceolatis erectis, interioribus filiformibus recurvis sepalisque an- 
gustioribus ab A. equestri diversa. - A. Roezli Rgl. Grtfl. tab. 809. - Bulbus ovato-oblongus. Folia ensiformia, obtusiuscula, glabra, striata. Scapus ante folia evolutus, iisdem lateralis, fistulosus, teres, glaber, viridis, rore glauco tectus, suberectus, circiter $30 \mathrm{c.m}$. altus. Spathae phylla exteriora dorso carinata, rubescentia, pedunculos germinaque superantia; interiora filiformia, albida, mox recurva, pedunculos paullo superantia. Flores gemini, nutantes. Pedunculi teretes, erecti et apice paullo curvati, $2-2 \frac{1}{2}$ c. m. longi. Perigonium infundibulare; tubus cylindricus, fere calamum crassus, cylindricus, sulcatus, lurido-purpurascens, circiter 2 c. m. longus; limbus sexpartitus, infundibularis, irregularis, subringens, superne patentissimus, miniatus, basi interiore albidus; laciniae margine undulatae, apice recurvae, exteriores oblongolanceolatae ex apice rotundato-apiculatae, interiores laterales paullo minores oblongo-lanceolatae oblusae, interior infima anguste lanceolata porrecta obtusa exteriores aequans; laciniae tres superiores fauce utrinque fimbriatae. Genitalia declinato-adscendentia, perigonio concolora et eodem paullo breviora. Antherae oblongae, incumbentes, flavae.

6. Astragalus corydalinus bge (mss.).

A. (Euodmus) foliolis 6-10-jugis ellipticis obtusis, racemis longe pedunculatis, floribus cernuis, calyce tubuloso campanulato basi calcarato-saccato! bibracteolato parcissime basi nigro alboque setuloso; vexilli ungue hamato-curvato, alis carinaque persistentibus, ovario semibiloculari glabro 13-15-ovulato.

Hab. in montibus Irtasch Turkestaniae (Krause!). Calycis structura distinctissima species, forsan melius ad Calycocystin referenda, si calyx tunc demum turgescit, quod e specimine juvenili judicari nequit.

7 A stragalus cyrtobasis Bge (n. 950 b.).

Astragali subgenus Calycocystis, sectio nova Cyrtobasis (99 b.). Herba caulescens, caulibus brevibus erectis, pube patula medio fixa mere 
alba hirsuta. Stipulae lanceolatae inter se liberae breviter petiolo adhaerentes. Folia impari-pinnata, petiolus marcescens. Spicae ovatae capitatae dense multiflorae sessiles. Bracteae lineares elongatae, bracteolae nullae. Calyx basi compressus transverse dilatatus, ventre basi tenuissime membranaceus valde gibbus, sursum angustatus dentibus elongatis herbaceis lanceolato-subulatis conico-conniventibus. Corolla purpurascens persistens petalis longe unguiculatis calycem vix excedentibus. Vexilli lamina subpanduriformis apice integra basi obtusangula. Alae vexillum subaequantes. Carina alis paulo brevior, lamina minuta acutiuscula. Vaginae filamentorum subaequaliter connatorum basis transverse calycis basi adnata, ita ut ovarium et vexillum cum stamine solitario in angulo calycis interno inserta apparent, alae vero et carina cum filamentorum vagina basi unguium connatae ex angulo externo calycis oriuntur. 0varium subsessile subbiloculare 8-10- ovulatum. Stigma nudum. Legumen (juvenile) hirsutissimum, esulcatum, subbiloculare calyci inclusum oligospermum.

Habitat in Turkestaniae montibus centrasiaticis Mogol-tau, unica species, habitu A. chaetodontis, a quo differt calycis structura singulari et ovario biloculari. Specimina collecta duo tantum, quorum alterum nondum florens, alterum florere incipiens. (Coll. Sewerzow).

8. Astragalus cytisoides Bge (mss.).

A. (Erioceras) suffruticosus, stipulis petiolo brevissimo longe adnatis, foliolis ternatis obovatis subpungentibus, racemis abbreviatis pedunculatis, leguminibus rectis cuspidatis.

Specimina duo in jugo Karatau occidentali collegit Sewerzow.

Nulli aliae sectioni adjungendus nisi Eriocerati; A. arcuato et eriocerati evidenter affinis, attamen signis in diagnosi indicatis distinctissimus. Fruticulus, ut videtur in rupium fissuris crescens et solo adpressus. Caulis lignosus ramosissimus; rami abbreviati conferti, juniores sericeo-cani. Stipulae inter se liberae, quamvis amplexicaules, membranaceae, basi glaberrimae, apice extus inolliter sericeo-villosae. Foliola e basi cuneata obovata, cuspidato-subpungentia, utrinque pube prostrata 
cana, medium paullo majus ad summum $5^{\prime \prime \prime}$ longum superne fere $2^{\prime \prime \prime}$ latum. Pedunculi axillares pollice vix longiores, racemum brevem etiam fructiferum confertum 6-10-florum ferentes, patulo-albo-villosi pube nigra parca breviore immixta. Bracteae majusculae persistentes membranaceae oblongae obtusae albo nigroque villosae. Legumen oblongo-lineare, 14-16"' longum, $2^{\prime \prime \prime}$ latum, rectum rarius modice curvatum, in cuspidem rectum attenuatum, dense et longe villosum, esulcatum, complete biloculare.

\section{Astragalus eremospartordes Rgl.}

Pilis simplicibus adpressis subsericeus; suffruticosus, caespitosus, basi ramosissimus; ramis abbreviatis; petiolis aphyllis, teretibus, filiformibus, persistentibus, acutis (non spinescentibus); stipulis parvis, subrotundis breviter acuminatis $\mathbf{v}$. e basi late ovata lanceolato-acuminatis, petiolo adnatis; pedunculis nudis, tereti-filiformibus, petiolos usque duplo superantibus, apice remote 2-plurifloris; floribus brevissime pedicellatis, remotis; bractea minima, lanceolata, pedicello duplo breviore; calyce tubuloso-subcylindrico, non vesicario; corolla calycem plus duplo superante; legumine sessili, recto, subcylindrico, in rostrum breve acuminato, calyce triplo longiore.

Species defectu foliolorum, petiolis pedunculisque filiformi junciformibus excelsa. Radix caules abbreviati ramulique lignosi. Petioli 8-12 c. m. longi, $1 / 2-{ }^{3} / 4 \mathrm{~m}$. m. lati, pedunculi $15-25 \mathrm{c}$. m. alti. Pedicelli $1 \mathrm{~m}$. m. longi. Calyx $3 \mathrm{~m}$. m. longus, $2 \mathrm{~m}$. m. latus. Corolla ut videtur pallide flava, circiter $8 \mathrm{~m}$. m. longa. Legumen immaturum $1 \mathrm{c.}$. longum.

Habitat in desertis inter fluvium Syr Darja et Taschkentem. Legit 0. Fedschenko Majo 1871. 


\section{Astragalus Krauseanus Rgl.}

A. pilis bipartitis adpressis adspersus, virescens; caule erecto, angulato-sulcato; stipulis liberis, e basi dilatata submembranacea in apicem linearem herbaceum excurrentibus; pedicellis foliolo brevioribus; foliolis anguste lanceolato-linearibus, saepissime 4- jugis; pedunculo stricto, erecto, folium superantibus; floribus laxe racemosis, brevissime pedicellatis; racemis elongatis, laxis, folio triplo longioribus; bracteis lineari-lanceolatis, pedicellum superantibus; calycis tubo subinflato-cylindrico, pilis bipartitis dense vestito; calycis dentibus subulato-subsetaceis, pilis simplicibus hirtis, subaequilongis, tubo $3-4$ plo brevioribus; petalis flavis.

Astr. pallescenti M. B. affinis, differt autem caule erecto, pedicellis foliolo brevioribus, foliolis 4 -jugis, calycis tubo-subinflato pilis bipartitis adpressis dense vestito, dentibus subaequilongis.

Turkestaniae in montibus Irtaschtsche leg. Krause.

\section{Astragalus leiophysa Be (mss.).}

A. (Eremophysa Bge) glabratus; caule simplici erecto glabro, foliolis $6-8$ jugis suborbiculatis ovatisve subtus ad nervos marginemque parcissime puberulis denique glabratis, spicis axillaribus abbreviatis sessilibus, calyce denique glabro, vexilli lamina integra ovata, legumine glaberrimo.

Hab. in deserto Kisil-kum a monte Karak usque ad Korshun. Majo 1871. (0. Fedschenko).

Proxime affinis A. sphaerophysae, sed abunde distinctus videtur caule glabro foliolisque multo minoribus plurijugis utrinque viridibus glabratis, calycibus etiam junioribus fere glabris, dentibus neutiquam villosis at in illo, sed ciliatis tantum, tum vexilli lamina, quae in illo fere orbicularis, emarginata, supra latior.

Uni-bi-pedalis; folia inferiora usque ad 8 pollices longa; foliola semipollicem longa et lata, vel paulo minora. Calyx sub anthesi cum dentibus $6^{\prime \prime \prime}$ parum excedens, fructifer ambitu pollicaris. Vexillum $7^{11 / 2}{ }^{\prime \prime \prime}$ lon- 
gum. Alae $8^{\prime \prime \prime}$ parum excedentes; carina vexillum aequans. 0rarium 12 ovulatum.

\section{Astragalus mucinus Bge (mss.).}

Mogol-tau. 28, 29 April leg. Sewerzow.

A. (Erionotus) molliter albo-lanatus, subacaulis vel caulescens; caulibus adscendentibus, stipulis petiolo breviter adnatis membranaceis, foliois $15-20$-jugis ellipticis supra dense patulo albo-lanatis, racemis breviter pedunculatis subradicalibus axillaribusve $3-5$ floris, bracteis pedicellum superantibus, calycis tubulosi denique recurvati molliter longe larato-villosi dentibus tubum vexillumque subaequantibus subulatis, vexilh extus sericeo-villoso, alis carinaque parce pilosis, ovario longe stipitato 8-10-ovulato, legumine ovato-trigono semibiloculari farcto.

Frope A. lanuginosum Kar. et Kir. ponendus, cui valde affinis, sed magis lanatus, flores multo minores, calycis dentes ratione tubi multo longiors, legumen multo brevius; a caeteris speciebus sectionis longius distat. Soecimina juniora, attamen jam leguminibus immaturis instructa, subacaula A. erionotum et sisyrodytem referunt; alia vero nondum fructifera jan caulem tripollicarem ostendunt. Folia $3-\left.4^{1}\right|_{2}$ pollicaria. F0liola 3 -4" longa, $1^{3} / 4^{\prime \prime \prime}$ lata. Calyx cum dentibus $7^{\prime \prime \prime}$ loagus, vexillum $7^{1} / 2-8^{\prime \prime \prime}$, lae $7^{\prime \prime \prime}$, carina $6^{\prime \prime \prime}$ longa, cum in A. lanuginoso calyx $9^{\prime \prime \prime}$, tubus $6^{\prime \prime \prime}$, exillum $\left.12^{1}\right|_{2} ^{\prime \prime \prime}$ alae $\left.11^{1}\right|_{2} ^{\prime \prime \prime}$, carina $\left.10^{1}\right|_{2} ^{\prime \prime \prime}$ longa. Carinae lamina ratiob longitudinis totius carinae brevior et latior. Legumen, qnamvis omnno maturum ignotum, $5^{\prime \prime \prime}$ (nec $9^{\prime \prime \prime}$ ut in illo) longum, ratione longitudiis latius.

\section{Astragalus nematodes Bge (mss.).}

Nogol-tau. (1乞 März, 25. 29. April) Dshun bulak (20 April) coll. Sewerzow.

A. (Corethrum) abacaulis, canus; stipulis brevissime petiolo adnatis inter se liberis, fciolis 1-3-jugis lineari-filiformibus longissimis, scapis racemoque laxo longatis, floribus nutantibus, bracteis pedicellum 
aequantibus, calycis pube mere alba cani laciniis subulatis tabum aequantibus, corollae vexillo valde resupinato suborbiculari bilobo, alis obovato-oblongis subintegris, ovario 8-10-ovulato, legumine calycem quadruplum aequante lineari-oblong0 obtuso abrupte cuspidato.

Habitus A. taurici, praesertim varietatis scopaeformis, sed affinior A. Semenovii et scopario, quibus in sectione Corethrum associandus est, abunde signis in diagnosi indicatis ab illis distinctus. Cum inflorescentia semipedalis. Foliola tenuissima saepe pollice longiora. Racemi minus laxi quam in affinibus, $10-18$ flori. Vexillum brevius, latius, $4^{1} / 2^{\prime \prime \prime}$ longum, $3^{\prime \prime \prime}$ latum. Alae aequilongae, unguibus valde curvatis. Carina $3^{\prime \prime \prime}$ parum excedens. Legumen nondum maturum sine mucrne $7^{\prime \prime \prime}$ longum.

\section{Astragalus Sewerzowi Bge (mss.)}

A. (Myobroma; Psilostigma) acaulis, exscapus, praeter varium glaberrimus, foliolis sub-15-jugis ovatis acutis, calycis lacinis tubo suo duplo longioribus alas superantibus, ovario villoso.

Unicum frustulum florens collectum in montibus Karatau a Severzowio. Species glabritie omnium partium et calycis laciniis subulato-lliformibus fere vexillum aequantibus ab omnibus speciebus sectionis hunsque notis facillime distinguenda. In folio unico completo e cicatricibus rumeravi juga circiter 15; alterius folii pars superior abrupta. Foliola rajora 5-6 longa, $2^{1} / 2^{\prime \prime \prime}$ lata, vel paullo latiora, ovata, acuta. Pednculi radicales brevissimi racemos abbreviatos $7-10$-floros gerunt cogestos ad basin foliorum. Calycis membranacei albidi tubus $3^{\prime \prime \prime}$ longus, dentes inferiores paullo longiores, 6 "' longi. Vexillum subspathulato-obsngum, infra medium parum dilatatum, in unguem brevem latumabiens, subrectum emarginatum $10^{\prime \prime \prime}$ longum, $3-\left.3^{1}\right|_{2} ^{\prime \prime \prime}$ latum; alae ${ }^{1} \mid 2^{\prime \prime \prime}$ longae, linearioblongae. Carina $7^{\prime \prime \prime}$ longa. Ovarium cum styli bsi sericeo-villosum, 16-18 ovulatum biloculare. Fructus ignotus. 
15. A STRAGALUS SiSYRODYTES BgE (msS.).

A. (Dasyanthus) acaulis, exscapus; foliis 11 - 13-jugis, floribus subradicalibus subsolitariis, sessilibus, petalis omnibus extus sericeis, ovario sessili.

Frustulum speciei distinctissimae collectum cum praecedentibus, affine A. pellito Bge. et erionoto Bth., a priore differt praeter alia foliolorum multo minorum numero multo majori, ab altero ovario sessili, foliolorum numero multo minori, floribusque sessilibus. E rudimento planta videtur humilis caespitosa, radice crassa multicipite. Foliola minuta orbiculari-oblonga, utrinque molliter patule breviter villosa. Flores minuti, inter foliorum bases fere occulti.

16. Astragalus tURKestanus Bge (mss.).

Mogol-tau 29. April. coll. Sewerzow.

A. (Christiana) erectus, strictus, virens, albo nigroque hispidulus ; foliolis 15-28-jugis complicatis ovato-oblongis retusis supra glabris subtus parce prostrato-pubescentibus, racemis axillaribus subsessillibus 2-4 floris laxis, calycis pube prostrata nigra brevi pilis albis subnullis hispiduli dentibus subulatis tubum dimidium vix superantibus, vexillo infra medium subconstricto basi obtusangulo, alis carinam antice retasam apice obtuse productam superantibus, ovario hirsuto 7-ovulato, legumine....?

Ad calcem seriei Christianarum ponendus, solummodo cum A. retamocarpo et leucomelano comparandus. A priore differt praesertim ovario hirsuto, foliolorum forma et indumento calycis foliorumque, ab altero indumento, foliolorum forma et alis carinam superantibus. Specimina juniora florida tantum collecta. Caules ex una radice videntur plures usque ad 10-pollicares, tunc demum altius excrescentes, angulati. Folia 5-pollicaria, foliolis plerumque ultra 50 sat densis $\left.3^{1}\right|^{2}-4^{\prime \prime}$ longis diu complicatis. Calyx cum dentibus $5^{\prime \prime \prime}$ longus. Vexillum $\left.8^{1}\right|^{2 \prime \prime \prime}$. Alae fere $8^{\prime \prime \prime}$. Carina $6^{\prime \prime \prime}$ longa. 


\section{Calochortus pulchellus $\beta$ parviflorus Rgl.}

C. pulchellus $\alpha$.typicus; floribus majoribus campanulato-subglobosis. C. pulchellus parviflorus Grtfl. tab. 802 - Cyclobothra pulchella Benth. in hort. trans. nov. ser. I pag. 415. tab. 14 fig. 1.-Bot. reg. tab. 1662 .

$\beta$. parviflorus; floribus campanulatis minoribus.-Glaber. Caulis erectus, teres, apice dichotome - v. trichotome-corymbosus, corymbo 4 plurifloro. Folia plana, late linearia v. inferiora lineari-lanceolata, supra laete viridia, subtus glauca; superiora breviora flores fulcrantia, pedunculos subaequantia v. iis longiora. Flores campanulati; sepalis ovatolanceolatis, acuminatis, glabris, $10-12 \mathrm{~m} . \mathrm{m}$. longis, virescenti-liteis; petalis aequilongis, ovatis, obtusis, aureis, extus glabris, intus-margineque papillis elongatis obtusis simplicibus $\mathrm{v}$. rarius ramusis barbatis. Germen angulato-trigonum, stigmatibus tribus. recurvis coronatum. C. pulchellus $\beta$ Grtfl. tab. 802 .

18. Co le US mi CRANthus Maxim.

(Solenostemon Benth.). Annuus, cuele crasso ramoso alato-quadrangulo retrorsum hispidulo, foliis longe petiolatis ad axillas petiolos et basi subtus ad costam paleaceo-longe pilosis superne molliter adpresse, subtus ad reticulum substrigoso puberulis, rugulosis, herbaceis, ovatis acutis crenatis basi in petiolum cuneo angusto decurrentibus; racemis terminalibus elongatis ob folia floralia minuta mox decidua nudis, interruptis; cymis in quovis verticillastro binis oppositis sessilibus 10 floris; floribus minutis ( 3 mill. longis) pedicello strigoso pubescente brevioribus; calycis similiter pubescentis lacinia summa oblongo-ovata infimas in labium acnte bidentatum connatas aequante, laterales quadratas superante; corollae tomentellae coerulescentis calyce duplo longioris tubo arcuatodeflexo limbo parvo labiis subaequilongis: superiore trilobo, inferiore anguste oblongo concavo; staminibus parum inaequalibus styloque corollam aequantibus. 
Hab. in Abyssinia, unde semina accepimus a cl. Schimpero a. 1872.

Proximus C.latifolius Hochst. a nostro distinguendus pube diversa, foliis membranaceis brevioribus et latioribus, floribus triplo majoribus, calycis dentibus infimis supremo longioribus, corollae labio inferiore superius duplo superante et latiore, stylo breviter, in nostro longiuscule bifido. - Frons in nostro obscure subcinereoviridis. Planta tripedalis, racemis palmaribus, valde graveolens. Folia omnia acuta crenis crebrioribus et minoribus, ceterum illis C. latifolii subaequimagna. Calyx florifer tantum notus herbaceus, intus glaber. Antherae violaceae ovoideae, rarius duae superiores minores. Calyx defloratus deflecti videtur.

\section{Conyza spatholif olia Maxim.}

(Dimorphanthes DC.) herbacea erecta tota molliter pubescens viscidoque punctata, foliis spathulatis obtusis basi breviter auriculatis a medio apicem versus pauciserratis, summis integerrimis; panicula ramosa corymbosa polycephala, capitulis parvis, involucri squamis linearilanceolatis acuminatis disco brevioribus; floribus femineis numerosissimis exterioribus obsolete ligulatis, achaenio pubescente.

Hab. in Abyssinia, unde semina, altit. 7-8000 pedum collecta, ' misit cl. Schimper a. 1872.

$\mathrm{Ab}$ affini ${ }^{-}$. absinthiifolia $\mathrm{DC}$. differt punctis viscidis caulis, $\mathrm{f} 0$ liorum et involucri, foliis rite spathulatis versus basin sensim lateque attenuatis et basi auriculata sessilibus, pappo sordide albido neque rufo, achaenio pubescente neque glabro. Sed habitus idem et capitula aequimagna.

Annua, 1-2-pedalis. Folia media $3^{1 / 2}$ cent. longa, 1 cent. an- 
gustiora. Flores flavi, feminei stylo breviores 3 -dentati, extimi hinc breviter fissi, ceteri regulares. Flores hermaphroditi $2-4$, triplo saltem crassiores, 5-dentati. Stigmata floris hermaphroditi lanceolata planocompressa. Antherae basi rotundatae ecaudatae, a se invicem fere liberae. Achaenium compressum submarginatum pallidum, illi $C$. absinthiifoliae aeque magnum et consimile.

Ad Conyzam sensu Lessing et Bentham pertinet ob flores femineos, antheras et achaenium.

Maxim. (*).

\section{Crassula Cooperi.}

C. perennis, inulticaulis, caespitosa; caulibus decumbentibus, pilis patentibus rigidis diaphanis hirtulis; foliis oppositis, oblongo-lanceolatis, acutis, utrinque glabris, margine setuloso-ciliatis; cyma pauciflora, terminali; floribus breviter pedicellatis; calycis laciniis lanceolatis, acutis, margine ciliatis, caeterum glabris, quam petala duplo brevioribus.

Caules spithamaei, filiformes, flexuosi, vix ramulosi. Folia remota, $5-10 \mathrm{~m} . \mathrm{m}$. longa, basi tantum connata, crassiuscula, supra planiuscula, punctis impressis paucis, infra convexa, sub lente impresso-punctulata. Flores 5 v. 4 . meri, parvi, $3 \mathrm{~m}$. m. in diametro; flos inferior saepissime in dichotomia inflorescentiae alaris, pedicello florem subsuperante suffultus; flores superiores breviter pedicellati, corymbos 35 flores formantes. Petala basi connata, nivea, ovata. Carpella stylo brevissimo coronata. - Nomine «Crassulae Cooperi» ex horto «Haage et Schmidt» accepimus. - C. Cooperi Gartenfl. tab.786.

Crassula expansa Ait., cui planta nostra habitu affinis, differt foliis lineari-lanceolatis glabris, floribus longe pedicellatis, calycis laciniis obtusis glabris corollam subaequantibus.

(*) Ne 18 et 19 auctore C. J. Maximowicz. 


\section{ENCEPALA RT OS VerschafFelti RgL.}

E. trunco ovato-conico (deinde verosimiliter cylindraceo), apice ad squamas cinereo-tomentoso; petiolo tomento detergibili denso cinereo vestito, rhachique semitereti; rhachi initio laxe cinereo-tomentosa; deinde glabra, foliolisque saturate viridibus; foliolis oppositis v. subalternis, 11-13 nerviis, lineari-lanceolatis, subfalcatis v. rectis, planis, basi in lineam paullo elevatam obtusam decurrentibus, apice acuminatopungentibus, margine integerrimis.

Folia (frondes) $70-80 \mathrm{c.} \mathrm{m}$. longa, pinnata. Foliola usque $6-7$ c. m. longa et $11 \mathrm{~m}$. m. lata, margine initio villosula, demum totidem glabra, valde decrescentia, inferiora minima vix $1 / 2 \mathrm{c} . \mathrm{m}$. longa, omnia rhachi oblique denseque inserta et conniventi-adscendentia (nec horizontaliter patentia). Petiolus 5-10 c. m. longus.

E. cycadifolius hort. J. Versch.

Affinis E. cycadifolio Lehm. et E. Lehmanni Lehm.; alter foliolis linearibus margine revolutis $3-5$ nerviis; alter trunco foliisque glabris, foliolis glaucis basi non decurrentibus, in latere inferiore convexis, latere superiore marginibus subcanaliculato incurvatis, usque $40 \mathrm{c.} \mathrm{m}$. longis et $8 \mathrm{~m}$. m. latis, $18-20$ nerviis, basilaribus vix quam intermedia dimidio brevioribus facile dignoscuntur.

\section{GeNERIS ENCEPHALART I}

conspectus specierum adhuc cognitarum.

A. Foliola linearia, margine revoluta, pungenti-acuta.

1) Encephalartos cycadifolius Lehm. (D. C. 531) (*).

Foliola pungenti acuta; integerrima, $8-10$ c. m. longa, circ. $4 \mathrm{~m}$. m. lata, $3-5$ nervia.

a. glaber., truncoglabro, petiolo rhachique initio laxe tenuiterque tomentosis mox glabris. E. cycadifolius Lehm.

*) Wir citiren im Allgemeinen nur Decandolle Prodr., XVI. II. jas. u30533. Nur wo die Arten in De Candolle nicht aufgenommen oder wo es der Deutlichkeit halber nothwendig, haben wir mehr Citate gegeben. 
Cyc. pag. 13.-Zamia cycadifolia Jacq. fragm. tab. 25 et 26 .

ß. Friederici-Guilielmi., trunco apice lanuginoso, petiolo. rhachique initio tomento detergibili denso vestitis, demum subglabris.-E. Friederici Guilielmi Lehm. Cyc. pag. 8. tab. 1-3.-E. Ghellincki Lem. Ill. hort. 1867 pag. 80 . et anno 1868 tab. 567.

B. Foliola linearia, plana, pungenti-acuta.

2) E. pungens Lehm. (D. C. 533) (mihi ignotus).

C. Foliola lineari-lance ol at a, pungenti-acuta.

a. Folia saturate viridia.

3) E. Verschaffelti Rgl., foliolis integerrimis, 7-plo longioribus quam latis.

4) $\boldsymbol{E}$. elongatus Miq., foliolis integerrimis v. versus apicem unidentatis, 14-plo longioribus quam latis. (Cfr. D. C. 533. (Mihi ignotus).

5) $E$. villosus Lem., foliolis spinoso-dentatis, 14-plo longioribus quam latis, dentibus subulatis erectis $\mathbf{v}$. subadpressis. - E. villosus Lem. Ill. hort. 1867 pag. 80. - 1868 tab. 557. Truncus apice cinereo-tomentosus. Petiolus et rhachis initio laxe tomentosi, demum glabri. Foliola laete viridia 20 c. m. longa et circ. $1^{1 / 3}$ c. m. lata.

b. Folia glauca.

6) E. Lehmanni Lehm. (D. C. 531).

a. typicus., foliolis integerrimis.

ß. spinulosus Miq., foliolis spinuloso-dentatis. (Cfr. D. C. 1. c.).

D. Foliola I anceola ta v. rarius elliptico- lance ol at a.

a. Foliola inferiora pungenti-acuta, superiora obtusa v. hamuloso-obtusa.

7) E. longifolius Lehm., (Cfr. D. C. 531).

Folia viridia. Variat: 
a. typicus; foliolis laalcelatis, planis.

E. longifolius $\gamma$. angustifolius et $\delta$. Hookeri D. C. I. c.-Zamia longifolia Jacq. fragm. tab. 29. - E. caffer Hook. bot. mag. tab. 4903 . - Foliola $12-16 \mathrm{c.} \mathrm{m}$. longa, $\left.2^{1}\right|_{4}-3 \mathrm{c.m}$. lata. ß. revolutus; foliolis lanceolatis, margine revolutis. (Cfr. D. C. 531).

$\%$ latifolius; foliolis elliptico-lanceolatis, margine revolutis. Foliola $12-13 \mathrm{c} . \mathrm{m}$. longa et $4 \mathrm{c} . \mathrm{m}$. lata, margine inferiore obtuse 1-2-dentata, rarius integerrima. - E. Almasianus h. Paullowsk.

\section{b. Foliola omnia pungenti-acuta.}

* Folia viridia. Foliolola integerrima v. obtuse dentata.

8. E. caffer Miq.

(Cfr. D. C. pag. 532). Variat:

a. integrifolius; foliolis glabris integerrimis.

ß. unidentatus; foliolis glabris saepe unidentatis.

$\gamma$. brachyphyllus; rhachi paginaque inferiore foliolorum arachoideo-pubescentibus. (Cfr. D. C. I. c.).

** Folia viridia. Foliola acute lobato-dentata.

9. E. lanuginosus Lehm., foliolis margine inferiore 1-4lobato-acuteque dentatis.

Foliola oblonga v. elliptico-lanceolata. E. lanuginosus Lehm. Cyc. pag. 14. - D. C. 533. - Zamia lanuginosa Jacq. fragm. tab. $30,31 .-\mathrm{E}$ horridus $\beta$. lanuginosus Miq. Ann. sc. nat. ser. II pag. 367. - E. horridus latifrons Miq. monogr. pag. 59.

*** Foli a gl a uc a.

10. E. horridus Lehm., foliolis pungenti lobato-dentatis, lobis saepe divaricatis. - D. C. prodr. 532. excl. var. Zamia horrida Jacq. fragm. tab. 27 et 28. - E. Van Hall Vriese teste Miq. -E. nanus Lehm. Tijdschr. IV 421 tab. 8 fig. C -E. horridus trispinosus Hook. bot. mag. tab. 5371. 
**** F o lia viridia. Foliola lance 0 lata spinoso-dentata, dentibus subulatis erectis..

11. E. Altensteini Lehm.

a. typicus; trunco glabro, foliolis densis, utrinque spinoso1-3.

dentatis rarius integerrimis, usque $17 \mathrm{c}$. $\mathrm{m}$. longis et $2 \frac{1}{2}-3$ c. m. latis. - E. Altensteini Lehm. Cyc. pag. 11 et 13 tab. 4 et 5. - D. C. prodr. XVI. II. 531. -

E. Altensteini et var. angustifolia Miq. monogr. pag. 51 et 52.-Zamia spinosa Lodd. cat.

$\beta$. paucidentatus; foliolis aut in margine superiore aut in margine inferiore $1-3$-dentatis aut utrinque integerrimis.

Cetera ut var. $\alpha$. - E. Altensteini var. semidentata Miq. monogr. pag. 52.-E. Murumi Vriese in Tijdschrft V. 188.

$\gamma$. distans; foliolorum jugis $3-4$ c. m. distantibus. Cetera ut var. $\alpha$. - Zamia vernicosa hort. Jean Versch.

j). parvifulius; trunco glabro, foliolis densis, 7-8 c. m.

longis et vix 2 c. $\mathrm{m}$. latis, utrinque $2-4-5$ dentatis. Zamia elegantissima et Z. Van den Heckei h. Jean Versch.

-Enceph. Vromii h. Jean Versch.

¿. eriocephalus Vriese; trunco sursum lanuginoso. Cetera ut var. $\alpha_{\text {. }}$ - E. Altensteini eriocephalus Vriese descr. pl. nouv. Jard. de Leyde pag. 1. tab. 1 et 2.

\section{SPECIES EXCLUSA.}

E. tridentatus Lehm. = Macrozamia Miqueli A. D. C.

22. He L IOTROPIUM 0 LGA BaE (mss.).

H. (Agoraea Bge.) annuum, ramosissimum, virens; foliis petiolatis superioribus suborbiculatis rugosis supra viridibus, subtus densius strigulosis, spicis ebracteatis subternis confertis secundis, calycis sessilis 
persistentis profunde 5-partiti laciniis linearibus acutis denique imcurvopatulis tubi trientem aequantibus, corollae tubo elongato intus aequabiliter pubescente, limbi patentis laciniis late orbicularibus intercalaribus nullis, antheris subbasilaribus longe a fauce remotis obtusis, stylo glaberrimo quan stigma conicum glandulosu-hirsutum vix breviore, nuculis laevissimis glabris.

Hab. in regno Kokand prope Usyent, et inter Jaipan et Isfara 18 Juni et 14 August 1871. (0lga Fedschenko.) Habitus fere H. europaei, Eichwaldi et lasiocarpi, a quibus facillime distinguitur corollae multo majoris tubo elongato intus pubescente, stylo distincto et defectu laciniarum intercalarium. Ab. H. suaveolenti et affinibus jam stigmate conico elongato differt. H. cinerascens longius distat. Spicis quodammodo accedit ad species sectionis Hedyosma, ;recedit vero nuculis a calyce seorsim deciduis, calyce diutius persistente sessili.

\section{EREMURUS KOROLKOWI RGL.}

Eremurus. B. Sepala omnia nervo unico intermedio crasso apice subexcurrente. a. Folia glabra, bracteae margine vilioso ciliatae.

(Rgl. Eremurus in Труды Имп. Боч. Сада. tom. II. pag. 425).

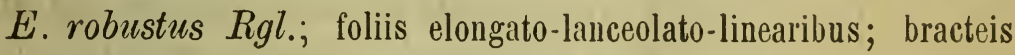
lineari-subulatis, margine hyalino-albido angusto involuto, pedicellum dimidium circiter aequantibus. - Folia basi $3-5 \mathrm{c}$. m. lata, quam inflorescentia breviora.

$E$. Korolkowi $R g l$; foliis ligulato-linearibus; bracteis anguste lineari-lanceolatis, hyalino-albis, planis, nervo intermedio valido instructis, pedicellum initio superantibus, deinde eo paullo brevioribus.-Folia $1 / 2-1^{1 / 2} \mathrm{c}$. m. lata, inflorescentiam saepissime superantia.

E. Aucherianus Boiss; bracteis pedicellos circiter aequantibus.Folia basi circiter $2^{1 / 2}$ c. m. lata. 


\section{E. KOROLKOWI RGL.}

E. caule inclusa inflorescentia $20-40 \mathrm{c.} \mathrm{m}$. alto foliisque glaucis integerrimis; racemo initio denso, deinde laxiore, $5-25$ c. m. longo; pedicellis filiformibus, continuis, patulis, bracteas anguste lineari-lanceolatas planas hyalinu-albas margine villosas deinde $1 / 3$ superantibus, initio iisdem brevioribus: perigonii rosei foliolis patulis, omnibus uninerviis, post florescentiam rectis; capsulis globosis, ut videtur rugosis.

E. robusto in habitu simillimus, statura humiliore, foliis plus triplo angustioribus, bracteis planis eximie albo-hyalinis ante florescentiam pedicellum alabastrumque superantibus, florescentiae temporis ${ }^{2} / 3$ longitudinem pedicellorum circiter aequantibus, - facile dignoscitur. - Flores pulchre rosei, magnitudine E. robusti. - Habitat Turkestaniae prope puteum Sultan-Bibi in collibus Kuldschuk-Tau in arenosis lutosis. (Ko. rolkow).

\section{HedYSARUM SEWERZ OW I BGE (mSS.).}

H. pube patula griseum, radice lignosa multicipiti, caulibus abbreviatis, stipulis connatis oppositifoliis, foliolis $4-5$-jugis lineari-oblongis complicatis utrinque acutis supra glabratis impunctatis, pedunculis folio brevioribus, capitulis ovato-globosis confertis, bracteolis subulatosetaceis calycis tubum longe superantibus, calycis dentibus lanceolatosubulatis tubo suo longioribus, vexillo glabro obcordato carinam angulo obtuso infractam parum alas plus duplo superante, ovario quadriovu. lato muriculato-puberulo.

Quamvis e specimine unico vix florere incipiente tantummodo nota, sine dubitatione species nova, habitu quodammodo affinis H. microptero, speciei persicae novae, sed jam indumento, calyce, vexilli et carinae forma diversa; magis forsan fructu discrepat. Ab omnibus caeteris speciebus longius distat. In Turkestania leg. Sewerzow. 


\section{1}

25. MimOSA PROSTRATA.

(Eumimosa $\S 3$ Castae Benth. in Walp. rep. I. 866).

Fruticosa, ramosa, prostrata, inermis ; caule petiolis pedunculisque patentim setoso-hispidis; petiolo brevissim0. - Folia bipinnata; pinnae unijugae, terminales; foliola 7-25 juga, elliptico-oblonga, acuta, marginata, utrinque glabra, margine villoso-ciliata. Capitula subglobosa. Flores 5-meri. Sepala minuta, ciliata. Corolla virescens. Stamina 5, longe exserta, lilacina. Stipulae lanceolatae, persistentes. Pedunculi axillares, folia pluries superantes.

M. oblonga Benth., cui proxime affinis : «aculeis tenuibus recurvis, caule pedunculisque patentim setoso-hispidis et pube brevi intermixta canescentibus, foliolis $25-35$-jugis linearibus» facile dignoscitur. Il. prostrata hort. - Patria ignota.

\section{OXALIS 0RTGIESI RGL.}

0 . pilis adpressis laxe vestita; radice fibrosa perenni; caule suffruticoso, carnoso, erecto, purpureo; foliis petiolatis, ternatis, exstipulatis, trifoliatis; foliolis breviter pedicellatis, ovato-triangulis, apice late exciso-truncatis, lateralibus inaequilateris; pedunculo folia duplo superante; cyma dichotoma, multiflora, sepalis lanceolato-oblongis, obtusiusculis, corolla flava subduplo brevioribus; filamentis stylisque subaequilongis breviterque hispidulis.

Petioli teretes $6-8 \mathrm{c.}$. longi, purpurei. Pedicelli patente-pubescentes. Folia supra saturate viridia nitentia, infra purpureo-violacea, apice $1 \frac{1}{2}-2 \mathrm{c}$. In. lata, subaequilonga quam lata, nervo intermedio ex incisura paullo excurrente; nervis lateralibus utrinque $3 \mathrm{v}$. rarius 2.

Pedunculus basi purpurascens, apice virescens. Sepala circiter $6 \mathrm{~m}$. m. longa, basi viridia, apice leviter virescentia. Petala obverse oblonga, 5-nervia, apice truncato-rotundata $v$. leviter emarginata, citrina.

Habitat in America tropica. 


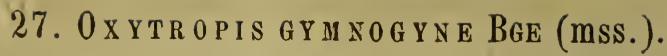

0. dense caespitosa multiceps griseo-canescens; caudiculis brevissimis confertis, stipulis inter se liberis petiolo ad medium adnatis ovato. lanceolatis membranaceis extus praeter apicem glabris ciliatis, foliolis 5-7-jugis diu complicatis, oblongis obtusis utrinque prostrato-pilosis, scapis laxis folium superantibus patentim villosis superne nigrescentibus, capitulis laxis sub 5-floris, bracteis linearibus calycis tubo brevioribus, calycis campanulati albo nigroque villosuli dentibus tubum dimidium superantibus, vexilli lamina latissime orbiculari retuso-subemarginata, alis oblique retuso-subbilobis vexillum aequantibus, carinae alis brevioris acumine brevi recurvo, ovario longe stipitato glabriusculo 21-ovulalato; legumine. ... ?

Mogol-tau. 15 März. Legit Sewerzow.

0 . humifusae affinis, sed stipulae a basi glabrae, latiores breviores acutiusculae, nec basi adpresse sericeae acuminatisssimae lanceolatae, inter ramos caudicis occultae, nec longe imbricatae nitidae, foliola obtusa nec acutissima, praesertim vero corollae structura diversa, cum in 0 . humifusa vexillum obcordatum et alarum ungues ratione laminae multo lon giores, et ovario 21, nec 8-10-ovulatum. Specimina duo collecta cum scapis capitulisque sub anthesi $2-3$ pollicaria. Calyx $2^{1} / 2^{\prime \prime \prime}$ longus. Vexillum vix $6^{\prime \prime \prime}$ longum, in parte inferiore laminae $5^{\text {"II }}$ latum. Alarum ungues $1^{1} / 2^{\prime \prime \prime}$, lamina $4^{1 / 2} 2^{\prime \prime \prime}$ longa. Carina cum mucrone lato brevi vix $5^{\prime \prime \prime}$ longa.

\section{0xytropis INTEGRIPETALA Bge (mSS.).}

0 . e caudice brevi lignescente multicipite acaulis, sericeo-villosa; stipulis basi inter se connatis petiolo ad medium adnatis parte libera lineari-subulatis hirsutis, foliolis $15-20$ jugis oblongo-lanceolatis acutissimis prostrato-sericeo-villosis, scapo adscendente folia superante patulo-piloso, racemo abbreviato $10-12$ floro, bracteis linearibus pedi- 
cello duplo longioribus, floribus natulis, calycis tubuloso-campanulati pube alba longiore nigraque minuta villosuli dentibus subulatis tubum dimidium aequantibus, vexilli lamina late ovata integerrima, alis multo brevioribus lineari-oblongis integerrimis, carinae mucrone elongato-lanceolato porrecto alas aequante, ovario stipitato villosissimo $18-20-0$ vulato, legumine..... ?

In promontoriis jugi Kcharly-tau; 7 Mai (leg. Sewer\%ow). Ex affinitate 0 coeruleae, brevicaulis, Semenovii rtc., priescrtim carinae structura; attamen ovario distincte stipitato, racemo densiore albbreviato, indumento ab omuibus recedit. Caudices subterranei lignosi crassi reliquiis stipularam tecti. Folia bipollicaria. Scapns sim racemo tripollicaris, ra cemus ipse sub anthesi pollicaris tantum. Calyx cum dentibus $\left.4^{1}\right|_{2} ^{\prime \prime}$ longus. Vexillum 8 "' longum, versus basin laminac ultra 4 "latum. Alae semipollicares, apice linea parum latiores; carinae cuspis fere $\left.1^{1}\right|^{2 \prime \prime}$ longus.

\section{OXYTROPIS SFW F R}

0. multiceps, caespitosa, molliter patulo-cano villosa, subacaulis; caudicibus ramosissimis elongatis laxis gemmifrris, stipulis petiolo adnatis illter se liberis ovatis acutissimis extus serice 0 -villosis, foliolis $9-12 \mathrm{jugis}$ ovato-oblongis acutis planis utrinqu: molliter patule cano-villosis scapis folium supcrantibus patule albo-villosis pubeque uigra sursum deusiore breviore nigricantibus, capitulis globosis $10-16$ floris, bracteis linearibus calycen subacquatibus albo-nigroque villosis, calycis campanulati albo nigroque serice-villosi dentibus subulatis tubo vix brevioribus, vexilli lamina ovato-suborbiculari apice bilobo-emarginata, alis vexillum subaequantibus apice ventre obtuse productis, carinae alis brevioris acumine recurvo brevi, ovario stipitato villoso 6-7-ovulato, legumine ...?

Prope Wernoje 30 Ilai leg. Sewerzow. Ex affinitate 0 . albanae, cyaneae, humifusae etc., ab omnibus vero distincta jam indumento, calyce. ovarioque villoso. - E radice crassa lignescente prodeunt caudiculi laxi numerosi, ramosissimi, gemmulas numerosas imbricato-squamatas ferentes, 
caespitem amplum foliorum, scaposque emittentes. Folia $2-2^{1} / 2$ pollicaria. Foliola $2-\left.2^{1}\right|_{2} ^{\prime \prime \prime}$ longa, vix ultra $\left.1^{1}\right|_{2}{ }^{\prime \prime \prime}$ lata. Scapi graciles, sub anthesi vix tripollicares. Vexillum $5^{\prime \prime \prime}$ longum, medio $3^{\prime \prime \prime}$ latum; carina vix $4^{\text {in' longa. }}$

\section{0xytropis trichocalycina Bge (mSs.).}

0 . acaulis, caespitosa, sericeo-cana, stipulis ad medium petiolo adnatis, foliis' $6-8$ jugis, scapis folia subaequantibus, floribus globosocapitatis, calycis breviter campanulati laciniis longissimis plumosis corollam aequantibus, ovario sexovulato, legumine (juniore) uniloculari oligospermo calyci incluso oblongo depresso sericeo.

Speciei nulli e notis vere affinis, habitu quodammodo ad 0. pumilam accedens, sed jam foliolis conjugatis nec verticillatis diversa; inter omnes species calycis et leguminis structura insignis. In Turkestania leg. 0 . Fedschenko.

31. Pentstemon glaber Pursh. $\delta$. stenosepalus.

a. typicus; foliis caulinis sessilibus subamplexicaulibus lanceolatis, sepalis late ovatis margine membranaceis, filamento sterili antherisque hirsutis. P. glaber Pursh. fl. am. septr. II. 738.-Bot. mag. tab. 1672.-P. eriantherum Fras ex Nutt. gen. II. pag. 53. -Bentl. in.D. C. prodr. X. 321.-Corolla purpurea.

B. speciosus; glaucus, glaberrimus, fol. caulinis lanceolatis, sessilibus; calycis segmentis ovato oblongis acuminatis margine membranaceis ; filamento sterili antherisque glabris. - P. speciosus Dougl. in Lindl. bot. reg. tab. 1270.-Benth. in D. C. prodr. X. 323.-P. glaber $\beta$ occidentalis Asa Gray rev. Pentst. in proceed. Am. Acad. VI. 59. — S. Wats. Bot. pag. 217. - Flores cyanei. 
\%. utahensis Wats; glaber, fol. caulinis oblanceolatis sessilibus basin versus attenuatis, sepalis ovatis acuminatis membranaceis v. nonnullis totidem herbaceis, filamento sterili antherisque hirsutis. S. Watson Botany of the Geolog. explor. pag. 217.

o. stenosepalus; viridis, caule foliisque glabris; fol. caulinis e basi amplexicauli Iatiore lanceolatis, sepalis lanceolatis acuminatis pedicellisque minute glanduloso-puberulis, totidem herbaceis, filamento sterili antherisque breviter hirsutis.

In den Gärten ist in den letzten Jahren ein Pentstemon, ziemlich allgemein als P. speciosus verbreitet worden, das sich, wenn man Benthams Diagnose und die von Lindley im Botanical Register gegebene Abbildung vergleicht, durch nicht blaugrüne, sondern grüne mit breitem Grunde sitzende Blätter, lanzettlich lang zugespitzte kurzdrüsig behaarte Kelchblättchen, welche nicht häutig gerandet sind, und durch den kurz behaarten sterilen Staubfaden und Antheren unterscheidet. Wir würden diese Pflanze für eine neue noch unbeschriebene Art gehalten haben, wenn nicht $\mathrm{S}$. Watson in der Beschreibung der bei Gelegenheit der Geologischen Erforschung der 5. Parallele der Nordamerikanischen Staaten gesammelten Pflanzen, schon auf pag. 217, (indem er Asa Gray theilweise folgt) in erster Linie P. speciosus Dougl. zu P. glaber als Form gezogen hätte und in 2. Linie noch eine andere Form beschrieben hätte, die unserer Pflanze schon näher steht. Dagegen ist $\mathrm{S}$. Watson in so fern nicht Asa Gray gefolgt, als er P. cyananthus Hook. nicht zu den Formen von P. glaber zieht, sondern wie auch uns scheint, mit vollem Rechte als eigne Art festhält.

\section{Philodendron Melinoni.}

Caudex abbreviatus, crassus, vaginis (stipulis?) deinde in fibras solutis involutus. Petiolus crassus, semiteres, latere interiore eximie canaliculatus, $40-80 \mathrm{~s}$. m. longus, $2-3 \mathrm{c} . \mathrm{m}$. in diametro, initio purpureus, deinde olivaceus, basi vaginis stipulaceis oppositis membranaceo- 
scarinsis deinde in rete fibrarum solutis involutus. Lamina maxima, e basi cordato-hastata ovato-oblonga, apice breviter acuminata integerrima, margine undulata, $40-60 \mathrm{c}$. m. longa, basi $25-40 \mathrm{c}$. m. lata; costa intermedia lateralibusque alternantibus in pagina inferiore valde prominentibus rufescentibusque; lobis basilaribus apice rotundato-obtusis. Pedunculus brevissimus. Spatha cylindrica, apice cuspidata, marginibus involutis spadicem omnine occultans, extus rufescens. Spadicis cylindrici spatha brevioris mascula pars quan foemina plus duplo longior. Ovaria stigmatibus fusen-purpureis. - Crescit in Cayenne.

Philodendron spec. de Cayenne et Ph. Melinoni Brongn. in hortis. Spatha circiter $18-20 \mathrm{c}$. m. longa.

Affinis Philodendro pinnatifido Knth. et Ph. pinnatisecto Schott.

\section{Piroxneava Morreniana Rat.}

\section{Bromeliaceae.}

Pironneava. Panicula terminalis, simplex vel ramosa: scapms fo. liis bracteiformibus non coloratis (viridibus $v$. subseariosis) vestitus. Bracteolae flore's fulcrantes integerrimae, in acumen pungentem acuninatae. Calyx a basi ad medium ovario adnatus, 3 -lobus, lobis imbrica. tis, carinatis, in acumen pungens acuminatis. Corolla superi, tripetala: petalis erectis, valvatis, annulo styli bạsin cingenti insertis. Stamina sex, tria cum petalis alternantia, '(um petalis inserta, lihera; tria petalis totidem adnata. Antherae oblongae, biloculares, supra basin dorso affixac. Germen inferum, triloculare, annulo epigyno co. ronato; stylus filiformis; stigma capitato-clavatum, spira!iter tortum. 0vula anatropa, supra chalazam in appendiculum oblongum producta.

P. Morreniana; robusta; foliis urceolum magnum formantibus, elongato-0hlongis, $60-80 \mathrm{ccm}$. longis, $6-9 \mathrm{c.}$ m. latis, a basi sul apicem seusim latioribus, ex apice obtuso breviter acuminatis, canalicu. latis, margine spinuloso-serratis, glabris, sub lente albido-punctulatis, utrinque laete viridibus, erectn-patentibus et apicen versus plus minus 
recurvis; scapo foliis breviore, albo-floccoso, foliis bracteiformibus oblongis acutis albido-scariosis vestito; panicula simplici; paniculae ramulis abbreviatis, inferioribus distantibus brevissime stipitatis, superioribus dense glomeratis sessilibus; floribus ramulorum brevissimorum glomeratis, basi bracteola colorata calycem aequante fulcratis; bracteis bracteolis calycibusque glabris, petalis coeruleis, basi squama duplici oblonga; staminibus exterioribus liberis, interioribus petalo adnatis; ovulis appendice oblongo, ovulo ipso triplo breviore.

Florum glomeruli inferiores brevissime stipitati, superiores sessiles, hractea ovata acuminata scariosa fulcrati. Bracteae flores fulcrantes seiniamplexicaules, late ovatae, in acumell spinescens acuminatae, roseopurpureae, calycem vix aequantes, excavatae, dorso vix carinatae. Calycis lobi laterales dorso acute carinati, dorsali dorso rotundato, marginibus sese amplectentes, in acumen spinescens exeuntes, basi vires. centes, medio rosei, apice coerulei, flore coeruleo sesqui breviores. Petala oblonga, apice spathulato-dilatata, coerulea.

Pironneava glomerata Gaudichaud, cui planta nostra satis affinis dignoscitur: foliis scapi viridibus, paniculae ramis inferioribus elongatis iterato ramosis, bracteis bracteolisque viridibus hirtulis, petalis fla. vescentibus, ovulis cuspide lineari ovulum aequante.

Die schöne Bromeliacee welche Gartenflora tab. 805 abgebildet wird, gehört zu der von «Gaudichaud in Vaillant, Voyage de la Bonite» aufgestellten Gattung Pironneava. Leider gab Gaudichaud-Beaupré in diesem Werke nur die Abbildungen eines Theils der auf jener Reise gesammelten Pflanzen, die Beschreibungen sind aber nie veröffentlicht worden. C. Koch hat in der Wochenschrift (III. 1860 pag. 337) nach jencn Abbildungen die Gattung Pironneava als eine gute festgehalten und wir stimmen da mit unserm geehrten Freunde ganz überein und gaben im Obigen den Gattungscharakter. Zunächst steht diese Gattung den ron Bcer aufgestellten Gattungen Hoplophytum und Lamprococcus. Gaudichaud hat 2 Arten abgebildet, nämlich tab. 63. P. glomerata, welche unserer Pflanze nahe kommt. Nehmen wir nun auch an, dass unsere Pflanze (ob- 
gleich solche sehr üppig entwickelt ist) auch einen ähnlichen stärker verästelten Blüthenstand entwickeln könnte, so bleiben in erster Linie die ganz anders gestalteten Eier unserer Pflanze und ferner der gänzliche Mangel einer Behaarung an Brakteen und Kelch, während solche auf Gaudichauds Abbildung als behaart angegeben. Ausserdem hat C. Koch (l. c.) nach einer lebenden Pflanze des Berliner Gartens eine Beschreibung vou P. glomerata gegeben und sagt da, dass deren Schaftblätter Brakteen und Kelche grün und die Blumenblätter gelblich.

P. platynema Gaud. 1. c. tab. 64 unterscheidet sich ebenso wie die von C. Koch aufgestellte $P$. spectabilis durch eine verästelte Rispe. Vergleichen wir aber C. Kochs Beschreibung mit Gaudichauds Abbildung, so scheint es uns unzweifelhaft, dass Kochs Pflanze zu P. platynema als Synonym gehört. Wir hätten damit also 3 Arten der Gattung Piron. neava, welche sich in folgender Weise unterscheiden.

a. Flores paniculati, paniculae rami racemosi,

P. platynema Gaud. in Vaill. voyage de la Bonite tab. 64. P. spectabilis C. Koch in Wochenschr. III. pag. 338. - Bracteae calycisque lobi subito in acumen spinescentem desinentes. 0vulorum appendix linearis ovulum aequuans.

B. Flores paniculati, flores ramulorum dense glomerati.

P. glomerata Gaud. in Vaill. voyage de la Bonite tab. 63 ; bracteis calycibusque hirtulis, appendice ovulorum lineari ovulum aequante.

P. Morreniana; bracteis calycibusque glabris, appendice, ovulorum oblongo ovulo triplo breviore.

\section{Pitcairia (Pourretia) ploccosa.}

P. floccosa; caulescens, foliis longissimis circiter $1 \mathrm{~m}$. et ultra longis, basi circiter $2 \mathrm{c} . \mathrm{m}$. latis, sensim in apicem filiformem attenuatis; e basi ad mediun erecto-patentibus, apicem versus recurvato-de- 
pendentibus, margine spinuloso-serratis, spinulis sursum versis, supra glabris nitentibus atroviridibus, infra albidis strigosoque pilosis; scapo $1 \mathrm{~m}$. et ultra alto, usque ad paniculan terminalem foliis remotis decrescentibus vestito, rhachique griseo-floccoso; paniculae simplicis pyrumidatae 50 c. Ill. altae ramis horizontaliter patentibus, spicato 7-10-floris, basi bractea ovato-lanceolata acuminata spinuloso-serrulata suffultis; bracteolis ovatis, acuminatis, quam calyx ${ }^{1} / 3-\left.{ }^{1}\right|_{2}$ brevioribus, bracteis calycibusque albido-floccosis; floribus sessilibus; calycis laciniis lanceolatis, acutis, canaliculatis, crectis, 3 c. m. longis, quam petala $1 / 3$ brevioribus; petalis erectis, ovato-oblongis, basi nudis, marginibus sese anplectentibus, acutis, 4 c. m. longis, apice saturate caeruleis, dorso et basin versus ex albido-virescentibus; staminibus saturate caeruleis, initio inclusis, mox exsertis; antheris oblongis polline aurautiaco; ovario sublibero, basi tantum calycis tubo connato, trigono, triloculari; styli exserti stigmatibus tribus convolutis; ovulis anatropis, raphi lata, ovuli tegumento exteriore quam interius rostelliforme porrectum breviore; capsula septicida.

Pourretia floccosa C, Koch. Wochenschr. III. pag. 251. - Pourretia lanuginosa hort. - Pourretia violacea h. Laurentius.

Die Gattung Pourretia ward ursprünglich durch gänzlich überständigen Fruchtknoten und fächerspaltende Capsel von Pitcairnia getrennt. Ob es ächte Pourreticı mit fächerspaltender Capsel wirklich giebt, ist bis jetzt nicht nachgewiesen.

Für die in Rede stehende Art, wies schon C. Koch in dem Jahrgange 1858 p. 266 der Allgemeinen Gartenzeitung nach, dass solche gleich Pitcairnia eine scheidewandspaltige Capsel besitzt, was schon am Fruchtknoten der Blume beim Querdurchschnitt zu erkennen ist. Der zweite Charakter, nämlich ein vollständig freier Fruchtknoten, der Pourretia von Pitcairuia unterscheiden soll, ist ebenfalls bei unserer Pflanze so undeutlich und zweifelhaft ausgebildet, dass wir darin keinen trennenden Charakter von Pitcairnia erblicken können, denn der Fruchtknoten ist bei P. floccosa mit seinem untersten Theil in den aus Verwachsung 
der Kelchröhre mit dem Fruchtboden gebildeten untersten Theils des Blüthenbodens etwas eingesenkt, also auch nicht vollständig frei, wie überhaupt dieses Verhältniss auch bei den zu Pitcairnia gerechneten Arten mehrfachen Abänderungen unterworfen ist (*).

Da nun ferner auch die Tracht der in Rede stehenden Art, mit den mit $P$. ramosa verwandten Arten übereinstimnt, so glauben wir, dass wir nicht fehlen, wenn wir solche einfach zu Pitcairnia stellen, indem wir derselben den Speciesnamen lassen, den unser in Gebiete der Gartenpflanzen unermüdlich thätiger Freund C. Koch dieser Art gegeben hat. Dieselbe fand sich früher unter dem Namen Pourretia lanuginosa $R$. et P. in den Gärten, schon ein flüchtiger Blick auf die von Ruiz et Pavon in der Flora Peru's gegebene Abbildung jener letzteren Pflanze genü̈gt, um zu zeigen dass diese mit P. floccosa C. Koch gar nichts zu thun hat. - Ein eigenthümlicher Charakter der P. floccosa liegt in der Bildung der Eier, bei denen die innerste Eihaut die äussere bedeutend überragt und sich schnabelförmig vorstreckt.

Unsere P. floccosa unterscheidet sich schon durch den rispenförmigen Blüthenstand mit wagerecht abstehenden Aesten, durchaus sitzende Blumen, vorn dunkelblaue Blumenblätter, die langen grazil überhängenden schmalen scharf stachelig gezähnten Blätter, die auf ihrer untern Seite weiss und ausserdem mit angedrückten steifen Haaren besetzt, wie endlich auch durch den graulich weissen flockigen Ueberzug von Blüthenschaft, Blüthenspindel, Brakteen und Kelch, von allen andern bekannten Pitcairnien und gehört zu den stattlichsten Arten dieser Gattung, denn die Blätter werden über ein Meter lang und der beblätterte Blüthenschaft mit der Blüthenrispe erhebt sich ebenfalls über einen Meter. Blühete in Kais. Botanischen Garten im November und December 1873. Die Blumen-

(*) Mehrere verglichene Abbildungen ächter Pitcairnien geben in dieser Beziehung keine Aufklärung, dagegen zeigten im trocknen Zustande verglichene Pitcairnien, wie z. B. Pitcairnia albitios, einen noch freieren Fruchtknoten als unsere Art. 
blatter, welche um 'is langer als die Kelchblatter, sind anfangs tief blau, nach dem Abblühen färben sic sich röthlich.

35. PrIMULAE SPECIES IMPEGIUM ROSSICUM HANDSCHURIA MQUE H A BIT A NTES.

I. Conspectus specierum.

A. Folia petiolata, cordato-ovata v. cordat o-oblonga.

1. $P$. cortusoides $L$., foliis crenato-lobulatis, lobulis crenatis.

2. P. Meyeri Rupr., foliis inaequaliter crenato dentatis, corollae lobis obcordato-bifidis.

3. P. grandis Trautv., foliis inaequaliter crenato-dentatis; corollae lobis obtusis vix emarginatis.

B. Folia cordato-orbicularia.

4. P. Kaufmanniana Rgl., foliis lobatis; lobis grosse crenatodentatis v. grosse duplicato-dentatis.

C. Folia in petiolum attenuatav. rarius basi rotundata.

a. Calyx argute angulatus.

5. $P$. officinalis Jacq., corollae limbo concavo.

6. P. elatior Jacq., corollae limbo plano, umbella pedunculata multiflora.

7. P. acaulis Jacq., corollae limbo plano, pedunculis radicalibus unifloris.

b. Calyx cylindricus v.campanulatus angulis destitu. tus.

* Corollae laciniae obtusae integerrimae.

+ Calyx subcampanulatus, 5-dentatus, dentibus tubum subaequantibus $v$. superantibus.

a. Involucrum brevissimum, florescentice tempore pedicellis duplo brevius. 
8. P. Fedschenkoi Rgl., corolla calycem subtriplo superante.

३. Involucri foliola subulato-acuminata, florescentiae tempore pecticellos aequantia $v$. superantia.

9. P. nivalis Pall., corollae tubo calycem aequante usque duplo superante.

++ Calyx tubulosus, 5-dentatus, dentibus tubo plus duplo brevioribus.

10. Pr. Maximowiczi Rgl.

** Corollae laciniae emarginatae.

11. P. stricta Hornm; calycis dentibus obtusis tubo brevioribus; corollae tubo calycem subduplo superante. -

Folia utrinque glabra, subdenticulata.

** Corollae laciniae obcordato-bifidae.

+ Involucri foliola basi exauriculata $v$. subgibba.

๙. Folia subtus farinosa.

12. $P$. farinosa $L$., calycis tubulosi dentibus tubum subaequantibus $\mathrm{v}$. eo brevioribus.

Folia obovato-oblonga v. oblonga, crenulata v. subintegerrima $\mathrm{v}$. eroso-denticulata. Umbella saepissime densa, pedunculis erectis flore brevioribus $v$. longioribus.

13. P. farinifolia $R u p r$. ; calycis campanulati dentibus tubum superantibus.

Folia obovata, in petiolum longum attenuata, argute serrato-dentata. Umbella laxa, pedunculis longissimis filiformibus flexuosis.

ß. Folia utrinque glabra.

0. Folia argute denticulata. Flores lutei.

14. P. luteola Rupr.

00. Folia argute denticulata. Flores lilacini, rosei $v$. purpurei.

15. P. auriculata Lam; pedunculis quam flores plus duplo pre- 
Hian brevioribus, corollat tubo ealycem sesqui-duplo superante, calycis laciniis tubum aequantibus $\mathbf{v}$. superantibus.

16. P. darialica $R u p r$., peduneulis flores aequantibus v. superantibus, calycis sub campanulati dentibus tubum aequantibus, corollae tubo calycem paullo-sesqui superante

17. P. algida Adams., pedunculis flores saepissime plus duplo brevioribus rarius flores subaequantibus, calycis tubulosi laciniis tubo paullo brevioribus, corollae tubo calycem aequante v. paullo superante.

000. Folia integerrima $v$. crenulata, $v$. obtuse, - v. eroso paucidenticulata.

18. P. longiscapa Ledb., foliis obverse lanceolato-oblongis $\mathbf{v}$. obovato-oblongis. in petiolun sensim angustatis.

19. P. borealis Duby., foliis obovatis v. spathulatis, subito in petiolum lamina saepissime longiorem attenuatis.

0000 . Folia apice grosse dentato-serrata.

20. P. cuneifolia Ledb.

+ Involucri foliola basi appendiculato-saccata.

21. P. sibirica Jacq., foliis elliptico-orbiculatis v. oblongo-ellipticis in petiolum ipsis longiorem attenuatis, pedicellis floriferis involucrum $2-3$ plo superantibus rarius subaequantibus.

22. P. Olgae Rgl., ioliis obovato-oblongis, in petiolum brevem membranaceo-alatum attenuatis; pedicellis floriferis involucro brevioribus.

\section{Enumeratio specierum.}

1. Primula cortusoides $L$.

L. spec. 206. - Lehm. monogr. gen. Prim. pag. 23. D. C. prodr. VIII. 36. - Ledb. fl. ross. III. 8.

Variat: $\alpha$. typica: foliis subtus ad nervos plus minus villosis, calycibus glabris $\mathbf{v}$. subglabris. 
Hab. in Sibiria uralensi, altaica, baicalensi et in regione amurensi.

5. tomentella; foliis subtus calycibusque canescenti-tomentosis.

In Sibiria altaica (Karelin et Semenow.)

2. Primula Meyeri Rupr., foliis cordato-ovatis v. cordatooblongis $v$. inferioribus basi in petiolum attenuatis, obtusis, inaequaliter dentato-crenatis v. crenato-repandis, subtus glabris v. dense cinereo-tomentosis; petiolo glabro; scapo glabro, stricto; umbella pluriflora; calycis glabri angulato-cylindrici dentibus lanceolatis, acutis v. obtusiusculis, tubo brevioribus, margine ciliolatis; corollae tubo calycem paullo-sesqui superante, limbi laciniis 0 bcordato-bifidis.

Involucri foliola lanceolato-subulata, pedicellis duplo-pluries breviora v. eos subaequantia, basi exauriculata. Flores rosei v. flavi. - Variat:

a. typica; foliis subtus cinereo-tomentosis, floribus roseis.

Pr. Meyeri Rupr. Cauc. Prim. in Melang. biol. Ac. Petr. 1863. pag. 284.

Hab. in prov. caucasicis in monte Elbrus (C. A. Meycr) et prope Pari 5-9000' s. m.

ß. cordifolıa; foliis subtus glabris, fluribus flavis (?).Pr. cordifulia Rupr. 1. C. prag. 286 . - Hab. in provinciis caucasicis prope Kaslk k $t$ Kubi (Ruprecht), in Somchetia et Bambaki (C. Koch).

Ruprecht vergleicht diese noch wenig hekante Art des Caucasus, wegen der auf der Ritckscite filz: gill Liliıtı der Form $\alpha_{\text {, }}$, mit der Pr. amoena 11 B., welche wir als Form in $t$ unt rlialb tilzigen Bititt rn. zu Pr. clatior nach Ledibour's Vorgange ziehell. Mehr ond r w nigr unterhalb brhaarte Blitter kımmen bei vi lén Arten vonl Primula vor. Die mit unterhalb dünı lilzigcin Blittern versehtenen Furm von Pr. curtu- 
soides, die wir im Vorhergehenden auffühten, ist eine parallele Form. Ebenso verhält sich Pr. amoena zu Pr. elatior und Pr. cordifolia zu Pr. Meyeri.

Die Primula Meyeri steht gleichsam zwischen Pr. cortusoides und Pr. elatior. Von Pr. cortusoides unterscheidet sie sich durch lappiggekerbte Blätter, sowie ferner durch die fast kahlen Blattstiele die bei Pr. cortusoides stets zottig behaart. Pr. elatior mit seinen Formen unterscheidet sich dagegen leicht durch an Grunde niemals herzförmige und in den Blattstiel verschmälerte Blätter.

3. Primula grandis Trautv., foliis cordato-ovatis, irregulariter duplicato-dentatis, supra glabris, subtus pulveraceo-puberulis, petiolo longissimo anguste alato suffultis; umbella terminali, anplissima; calycis glabri campanulati dentibus ovatis v. lanceolatis, acutis v. obtusiusculis, tubum vix aequartibus; corollae tubo calycem circiter aequante $\mathbf{v}$. paullo superante, limbi laciniis oblongis, obtusis, apice minute emarginatis.

Suhglabra. Folia maxima, $11 \mathrm{c.} \mathrm{m}$. longa, $8 \mathrm{c.m}$. lata. Petioli 26 c. m. longi. Scapus 25 c. m. longus Involucri foliola lanceolato-subulata pedicellis elongatis filiformibus pluries breviora, basi exauriculata. Flores lutei.

Hab. in prov. cauc. in montium jugo Dadiash 6-9500 alt. (Radde).

P. grandis Trautv. Bull. Ac. Petr. 1866 pag. 395. -

4. P. Kaufmanniana Rgl., foliis petiolatis, cordato-orbiculatis, lobatis; lobis $1 / 3$ laminis dimidii attingentibus, grosse duplicato-dentatis $\mathbf{v}$. iterato lobatis, lobulis apice dentatis; umbella v. racemo 1 luri - multifloro; calycis cylindrici v. demum subcampanulati dentibus lanceolatis, acutis $\mathbf{v}$. obtus.usculis, tubum subaequantibus, erectis; corollae tubo tenui cylindrico, calycem duplo v. plus duplo superante, limbi laciniis obec rdato bifidıs.

Cortusae Matthioli habitu valde similis. Petioli anguste alati, 
villosi, laminam saepissime superantes, $1^{1} / \Omega-12 \mathrm{c.m}$. longi. Lamina in pagina superiore atroviridis glabra $\mathbf{v}$. ad nervos sparsim pilosa, infra pallidior ad nervos plus minus villosa; $2-8 \mathrm{c}$. m. lata et longa. Scapus folia superans, breviter sparsimque pilosulus, exclusa in florescentia $8-20 \mathrm{c.} \mathrm{m}$. altus, erectus. Inflorescentia v. umbellata v. verticillato-racemosa. Inv0lucri foliola bracteaeque lineari-lanceolatae $v$. lanceolatae, acutae, integerrimae $r$. apice paullo dilatato-dentatae, initio pedicellos filiformes glabros superantes, demum iis duplo longiores, $5-9$ m. m. longae. Calyx glaber, $4-6 \mathrm{~m}$. m. longus. Corollae saturate violaceae tubus $10-12 \mathrm{~m}$. m. longus et $1-2 \mathrm{~m} . \mathrm{m}$. latus, limbus explanatus $8-16 \mathrm{~m}$. m. in diametro.

In regionibus cisiliensibus prope Kopal et in trajectu Zauku (Thian-Shan) leg. Semenow, in Turkestania prope Wernoje (Semenow) et prope Dschasyl-Kul (Kuschakcwicz).

Pr. cortusoides Herder pl. Semenow. n. 682 ex parte.

Wir haben diese ebenso schöne als ausgezeichnete neue Art, dem General-Gouverneur von T'urkestan, dem Herra General von Kaufmann, gewidmet; auf dessen Veranlassung die reiche Flora und Fauna Turkestans gründlich erforscht wird.

Charakterisirt ist diese Art durch die kreisrunden gelappten Blätter, mit abermals doppelt gezähnten oder gelappten Lappen, die grazilen dünnen Röhren der Blumenkrone, die mindestens noch einmal so lang als der Kelch und den Blüthenstand, der bald eine einfache Dolde bildet, bald durch Auswachsen zur quirligen Traube wird.

5. Primula officinalis Jacq.

Jacq. misc. I. 157. - D. C. prodr. VIII. 36. - Ledb. fl. ross. III. 8.

ß. inflata Ledb. I. c.

Pr. inflata Lehm. monogr. pag. 26. tab 2. -

Pr. macrocalyx Bunge in Ledb. fl. alt. I. pag. 209. - 
Rupr. Cauc. Priın. in Melanges biol. Ac. Petr. 1863 p. 287.

Pr. uralensis Fisch. in Rchb. pl. crit. VII. fig. 861.

Hab. a Rossia occidentali ad Sibiriam altaicam, in Caucaso Turkestania et Soongoria.

\section{Primula elatior Jacq.}

Jacq. misc. I. pag. 158. - D. C. prodr. VIII. 36. Ledb. fl. ross. III. pag. 9. - Pr. elatior et P. Pallasii Lehm. monogr. pag. 33 et 38 tab. 3.

Hab. in Rossia, in provinciis caucasicis, in Sibiria uralensi et altaica.

- amoena; foliis subtus tomentosis. - Variat floribus purpureis et flavis. Pr. amoena M. B. A. taur. cauc. I. pag. 138. Lehm. monogr. 33. tab. 3.-Rupr. Cauc. Pr. 1. c. pag. 284.

Die zur Stanmart citirte Pr. Pallașii bildet in Bezug auf die Behaarung den Uebergang. Ruprecht führt noch als Unterscheidungszeicheu der Pr. aịnoena die schmalere Kelchröhre auf, welche auf dem von Lehnann abgebildeten Exemplar allerdings sehr auffallend ist, bei der gelbblumigen Form des Caucasus aber vollständig übergeführt zum Kelch der gewöhnlichen Form wird.

7. Primula acaulis Jucq.

Jacq. misc. I. pag. 158. - Ledb. il. ross. III. 10. Lehm monogr. p. 30 - Pr. grandiflora Lam. et D. C. fl. fr. II. 248. - D. C. prodr. VIII. 37.

Hab. in Rossia australi et in prov. caucasicis.

In Kultur finden sich häufig Uebergänge von Pr. acaulis zu Pr. elatior, unter den wild gesammelten Exumplaren finden sich diese nicht. Es ist daher selir wahrscheinlich, dass jene in der Kultur entstandenen Mittelformen durch gegenseitige Befruchtung beider Arten hervorgegangen sind.

8. P. Fedschenkoi Rgl., foliis obovato-oblongis, in petiolum alatum attemnatis v. subsessilibus, rotundato-obtusis, crenato- 
dentatis, glabris; umbella pauci-pluriflora; involucrí foliolis paucis, ovato-lanceolatis v. lanceolatis, obtusis v. breviter acuminatis, initio pedicellos dimidios circiter aequantibus, demum iis 2-4-plo brevioribus; calycis breviter campanulati laciniis lanceolatis, acutis v. obtusiusculis, tubum subaequantibus v. brevioribus; corollae tubo apicem versus ampliato, calycem 23-plo superante, limbi plani laciniis ellipticis obtusis integerrimis v. vix conspicue emarginatis.

Folia utrinque viridia, glaberrima v. subtus farina sparsa virescenti vestita, $3-6$ c. m. longa, $7-20 \mathrm{~m}$. $\mathrm{m}$. lata. Scapus erectus, saepe curvatus, glaber v. apice sub involucro albo-farinosus, folia superans, $7-14$ c. m. altus. Involucri foliola $2-3 \mathrm{~m} . \mathrm{m}$. longa, basi coalita et exauriculata. Pedunculi florescentiae temporis $4-6 \mathrm{~m}$. m. longi, demum magis elongati, glabri v. sparsim albo-farinosi. Calyx virescens et apicem versus purpurascens, glaber v. margine intusque albo-farinosus, $3-4 \mathrm{~m}$. m. longus. Corolla ut videtur purpureo-violacea, tubo 8-11 m. m. longo, limbo 12-14 m. m. in diametro.

In Turkestaniae montibus Tschupanata, leg. A. et 0 . Fedschenko.

Wir nannten diese Art nach unserm für die Wissenschaft viel zu früh dahingegangenen geehrten Freund Alexei Pawlowitsch Fedschenko, der dieselbe gemeinsam mit seiner Gemahlin am 18 März 1869 blühend sainmelte. Nah verwandt der Pr. nivalis Pall., aber kleiner in allen Theilen, sowie durch vorn stumpf abgerundete Blätter, die wenigen sehr kurzen Hüllblättchen und den kleinen Kelch der meist fast 3 mal kürzer als die Blumenröhre, gut unterschieden.

9. P. nivalis Pall., foliis ovato-oblongis v. oblongis v. lanceolatis, in petiolum alatum sensim attenuatis, argute dentatis v. crenatis v. subintegerrimis; umbella multiflora v. rarius pauciflora; involucri foliolis numerosis, e basi coadunata acuminato-subulatis, florescentiae tempore pedicellos superanti- 
bus, demum iis brevioribus; calycis laciniis lanceolatis, acutis v. obtusiusculis, tubum subaequantibus v. superantibus; corollae tubo calycem aequante v. usque duplo superante; limbi laciniis oblongis $\mathbf{v}$. elliptico-oblongis, obtusis, integerrimis. - Capsula saepissime calycem plus duplo superans v. rarius vix superans. Umbella simplex $\mathrm{v}$, prolificatione in racemum e verticillis duobus compositum transiens.

Variat:

х. typica; robusta, clata, farina destituta; foliis oblongo-lanceolatis $v$. rarius anguste lanceolatis, crenato-dentatis ; involucro virescente; calycibus virili-pupurascentibus.

Folia acuta v. obtusiuscula, $7-20 \mathrm{c}$. m. longa. Scapus robustus, folia superans. Calycis $8-10 \mathrm{~m} . \mathrm{m}$. longi dentes saepe acuti, saepissime tubum subaequantes, rarius eo breviores v. longiores. Corolla purpurea, maxima, $1^{1 / 2}-2^{1 /}$ 。 c. In in diametro; tubo calycem paullo-duplo longiore.

Habitat in Sibiria altaira et baicalensi et in insula St.-

- Georg ad fretum Beringianum - Pr. nivalis Pall. III. app. 11. 81. tab. G. tig. 2. - D. C. prodr. VIII. pag. 39. Leảb. fl. ross. III. pag. 10

P. farinosa; robusta, elata; foliis elliptico-oblongis, in petiolum attenuatis, acutis $\mathrm{v}$. rarius obtusis, renato-dentatis, in latere inferiore marginem versus v. margine tantum albofarinosis; pedicellis saepissime farinosis; calycibus plus minus purpurascentibus, margine et intus saepissime farinosis. Cetera ut var. $\propto$.

P. nivalis farinosa Schrenk. enum. pl. nov. I. 2\%. Ledb. fl. ross. III. 10.

Hab. in Soongoriae montibus Alatau (Schrenk) et in alpibus sajanensibus Transbaicaliae (Radde); in montibus Alatau transiliensis $7500-9000^{\prime}$ alt. (Semenow); in Turkestania 
prope Wernoje (Semenow), in trajectu Zauku montium Thian. Shan (Semenow).

$\gamma$. longitolia; foliis anguste lanceolatis $v$. lanceolato-oblongis, crenato-dentatis. - Folia usque 25 c. $\mathrm{m}$. longa et $2-3$ c. m. lata. - Cetera ut var. $\beta$.

Hab. in montibus Alatau (Schrenk).

j. colorata; foliis elliptico-lanceolatis, subacutis, crenato-dentatis; involucris calycibusque atroviolaceis. - Folia 6-14 c. m. longa, saepissime nervo intermedio violaceo picta. - Cetera ut var. 3. - In Turkestaniae trajectu Sujuk, $10-12000^{\prime}$ alt. leg. Scharnhorst, in trajectu Kok-tau leg. Kuschakewicz.

๕. Bayerni; foliis elliptico-oblongis v. lanceolatis, crenato-dentatis $v$. argute dentatis, subtus margine plus minus late denseque albo-farinosis; involucris calycibusque virescentibus; floribus albis.

Folia 4-20 c. m. longa, initio scapum subaequantia, demum eo valde breviora. Pedunculi saepe albo-farinosi. Calycis dentes lanceolati, tubum aequantes v. superantes, - margine intusque plus minus albo-farinosi. Corollae tubus calycem paullo superans, limbi circ. $\mathbf{1}^{1 / 2} \mathrm{c}$. In. lati laciniis obovatis.

Hab. in Caucaso in regio alpina ad fontes fluvii Archot (Bayern), in distr. Alagir et Rodscha (Ruprecht). -

Pr. Bayerni Rupr. Cauc. Pr. in Mel. biol. Ac. Petr. 1863, pag. 306.

๘. subintegerrima; robusta, loliis anguste lanceolatis $\mathbf{v}$. rarius elliptico-lanceolatis, subtus initio tenuiter farinosis demum glabris, margine integerrimis v. obsolete crenulatis; involucro calycibusque virescentibus; pedunculis saepe farinosis; calycis dentibus margine intusque farinosis.

Folia calyces floresque purpurei inagnitudine var. $\alpha$. Habitat in alpibus Dahuriae (Radde), in Sibiria orientali ad quvium Engate (Stubendorff) et in Kamtschatka (Rieder). 
\%.purpurea; robusta, folis lanceolatis, repando-crenulatis, subtus luteo-farinosis, involucris calycibusque atroviridibus; pedunculis ralycibusque intus luteo farinosis; calycis laciniis lineari-lanceolatis, obtusiusculis, tubum superantibus; corolla atroviolacea.

Folia $8-12$ c. m. longa, obtusiuscula. Corollae tubus calycem sesqui-duplo superans, limbi usque $2^{1} / \mathbf{2} \mathrm{c} . \mathrm{m}$. lati laciniae ovato-oblongae. - P. purpurea Royle ill. 311, tab. 377, fig. 2. - D. C. prodr. VIII, pag. 40. - P. atroviolacea Jacquem. teste D. C. 1. c. -

Hab. in montibus altioribus Nepaliae.

o. pumila; humilis, foliis oblongis v. obverse oblongis, acutis v. obtusiusculis, subtus glabris, integerrimis v. crenatis $\mathbf{v}$. apicem versus crenato-dentatis; umbella pauciflora; calycis laciniis tubum saepe superantibus; corollae tubo calycem sesqui-duplo superante. - Folia $2-6$ c. m. longa, $1 / 2-11 /$ a c. m. latae. Scapus 4-12 c. m. altus. Calyx $4-5 \mathrm{~m}$. m. longus, intus ut pedicelli saepe albo farinosi. Corollae limbus $8-10 \mathrm{~m}$. m. in diametro.

Habitat in terra Tschuktschorum, ad sinum St. Laurentii et in Unalaschka (Eschscholtz), in Aleutorum insulis et in Kantschatka.

P. nivalis $\gamma$. pumila Ledb. fl. ross. VIII pag. 10 .

Die Primula nivalis ist vour den Alpen des Caucasus durch das Alpengebiet Turkestans und der Soongarei, danu nördlich nach dem Altai, Transbaikalien, Dahurien, Ostsibirien bis Kamtschatka und dem nordöstlichsten Asien und nordwestlichen Gebiete Amerikas; sowie südlich bis zu den Alpen Nepals verbreitet. Dieselbe kommt mehr oder weniger weiss- oder gelb-bestäubt und auch durchaus kahl vor. Die Blätter wechseln vón der länglich-ovalen Gestalt bis zur länglichen oder lan. zettlichen Form, dieselben sind spitz oder stumpf, ganz 
randig, schwach oder deutlich gekerbt-gezähnt oder selbst scharf gezähnt.

Vom hohen robusten Wuchs sinkt dieselbe in Hochnorden bis zur kleinen nur einige Zoll hohen Pflanze hinab und ebenso die vielblumige Dolde, welche häufig eine zweite Dolde aus ihrer Mitte entwickelt, bis zur arınblumigen Dolde. Der Kelch ist bald bis fast zur Mitte, oft aber auch bis zu $\left.{ }^{2}\right|_{3}$ in Lappen gespalten und die purpurrothe, violette oder weisse Blumenkrone besitzt eine Röhre, die bald fast ebenso lang oder bis fast noch einınal so lang als der Kelch wird.

Als der Referent die zahlreichen, in unsern Herbarien befindlichen Exemplare durchmustert hatte, glaubte er anfänglich, dass wirklich mehrere getrennte Arten unter I'r. nivalis zusammengefasst seien, überzeugte sich aber danı, dass keines der genannten Merkmale konstant sei und dass weder nach der tiefern oder flachern- Theilung des Kelchs, noch nach der verhältnissmässigen Länge der Blumenröhre, noch nach Vorhandensein oder Fehlen des Puders an Blätteru, Blüthenstielen und Kelch, noch endlich nach Gestalt und Zahnung der Blätter. Arten abgetrennt werden könnten. Es giebt endlich noch ciil auffallendes Merkmal bei den Formen dieser Art, nämlich cine Kapsel, die bei ihrer Reife noch eininal so lang oder noch länger als der Kelch, die aber bei einzelnen Exemplaren auch uar eben so lang als der Kelch vorkommt. Es kommt aber bei sonst durchaus übereinstimmenden Exemplaren des gleichell Bezirks die kurze und lange Kapsel vor, so z. B. bei der Forin des Caucasus mit schmalern scharf gezähnten Blättern, beobachteten wir die kurze Kapsel, die so lang als der Kelch und die lange Kapsel die noch einmal so lang als derselbe.

Wir haben nun im 0bigen die verschiedenen liormen, welche uns von P. nivalis vorlagen charakterisirt, wollte man 
einzelne charakteristische Exemplare jeder dieser Formen herausgreifen, so hätte man scheinbar ebenso viele leicht zu trennende Arten.

10. P. Maximowiczi Rgl.; glabra, foliis elliptico-oblongis, in petiolum membranace-alatum sensim attenuatis, rotundato-obtusis v. subacutis, obtuse v. acute crenulato-denticulatis; scapo folia duplo v. plus duplo superante; umbella pauci-multiflora v. prolificatione subracemosa; involucri foliolis numerosis, basi coadunatis exauriculatis, lineari-lanceolatis, acuminatis, initio pedicellos subaequantibus, demum iis duplo - pluries brevioribus; calyce tubuloso, 5-dentato, dentibus ovato-lanceolatis acutis tubo plus duplo brevioribus; coro llae tubo calycem sesqui-duplo superante, limbi laciniis oblongis obtusis integerrimis v. rarius obsolete emarginatis.

Folia $4-11$ c. m. longa, $1^{1} / 2-3$ c. m. lata. Scapus erectus, $12-22 \mathrm{c} . \mathrm{m}$. altus. Involucri foliola $3-5 \mathrm{~m}$. m. longa. Calyx $6-8 \mathrm{~m}$. m. longus, $3-4 \mathrm{~m}$. m. latus. Corolla purpurea, limbo $13-15 \mathrm{~m}$. m. in diametro.

Habitat in China boreali (Tatarinow), in montibus BuchuauT'schau prope Pekinam (Bretschneider).

Primula nova spec. aff. P. nivali Maxim. ind. Pekinensis in Prim. fl. amur. pag. 474.

11. P. stricta Hornm; glabra, foliis oblongis v. obovato-oblongis, subintegerrimis v. paucicrenulato-denticulatis, ir petiolum attenuatis; scapo folia longe superante; umbella pauciflora, erecta; involucri foliolis lanceolatis, basi vix gibbis, pedunculos initio subaequantibus, demum iis pluries brevioribus $v$. rarius ab initio brevioribus; calycis campanulato-tubulosi dentibus obtusis, tubo brevioribus, intus et margine farinosis; corollae tubo calycem sesqui-duplo longiore, limbi laciniis cuneato-obovatis emarginatis.

Pr. stricta Hornm. fl. dan. tab. 1385. - D. C. prodr. 
VIH. 44. - Ledb. fi. ross. III. pag. 13. - Pr. Hornemanniana Lehm. monogr. Pr. p. 55. tab. 4. - P. farinosa $\beta$. stricta Wahlbrg. fl. Lapp. p. 60.

Hab. in Rossia septentrionali et aretica.

Von der Pr. longiscapa Ledb. eigentlich nur durch die flachere Ausrandung der Blumenkronenlappen, sowie durch stumpfe Kelchzähne, die nur ungefähr halb so lang als die Kelchröhre, verschieden. Die meisten der uns aus dem Norden Russlands vorliegenden Exemplare besitzen Blüthenstiele, die zur Zeit der Blüthe kürzer oder so lang als die Hüllblättchen der Dolde. Nur bei einem Exemplare sind die Blüthenstiele scholl zur Zeit der Blüthe mehrmals länger als der Kelch.

12. $P$. farinosa $L$., foliis infra farinosis, obovato-oblongis $v$. oblongis v. obverse lanceolatis, in petiolum late alatum brevem $\checkmark$. magis elongatum attenuatis, obtusis $\mathrm{r}$. acutis, crenatis $\mathbf{v}$. obtuse $v$. acute denticulatis $\mathbf{v}$. subintegerrinis; unbella multiflora; involucri foliolis e basi subgibba lineari-lanceolatis; pedunculis flore saepissime plus duplo brevioribus, rarius magis elongatis florem superantibus; calycis tubulosi dentibus obtusis $\mathbf{v}$. acutis; tubo paullo $-1 / 3$ brevioribus; cerollae tubo calycem aequante v. usque sesqui superante; limbi laciniis obcordato-bifidis. -

Pr. farinosa L. spec. 205. - D. C. prodr. VIII. p. 44.Ledb. fl. ross. III. pag. 13.

x. typica; foliis subtus albo-farinosis, crenulatis v. subintegerrimis v. subargute denticulatis. Scapus humilis v. usque $20 \mathrm{c.} \mathrm{m}$. altus, folia saepissime pluries superans $\mathbf{v}$. rarius ea subaequans. Folia subtus dense albo-farinosa v. initio tenuiter albo-farinosa demum sub-glabra. Pedicelli plus minus albo-farinosi v. glabri. Corolla rosea v. lilacina v. rarius alba.

A Rossia septentrionali ad Sibiriam orientalem et Kamtschatkam. 
d0. 4h Aus Turkestan liegt uns eine Form von Frau 0. Fedschenko gesammelt vor, mit oval-länglichen kurz gestielten und regelmässig klein aber scharf gezähnelten Blättern, die unterhalb dicht weiss mehlig und mit sehr kurz gestielten, eine kopföörmige Dolde bildenden Blumen, deren Kelche wie bei var. 3. a. kahl und nach oben violett gefärbt sind. Es ist das also die Parallelform von P. farinosa $\beta$. a. nur mit weisser Bestäubung. Vom Fluss Utschur in 0stsibirien besitzen wir eine andere Endform mit verkehrt-länglichen sehr dünnhäutigen fast ganzrandigen oder ausgeschweift gekerbten Blättern, die nach unten in einen langen dünnen Stiel verschmälert und nur anfangs auf der untern Seite mit einem schwachen weisslichen Reif belegt sind, der bei den ältern Exemplaren ganz verschwindet. Die Blumen sind von dünnen Blüthenstielen getragen, die 2 mal so lang als die Hüllblättchen und auch länger als die Blumen. Diese letztere stellt daher die Parallelform von var. . c. vor. Zwischen diesen beiden Extremen bewegen sich eine Masse ron Mittelformen, die ganz allmälig von der einen zur andern überführen. Ebenso wechselt die Höhe des Schaftes von $1^{1}$ /2 c. m. bis 20 c. m. Pr. caucasica C. Koch teste Rupr. Cauc. Pr. 1. c. 301. Pr. algida $\gamma$. albo-farinosa Rupr. l. c. quoad spec. cauc.

₹. luteo-farinosa; foliis subtus dense luteo-farinosis, saepissime subargute denticulatis $v$. crenulato-denticulatis $v$. rarius subintegerrimis. - Scapus $1 \frac{1}{2} \longrightarrow 12$ c. m. altus, sub involucro saepe farinosus. Umbella densa, multiflora. Pedicelli saepissime floribus plus duplo breviores, rarius longiores. Calyx virescens v. apicem versus violaceus. Crescit in regionibus alpinis Caucasi, Turkestaniae, Transbaicaliae et in Sibiria orientali.

P. algida $\%$. luteo-farinosa Rupr. Canc. Prim. in Mel. 
biol. Ac. Petr. 1863 pag. 301, quoad formam foliis sub acute denticulatis calyce apicem versus violascente.

Ruprecht zieht die gelbbepuderte Primula farinosa des Caucasus als Form zu Pr. algida, weil deren Blätter unterhalb dicht gelb bepudert und schärfer gezähnt und deren Kelch kahl und nach der Spitze zu violett gefärbt seien. Uns liegen aber aus dem Cancasus auch Formen mit unterhalb dicht und solche mit schwach bepuderten Blättern vor, die am Rande allerdings meist scharf kleinzähnig; die von Kolenati auf dem Kaepe-Dagh gesanmelten Exemplare haben Blätter mit gelbem Puder und theils scharf, theils stumpf kerbartig klein gezähntem Rande und die von Wilhelms in der Provinz Iberien gesammelten Exemplare haben nur gekerbt-gezähnte Blätter. Ebenso wechselt die Färbuıg der Kelchzähne von der violetten bis zur grünen bei den Exempliren des Kaukasus. Wer daher die gelbpuderige Primula des Caucasus als Form von Pr. algida betrachten wollte, der müsste consequenter Weise Pr. algida und aurh Pr. Inngiscapa eiıfarh als Furmen zu Pr. farinosa ziehen, wogegen wir nicht blos niclits einzuwenden hätten, sondern dieses sugạr für das Richtigere halten wür den. Wir erwähnen noch schiesslich dir fulgenden Unterformen von Pr. farinosa lut o-fariıosa:

lusus a. caucasica; foliis sappissime subarute denticulat:s, calycis glibri dentibus silep. violi.serntilius. Folia in petiolum brevem litum att Indita Floris sirpissime brevissime pedunculati; prtiul.s iuvolure I revioribus v. rarius id excedentions. Corollate tubus ailycem circiter arquans. - Hab. in Cauciso et in T'urkistunial (Korolkuw).

Lusus b. turkestanica; follis ol ovato-1 ble nugis. in pretio. lum brevem late alatum altemnitis, marquine or mulatodenticulatis r. subint gr rims. - Hor.s Lror ssime 
pedunculati. Involucri foliola petiolos superantia. Calyces virides, glabri v. paullo farinosi. Corollae tubo calycem circiter aequanté.

Hab. in Turkestania (Korolkoff) et in Iberia (Wilhelms).

Lusus c. sibirica; foliis obverse oblongis v. subspathulatis, saepissime in petiolum magis elongatum attenuatis; integerrimis v. crenulato-denticulatis v. singulis subacute denticulatis. - Involucri foliola pedunculos aequantia v. saepe superantia. Calyces virescentes, saepe farinosi. Corollae tubo calycem aequante $\mathbf{v}$. usque sesqui superante.

Habitat in Baicalia prope Irkutiam (Turczaninow), in Transbaicaliae alpibus (Radde), in Dalıuria ad fluv. Schilkam (Maximowicz), in Sibiria orientali prope Ajan (Tiling).

13. Pr. farinifolia Rupr; foliis infra farina candida vestitis, obovatis v. spatlulatis, in petiolum laminam saepissime superantem anguste alatum $v$. rarius quam lamina breviorem et plus minus late alatum attenuatis, obtusis v. ex apice rotundato apiculatis, argute serrato-dentatis; involucri foliolis numerosis, e basi exauriculata lineari-lanceolatis, mox recurvis; pedunculis filiformibus, longissinis, plus minus curvatis, flores involucrumque pluries superantibus; calycis campanulati lacimis lanceolatis, acutis, tubo longióribus; corollae tubo calycen demum longe superante; limbi laciniis obcordato-bifidis.

Folia incluso-petiolo $2^{1 / 2}-13$ c. m. longa, $1-3^{1 / 2} \mathrm{c.} \mathrm{m}$. lata. Scapus glaber, folia subaequans v. plus duplo superans. Umbella laxa. Pedunculi $1-5 \mathrm{c}$. m. longi, lattrales curvato. adscendentes v. rarius recti. Caljx circiter $3 \mathrm{~m}$. $\mathrm{m}$. longus et latus, satpe farinosus. Corolla rosea; tubo calycem duplo superante. 
In Caucaso orientali leg. Ruprecht.

P. farinifolia Rupr. Cauc. Pr. in Melanges biol. Ac. Petr 1863 pag. 303.

Ruprecht sammelte diese in Habitus bedeutend abweichende Art an halbdunkeln nassen Felsenhöhlen uud an Quellen im östlichen Caucasus. Nach Ruprecht ist die Blume zur Zeit der Blüthe ungefähr $6 \mathrm{~m}$. m. lang, rosenroth, am Schlunde gelb und der Saum hat nur 3-4 m. m. in Durchmesser. Wir sahen die zahlreichen im Herbarium der K. Academie aufbewahrten Exemplare, welche aber alle nach der Blüthe gesammelt sind. Die Röhre der verblüheten Blumen ist ungefähr $7 \mathrm{~m}$. $\mathrm{m}$. lang.

14. P. luteola Rupr., foliis utrinque glabris, obverse lanceolatise v. elliptico-oblongis in petiolum membranaceo-alatum attenuatis, rotundato-obtusis v. subacutis, inaequaliter v. subduplicato argute serrato-dentatis; umbella multiflora: involucri foliolis numerosis, e basi gibba lineari-lanceolatis, pedicellos initio subaequantibus, demum iis pluries brevioribus; pedicellis filiformibus; florescentiae tempore flores aequantibus usque iis duplo longioribus ; calycis initio tubulosi demum campanulati laciniis lineari-lanceolatis, acutis, tubum superantibus, corollae luteae tubo calycem sesqui-duplo superante, limbi laciniis obcordatobifidis.

Elata. Folia incluso petiolo $10-30 \mathrm{c}$. In. longa, $2-5^{1 / 2}$ c. m. lata, utrinque laete viridia. Srapus $25-50 \mathrm{c}$. m. altus, apicein versus albo-farinosus. Umbella speciminu in caucasicorum simplex, speciminum cultorum prolificatione saepe verticillatoracemosa. Involucrum, pedunculi et calycis margines glabri $\mathbf{v}$. plus minus albo-farinosi. Calyx $5-7 \mathrm{~m}$. m. longus. Corollae tubus, $9-11 \mathrm{~m}$. m. longus, limbus circ. $12-15 \mathrm{~m}$. m. in diametro, pallide sulphureus, fauce aureus.

In Caucaso orientali (Ruprecht).

P. luteola Rupr. Cauc. Pr. in Mel. biol. Ac. Petr. 1863 
pag. 298. - Rgl. Grtfl. 1867 pag. 129 tab. 541.

15. P. auriculata Lam. Lam. ill. n. 1931. - Ejusd. encl. meth. V. pag. 625. - D. C. prodr. VIII. pag. 38. - Vent. hort. Cels. tab. 42. - Rupr. Cauc. Pr. 1. c. pag. 288. - P. auriculata $\alpha$. et P. pycnorhiza Ledb. fl. ross. III. prag. 10. - P. longifolia Curt. bot. mag. tab. 392. - Lehm. monogr. pag. 50. - P. pyenorhiza Rgl. Grtfl. 1863. tab. 391. - Pr. macrophylla C. Koch Linnaea XXIII. pag. 615 (?).

Habitat in regionibus alpinis Caucasi. - Glabra v. scapus apice calycesque paullo farinosi, saepisse elata. Folia obovatooblonga v. obverse lanceolata v. rarius subelliptica, obtusa v. acuta, argute denticulata, $3-15$ c. m. longa.

Scapus folia paullo-pluries superans. Umbella multiflora, densa. Involucri foliola numerosa, basi gibba, pedunculos florlferos superantia. Calycis laciniae lanceolatae, obtusiusculae, tubum paullo superantes. Corolla rosea v. violacea, tubo calycem sesqui-duplo superante, limbi laciniis obcordato-bifidis.

Von Pr. luteola nur durch die Blüthenfarbe, etwas kürzere Blüthenröhre und den an Stengel und Kelchen selten auftretenden Puder, - von' Pr. algida durch üppigeren Wuchs, grös sere Blumen, tiefer getheilten Kelch, längere Röhre und grössere dichtere Blüthendolde verschieden. Die von Ledebour aIs var. 3 . sibirica hierher gezogene, von Karelin und Kirolow im Alatau der Soongorei gesammelte Pflanze, welche C. A. Meyer P. Bungeana genaunt hat, gehört zu Pr. algida.

16. P. darialica Rupr., glabra, foliis obovato-lanceolatis v. obverse lanceolato-oblongis, in petiolum cuneato-attenuatis, obtusis v. acutis, argate denticulatis; involucri foliolis basi exauriculatis, lineari-lanceolatis, quam pedicelli paullo-pluries brevioribus; umbella laxa, pauci-pluriflora; pedicellis filiformibus, florem aequantibus v. usque plus duplo longioribus, flexuosis; calycis campanulati dentibus lanceolatis, acutis, tubum circiter 
aequantibus; corollae tubo calycem paullo usque sesqui superante, limbi laciniis obcordato-bifidis.

Habitu P. farinifoliae Rupr. valde affinis, folia autem glabra et sensim in petiolum breviorem attenuata, $2-8 \mathrm{c}$. $\mathrm{m}$. longa. Scapus folia paullo usque subduplo superans. Involucri foliola saepissime numerosa, rarius pauca, florescentiae tempore saepissime patula v. recurva. Calyx $4-5 \mathrm{~m}$. m. longus, virescens. Corollae limbus $12-14 \mathrm{~m}$. m. in diametro, e roseo kermesinus.

Habitat in Caucaso ad fontes fl. Terek. (Ruprecht).

P. darialica Rupr. Cauc. Pr. 1. c. p. 302.

Ruprecht, der diese Art entdeckt hat, hat solche unweit Darial gefunden und darnach den Namen gegeben.

17. P. algida Adams. Adams in Web. et Mohr Beitr. I. pag. 46. - Lehm. monogr. Pr. p. 68, tab. 7. - D. C. prodr. VIII pag. 39. - Pr, algida et Pr. auriculata $\beta$. sibirica Ledb. fl. ross. III. pag. 11 et pag. 12. - P. Bungei C. A. Mey. in Beitr. z. Pflzk. d. R. R. 22.-P. auriculata Ledb. fl. alt. I.pag. 211. - Ejusd. ic. pl. fl. ross. tab. 243. - Pr. algida $\alpha$. denudata Rupr. Cauc. Pr. l. c. pag. 299. - Pr. glacialis Adam?

Foliis glabris argute dentatis a Pr. farinosa distinguitur. Hab. in regionibus alpinis Caucasi, Turkestaniae (Kuschakewicz, Krause), regionum cis- et transiliensium (Semenow), Soongariae (Kar. et Kiril., Schrenk) et in Sibiria altaica (Ledeb.).

Der weniger tief getheilte Kelch und kleinere Blumen deren Röhre nur so lang als der Kelch oder nur wenig länger, sowie weniger hoher und üppiger Wuchs, scheiden diese Art von P. auriculata.

Von den zahlreichen Formen der folgenden Art unterscheidet sie sich nur durch die schärfere Zahnung des Blattrandes.

Eine Form mit besonders spitzen und lang vorgezogenen Zähnen des Blattrandes, ward von mir aus turkestanischen Samen 
erzogen und in der Gartenflora als Pr. algida cuspidens abgebildet. Wir unterscheiden demgemäss als Formen :

a. typica; foliis argute denticulatis, calycibus viridibus.

$\beta$. cuspidens; foliis cuspidato-denticulatis, calycibus viridibus. - Hab. prope Wernoje et in montibus Alatau Soongoriae.

$\gamma$. colorata; foliis argute denticulatis, calycibus apicem versus atroviolaceis. - Hab. in Turkestania (Kuschakewicz et Krause).

18. $P$. longiscapa $L e d b$; foliis utrinque farina destitutis. - Cetera ut P. farinosae. - Ledb. in Mem. Ac. Petr. V. 520. (Anno 1814). - Variat:

a. typica; foliis integerrimis $\mathbf{v}$. obsolete-crenulatis.

Folia obverse lanceolato-oblonga v. obovato-oblonga, 2-8 m. m. longa, obtusa v. subacuta. Scapus folia semper superans, saepissime elongatus, $10-30 \mathrm{c}$. m. longus, rarius humilis, glaber v. sub apice albo-farinosus. Involucri foliola pedicellos floriferos subaequantia v. superantia $v$. iis rarius $2-3$-plo breviora. Corollae tubus calycem aequans v. usque sesqui superans. Flores rosei, limbo $5-10 \mathrm{~m}$. $\mathrm{m}$. in diametro.

Hab. in Sibiria altaica et baicalensi, in montibus editioribus Soongoriae et regionum cis - et transiliensium in Dahuria, inqne in Caucaso (Bayern).

P. longiscapa Ledb. I. c. - Ejusd. ic. pl. ross. IV. tab. 348. - Ejusd. fl. ross. IV. pag. 12. - P. exaltata Lehm. monogr. Prim. pag. 57. - P. davurica Lehm. monogr. pag. 58. - Pr. intermedia Curt. bot. mag. tab. 1219. - P. altaica Lehm. monogr. pag. 59. tab. V. D. C. prodr. VIII. 43.

B. undulata Fisch.; foliis crenulato-denticulatis.

Scapus 7-14 c. m. altus. Umbella pauci-multiflora. 
Pedicelli floriferi flore plus duplo breviores v. usque plus duplo loggiores. Corollae tubus calycem aequans v. usque sesqui superans.

Lus. a. parviflora; corollae limbo $6-8 \mathrm{~m}$. m. in diametro. - b. grandiflora; corollae limbo 10-14 m. m. in diametro.

Hab. in Dahuria, in regione amurensi, in Sibiria orientali, inque in Curonia.

P. undulata Fisch. herb. et Rchb. ic. crit. v. tab. 468 .

Längere und kürzere Blumenröhre, länger und kürzer gestielte Blumen, ganzrandige und mehr oder weniger deutlich gekerbte Blätter mit kurzem oder langem Stiele, kommen bei Exemplaren der gleichen Lokalität vor, so dass alle die von Lehmann aufgestellten Arten, nicht einmal Formen darstellen. Ledebour (Fl. ross. III. 12), unterscheidet noch eine Form $\beta$. grandiffora, mit fast gekerbten Blättern, armblumigeren Blüthendolden und einer Röhre der Blumenkrone die halbinal länger als der Kelch. Wollte man alle diese Merkmale genau berücksichtigen, dann müsste man eine llenge von Formen aufstellen.

Wir halten daher nur die Formen mit fast ganzrandigen oder undeutlich gekerbten Blättern, - und andererseits die mit deutlicher kerbzähnigen Blättern aus einander. Die letzteren sind grösstentheils mehr im 0sten Sibiriens heimisch, gemeiniglich von niedrigerm Wuchs, mit kurz- oder langgegestielten Blumen und im letzteren Falle mit lockerer Blüthendolde.

Pr. farinosa L. ist nach unserer Ansicht, die Stammart von Pr. algida, Pr. longiscapa und Pr. borealis. In den Alpen und dem Norden Europas tritt dieselbe nưr mit weisser Bepuderung auf der Rückseite der Blätter auf; im Caucasus kommt die weiss- 
und gelbbepuderte Form vor und ist die letztere ausserdem durch schärfere Blattzahnung und theils gefärbte Kelche ausgezeichnet. In Turkestan kommen weiss- und gelbbepuderte Formen vor, die weiss bepudertè ebenfalls mit gefärbtem Kelch, gelb bepuderte ganz von der Gestalt der Pflanze des Caucasus, aber mit stumpfen kleinen Kerbzähnchen des Blattrandes. Bei den gelbbepuderten Formen Baicaliens und Sibiriens, sind die Zähnchen des Blattrandes meist stumpf und die Blätter und Blüthenstielchen meist mehr gestreckt.

Die nicht mit Pudermehl auf der Rückseite der Blätter versehenen Formen, stellen, wenn sie schàrfe Blattzähnc hen haben, die P. algida dar; welchè zu Pr. longiscapa $\beta$. den Uebergang bilden und die Pr. longiscapa ist einfach als die Form mit nicht bepuderten Blättern von Pr. farinosa zu deuten, welche Form bekanntlich nicht blos in Sibirien, sondern zuweilen aüch in Europa einzeln zwischen den normalen Pflanzen vorkomint. So liegen uns z. B. Exemplare der Pr. farinosa mit nicht bepuderten Blätter aus Kurland vor.

Wir haben trotz dieser unserer Ueberzeugung, dass Pr. algida, longiscapa und borealis nur Formen der Pr. farinosa sind, diese Arten vorläufig noch festgehalten, weil wir solche erst noch in der Cultur beobachten möchten, bevor wir eine Vereinigung derselben definitiv proponiren wollten. F. v. Herder hat in Труды И. Б. С. I. 390 schon Pr. longiscapa mit Pr, farinosa vereinigt, trennt aber noch die ganz zu Pr. farinosa übergehende gelbbepuderte Forin.

19. P. borealis Duby.

Duby in D. C. prodr. VIII, pag. 43. - Ledb. fl. ross. III, pag. 15.-Pr. mistassinica Cham. et Schl. Linnaea I. 213.P. gigantea Jacq. misc. I. pag. 160. - Lehm. monogr. Prim. p. 61 tab. 6. - P. parvifolia Duby in D. C. prodr. VIII. 42. 
Hab. in Terra Tschuktschorum, in Kamtschatka et in America boreali.

Ist wohl nur die hoch nordische Form der Pr. longiscapa und unter den Exemplaren der var. $\beta$. b. der letzteren, befinden sich Exemplare mit lang und dünn gestielten Blättern, die schon ganz zu P. borealis hinneigen. Pr. gigantea wird von Ledebour zu Pr. sibirica gezogen, die von Lehmann (l. c.) gegebene Abbildung ist ein üppiges Exemplar von Pr. borealis. Zu Pr. sibirica kann dieselbe schon deshalb nicht gehören, weil den Blättchen der Hülle die sackartigen Anhängsel gänzlich fehlen.

20. P. cuneifolia Ledb.

Ledb. Mem. Ac. Petr. V. 522. (1844). - Ejusd. fl. ross. III. 15. - P. saxifragifolia Lehm. monogr. Pr. pag. 89. tab. 9. (anno1817). D.C. prodr.VIII.p. 39.-Hab. in Sibiria orientali et in Kamtschatka.

21. P. sibirica Jacq.

Pr. sibirica Jacq. misc. I. pag. 161. - D. C. prodr. VIII. 43.

Glabra. Folia elliptico-suborbiculata v. elliptico-oblonga, integerrima v. obsolete denticulata, in petiolum saepissime laminam superantem attenuata. Involucri foliola basi saccato-appendiculata, saepissime pedicel lis $2-3$-plo breviora v. rarius eos subaequantia. Umbella pauci-pluriflora. Calycis tubulosi dentes subacuti v. obtusi, tubo $2-3$ plo breviores, margine brevissime glanduloso-puberuli. Corollae roseae tubus calycempaullo-duplo superans, limbi laciniae obcordato-bifidae.

a. grandiflora; florum limbo $1-1^{1} / 2 \mathrm{c.} \mathrm{m}$. in diametro.

a. genuina Trautv.; tubo corollae calycem parum superante.

P. sibirica $\alpha$. gen uina Trautv. imag. pl. fl. ross. pag. 44. tab. 30. - Ledb. fl. ross. 1. c. - P. rotundifolia Pall. it. III. 223. - P. nutans Georgi it. I. p. 200.

b. brevicalyx; corollae tubo calyce subduplo longiore.-P.sibirica $\beta$. brevicalyx Trautv. l. c. fig. g-i.-P. sibirica Lehm . 
monogr. Pr. tab. V. - Bot. mag. tab. 3167 et tab. 3445. -

P. norwegica Retz fl. scand. n. 240.

Habitat a Rossia septentrionali ad Sibiriam orientalem.

ß. parviflora; corollae limbo 6-8 m. m. in diametro, tubo calycem paullo — duplo superante. - P. finnmarchica Jacq. misc. p. 160. - P. sibirica $\beta$. finnmarchica Rupr. fl. Samoj. n. 203. - P. intermedia Ledb. in Mem. Ac. Petr. V. 519. P. egallicensis Wormsk. in Lehm. monogr. Pr. pag. 64 . tab. 7. - Pr. longiscapa Herd. pl. Semenow. n. 686.

Habitat in Rossia septentrionali, in Turkestania, in regionibus cisiliensibus, in Sibiria orientali et in Kamtschatka.

Die zahlreichen uns aus den Gebirgen Turkestans, (in einer Höhe von $7500^{\prime}$ von 0 . Fedschenko in verschiedenen Lokalitäten, sowie von Scharnhorst bei noch bedeutenderer Höhe gesammelten vorliegenden Exemplare, gehören meistens zur Form $\beta$. Nur von 2 Lokalitäten des Kokanischen Bezirks, liegen uns Exemplare der Form $\alpha$. a. von Baron Kaulbars und von 0. Fedschenko gesammelt, vor. Beide haben ein eigenthümliches Ansehen, indem sie von kräftigern, aber nicht höhern Wuchs, ferner mit länglich-elliptischen schwach gekerbten Blättern und vielblumigem Blüthenstand, so dass sie schon eine nach der folgenden Art hinüber neigende Form bilden.

23. P. Olgae Rgl; glabra; foliis obovato-oblongis, in petiolum late membranace 0 - alatum brevem attenuatis, obtusis v. subacutis, crenulato-denticulatis v. subintegerrimis; involucri foliolis lanceolatis, acutis, basi appendiculato-saccatis, pedicellos floriferos superantibus; umbella pluri-multiflora, densa; pedicellis brevibus, quam flores plus duplo brevioribus; calycis breviter campanulati laciniis lanceolatis acutis tubum subaequantibus; corollae tubo calycem duplo v. plus duplo superante, limbi laciniis obcordato-bifidis. 
Folia $\left.1^{1}\right|_{2}-3$ c. m. longa. Scapus folia saepissime plus duplo superans, rarius initio subnidulans, usque $7 \mathrm{c.} \mathrm{m}$. altus. Involucri foliola $5-7 \mathrm{~m} . \mathrm{m}$, longa. Calyx $3-4 \mathrm{~m} . \mathrm{m}$. longus, viridis, saepissime striolis brevibus purpureis pictus. Corollae tubus pallidus, circiter $8 \mathrm{~m}$. m. longus, limbo ut videtur e roseo-lilacino, 10-14 m. m. in diametro.

P. sibirica Jacq. cui proxime affinis, facile distinguitur: «foliis elliptica-orbiculatis v. oblongo-ellipticis, in petiolum laminam superantem attenuatis; involucri foliolis pedicellis saepissime plus duplo brevioribus, rarius subaequantibus; calycis tubulosi dentibus tubo plus duplo brevioribus.»

Habitat in Turkestaniae valle Sarawsehansk 7-12000' alt. (0. Fedschenko).

\section{SEemania BenaRYi RgL.}

Seemannia Rgl. cfr. Grtfl. 1865, pag. 183 tab. 122.

S. Benaryi Rgl., pilis adpressis brevibus dense hirtula, foliis caulis floriferi saepissime verticillato-quaternis v. rarius quinternis; floribus in axillis foliorum superiorum binis. - Tota planta pilis brevibus appressis hirtula. Herba rhizomate squamoso, perennante. Caules erecti, purpurascentes, a basi supra medium quadranguli, apicem versus teretiusculi. Folia lanceolata, acuminata, integerrima, brevissime petiolata, supra viridia, infra pallidiora, opposita v. terna, caulium „floriferorum quaterna v. quinterna. Flores racemum foliatum elongatum a medio ad apicem caulis formantes, in foliorum superiorum axillis bini, in fol. inferiorum axillis saepe solitarii. Pedunculi folio breviores, altero longiore, altero breviore, purpurascentes. Calyx, corolla, annulum perigynum, germen et stigma ut generis. Corolla oblique adnata, purpurea, basi aequalis, subtus ventricoso.inflata, fauce vix constricta $\left.{ }_{2} 1^{1}\right|_{2}$ c. m. 
longa, 1 c. m. in diametro, limbo brevi erecto aequaliter quinque dentato. Legit cl. Roezl in America tropica.

\section{STANGERIA KATZERI RGL.}

St. Katzeri Rgl., foliis usque 11-jugis; foliolis obverse oblongis, ex apice rotundato-mucronato acutis, margine leviter undulato-repandis, apicem versus repando-crenatis, sub apice interdum dente uno alterove subspinescente.

Planta humilis, caudice brevi rapiformi, vix cicatricato; foliis paucis, ex apice caudicis evolutis, pinnatis, glaberrimis. Petioli teretes, 2837 c. m. longi, apice tantum in latere superiore canaliculati, basi squamis tomentosis parvis suffulti. Lamina $32-40$ c. m. longa, rhachi semitereti. Foliola subopposita, obverse-oblonga, acuta, decrescentia; inferiora in petiolum gracilem $v$. rarius brevem attenuata, cum petiolo $12-19 \mathrm{c.} \mathrm{m}$. longa, supra medium $4-6 \mathrm{c.} \mathrm{m}$. lata; intermedia brevius petiolata, suprema tantum sessilia decurrentia; omnia venis cos. tae perpendicularibus creberrimis passim furcatis, margine leviter undulato-repanda v. apicem versus crenato-repanda, ex apice rotundato apiculato-acuta, sub apice hinc inde denticulo subspinescente instructa. Amentum masculum oblongo-cylindricum, petiolo crasso apicem versus incrassato circiter 6 c. m. longo suffultum; squamis arcte imbricatis, apice inflexo trapezoideo ferrugineo-tomentoso terminatis. Stamina numerosa superficie inferiore squamae adnata.-St. Katzeri Rgl. Grtfl. tab. 798.

Stangeria paradoxa Hook. «foliolis oblongo-lanceolatis acuminatis a medio ad apicem v. rarius apicem versus tantum spinuloso-serratis» facile dignoscitur. 


\section{Tillandia juncifolia Rgl.}

Tillandsia $L$. Perigonii liberi sexpartiti laciniae exteriores calycinae aequales, basi cohaerentes, rectae v. spiraliter tortae, duo altius inter se connatae, tertia supra basin libera, saepe paullo minor; laciniae interiores petaloideae, in tubum convolutae $\mathrm{v}$. connatae, superne patentes $\mathrm{v}$. erectae, basi nudae v. squamosae. Stamina 6 , hypogyna, omnia libera v. alterna perigonii laciniis interioribus adhaerentia; antherae incumbentes, basi sagittato-emarginatae v. subintegrae. 0varium liberum, triloculare. 0 vula in loculorum angulo centrali affixa, bi-pluriseriata, adscendentia, anatropa, apice saepissime appendice lineari. Stylus filiformis; stigma trifidum, nunc lobis abbreviatis dilatatis subcapitatum, nunc lobis filiformibus aut apice dilatatis rectis v. contortis. Capsula cartilaginea, linearis v. "ovata, trilocularis, loculicido-trivalvis. Semina plurima, e basi dissepimentorum erecta, lineari-clavata, stipitata; stipite pilis papposis cincto. - Herbae lepidotae, caulibus foliosis simplicibus v. rarius ramosis, foliis saepe angustis lanceolato-linearibus v. linearibus v. junciformibus, floribus spicatis v. paniculatis v. rarius solitariis.

Sectio Calypstrosperma Rgl. Folia junciformia. Panicula coaretata, e spiculis compressis distichis composita. Calycis segmenta recta. Petala ad apicem recta. Filamenta omnia libera. Antherae basi integrae. 0 vula apice appendice filiformi.

T. juncifolia $R g l$. Caulis simplex, basi dense rosulato-foliatus; caule florifero foliis inferioribus breviore, descrescente laxe foliato; bracteis foliisque in pagina inferiore albido-lepidotis. - Folia e basi dilatato-vaginata fusca mox subulato-semiteretia et in apicem setaceum attenuata, infra albido-lepidota, supra canaliculata viridia glabra, 25-30 c. m. longa. Caulis floriferus (scapus) rufescens, circ. 16 c. m. altus, foliis brevior, apice spicis plurimis (circiter 6) compressis sessilibus congestis erecto-patentibus paniculam congestam formantibus terminatus. Folia caulina iis rosulae similia, breviora autem, superiora rufescentia, 
suprema bracteiformia quam inflorescentia breviora, rosea, e basi ovata in apicem subulatum exeuntia. Spiculae compressae, distichae, circiter 6 florae, 3 c. m. longae, dense congestae. Spicularum bracteae pergameneae, virides, solitariae, distichae, carinatae, calycem amplectentes, e latere lanceolato-oblongae, acutiusculae, dorso dense albido-lepidotae, circiter 2 c. m. longae. Calyx (perigonii laciniae exteriores) bracteam paullo superans, viridis; laciniis duabus in unam bicostatam ventre marginibus inflexis sub apicem connatis, lacinia tertia basi tantum adnata, caeterum libera, lineari-lanceolata, acuta, laciniis lateralibus coalitis quadruplo angustiore et vix breviore. Petala (perigonii laciniae interiores) oblonga, caerulea, a basi ad apicem erecta, in tubum convoluta, basi nuda, calycem duplo superantia, apice obtuso vix reflexo. Filamenta 6 , omnia ad basin libera, filiformia, sub apice paullo dilatata, corolla $1 / 6$ longiora; antherae incumbentes, versatiles, oblongae, biloculares, rimis longitudinalibus rumpentes, basi subintegrae. 0varium oblongo-trigonum. Stylus stamina aequans; stigmate breviter trifido, lobis apicem versus dilatatis et inter se subcoalitis. 0vula in loculorum angulo affixa, adscendentia, pluriserialia, oblongo-linearia, anatropa, apice appendice lineari terminata. - Capsula seminaque ignota. - T. juncifolia Rgl. Grtfl. tab. 811. - T. staticiflora hort. Par. nec. Morren. - T. filiformis hort. Belg. - Habitat verosimiliter in arborum truncis Americae tropicae regionum elevatiorum.

Affinis Tillandsiae (Bonaparteae) junceae Ruiz et Pav. (P'latystachys juncea Beer. Brom. 86) et Tillandsiae divaricatae Benth.

T. juncea Ruiz et Pav. (Fl. peruv. IV. pag. 38. tab. 262 sub B0napartea) caule elatiore foliato, antheris basi sagittatis, stigmatis lobis linearibus facile dignoscitur. - T. divaricata Benth. (Botany of the voyage of Sulphur pag. 174) spiculis 12-15 floris divaricatis breviter pedunculatis, foliis caulinis pilosiusculis diversa videtur. (Stigmatis antherarum et ovulorum figuratio ignota).

Die Gattung Tillandsia umfasst eine Masse von noch sehr unvollkommen bekannten Arten. Die sehr wechselnde Form des Blüthenstandes, 
der Staubbeutel, die Einfügung der Staubfäden, die Form der Narbe un der Eichen, scheinen gute Charaktere zur Abtheilung und Unterscheidung in mehrere Gattungen zu bieten. Der nicht gedrehte Kelch, die bis zum Grunde freien Staubfäden, die am Grunde nicht zweitheilige Anthere, die nach oben verbreiterten in eine kopfförmige Narbe verwachsenen Lappen derselben, durchaus aufrechte Blumenblätter und die mit einem langen linearen spitzenständigen Anhängsel versehenen Eichen, sowie endlich die aus zusammem gehäuften zweizeiligen kurzen Aehrchen bestehende Rispe, scheinen unsere oben beschriebene Art von dem Gattungscharakter, wie solcher gemeiniglich von Tillandsia gegeben wird, zu unterscheiden und zum Typus einer Gattung oder Untergattung zu machen. So lange aber nicht die vielen andern sogenannten Tillandsia-Arten genauer bekannt sind, so lange muss man sich begnügen, die wenigen besser bekannten Arten als Sectionen aufzuführen, wie wir dies mit Wallisia und der in Rede stehenden Art gethan haben.

\section{TULIPA EICHLER RGL.}

Bulbi tunicis externis apice intus strigoso-pilosis; caule elato sesquipedali et ultra, sub lente pedunculoque dense puberulo; foliis loriformi-lanceolatis, attenuato-acuminatis, supra dense minutissime puberulis, caulem superantibus, glaucis; sepalis elliptico-lanceolatis, apice convoluto apiculatis, interioribus obovatis ex apice subtruncato vix apiculatis, omnibus purpureis, basi staminibusque glaberrimis, maculaque nigra luteo-marginata ad basin notatis.

Stamina purpurea, autheram linearem circiter aequantia. Germen cylindricum, antheras subaequans, stigmate trilobo germinis diametro latiore coronatum.

Corollae petala patentissima. - T. Eichleri Grtfl. tab. 799. Prope Baku legit cl. Eichler. Affinis Tulipae Greigi et T. Didieri, T. Oculus solis, T. Borszczowi, T. Julia et T. montana, quae subaequantibus notis dignoscuntur : 
T. Greigi; eaule spithamaeo, follis inferioribus ovatis undulatis cartilagineo-marginatis, sepalis ovatis $\mathrm{v}$. cuneato obovatis.

T. Didieri; pedunculo glabro, sepalis ovato-ellipticis.

T. Oculus solis, T. Borszczowi, T. Julia et T. montana bulbi tunicis intus lanatis v. lanuginosis.

Nachträgliche Bemerkungen zu meiner Aufzählung der Arten der Gattung Tulipa (Труды II. 389) und Vitis. (Труды II. 437).

Es ist mir von verschiedenen Botanikern, deren Stimme von bedeutendem Gewicht ist, der Vorwurf gemacht worden, die Arten der Gattungen Tulipa und Vitis zu sehr zusammen gezogen zu haben. Eine erneute Durchsicht beider Gattungen überzeugte mich, dass im Gegentheil noch theils zu viel Arten, namentlich bei der Gattung Tulipa, aufgestellt wurden .

Die Ansicht was Art, - was Form, -richtet sich bei vorurtheilsfreier Untersuchung wesentlich nach dem Naterial, was der Untersuchung zu Grunde liegt. Liegen die verschiedenen Arten nur von einem oder wenigen Standorden vor, - dann sind die verschiedenen im Begriff der Art sich bewegenden Endformen, nicht blos scharf ausgeprägt, sondern es fehlen auch die Uebergänge nach den andern Formen der gleichen Art und so müssen diese Formen consequenter Weise vom betreffenden Autor noch für gute Arten genommen werden.

Liegt dagegen die Art von zahlreichen Standorten aus einem weiten Verbreitungsbezirk vor, dann treten auch bei den wild gesammelten Pflanzen alle jene zahlreichen Abänderungen auf, die auch bei der Cultur unter verschiedenartigen Bedingungen und stets erneuter Anzucht aus Samen, so häufig zu beobachten sind. Deshalb schlossen die Systematiker des alten Schlages, Kulturexemplare bei Entwerfung ihrer Diagnosen und der Beschreibung der Arten gänzlich aus, oder bildeten wie Schrader z. B. bei der Gattung Berberis, aus jedem Individuum eine besondere Art. Es herrschte ferner früher ziemlich allgemein die Ansicht, dass eine in Nordamerika heimische Pflanze, mit einer in Europa oder Asien heimischen Art nicht identisch sein könne. Es war dies nicht nur ein früher 
von allen Systematikern angenommenes Prinzip, sondern es gehört diese Ansicht trotz der zahlreichen von Asa Gray, Maximowicz, sowie von mir und andern gegebenen Beispielen, in gewissen Kreisen die vor den vorhandenen Thatsachen die Augen zu schliessen belieben, immer noch nicht zum überwundenen Standpunkte. Zunächst nun auf die Gattung Tulipa eintretend, lag mir aus dem Kreise der mit Tulipa sylvestris verwandten Arten, ein ausserordentlich reiches Material vor. Dies berechtigte mich die aus der Verwandschaft v. Tulipa sylvestris zahlreich aufgestellten Arten, die eigentlich zum Theil nur auf die bei den Tulpen so veränderliche Färbung der Blumen, sowie deren Grösse fusste, als Formen zu T. sylvestris zu ziehen. Zu diesen Formen dürfte unter andern wohl auch die von mir noch als T. saxatilis Sieb. fest gehaltene Art gehören, während meine T. sylvestris $L$. n turkestanica nach erneuter Untersuchung richtiger zu den Formen von T. biflora L. gestellt werden dürfte.

Zu Tulipa Gesneriana $L$. habe ich einen Irrthum zu verzeichnen. Es lagen mir zur Untersuchung grossentheils kultivirte Exemplare vor, an denen die äussern Zwiebelhäute entfernt waren. Ich habe in Folge dessen irrthümlich alle Zwiebelhäute von T. Gesneriana als innen kahl beschrieben, dies ist aber nur bei den inneren Zwiebelschuppen der Fall, während an den äussern auf der innern Seitenach oben zu, sich eine zerstreute oder auch dichtere steife angedrückte Behaarung findet. Damit fällt der Unterschied der zwischen T, Gesneriana und der von mir $T$. Schrenkiana genannten Art fort. Allerdings besitzt letztere kleinere Blumen und eine stets dichter gestellte fast die ganze innere Seite der äussern Zwiebelschuppen bekleidende steife angedrückte Behaarung, aber doch ist solche sicherlich nur die von mir verkannte wild wachsende Stainmform der T. Gesneriana.

Zu T. suaveolens Roth. ist zu bemerken, dass ich dieselbe nachträglich auch in im Caucasus wild gesammelten Exemplaren sah und dass ich gegen eine Vereinigung von T. strangulata Reboul und T. altaica Pall. mit T. suaveolens, durchaus keinen Protest einlegeu würde. Ferner 
sah ich T. Didieri Jord., T. Lehmanniana Merklin, T. soogdiana Bge., T. armena Boiss., T. Sibthorpiana Sm., entweder gar nicht oder nur in mangelhaften Exemplaren, so dass ich mir über diese Arten noch keine feste Ansicht bilden konnte.

Endlich habe ich von Th. v. Heldreich in Athen kürzlich die Abbildung und Beschreibung einer neuen Tulpe (Tulipa Haageri) erhalten, welche in der Gartenflora Tafel 790 publicirt worden ist. Es ist das eine der schönsten Formen von T. sylvestris, die unmittelbar neben T. syl-

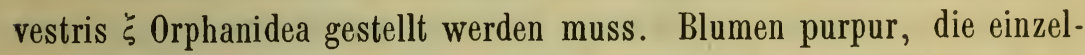
nen Blumenblätter mit gelbem Mittelstreifen und mit blauschwarzem Flecke aul Grunde der Blumenblätter. .

Zur Gattung Vitis übergehend, ist mir in erster Linie entgegen gehalten worden, dass die in America heimischen Arten dieser Gattung sicherlich gut spezifisch von den in Asien heimischen Formen verschieden seien. Schon Asa'Gray, der tüchtigiste Kenner der Pflanzen Nordamerikas, der auch die Flora Japans gründlich studirt hat, zog mit vollster Berechtigung V. Thunbergi einfach zu V. Labrusca und ich kann nur auf's Neue bestätigen dass nicht nur zwischen dieser ersteren Art, sondern auch zwischen den asiatischen Formen der Vitis vulpina und denen Nordamerikas sicherlich kein spezifischer Unterschied stattfindet,- sondern dass wenn ich einen Zweifel habe, dieser nur darin besteht, - ob nicht $V$. amurensis und $V$. aestivalis, richtiger als Uebergangsformen von V. vulpina zu V. Labrusca zu betrachten sind.

Der zweite mir gemachte Vorwurf besteht darin, dass die buchtig gelappte Form von Vitis heterophylla (V. heterophylla is Maximowiczi), ferner von V. Labrusca ( $V$. Labrusca c. ficifolia und d. sinuata), schon deshalb gut verschiedene Arten seien, weil solche im Garten kultivirt, ihre Form nicht veränderten. Wer aber, frage ich, ist im Zweifel darüber ob die schlitzblättrigen Formen von Alnus incana und A. glutinosa, von Betula alba, Tilia parvifolia, Sambucus nigra u. a. m. nur Formen oder gute Arten sind und dennoch bleiben auch diese ungeschlechtlich vermehrt, sich unter allen Verhältnissen in der Kultur treu.

Die buchtig lappigen Formen von V. heterophylla und V. Labrusca, 
werden in Kultur aber ebenfalls nur ungeschlechtlich fortgepflanzt und behalten in Folge dessenihre spezielle Gestalt bei. Herr C. Maximowicz, der diesse buchtiglappigen Formen beider Arten in Japan beobachtete, theilte mir mit, dass an sonnigen Standorten die buchtig lappige, an schattigen Standorten die gewöhnliche Form vorherrsehe und dass man an 0rt und Stelle sich leicht überzeugen könne, dass ein spezifischer Unterschied da nicht existire. Bei V. heterophylla ist die buchtig lappige Form, wahrscheinlich nur die Form der spätern Entwickelung, welche dann durch die ungeschlechtliche Fortpflanzung festgehalten wird, wie dies z.B. auch bei den ganzblättrigen Formen des Epheu der Fall ist.

Bei V. Labrusca und V. aestivalis geht dagegen die Form mit ungetheilten oder eckiglappigen Blättern ganz allmälig bis zur Form mit buchtig-lappigen Blättern über. Bei Vitis vinifera $L$. endlich, sind seit alten Zeiten verschiedene schlitzblättrige Formen bekannt, welche seit Jahrhunderten ungeschlechtlich fortgepflanzt werden, ohne ihre Blattform zu verändern und keiner denkt daran solche zu eignen Arten erheben zu wollen.

Wenn ich also bei meiner Zusammenstellung der Tulpen und Weinreben gefehlt habe, so ist nach meiner Ansicht dieser Fehler nicht in der Aufstellung und Annahme von zu wenig Arten, - sondern im Gegentheil in der Annahme von noch zu viel Arten begangen worden, indem ich bei meiner Bearbeitung vom Grundsatze ausging, noch alle die Arten zu halten, wo nicht unmittelbar Uebergänge vou der einen Art zur andern vorlagen. Da, wo also das mir vorliegende Material mangelhaft war, musste ich manche wahrscheinlich unhaltbare Art, noch als Art beibehalten. Jeder der je an die vorurtheilsfreie Bearbeitung einer Gattung oder Familie gegangen ist, der weiss es, wie leicht es ist, zwischen nah verwandten Arten scharfe Unterschiede fest zustellen, sofern nur einzelne Exemplare zur Vergleichung und Untersuchung vorliegen, dass aber solche scharfe Unterschiede sich um so schwerer auffinden lassen, je reicher das vorliegende Material an Exemplaren von verschiedenen Florengebieten und Standorten, wo dann bei genauer Vergleichung 
zuletzt viele sogenannte Arten zu den F́ormen einer einzigen weit verbreiteten und vielgestaltigen Art vereinigt werden müssen.

Hieran scheint es mir nothwendig einige Worte über dic hedeutende Verwandtschaft der Florengebiete des 0stens des mittlern und südlicheu Asiens mit denen der Vereinigten Staaten Nordamerika's, sowie über das was ich für Art halte, anzureihen.

Schon im Jahre 1861 bei der Bearbeitung der von llaack im Ussu. rigebiete gesammelten Pflanzen (Tentamen Florae Ussurieusis, Hém. de l'Ac. St. Pétersb. tom. IV n. 4, pag. 220-221), gab der Referent till Verzeichniss von 156 Pflanzenarten, welche dem Ussurigebiet und den Vereinigten Staaten Nordamerikas gemeinsam. Von diesen waren allerdings nur 27 diesen beiden Gebieten ausschliesslich eigenthümliche Pflanzeurarten, während der Rest die überhaupt weit verbreiteten gemeinen Pflanzen repräsentirt. Ich sprach mich damals dahiu aus, dass vou den 27 ersteren, 15 im Ussuri-Gebiet ihre Nordgränze erreichen und also entweder nur in Folge einer südlichern in frühern Perioden bestandenen Verbindung zwischen den Staaten Nordamerikas und 0stasien übergetreten sein könuten, - oder dass sie als Reste aus der Tertiärzeit $z u$ betrachten seien, indem sie in dem zu jener Epoche noch verbundenen Norden Asiens und Nordamerikas lebten und sich von da aus bis zu den südlichern Breitegraden beider Welttheile verbreiteten, später aber im Norden in Folge des veränderten Klimas ausstarben und nur in den südlichern Breitegraden beider Welttheile erhalten blieben.

Seitdem ist vieles geschehen was zur Begründung der letztern Ansicht beiträgt, dass nämlich alle der alten Welt und Nordamerika gegenwärtig gemeinsamen Arten, soweit solche nicht durch den IIenschen eingebürgert wurden, als Reste der Tertiärzeit betrachtet werden müssen. Die Polarländer waren damals sehr wahrscheinlich untereinander verbunden und besassen die Flora des kalten gemässigten oder warmen gemässigten Klimas unserer Epoche. Bei der allmäligen Umänderung des Ḱlimas iı den späteren Epochen der Tertiärzeit, während der Diluvialzeit und der allmäligen Vergletscherung des Nordeus, mussten dieselben immer mehr 
nach dem Süden beider Continente fortwandern, wo uns solche jetzt erhalten geblieben sind.

Heer's Untersuchungen über die Flora der Polarländer der Tertiärzeit, hat dort eine grössere Zahl der Typen nachgewiesen, die als die Stanmältern mancher jetzt in Nordamerika nnd dem südlichern 0stasien heimischen Pflanzenformen angesehen werden müssen. Die Flora Japans ist durch $C$. Maximowicz und Asa Gray viel genauer bekannt geworden und letzterer hat kürzlich wieder in seiner Adresse an die *American Association for the advancement of science», die Uebereinstimmung vieler Pflanzentypen der Flora 0stasiens und des Mississippi-Gebietes der Vereinigten Staaten nachgewiesen und gleichfalls diese Uebereinstimmung aus der Pflanzenwanderung in der auf die Tertiärzeit folgenden und zu unseren Jetztwelt übergehenden Periode erklärt. Asa Gray hat jene Adresse eigentlich an diejenigen Systematiker gerichtet, welche jetzt noch annehmen, dass alle in Amerika heimischen Pflanzen, von den durchaus ähnlichen Formen Asiens oder Europas specifisch verschieden seien, - eine Annahme die vor 40 Jahren unter den Systematikern als allgemein gültiges Gesetz galt und jetzt noch von manchem der ältern hochstehenden Systematiker vertreten wird.

In der von uns angezogenen Schrift hat Asa Gray noch auf ein anderes sehr interessantes Faktum hingewiesen, - dass nämlich die Flora Californiens und des Oregon-Gebietes, welche beiden Gebiete dem 0sten Asiens ja am nächsten liegen, viel weniger Typen aufzuweisen hat, welche mit Pflanzentypen 0stasiens nahe verwandt sind, (wie z. B. die Gattung Philadelphus eins dieser wenigen Beispiele ist), als die westlicheren Gebiete Nordamerikas.

Die weit grössere Annäherung und Verwandtschaft zeigen nämlich die Mandschurei, Japan, China und der Himalaya einerseits und die atlantischen südlichern Staaten Nordamerikas inclusive des Mississippi-Gebiet andererseits, in vielen gemeinsamen oder nahe mit einander verwandten Typen ihrer gegenwärtigen Pflanzenwelt. Wahrscheinlich haben die hohen Gebirgsketten, welche die Küstengebiete des Westens der Ver- 
einigten Staaten auch für die Jetztwelt abschliessen und seiner ganzen Pflanzenwelt ein vom 0sten durchaus verschiedenes Gepräge verliehen haben, die Pflanzenwanderung der Tertiärflora auch damals schon nur partiell zugelassen, während die östlichen ebenen Theile Nordamerikas dieser Pflanzenwanderung nach den Süden keine Hindernisše entgegen stellten.

So sind z. B. wie das Asa Gray in jener Schrift zeigt, die beiden Sequoia-Arten Californiens aus der Tertiärzeit nur dort erhalten worden, das über den grössten Theil des Gebietes der alten Welt und Nordamerikas in der Tertiärzeit verbreitete Taxodium distichum, ist dagegen in Californien nicht mehr vorhanden, sondern nur in den westlichen Staaten Nordamerikas bis Texas hin erhalten geblieben. Torreya macht eine Ausnahme, (Taxites, der Tertiärflora) indem diese Gattung jetzt noch in Californien, den Oststaaten Nordamerikas und in Japan und China seine Vertreter hat. Den atlantischen Staaten Nordamerikas und dem 0sten Asiens, sind aber viel zahlreichere Gattungen und Arten gemeinsam geblieben, von denen die Stammeltern auch schon in der Flora der Tertiärzeit der Polarländer nachgewiesen sind, so Platanus, Acer, Liquidam. bar etc. - Wir führen dies hier an, weil Asa Gray damit gezeigt hat, dass die Annahme einer Wanderung von 0sten nach Westen mittelst einer versunkenen Landverbindung, unmöglich ist.

Der Begriff was Art im Pflanzenreiche wird sehr verschieden gefasst und hängt wie ich oben sagte theils von dem Material was der betreffende Autor zur Untersuchung vor sich hatte, theils von dein was er selbst in der Natur im Freien beobachtete und wie er den einzelnen Pflanzenarten auf feuchtem und nassen Boden, (z. B. Ranunculus aquatilis) in der Sonne und im Schatten, oder auf verschiedene Standorte in der Ebene und in der Höhe der Gebirge, auf verschiedenen Bodenarten, -ja selbst über weitere Ländergebiete nachging, theils endlich ob er Gelegenheit hatte das Verhalten der Pflanzenart im Kulturzustande bei fortgesetzter Fortpflanzung aus Samen, oder endlich die scheinbare Verbin- 
dung zweier an sich gut getrennter Pflanzenarten durch Erzeugung von Bastarden und Mischlingen, zu beobachten,

Nur wer alles das in unbefangener Weise zu beobachten Gelegenheit hatte und von der Eitelkeit fern ist, eine Menge neue Arten auf Formen der gleichen Art zı gründen, oder der im Falle des Irrthums gern seinen Irrthum zurück nimmt, um so mehr als es keinen Systematiker giebt, der in dieser Beziehung nicht zahlreiche Irrthümer begangen hätte, - kanı ein freies unbefangenes Urtheil, über das was Art, was Form, was Bestard, was Mischling, was Raçe im Pflanzenreich ist, beanspruchelı.

Es ist eine bekannte Sache, dass unter den Milliarden von Blättern der gleichen Pflanzenart, wohl kaum ein Paar gefunden werden, die einander vollkommen gleich. Noch weniger gleichartig bilden sich die Individuen der gleichen Art unter ganz gleichartigen Verhältnissen aus. Diese Verschiedenheit der Individuen nimmt natürlich zu, wie Boden, Standort, Klima etc. sich ändern. Letztere Verschiedenheiten werden unter fortdauernd gleichartigen Verhältnissen von Generation zu Generation gleich den Raçen der Kultur, mehr oder weniger fixirt, so dass selbst unter veränderten Verhältnissen derartige Formen einige Generationen hindurch zuweilen ıhre Eigenthüınlichkeiten behalten, wie z. B. die von Larix europaea (Die Form mit niederliegendem Stamme oder mit hängenden Zweigen, welche als Larix pendula beschrieben ist) ferner Larix dahurica Trautv., (in den Gebirgen Dahurieus als niederliegender Strauch, im liesigen Garten und den mandschurischen Waldungen als hoher mächtiger Baum).

Nehmen wir nur im Allgemeinen diesen Gang der Veränderung der Art innerhalb ihres Artbegriffes an. so musste auch die von der Tertiärzeit auf unsere Jetztwelt übergegangne Pflanzenart, sich unter den jetzt ganz veränderten Wohuplätzen und Verhältnissen etwas verändern, weshalb die unsern Pflanzen der Jetztwelt ähnlichen Pflanzen der Vorwelt, meist einen andern Namen erhielten. Dass diese Veränderungen welche die Pflanzenart in jenem immens langen Zeitraume erlitt, eine so ge- 
ringfügige ist, so dass sich jetzt noch die Identität nachweisen lässt,spricht für die Beständigkeit der Art und nicht für die Entstehang der einen Pflanzenart aus einer andern. Sehen wir doch ähnliche u:bedeutende Abänderungen bei den Pflanzenwanderungen über weite Strecken, auch jetzt noch entstehen. So wird, wenn wir bei dem Beispiel der Gattung Ranunculus bleiben wollen, bei der Wanderung von dem Westen nach 0 sten der alten Welt, aus Ranunculus auricomus L. der R. cassubicus L. - aus Ranunculus Flammula L. der R. reptans L. Ich habe hier ahsichtlich Beispiele aus dem Bereich der vom Vater der Systematik aufgrstellten unhaltbaren Arten herausgegriffen. Ich brauche blos die Gattungen Hieracium, Rubus, die auf Ranunculus aquatilis und Scleranthus amnuus gestützten Arten zu nennen, un daran zu erinnern, in welcher unbegreiflicher Weise und mit welcher absichtlichen Blindheit gesündigt worden ist und wie mancher Autor da seine ganze Weisheit aufgeboten hat, um zu zeigen wie scharf er noch das unterscheiden könne, was gewöhnliche Augen und Urtheil unbedingt als das Gleichartige erklären müssen.

Wenn ich so einerseits auf die Wandelbarkeit der Art innerhalb ihres drtbegriffes unter verschiedenartigen Verhältnissen hingewiesen, wenn ich andrerseits die Abstammung einer grossen Zahl der Pflanzenarten unserer Jetztwelt aus denen der Tertiärzeit vertreten und wenn ich endlich das allmälige Aufbauen des Pflanzen- und Thierreiches im Laufe der verschiedenen Epochen die unsere Geologen in der Bildungsgeschichte uuseres Erdballes unterscheiden, von dem Unvollkommnern zum Voll. kommnern als eine Thatsache anerkenne, - so halte ich andrerseits auch ebenso entschieden meine mehrfach in frühern Schriften ausgesprochene Ansicht fast, dass mit dem Entstehen des ersten Individuums irgend einer Art, auch deren Artbegriff geschaffon ward, der ill den folgendell Generationen sich consequent fortpflanzt und bei den untergegangenen Arten von Pflanzen und Thieren auch mit dem letzten Gliede für immer verloren ging, ohne sich aus den noch vorhandenen niederen 0rganismen wieder erzeugeu zu können. 
Wenn die Pflanzenart sich innerhalb ihres Artbegriffes in einer Menge von Formen bewegt und diese Formen fälschlich als Arten beschrieben werden und dadurch nur die falschen Beispiele für das Uebergehen der einen Art in die andere geliefert werden, - wenn in der Kultur durch Bastard- und Mischlings-Erzeugung Raçen hervorgebracht werden, die für die speciellen Zwecke des menschlichen Haushaltes von grössern Nutzen sind, - so sind damit wohl Beispiele einerseits der Veränderlichkeit der Art innerhalb ihres Begriffes, andrerseits für das Entstehen neuer Mittel-Formen durch geschlechtliche Vermischung zweier Arten hingestellt; aber damit ist auch nicht im Geringsten der Beleg für die allmälige Umbildung vom einfacheren zum vollkommeneren 0rganismus gegeben.

\section{VER ONICA NUdiCAULiS Kar. ET Kir.}

Annua, humilis, puberula, superne glandulifera; foliis oblongis v. lanceolato-oblongis, basi attenuatis, pedicellis calycem superantibus, initio erecto-patentibus, deinde plus minus recurvatis, calycis ségmentis quatuor, basi per paria breviter connatis, oblongis v. lanceolatis, obtusiusculis v. subacutis, margine sub lente ciliolatis, capsula immatura longioribus, matura paullo brevioribus, unineriiis $v$. obscure trinerviis; capsula tranverse latiore, profunde biloba, glandulosopilosa ciliataque, lobis obtusis; seminibus oblongo-cylindricis, tranverse elevato-rugulosis.

a. simplex; caule erecto, simplici, 4-6 c. m. alto, basi nudo, foliis integerrimis. - V. nudicaulis Kar. et Kir. enum. pl. Soong. n. 608. - Ledb. fl. ross. II. 252.

3. ramosa; caule erecto $\mathrm{v}$. adscendente $\mathrm{v}$. e basi procumbente ad. scendente; foliis inferioribus grosse-v. crenato-dentatis, superioribus integerrimis. - V. nudicaulis Rgl. in plant. Semenov. n. 801.

Habitat in dese.tis soongoro-kirghisicis, in regionibus iliensibus et in Turkestania. 
Die V. nudicaulis ist von Karelin und Kirilow nach mageren dürftigen aufrechten nicht verästelten Exemplarn f st gestellt worden, wilche noch keine reifen Früchte besassen, weshalb sowohl von diesen Autoren, wie nach denselben von Ledebour, diese Art als einfach und vom Grunde aus kahl (ohne Blätter) und die Kelchlappen als etwas länger als die Capsel, beschrieben wurde, was aber nur bei den noch jungen unreifen Früchten der Fall ist. Schon aus dem Ili-Gebiet lagen uns verästelte, aber noch grossentheils aufrechte oder schwach aufsteigende Exemplare vor, deren untere Blätter gekerbt-gezähnt. Jetzt endlich haben wir aus Samen, die Oberst Korolkow und Krause auf der Chiwa-Expedition gesammelt haben, Pflanzen erzogen, die stark verästelt, aus niederliegendem Grunde aufsteigen und deren untere Blätter scharf und fast grob gezähnt. Diese lebenden Pflanzen trugen auch reife Kapseln, wonach wir die eigenthümlichen Samen beschrieben, sowie feststellen konnten dass die Fruchtstielchen sich zuletzt zurück biegen und auch die Kelch. lappen länger als die reife Capsel werden.

V. nudicaulis ist der V. biloba sehr nahe verwandt, unterscheidet sich aber durch meist nur einnervige, selten am Grunde undeutlich 3 nervige Kelchlappen, die kürzer als die reife Capsel, ebenso durch der Queere nach stark erhaben geringelte Samen.

41. Supplementum ad Pironneavam Morrenianam (n. 33 ).

Es ist uns bei der zerstreuten Literatur entgangen dass diese Art schon wiederholt beschrieben ward.

1864 im «Journal de la Sociéte centrale d'horticulture, pag 385, wird sie von Bronguiart als Hohenbergia erythrostachys beschrieben und abgebildet. 0b nun Pironneava als Gattung mit Hohenbergia, wie solche Brongniart definirt, zusammen fallen muss, das vormögen wir jetzt noch nicht zu entscheiden, es scheint uns aber Pironneava gut begründet, auch war diese letztere Gattung schon aufgestellt, 
bevor Brongniart die von Schultes zu Hohenbergia gebrachten Arten in mehrere Gattungen vertheilte. 'Brongniart war die von Gaudichand aufgestrllte Gattung Pironneava, bei seiner Vergleichung der mit Aechmea und Hohenbergia verwandten Gattungen, entgangen und so dürfte Pironneava Gaudich. jedenfalls als Gattung aufrecht erhalten werden müssen, die sich durch den Blumenblättern ganz angewachsene Staubfäden und dic Form der Kelchblätter von Hohenbergia unterscheiden würde.

Ferner ward unsere Pflanze von Hooker (Bot. Mag. tab. 5668) als "Aechmea glomerata» beschrieben und fälschlirh für eine mit Pironneava glomerata Gaudich, identische Art gehalten. Auch Hooker waren weder Brongniarts noch C. Koch's Arbeiten in dieser Richtung hekannt.

C. Koch hat nämlich schon in der Wochenschrift 1861 pag. 189 eine Pironneava roseo-caerulea beschrieben, welche sofern sie mit unserer Pironneana Morreniana identisch sein sollte, in Bezug auf Beneunung die Priorität haben müsste. Diese letztere Art müste aber hevor man eine solche Vereinigung vornehmen könnte, noch mit unserer Pflanze genau vorglichen werden, indem sich dieselbe $\mathrm{z}$. B. nach $\mathrm{K} 0 \mathrm{chs}$ Beschreibung durch gelbliche Brakteen (die unserer Pflanze sind weiss. häutig) und gelbliche Brakteolen (die unserer Pflanze rosa-purpur) unterscheidet, wozu bei genauer Vurgleichung wohl noch andern Merkmale treten möchten,

Wir halten daher auch jetzt noch den unserer Pflanze, nach dem Monograph der Bromeliaceen Herrn E. MI o r ren, gegebenen Namen fest. bis die Identität unserer Pflanze mit P. roseo-coerulea C. K $0 \mathrm{ch}$, unzweifelhaft bewiesen ist. Herr E. Morren, der auch die Bromeliaceen der Herbariums unseres Gartens behufs seiner monographischen Bearbeitung erhalten hat, wird diese Frage am Besten beantworten können. Seinc uns brieflich gegebenen Notizen sind die Veranlassung dieses Nachtrages. 


\section{DESCRIPTIONES}

\section{PLANTARUII NOVARUII}

ET

\section{MINUS COGNITARUM.}

Fasciculus III.

AUCTORE

E. REGEL.

F' TIOTOLIS.

1875.

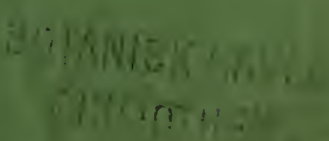




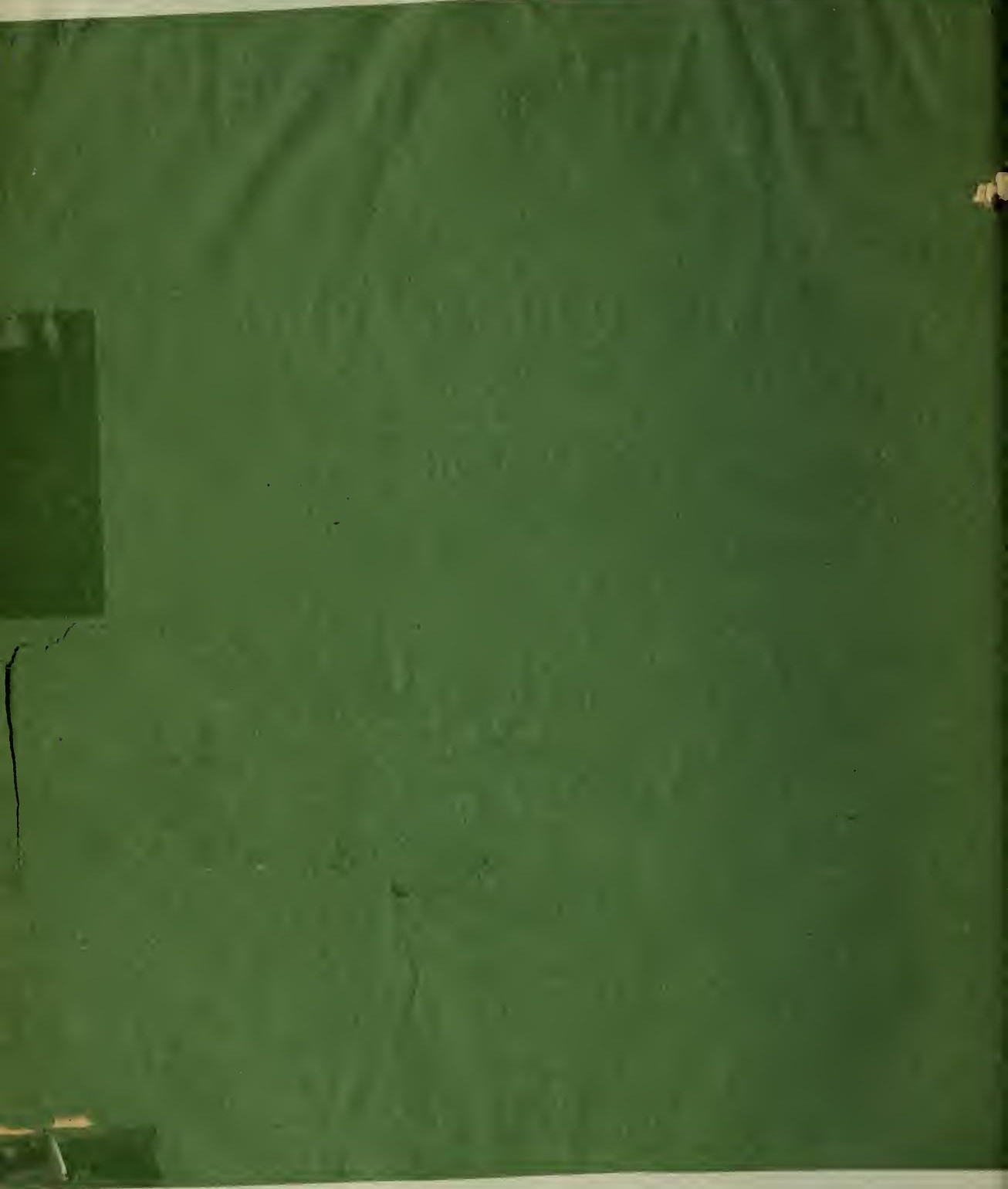




\section{DESCRIPTIONES}

\section{PLANTARUM NOVARUM}

ET

\section{MINUS COGNITARUM.}

Fasciculus III.

AUCTORE

E. REGEL.

PETROPOIIS.

1875.

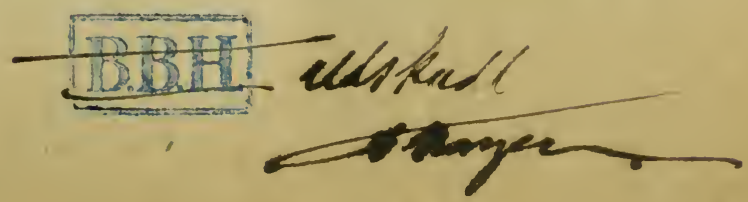


Типографія Братьевъ ІІумахеръ, Вас. Остр., Загибенинъ пер., № 1.

$$
\text { …tas }
$$




\section{A. DESCRIPTIONES PLANTARUII IN HORTO IMPERIALI BOTANICO PETROPOLITANO CULTARUII.}

\section{Billbergia Brongniarti Rgl.}

B. Brongniarti Pugl., foliis elongatis, initio erectis, demum a medio recurvato-dependentibus, late ligulatis, ex apice obtuso subito acuminatis, margine spinuloso-serrulatis, scapum longe superantibus; foliis caulinis bracteiformibus, persicinis, scapum glabrum arcte involventibus, apice breviter acuminatis; spica oblongo-cylindrica, densa; bracteis magnis, ellipticis, acutis, concavis, erectis, adpressis, persicinis, flores subaequantibus: floribus simplicibus, axillaribus, breviter pedunculatis, superioribus solitariis, inferioribus geminis, infimis in ramulum brevem triflorum bracteolatum dispositis, calyceque glaberrimis; calyce supero, trilobo; lobis ovatis, spiraliter sese amplectentibus, apice obtusis, sursum sub apice arista setacea auctis.

Folia glabra, margine et apicem versus in latere inferiore leviter purpurasccntia v. utrinque purpurascentia, basi late amplectente inermia, caeterum spinuloso-serrata, usque $70 \mathrm{c.} \mathrm{m}$. longa et $4-5 \mathrm{c}$. m. lata. Calyx basin versus germineque roseus, apice albus. Sepala caerulescentia, anguste oblonga, obtusa, initio erecta et conniventia, post anthesin patula. Stigmatis magni capitati lobis spiraliter contortis. - B. Porteana h. Makoy. Portea kermesina Brongn. (?) - Revue hort. 1870. p. 230. - Rgl. Grtfl. 1875. tab. 829. 
Ab omnibus affinibus speciebus «bracteis erecto-adpressis, floribus omnibus bractea magna stipitatis infimis in ramulum brevem dispositis, calycis lobis arista setiformi laterali auctis», facile dignoscenda.

\section{Calathea Körnickeana Rgl.}

Acaulis; petiolis longis, cylindraceis, basi vaginantibus, minutissime puberulo-scabriusculis; lamina elliptica, acuta v. apice breviter acuminata, glaberrima, supra nitida, margine undulata; spicis ovato-cylindricis floribusque glaberrimis, breviter pedunculatis; bracteis coloratis, latioribus quam longis, obtusis, crateriformi-patentibus, margine undulatis, quam flores paullo brevioribus; floribus albis, petalis oblongo-lanceolatis.

Petioli $10-20$ c. m. longi, virides, apice geniculo compresso-cylindraceo lateraliter utrinque violascente. Lamina $12-20 \mathrm{c.m}$. longa, 7 -12 c. m. lata, supra lucida, laete viridis, infra pallidior. Scapus $4-5$ c. m. altus, basi foliis tribus congestis distiche dispositis vestitus. Bracteae imbricatae, inferiores rubicundae, superiores albidae. Bracteolae dorso utrinque alatae, florum geminum tubum circiter aequantes. Sepala 3 , oblongo-lanceolata. Petala cum staminodiis in tubum angustum sepalis paullo longiorem connata, oblongo-lanceolata. Staminodium externum cucullatum, explanatum, subdeltoideum. Staminodia interna cum stamine fertili 3: externum magnum, ovato-oblongum, semibilobum, lobo callo terminato: internum cucullatum, apice capitatum rostratumque stylum involvens; stamen fertile petaloideum, oblique truncatum; anthera ovatooblonga, lateralis. Stylus apice rectangule infractus, stomate truncato. C. Riedeliana h. Paullowsk. - C. propinqua h. Petr.

Affinis C. grandifoliae et C. propinquae. Prima foliis petiolisque omnino viridibus duplo majoribus, scapo elato $1-2$ pedali foliis magis disjunctis vestito, bracteis viridibus, floribus majoribus luteis, - altera petiolis glaberrimis, spica sessili, bracteis acutis viridibus piloso-puberulis, corolla longe exserta tubo bipollicari villosulo, — facile dignoscuntur. Patria verosimiliter Brasilia. 


\section{Calochortus glaneus Rigl.}

Liliaceae.

Caule unifolio; folio glauco, lineari-lanceolato, umbellam superante; umbella triflora; bracteis foliaceis, oppositis, lineari-lanecolatis, pedunculis florentibus brevioribus, umbellae basin fulcrantibus; sepalis exterioribus lanceolatis, acuminatis, albidis, calvis, quam interiora brevioribus; sepalis interioribus ovato-subrotundis, breviter abrupte acuminatis, extus albidis calvis, intus basi tantum roseis calvis, caeterum albis setisque eglandulosis dense barbatis; setis exterioribus albis, interioribus basi plus minus purpurascentibus. - Sepala interiora circiter $15 \mathrm{~m}$. m. longa. 0varium oblongum, acute trigonum; stigmata 3 , linearia, patentia; stylus nullus.

Cyclanthera caerulea h. Ellwes.

\section{Rirbus Roezli Rgl.}

Inermis. Caules erecti, lignosi, decorticantes, ramosi. Rami teretes, juniores minute puberuli. Folia cordato-reniformia, obtuse $3-7$ loba, duplicato-dentataque, utrinque pilis minutis simplicibus glanduliferisque pubescentia, supra laete viridia, subtus pallidiora; petioli folium subaequantes, minute pubescentes. Stipulae scariosae, lanceolatae, ima basi interiore coalitae. Flores albi. Petiolus terminalis, solitarius, uniflorus, minute glanduloso-puberulus. Calyx glanduloso-puberulus; sepala petalis subduplo breviora, e basi ovata in cuspidem linearem acuminata. Petala e basi cuneata obovata, obtusa, antice grosse crenato-dentata.

Folia sub anthesi $3-3^{1} / 2$ c. m. longa et $3^{1 / 2}-4 \mathrm{c}$. m. lata.

Habitat in America boreali-occidentali in terra Colorado. Roezl semina misit. - Affinis R. nutkano, differt autem integumento minute puberulo, foliis minoribus, pedunculis unifloris, sepalis antice crenatodentatis.

\section{Schlimia Rgl.}

(Gentianearum genus novum.)

Calyx tubulosus, 5 -lobus; lobis imbricatis planiusculis. Corolla tubo valde elongato, medio clavato-inflato, utrinque attenuato, apice constricto ; 
limbi 5-partiti lobis erecto-patentibus. Stamina 5, corollae tubo supra basin inserta; filamenta longissima, tubum subaequantia. Antherae linearioblongae, biloculares, dorso supra basin affixae. 0varium liberum, annulo basilari destitutum, valvulis introflexis biloculare, multiovulatum. Stylus filiformis, elongatus; stigma bilamellatum.

\section{Schlimia princeps.}

Lisianthus princeps Lindl. in Gard. Chron. 1849. pag. 628. - Fl. des serres tab. 557. - Karst. fl. columb. tab. 141.

\section{Staphylea colchica Steven.}

Foliis pinnato $3-5$ phyllis; foliolis ellipticis, acuminatis, argute serratis; floribus racemosis; sepalis petalisque lineari-oblongis; staminibus corolla paullo brevioribus, glabris; stylis filiformibus, apice in stigma trilobum coalitis; capsula obovata, apice divergenti-triloba, lobis stylo filiformi acuminatis.

Frutex ramis fuscis, ramulis viridibus teretibus laevibus glabris. Folia longe petiolata, opposita; petiolus glaber, basi utrinque stipula linearifiliformi mox caduca fultus; foliola subtus basin versus ad nervum medium pilosa v. subbarbata, caeternm glabra, elliptica v. oblongo-elliptica, acuminata, in una eadem planta terna usque quina, lateralia sessilia stipellata; stipellis linearibus mox caducis. Florum racemus terminalis, nutans, foliis brevior. Flores albi. Sepala 5, alba, petaloidea, lineari-oblonga, obtusa, circiter $12 \mathrm{~m}$. m. longa et $3 \mathrm{~m}$. m. lata. Petala 5, oblonga, obtusa, sepalis vix longiora. Stamina 5 , corollam stylosque subaequantia; filamenta filiformia glabra.

St. pinnata, ,cui planta Steveni satis affinis: «foliolis 5-7, racemis folia superantibus, floribus brevioribus, sepalis petalisque ovatis, capsulae globosae lobis conniventibus, stylis persistentibus rectis coronatis» facile dignoscitur. St. colchica Steven in Ann. sc. nat. ser. IIl. tom. XII. pag. 375 . - C. Koch. dendr. I. pag. 517 (?).

Habitat in provinciis caucasicis.

Steven beschreibt diese Pflanze theils unvollkommen, theils in Folge der Verwechslung der bald aus einander tretenden Griffel mit den Narben- 
lappen, folgendermassen: "foliis teruatis; foliolis ovatis, serratis, ima basi subtus puberulis; floribus racemosis; stigmatibus subulato-filiformibus; capsulae lobis apice divergentibus».

C. Koch hat entweder gar kein Exenılar, oder noch wahı'scheinlicher eine falsche Pflanze bei der Eintwerfung seiner Beschreibung in der Dendrologie vor sich gehabt, denn von den charakteristischen Herkmalen, die diese Art von St. pinnata unterscheiden sagt er nichts, giebt dagegen Charaktere die gar nicht vorhanden, wie $\mathrm{z}, \mathrm{B}$. : «Nebenblättchen länger als Stiele, Staubfäden mit langen Haaren besetzt». Nun sind aber die Staubfäden kahl und die Nebenblättchen viel kürzer als die Blattstiele und selbst die Nebenblättchen am Grunde der Blättchen, können deshalb nicht länger als die Blattstiele sein, weil die seitlichen Blättchen, an deren Grunde diese Nebenblättchen stehen, gar keinen Stiel haben, sondern sitzen.

\section{Thibandia Hendersoni Rgl.}

T. Hendersoni; caule fruticoso, ramosissimo, ramis diffusis subscandentibus; ramulis teretibus, viridibus, dense pubescentibus; foliis breviter petiolatis, ellipticis v. elliptico-oblongis, basi obtuse rotundatis, superne in apicem obtusum acuminatis, tripli-quintuplinerviis, integerrimis, initio utrinque breviter puberulis, demum supra nitidis et ad nervos sub lente breviter hirtulis, subtus pallidioribus nigroque punctulatis; racemis terminalibus, breviter paniculatis; pedicellis flore brevioribus, pubescentibus, bractea ovata membranacea corollam dimidiam circiter aequante leviter roseo-colorata fultis; calycis glabri depresso-subglobosi limbo 5 -dentato, dentibus brevibus late triangularibus acutis; corolla tubulosa, sub limbo constricta, limbi 5-dentati dentibus erecto-patentibus triangularibus; filamentis 10 complanatis, basi corollae tubo adnatis; antheris elongato-linearibus, bilocularibus, loculis in tubulos vacuos subulatos corolla $1 / 3$ breviores elongatis.

Folia $5-6$ c. m. longa, $21 / 4-3$ c. m. lata. Petioli pubescentes, $3-4 \mathrm{~m}$. m. longi. Flores circiter $1 \frac{1}{2} \mathrm{c}$. m. longi, tubo purpureo, limbo luteolo.

T'. acuminata h. Henderson. 
T. acuminata Hooker (Ic. pl. II. tab. III.), ramulis glabris, foliis lanceolatis basi acutis apice attenuato-acutis, antheris corollam aequantibus, - T. acuminata Benth. (Benth. pl. Hartw. p. 223. - Proclesia Benthamiana Kl. in Linnaea tom. XXIV), ramis foliisque glabris, foliis in apicem acutum acuminatis, racemis basi bracteis imbricatis fultis, antheris corollam aequantibus, - et T. acuminata DC. (prodr. VII. pag. 565), foliis oblongo-lanceolatis utrinque attenuatis, racemis axillaribus bracteisque oppositis minutissimis - dignoscuntur. 


\section{B. DESCRIPTIONES PLANTARUM NOVARUII IN REGIONIBUS TUR- KESTANICIS CRESCENTIUUM.}

\section{B. Gagea Schult.}

\section{CONSPECTUS SPECIERUM FLORAM ROSSICAM INCOLENTIUM.}

I. Bulbi tres horizontales.

1. G. stenopetala Rchb., (cfr. Ledb. fl. ross IV. 137).

II. Bulbi solitarii v. bini v. gregarii.

A. Folia caulina opposita, umbellam fulcrantia. Pedunculi simplices, nudi $v$. basi foliis paucis bracteiformibus vestiti.

a. Sepala obtusa. Pedunculi nudi.

2. G. lutea Schult., folio radicali lineari-oblongo, pedunculis glabris. G. lutea Ledb. fl. ross. IV. 138. - G. rufescens Rgl. in ind. sem. h. Petr. 1862 p. 28. - Posterior formam intermediam (hybridam?) inter G. luteam et $G$. pusillam exhibit.

3. G. pusilla Schult., folio radicali anguste-lineari, pedunculis glabris.

fr. pusilla et G. emarginata Ledb. fl. ross. IV. p. 138.139.

4. G. Liotardi Schult., pedunculis villosis.

Ledb. fl. ross. IV. 146 . - fr. intermedia Rchb. ic. fl. germ. X. tab. 476 . 
b. Sepala acuta v. subacuta. Pedunculi basi nudiv. foliis paucis vestiti.

5. G. filiformis Knth., foliis caulinis quam pedunculi brevioribus (G. filiformis Ledb. 1. c. 139.)

6. G. arvensis Schult., foliis caulinis pedunculos superantibus.

G. arvensis et erubescens cfr. Ledb. fl. ross. IV. p. 141.

B. Folium caulinum solitarium, umbellam fulcrans. Pedunculi simplices $v$. ramosi, basi foliis linearibus saepe vesiiti.

7. G. minima Schult., sepalis acuminatis. (Ledb. fl. ross. IV. 139).

8. G. spathacea Schult., sepalis obtusis. (Ledb. I. c. 140).

C. Folia caulina 3-plura, subverticillata, umbellam 1-multifloram fulcrantia, - rarius caulis nullus et folia omnia radicalia.

9. G. reticulata Schult., sepalis acuminato-cuspidatis. Ledb. 1. c. 142 . - G. sarmentosa C. Koch in Linnaea XXII. 230. - G. triphylla C. Koch 1. c. p. 229. - G. rigida Boiss. et Spr. in Boiss. diagn. or. ser. I. fasc. VIl. p. 108. - G. taurica Ster. in Bull. Mose. 1857. III, 83 .

D. Caulis foliis alternis vestiius, simplex $v$. ramosus 1-pluriflorus. Flores speciminum pluriflororum racemoso-corymbosi. Stigma subtrilobum.

a. Fotia omnia in axillis bulbillifera.

10. G. bulbifera Schult., foliis superioribus paucis erectis laxe dispositis, bulbillis in foliorum axillis solitariis. - Ledb. 1. c. 142.

11. G. amblyopetala Boiss. et Heldr., foliis superioribus numerosis patulis, bulbillis in foliorum axillis 2-pluribus. Boiss. et Heldr. in pl. Tayg. exs. Febr. 1845. - Boiss. diagn. ser. I fasc. VII pag. 107. - F. thesioides C. A. II. in pl. Szovits. exs. 
b. Folia omnia basi bulbillis carentia v. caule imo v. foliis infimis basi bulbilliferis.

๙. Sepala minima, trinervia, nervis lateralibus sepalorum interiorum vix conspicuis. Folium caulinum infimum e basi clliptico-lanceolata acuminatum.

12. G. minutiflora Rigl.

3. Sepala 3-plurinervia. Folia caulina infima e basi lineari-lanceolata $v$. late lineari sensim attenuata.

* Bulbi tunicae apice parce laciniatae, bullum vix superantes.

+ Ovarium sessile.

13. G. chlorantha Schult., ovario oblongo. G. chlorantha Ledb. 1. c. 142 . - G. polyphylla Stev. in Bull. Mosc. 1857. III. p. 83. - G. chlorantha Rchb. ic. fl. germ. X. tab. 488. fig. 1047 ad speciem alteram pertinet.

14. G. bohemica Schult., ovario obovato. G. bohemica Ledb. I. c. 141. - G. saxatilis Koch syn. fl. gern. p. 824. - G. Billardieri Knth. enum. IV. 242. G. polymorpha Boiss. voyage Esp. p. 611. - G. anisanthos C. Koch Linnaea XXII. 230 et Ledb. 1. c. p. 140. - G. triflora Schult. cfr. Ledb. fl. ross. IV. 141.)

t+ Ovarium stipitatum.

15. G.stipitata Merckl.(cfr.Bnge. reliq.Lehm.n.1385.) ** Bulli tunicae filroso-subreticulatae, caulis basin cingentes.

16. G. Olgae Rgl.

E. Caulis foliis alternis vestitus, simplex $v$. ramosus 1-pluv $i$ florus. Stigma tripartitum, lobis lineari-oblongis.

17. G. pauciflora Turcz.

(Ledb. 1. c. 143.) 


\section{Gagea minutiflora Rgl.}

Bulbo minuto, subgloboso, solitario; caule tenui, flexuoso, humili, glabro, simplici v. superne dichotomo-ramoso, foliato; folio radicali solitario, filiformi, quam inllorescentia breviore v. longiore, glabro; foliis caulinis alternis: caulino infimo e basi elliptico-lanceolata lineari-acuminato, glabro, inflorescentiam subaequante v. ea breviore, ad basin inflorescentiae sessile $\mathrm{v}$. ab ea paullo remoto: caulinis superioribus bracteiformibus, glabris v. margine laxe piloso-ciliatis; floribus minimis, in racemum pauciflorum $v$. corymbum racemosum pluriflorum dispositis; sepalis oblongis, obtusis.

Caulis 3-6 c. m. altus. Folia caulina superiora pauca-plura, linearia, bracteiformia. Flores virescenti-luteoli. Sepala $2 \frac{1}{2}-3 \frac{1}{2} \mathrm{~m}$. m. longa, exteriora satis conspicue trinervia, interiora nervis lateralibus vix conspicuis. Stamina inclusis antheris ovatis quam sepala paullo breviora. 0varium ovatum, stylo staminibus breviore coronatum; stigma vix incrassatum, truncatum, vix conspicue trilobum.

Habitat in 'Turkestania in montibus Karatau. (Krause.)

\section{Gagea Olgae Rgl.}

Bulborum ovato-oblongorum saepissime gregariorum tunicis infra apicem subreticulato-fibrosis, caulis basin involventibus; foliis radicalibus $1-2$, lineari-filiformibus, inflorescentiam saepissime superantibus; caule humili, simplici, 1-3 floro., foliis caulinis alternis, anguste linearibus v. subfiliformibus, decrescentibus; floribus in caulis apice solitariis v. in racemum simplicem corymbosum 2-3-florum dispositis; pedunculis praecipue apicem versus minute pulverulento-puberulis; sepalis oblongis v. elliptico-oblongis, obtusis, interioribus trinerviis; ovario linearioblongo.

Caulis $1^{1} / 2-4^{1 / 2}$ c. m. altus, brevissime puberulus v. glabrescens. Folia caulina inflorescentiam superantia v. ea breviora, initio saepe laxe minuteque puberula v. ciliolata, demum glabra. Sepala 5-9 m. m. longa, intus aurea, extus pallide lutea, dorso virescentia v. plumbea, exteriora $5-7$-nervia. Stamina perigonio circiter $1 / 3$ breviora; antherae ovato- 
oblongae. Stylus stamina superans, stigmate capitato vix trilobo. $\rightarrow$ (i. persicae Boiss. et G. damascenae Boiss. affinis, ab ambabus antem bene diversa.

G. persica Boiss. «foliis caulinis lanceolato-linearibus pedunculisque glaberrimis, caule dichotome ramoso-corymboso, foliorum axillis saepe bulbilliferis et praecipice ovario obovato» facile dignoscitur. G. damascena Boiss. et Noë differt: "foliis caulinis margine villosis, floribus majoribus, sepalis usque $15 \mathrm{~m}$. m. longis interioribus 5 -nerviis.»

Habitat in Turkestania prope Samarkand ( 0 . Fedschenko) et prope puteum Ajak in desertis inter Turkestaniam et Khiwam (Korolkow et Krause).

\section{Kaufmannia Rgyl.}

(Genus novum Primulacearum.)

Calyx campanulato-tubulosus, 5-fidus. Corollae tubus cylindricus, subaequalis; limbus profunde 5-fidus, erecto-patulus. Stamina 5, corollae fauci inserta; filamenta totidem monadelpha, in annulum cupuliformem coalita; antherae biloculares, e basi cordata lanceolato-0blonga, connectivo excurrente acuminatae, exsertae. Stylus 1, filiformis, corollam duplo superans. Capsula 5-valvis, apice dehiscens, polysperma.

Herba perennis, foliis radicalibus longe petiolatis, floribus umbellatis luteis. «Corollae tubo aequali, limbo planiusculo profunde quinquefido, filamentis monadelphis, antheris exsertis, stylo longissime exserto» ab affinibus generibus Primulae et Cortusae facile dignoseitur.

\section{K. Semenovi.}

Cortusa Semenovi Herder pl. Semenor. n. 694 .

Folia longe petiolata; petioli laxe villosuli, $9-15$ c. m. longi, laminam plus duplo superantes; lamina orbiculato-reniformis, lobata duplicatove-dentata, utrinque ad nervulos hirtula, caeterum glabra. Scapi folia paullo superantes, laxe villosi. Umbella pluriflora, fastigiata. Involucrum initio pedicellos aequans, demum iis plus duplo brevius; foliolis flabellatocuneatis, apice inciso-dentatis. Pedicelli glanduloso-puberuli, floriferi circiter $1 \frac{1}{2} \mathrm{c} . \mathrm{m}$. longi apice leviter nutantes, fructiferi stricti $2-3 \mathrm{c} . \mathrm{m}$. longi. Calyx glanduloso-puberulus, 5 -fidus; lobis lanceolatis, tubo paullo 
brevioribus. Corolla lutea, tubo calyce paullo breviore, limbo ad $2 / 3$ longitudinis 5-lobo; lobis oblongo-ovatis, obtusis. Stamina, stylus et capsula generis.

Habitat in Turkestania in Alatau transiliensi in trajectu Schaty (Semenow).

\section{Bhinopetalum stenanthernm Rgl.}

Caule pedicellisque pilis brevissimis erassiusculis hirtulis; foliis inferioribus binis, suboppositis, ovatis v. ovato-oblongis, superioribus (si adsunt) paucis alternis angustioribus; bracteis linearibus geminis, flores superantibus; pedicellis flore brevioribus v. eum paullo superantibus, per anthesin patentibus et apice plus minus recurvis, post anthesin erectis; antheris lineari-oblongis; capsula hexagona, apice truncata, ad angulos alata, alis apice ill dentem productis.

Bulbus subglobosus. Caulis simplex, incluso racemo saepissime 6-10 c. m. v. rarius usque 20 c. m. altus, basi nudus. Folia glabra, saepissime tantum bina et subopposita; rarius plura et inferiora subopposita, superiora alterna v. rarissime omnia sparsa, infima ovata v. ovato-lanceolata v. lanceolata; superiora angustiora. Bracteae lineares, geminae, foliaceae. Flores subnutantes v. erectiusculi. Sepala ut videtur lilacina basi macula violacea picta, ovata usque oblong 0 -lanceolata, $3-5$-nervia, nervis lateralibus plus minus ramosis, obtusa, basi apiceque margine plus minus puberula, $12-18 \mathrm{~m}$. m. longa, superiorum trium fovea nectarifera profundius excavata in sacculum gibbum prominente. Filamenta filiformia, perigonio duplo v. plus duplo breviora, basin versus hirtula. Stylus stamina circiter aequans. Capsula breviter stipitata subglobosa.

Species altera adhuc cognita R. Karelini Fisch. differt» foliis inferioribus oblongis v. oblongo-lanceolatis; antheris subrotuudis v. ovatis, sepalo supremo tantum-basi saccato, capsula obtusangula apice rotundata, loculis dorso sub apice denticulo auctis».

Habitat in Turkestania prope Bugun (Sewerzow), in montibus Boroldai a. $2500-3500^{\prime}$, (Korolkow), prope Taschkent et in valle fluvii Sarawschan (0. Fedschenk0). 


\section{Scilla pusschkinioides Ryl.}

Foliis late linearibus, obtusis; racemo trecto, 2-5 lloro; pedicellis noribusque erectis, flore $3-4$-plo brevioribus, basi bracteolis duobus suffultis

Bulbus ovatus, tunicis fuscescentibus vestitus. Folia radicalia 2-4, glabra, late linearia, obtusa, glabra, 15-2()-nervia, 6-7 c. m. longa, usque $5 \mathrm{~m}$. m. lata. Scapus liumilis, glaber, $6-8$ c. m. altus. Pedicelli erecti, stricti, $4-5 \mathrm{~m}$. m. longi, basi bibracteati; bracteolac scariosohyalinae, pedicellis 2-3-plo breviores, apice saepe truncatae erosaeque, dentatae, rarius acuminatae. Perigonium campanulatum. Sepala lanceolatooblonga, ima basi coalita, apice obtusiuscula v. cucullato-subacuta, circ. $12 \mathrm{~m}$. m. longa, pallide caerulea, nervo medio intensiore. Stamina perigonio circiter $1 / 3$ breviora; filamenta basi inter se et cum perigonio coalita, e basi latiore subulata; antherac lineari-oblongae. 0varium ovatum triloculare, loculis triovulatis. Stylus filiformis, stamina subaequans, stigmate capitato. Capsula depresso-globosa.

Pedicellis brevibus basi bibracteolatis a Sc. bifolia, - pedicellis strictis floribusque erectis, sepalis angustioribus, filamentis basi in annulum brevem coalitis a Sc. cernua facile dignoscenda.

Turkestaniae in montibus Alatau (Krause).

\section{Tulipa Korolkowi RgI.}

Bulbi tunicis intus apicem versus adpresse strigoso-pilosis, caulis basin longe involucrantibus; caule humili, 2-3-folio, glabro, unifloro; foliis anguste lineari-lanceolatis usque lanceolatis, florem superantibus, glabris, undulatis, immarginatis; pedunculo glabro; sepalis patentissimis, cuneatoobovatis, apice rotundato breviter apiculatis filamentisque glabris; stigmate capitato, breviter trilobo, diametro ovarii paullo angustiore.

Caulis supra terram incluso petiolo vix $4 \mathrm{c}$. m. altus, infra terram 2-10 c. m. longus. Sepala purpurea, basi macula parva nigrescente, $3-31 / 2$ c. m. longa, infra apicem usque 2 c. m. lata. Filamenta basiu versus dilatata, antheras oblongas v. lineares subaequantia v. iis breviora, inclusis antheris perigonio 2-3-plo breviora. 
Ab affini T. Eichleri Rgl. (Grtflora tab. 799. - Труды Имп. Бот. Сада III. 156) «statura humiliore, caule foliis pedunculisque glabris sepalorumque configuratione» nostra species facile dignoscitur.

Habitat in solo lutoso in desertis inter Turkestaniam et Khiwam prope Farisch. (Korolkow et Krause.)

\section{Tnlipa tetraphylla Rgl.}

Pusilla; caule terra sepulto, unifloro; foliis 4 , in caulis apice confertis, subverticillatis, linearibus v. lineari-oblongis, florem superantibus, angustissime cartilagineo-marginatis, plus minus curvatis v. subcircinnatocurvatis; pedunculo glabro, unifloro; sepalis obovatis, obtusis; staminibus glabris.

Bulbus ignotus. Caulis totidem subterraneus, $2-3^{1} / 2 \mathrm{c} . \mathrm{m}$. longus. Folia margine piloso-ciliata v. glabra. Pedunculus erectus, $2^{1} / 2-3 \mathrm{c} . \mathrm{m}$. altus, solitarius, glaber. Sepala cuneato-0bovata, interiora pallide flava, exteriora violaceo-variegata, circiter $1 \frac{1}{2} / 2 \mathrm{c} . \mathrm{m}$. longa. Stamina perigonium dimidium circiter aequantia. Filamenta medio dilatata, utrinque attenuata, antheras oblongo-lineares paullo superantia. Ovarium oblongum, apicem versus sensim attenuatum, filamenta circiter aequans.

Filamentis glaberrimis a sectione Tulipae silvestris, - caule ad apicem terra sepulto tetraphyllo et praecipue filamentis utrinque attenuatis a T. sogdiana Bnge. et omnibus alteris speciebus facile dignoscenda.

Turkestaniae in valle Kotschkura leg. liber Baro a Kaulbars.

\section{Trilipa turkestanica Rggl.}

Bulbi tunicis intus praecipue apicem versus pilis longis villosis; caule bifolio, 1-6-floro; foliis linearibus usque lineari-lanceolatis, falcatis, recurvis v. suberectis; floribus erectis; sepalis apice glabris, interioribus staminibusque basi dense pubescentibus; stigmate subtrilobo; capsulae valvis cuspidato-acuminatis.

Caulis glaber, bifolius v. rarissime triphyllus, inclusis pedunculis $8-30 \mathrm{c.} \mathrm{m}$. altus. Folia pedunculos saepissime su:erantia, laxe minuteque puberula v. glabra, $4-13 \mathrm{~m}$. m. lata. Pedunculi saepissime mi- 
nute laxeque pubescentes v. glabrescentes. Sepala lineari-lanceolata usque ovato-lanceolata, acuta $v$ breviter acuminata, intus flava, extus saepo plus minus violascentia, $15-28 \mathrm{~m}$. m. longa, exteriora interioribus angustiora. Stamina perigonio plus duplo breviora; filamenta linearia, basin versus paullo latiora, antheris linearibus paullo breviora v. longiora. Capsu lae ovatae v. subrotundae valvis apice cuspidato-acuminatis.

T. silvestris $n$ turkestanica Rgl. in Труды Имп. Бот. Сада II. 443 .

Bulbi tunicis intus villosis, caule saepe 2-plurifloro, capsulae valvis apice cuspidato-acuminatis a T. silvestri et T'. biflora diversa.

Habitat satis frequenter in Turkestaniae provinciis. (0. Fedschenko, Korolkow, Krause, Kuschakewicz.) 



\section{ACTA \\ HORTI PETROPOLITANI.}

TOMUS IV.

Fasciculus II.

\section{ТРУДЫ}

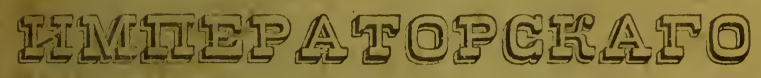

\section{- IЕТЕРБУРТССАГО БОТАНИЧЕСКАГО САДА.}

\section{TONIT IV.}

\section{В Ы II У C К Ђ II.}

С О ДЕP

Ciegel, $\quad$ Descriptiones plantarum novarum et minus cognitarum. Fasciculus IV. Pag. 273-340.

TR. Trautvetter, Plantæ a Dr G. Radde in isthmo caucasico anno 1875 lectæ. Pag. 341-406.

Регель; ІІзлеченіе пзъ отчета IIМЕРАТОРСКАГО С.-Петербургскаго Ботаншческаго Сада за 1875 г. Pag $407-420$. 



\section{DESCRIPTIONES PLANTARUM}

NOVARUM ET MINUS COGNITARUM.

Fasciculus IV.

AUCTORE

E. REGEL. 


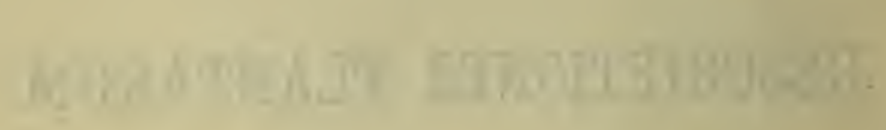

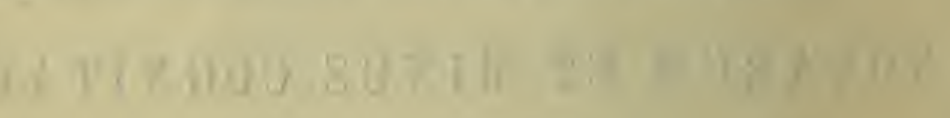

$1+$ ain

szodp $=$ 


\section{A. CYCADEARUM}

\section{GENERUM SPECIERUMQUE REVISIO.}

\section{EIN L E I T UNG.}

Alphons De Candolle hat im XVI. Bande II. Abtheilung des Prodromus erst vor einigen Jahren, eine vollständige Aufzählung der Gattungen und Arten der Familie der Cycadeen gegeben, so dass eine erneuerteZusammenstellung der'selben überflüssig erscheinen könnte. Es veranlasste mich aber die reiche Sammlung der Cycadeen des hiesigen Botanischen Gartens und die nicht minder vollständige Sammlung, welche der Herr GartenInspector Katzer, in den letzten Jahren in dem Garten Sr. Kaiserlichen Hoheit des Grossfürsten Constantin Nicolajewitsch in Paullowsk bei St. Petersburg, zusammengebracht hat, diese interessante Familie von Neuem zu studiren.

Die Feststellung der Arten und Gattungen wird wesentlich dadurch erschwert, dass es nur wenige Arten giebt, die häufig blühen, weshalb ebensowohl in den Sammlungen lebender Pflanzen, sowie in den Herbarien sich nur ein sparsames Material in dieser Beziehung findet. Dagegen ist die Zahl der in den letzten Jahren in lebenden Exemplaren aus dem Süden Asiens, aus Afrika, aus dem tropischen und subtropischen Amerika und aus Neuholland in unsere Gärten importirten Cycadeen sehr bedeutend gewesen und wächst jährlich noch. Dazu kommt, dass die grössern HandelsEtablissements Englands und Belgiens, welche diese Einführungen vermitteln, um deren Absatz zu ermöglichen und dabei ihre Kosten zu decken, den importirten Pflanzen nothwendiger Weise irgend einen Namen beilegen 


\section{CONSPECTUS GENERUM.}

A. Foliola nervo intermedio unico, nervis lateralibus nullis.

1. Cycas $L$.

B. Foliola nervo intermedio unico penninervio.

2. Stangeria Th. Moore.

C. Foliola nervis longitudinalibus pluribus instructa.

a. Folia in verticillos (nec unum post alterum) terminales provenientes.

* Perulae persistentes. Petioli basi exauriculati.

3. Encephalartos Lehm. - Squamae strobili fỏeminei stipitatae, pelta mutica glabra terminatae.

4. Lepidozamia Rgl. - Foliola flaccida, acutissima. Squamae strobili foeminei stipitatae, pelta sensim in acumen planiusculum attenuata glabra terminatae.

5. Dioon Lindl. - Foliola rigida, spinescentia. Squamae strobili foeminei stipitatae, lamina plana lanceolata acuminata lanata basi cordata terminatae.

* Perulae persistentes. Petioli basi vaginato-dilatata utrinque auriculati.

6. Ceratozamia Brongn. - Strobilorum squamae apice bicornutae.

*** Perulae marcescentes, caducae.

7. Aulacophyllum Rgl. - Foliola sulcato-nervosa.

8. Microcycas Miq. - Foliola laevia.

b. Folia unum post alterum provenientia.

* Perulae demum marcescentes deciduae.

9. Zamia L. - Folia pinnata.

10. Bowenia Hook. - Folia bipinnatisecta.

** Perulae persistentes, demum in fibras truncum vestientes soluti.

11. Macrozamia Miq. 


\section{ENUMERATIO GENERUM SPECIRRUMQUE.}

\section{Cycas L.}

Arbores trunco cylindrico. Perulae caducae. Folia in verticillos terminales provenientia, pinnata, vernatione rhachidis recta, segmentorum circinata. Foliola linearia v . anguste lineari-lanceolata, numerosa, integerrima, nervo intermedio unico percursa, nervis lateralibus nullis. Strobili masculi squamae imbricatae, cuneatae, apice saepe acuminatae subtus antheriferae. Florum foemineorum spadices (squamae, carpidia) in comum terminalem laxiuscule imbricati, singuli elongato-spathulati, plani, crenati; ovulis in crenaturis solitariis, sessilibus.

\section{Conspectus specierum.}

A. Foliola margine revoluta, inferiora sensim ad spinas transeuntia.

1. C. revoluta Thbrg.

B. Foliola margine revoluta. Petiolus inermis.

2. C. inermis Lour.

C. Foliola margine plana v. vix revoluta, inferiora subito ad spinas transmutata.

a. Petioli basi v. ad medium inermes, caeterum margine spinulis armati.

3. C. circinalis $L$., spinulis diametro petioli plus duplo brevioribus; foliolis $1^{1} / 2 \mathrm{c} . \mathrm{m}$. latis, in apicem vix spinescentem sensim attenuatis.

4. C. glauca Miq., spinulis diametro petioli plus duplo brevioribus; foliolis 2 c. $\mathrm{m}$. et ultra latis, sensim in apicem vix spinescentem attenuatis.

5. C. media $R$. Br., spinulis diametro petioli plus duplo brevioribus; foliolis rectis, circiter $7 \mathrm{~m}$. m. latis, apice subito in spinulam subulatam acuminatis.

6. C. gracilis Miq., spinulis diametro petioli $1 / 3$ brevioribus usque eum aequantibus v. superantibus.

b. Petioli ad basin spinulosi. 
7. C. siamensis Miq., foliolis apice subito in spinulam acuminatis, usque $7 \mathrm{~m}$. m. latis.

8. C. Riuminiana $R g l$, foliolis sensim in apicem non spinescentem attenuatis, $10-12 \mathrm{~m}$. m. latis.

c. Petioli inermes.

9. C. celebica Miq.

\section{Enumeratio specierum.}

1. Cycas revoluta Thbrg. (v. v.)

Thbrg. fl. jap. pag. 229. - Sm. trans. Linn. soc, VI. pag. 312. tab. 29. 30. - Bot. mag. tab. 2963 et 2964. - Miq. monogr. pag. 23. - Ann. sc. nat. XVI tab. 20. 21. - Miqu. in N. Verh. Ned. Ac. XII. tab. 1.- Denkschr. schl. Ges. 1853 tab. 10.-D. C. prodr. XVI. II. pag. 526. - Arbor catappoides sinensis Rumph Amb. tab. 24 (folium). - Variat caudice monstroso cristato. (C. revoluta cristata et $\mathrm{C}$. revoluta nana hort.).

Foliola plantarum juniorum saepe planiora et laxius disposita. (C. revoluta planifolia Miq. mon. pag. 25).

\section{Cycas inermis Lour.}

Lour. fl. cochin. II. 776. - Miq. ann. bot. ind. 2 (1851.) pag. 28. tab. 3 et 4. - D. C. prodr. XVI. II. 526. - Hab. in Cochinchina.

Simillima C. revolutae et solummodo petiolis inermibus diversa.

3. Cycas circinalis $L$. (v. v.)

L. spec. pag. 1658. - Bot. mag. tab. 2826 et 2827. - Miq. monogr. pag. 27. - D. C. prodr. XVI. II. pag. 526. - C. Rumphii hort. - Olus catappoides Rumph Amb. I. pag. 86. tab. 22 et 23. Blume Rumphia pag. $176^{b}$ et $176^{c}$. - C. circinalis et Rumphii hort. - C. circinalis, C. Rumphii, C. Wallichii et C. madagascariensis Miq. mon. p. 22, 23 et 32. - D. C. prodr. XVI. II. pag. 527 et 528 . C. undulata Desf. cat. hort. Par. 1820. teste D. C. prodr. l. c. p. 529. 
Truncus clatus, cylindricus. Folia demum glabra, incluso petiolo usque $2 \mathrm{~m}$. longa. Petiolus infra semiteres, supra triangulus, basi v. usque ad medium inermis, ceterum margine spinulosus. Spinulae dentiformes v. subsubulatae, rectae v. paullo recurvatae, diametro petioli duplo usque pluries breviores. Rhachis teres. Foliola dense disposita (unum ab altero $1-1 \frac{1}{2} \mathrm{c}$. m. remotum), patentissima, numerosa, utrinque 50-70, anguste linearilanceolata, recta $v$. falcata, plana v. paullo undulata, margine vix revoluta, in apicem non v. vix spinescentem sensim attenuata, basi plus minus decurrentia, usque $25 \mathrm{c.m}$. longa et $1 \frac{1}{2} 2 \mathrm{c} . \mathrm{m}$. lata, inferiora subito in spinulas transmutata. - Folia viridia, juniora minute fasciculato-fusco-pulverulento-pilosula, mox glabra. Strobilus masculus ovoideus, sessilis; squamis e basi obovato-deltoidea longe acuminatis, acumine pubescente. Strobili fem. cfr. D. C. 1. c. - Habitat in India orientali.

\section{Cycas glauca Miq. (v. v.)}

Miq. mon. Cyc p. 30. -- D. C. prodr. XVI. II. 528. - C. glaucophylla hort.

Antecedenti simillima, differt autem: "Foliis glaucis; foliolis minus numerosis, utrinque $18-20,2-2 \frac{1}{3} \mathrm{c}$. m. latis, uno ab altero $2-4$ c. m. remoto, inferioribus recurvo-patentibus, superioribus patentissimis; petiolis teretibus.

5. Cycas media R. Br. (v. v.)

R. Br. prodr. fl. Nov. Holl. 348. - Hiq. mon. pag. 26. tab. 3. - D. C. prodr. XVI. II. pag. $52 \%$.

Truncus elatus, $3-4 \mathrm{~m}$. altus. Folia initio tomento tenui pulverulento ferrugineo detergibili vestita, demum glabriuscula, numerosa, $3 / 4-11 / 4 \mathrm{~m}$. longa. Petiolus $25-30 \mathrm{c}$. m. longus, teres, initio satis dense ferrugineo-tomentellus, basi vel ad medium inermis, superne utrinque spinulis diametro petioli subtriplo brevioribus armatus. Rhachis teres, initio ferrugineo-tomentella, inermis. Foliola linearia, plana, numerosissima, utrinque $70-120$, circiter $7 \mathrm{~m}$. m. lata, $6-12 \mathrm{c.m}$. longa, (teste De Candollio usque 20 c. m. longa) apice in acumen spi- 
nescens cuspidata, satis dense disposita, superiora basi deorsum decurren. tia, inferiora vix decurrentia. Strobili fem. cfr. D. C. 1. c. - Habitat in Nova Hollandia tropica.

\section{Cycas gracilis Miq. (v. v.)}

Miq. over de Cyc. Nieuw. Holl. p. 15. - D. C. prodr. XVI. II. pag. 528. - Cycas spec. Queensland h. Haage et Schm.

Truncus cylindricus. Folia 50-70 c. m. longa. Petiolus teres, circiter 20 c. m. longus, initio puberulus, basi tantum v. ad medium inermis, caeterum utrinque spinulosus; spinulae subulatae, rectae v. vix recurvae, diametrum petioli subaequantes v. superantes, $3-4^{1} / 2 \mathrm{~m} . \mathrm{m}$. longae. Foliola utrinque $20-40$, late linearia, plana, recta v. vix falcata, sensim v. subito in apicem cuspidatum subspinescentem attenuata, 9-17 c. m. longa, $5-8 \mathrm{~m}$. m. lata, superiora basi deorsum decurrentia, inferiora vix decurrentia et subito in spinulas transmutata.-Rhachis teres, initio puberula, demum glabra.-Strobili masc. et fem.cfr.D.C.l.c.

a glauca; foliis glaucis, spinulis diametrum petioli subsuperantibus: - C. media h. Van Houtte. - C. Boddami h. Haage et Schm. - Nacrozamia latifrons h. Bull. - C. Normanbyana h. Belg.

ß. viridis; foliis viridibus, spinulis diametro petioli paullo brevioribus. - C. gracilis h. Paull. - C. Riumiana h. Turic. Habitat in Nova Hollandia tropica.

\section{Cycas siamensis Miq. (v. v.)}

Miqu. in Bot. Zeitung 1863 pag. 334. - D. C. prodr. XVI. II. pag. 528. - C. aurea h. Verschaffeltianus.

Folia $60-80$ c. m. longa, juniora hirtula, aetate glabrescentia. Petiolus compresso-teres, ad basin utrinque spinulosus. Spinulae remotae, recurvae, diametro petioli pluries breviores. Rhachis infra convexa, supra in carinam producta. Foliola late linearia, plana, apice subito in spinulam brevem acuminata, usque $16-20 \mathrm{c} . \mathrm{m}$. longa et circiter 7 m. m. lata, omnia basi deorsum decurrentia, inferiora subito in spinulas 
transmutata. - Truncus humilis, $2-3$ pedes altus. Foliola utrinque circiter 40 et plura, glaucescentia. Petiolus et rhachis luteola.

Habitat in regno Siam.

\section{Cycas Riuminiana Rgl. (v. v.)}

Rgl. Grtfl. 1864. pag. 63, tab. 405. - Lem. ill. hort. tab. 405. - D. C. prodr XVI. II. pag. 428.

Truncus cylindricus, $1-3 \mathrm{~m}$. altus. Folia laete viridia, $1^{1} / 4-2 \mathrm{~m}$. longa, glabra. Petiolus depresso-teres, glaber, a basi ad apicem utrinque spinulosus; spinulae satis dense disticheque dispositae, rectae, diametro petioli plus duplo breviores. Foliola numerosa (utrinque 60 vel plura), anguste lineari-lanceolata, recta v. paullo falcata, sensim in apicem non spinescentem attenuata, margine vix revoluta, plana v. saepe undulata, $10-12 \mathrm{~m}$. m. lata et $20-25 \mathrm{c} . \mathrm{m}$. longa, superiora basi deorsum decurrentia, inferiora non decurrentia et subito in spinulas transmutata. Strobili masculi oblongo-cylindrici, basi breviter stipitati. Strobili squamae extus fusco-pubescentes; infimae steriles, lanceolatae, longe acuminatae; ceterae subtus antheriferae, cuneato-obovatae; inferiores et superiores ex apice rotundato in cuspidem subulatam rostriformem sursum versus subito excurrentes, intermediae tantum breviter acuminatae.

Foliorum juniorum rhachis pilis fuscis laxe vestita, caeterum folia glaberrima. Trunco tenuiore humiliore, petiolis ad basin spinulosis, statura squamarum strobilorum masculorum facile a $\mathrm{C}$. circinali dignoscitur.

Habitat in India orientali.

\section{Cycas celebica Miq. (v. v.)}

Miq. comm. p. 126. - Miq. mon. p. 31. - D. C. prodr. XVI. II. pag. 528. - Olus catappoides Rumph. Amb. I. p. 87, tab. 20 et 21. - C. neocaledonica hort.

Truncus cylindricus. Petiolus inermis, teres; rhachis semiteres, supra planiuscula. Foliola anguste lineari-lanceolata, sensim in apicem non spinescentem attenuata, basi deorsum decurrentia. Squamae strobi- 
lorum masculorum (cfr. ic. Rumphii) ex apice rotundato subito in acumen subulatum rostriforme excurrentes.

Folia speciminis nostri initio glaucescentia, demum viridia, $40-100$ c. m. longa. Petiolus et rhachis initio laxe fusco-pilosa, demum glabra. Foliola utrinque $10-30$, recta v. vix falcata, $15-22 \mathrm{c} . \mathrm{m}$. longa, $10-12 \mathrm{~m}$. m. lata.

\section{Stangeria Th. Moore.}

Truncus humilis, napiformis, nudus, vix cicatricatus. Perulae caducae. Folia pinnata. Foliola 4-13 juga, saepissime opposita, penninervia, inferiora petiolata, superiora sessilia decurrentia. Strobili masculi oblongo-cylindrici squamae ovatae, basi late cuneatae, apice steriles acutae. Squamae (carpophylla) strobili foeminei ovato-oblongi, structura mascularum, breviores autem, magis concavae, basi utrinque in cavitate ovulum recondentes.

Arbuscula in Africa australi indigena.

Foliorum vernatio plicata. Foliola nervo intermedio crasso; nervis lateralibus e nervo intermedio egredientibus tenuibus, crebris, subperpendicularibus, semel v. bis furcatis, juxta marginem anastomosantibus.

\section{Conspectus specierum.}

1. S. paradoxa Th. Moore., foliolis oblongo-lanceolatis acuminatis, margine, plus minus spinuloso-serrulatis.

2. S. Katzeri Rgl., foliolis obverse,oblongis, ex apice rotundato mucronato-acutis, margine undulato-repandis v. repando-crenatis, sub apice interdum dente uno alterove.

\section{Enumeratio specierum.;}

1. Stangeria paradoxa Th. Moore. (v. v.)

Th. Moore. Natal Ferns in Hook. Journ. of bot. V. p. 228. Hook. bot. mag. tab. 5121. - D. C. prodr. XVI. II. 530. - Lomaria coriacea Knze. in Linnaea X. p. 506. - Lom. eriopus Knze. in Linnaea X. pag. 152 et XVIII. pag. 116. - Stangeria schizodon hort. 
Truncus circiter $30 \mathrm{c.m}$. altus. Folia 50 - $70 \mathrm{c.m}$. longa; petiolus $20-25$ c. m. longus, semiteres, ima basi tomentosus, cacterum glaber. Foliola 4-13 juga, oblongo-lanceolata, acuminata, 7-15 c. m. longa, $2^{1 / 2}-4$ c. m. lata, glabra, sacpissime a medio ad apicem, rarius apicem versus tantum $v$. a basi ad apicem serrata.

a. typica; foliolis a medio $\mathrm{v}$. apicem versus tantum serratis.

3. schizodon; foliolis a basi ad apicem serratis. Habitat prope Porte Natal.

\section{Stangeria Katzeri Rgl. (v. v.)}

Rgl. Grifl. 1874 pag. 163 tab. 798. - Stangeria spec. h. Paullowsk. -

Truncus humilis, vix $30 \mathrm{c} . \mathrm{m}$. altus. Petiolus teres $20-37 \mathrm{c}$. $\mathrm{m}$. longus, apicem versus in latere superiore canaliculatus. Lamina 32-40 c. m. longa. Foliola oblonga, 8-12 juga, 12-19 c. m. longa, 4-6 c. m. lata, glabra, margine leviter undulato-repanda v. apicem versus crenato-repanda, ex apice rotundato apiculato-acuta, sub apice interdum denticulo unico $\mathrm{v}$. alterove spinescente instructa.

\section{Encephalartos Lehm.}

Truncus crassus, demum cylindricus, initio globosus v. ovatus, perulis persistentibus (nunquam fibroso-laciniatis) onustus. Folia in verticillos terminales (nec unum post alterum) provenientia, vernatione recta imbricatave, pinnata. Foliola parallele pluri-multinervia, linearia usque oblongo-elliptica, integerrima v. varie dentata v. sublobata, basi exarticulata et ibidem non calloso incrassata, breviter v. non decurrentia, inferiora immutata $\mathrm{v}$. sensim v. subito ad spinas partitas $\mathrm{v}$. simplices reducta. Flores in strobilos crassos dispositi. Squamae strobili masculi patentes, subtus antheriferae, extremitate sterili pingui non latiore obtusa v. conico-truncata subquadrata. Squamae (carpophylla) strobili masculi pedunculato-peltatae, sub peltis crassis rhombeo-quadrangulis biorulatae. 


\section{Conspectus specierum.}

A. Foliola linearia, omnia pungenti-acuta integerrimaque.

1. E. cycadifolius Lehm., foliolis margine revolutis.

B. Foliola omnia pungenti-acuta, integerrima $v$. margine inferiore 1-3 dentata.

a. Foliola viridia, circiter 5-8-plo longiora quam lata.

2. E. brachyphyllus Lehm., foliolis lineari-lanceolatis, 7-11 nerviis, margine revolutis integerrimisque.

3. E. caffer Miq., foliolis lanceolatis, multinerviis, margine planis integerrimis v. margine infêriore dente-unico obtuso.

b. Foliola glauca, circiter 10-14-plo longiora quam lata.

4. E. Lehmanni Lehm.

C. Foliola lineari-lanceolata v. lanceolata, omnia pungenti-acuta, utrinque spinoso-dentata, dentibus erectis.

a. Foliola utrinque 3-5 dentata.

(E. Altensteini occurrit rarissime foliolis subintegris v. paucidentatis).

5. E. villosus Lem., foliolis 12-16-plo longioribus quam latis, nervis $20-25$ facile conspicuis, inferioribus ad spinas partitas paucas sensim reductis.

6. $E$. Hildebrandti $A$. Br., foliolis 5-6-plo longioribus quam latis, nervis circiter 16 difficile conspicuis; inferioribus sensim sensimque ad spinas numerosas $2-3$ fidas reductis.

7. E. Altensteini Lehm., foliolis 5-7-plo longioribus quam latis, nervis $20-30$ facile conspicuis, inferioribus ad spinas partitas paucas $\mathrm{v}$. nullas mutatis.

b. Foliola utrinque 8-10 dentata.

8. E. septentrionalis Schweinf.

D. Foliola inferiora pungenti-acuta, superiora obtusa v. hamuloso-obtusa, omnia integerrima $v$. margine inferiore 1-2 dentata.

9. E. longifolius Lehm. 
E. Foliola lanceolata $v$. elliptico-lanceolata, omnia pungentiacuta, margine inferiore lobato-dentata.

10. E. lanuginosus Lehm., foliolis viridibus margine inferiore

lobato 1-4-dentatis, dentibus breviter spinescentibus.

11. E. horridus Lehm., foliolis glaucis, margine inferiore lobato-dentatis, dentibus $1-3$ in spinam pungentem elongatam acuminatis.

\section{Enumeratio specierinm.}

1. Encephalartos cycadifolius Lehm. (v. v.)

Lehm. pug. VI. pag. 13. - Miq. mon. p. 43. - D. C. prodr. XVI. II. pag. 531. - Rgl. Труды III. I. pag. 111. - Ejusd. Grtfl. 1875 pag. 37.

Folia 1 c. m. et ultra longa, multijuga; rhachis semiteres, canaliculata, initio pubescens. Foliola anguste linearia, pungenti-acuta, integerrima, margine revoluta, $3-5$ nervia, $8-10 \mathrm{c.m}$. longa, $4 \mathrm{~m} . \mathrm{m}$. lata, mox glabra. Florum strobili glabri.

Habitat in Africa australi.

\section{Variat:}

a. typica; trunco glabro, petiolo rhachique initio pubescentibus, demum glabris. - E. cycadifolius Lehm. 1. c. - Zamia cycadifolia Jacq. fragm. tom. I. pag. 27 n. 91. - E. cycadifolius $\alpha$. Rgl. 1. c.

ß. Friderici Guilliemi; trunco laxe tomentoso, petiolis rhachibusque initio tomento detergibili vestitis. - E. cycadifolius ß. Rgl. l. c. - E. Friderici Guilielmi Lehm. pug. VI. pag. 8. - E. Ghellincki Lem. ill. hort. 1867 p. 80 et 1868 tab. 567 et xyl.

2. Encephalartos brachyphyllus Lehm. et de Vriese. (v. v.)

Lehm. et de Vriese in de Vriese nov. spec. Cyc. Afr. austr. pag. 6 tab. I et II et in Lehm. et de Vriese Tijdschr. nat. Gesch. IV, p. 414 tab. VI et VII. - Miq. mon. p. 49. - Zamia cycadifolia Lodd. cat.Pl. Dreg. exs. - Miq. in Bull. des sc. phys. et nat. 1838 p. 38. - 
E. Royeni Miq. manuser. - E. caffer $\beta$. brachyphyllus D. C. prodr. XVI. II. pag. 532. -- E. Verschaffelti Rgl. in Tруды tom. III. fase. I. pag. 111. - Ejusd. Gartenfl. 1875 pag. 35 tab. 822. E. cycadifolius h. Versch.

Truncus apice perulis tomentosis vestitus, caeterum glaber. Folia 70-80 c. m. longa. Petiolus initio laxe tomentosus, demum glaber. Rhachis semiteres, demum glabra, initio laxe tomentosa. Foliola multijuga, saturate viridia, 11-13 nervia, lineari-lanceolata, pungenti-acuta, plana, integerrima, $6-7$ c. m. longa, $8-11 \mathrm{~m}$. m. lata.

Habitat in Africa australi.

\section{Encephalartos caffer Miq. (v. v.)}

Miq. monogr. p. 53. - D. C. prodr. XVI. II. p. 532 excl. syn. - Rgl. Труды III. I. 113. - Cycas caffra Thbrg. in nov. act. soc. Ups. II. 283. - Zamia Cycadis L. fil. suppl. 443. - Zamia caffra Thbrg. fl. cap.

Truncus crassus, glaber; perulis initio villosulis, mox glabris. Folia initio tomento tenui detergibili vestita, mox glabra, $1 \mathrm{~m}$. et ultra longa. Petílus rhachisque obtuse tetragona. Foliola multijuga, anguste lanceolata, 25-35 nervia, omnia pungenti-acuta, integerrima $\mathrm{v}$. latere inferiore 1 - v. rarissime 2 -dentata, $12-18 \mathrm{c} . \mathrm{m}$. longa, $15-25 \mathrm{~m}$. m. lata, dentibus (si adsunt) rectangulo-patentibus obtusis. Foliola inferiora ad spinas nunquam transmutata. Squamae strobili masc. subtriquetrae, obtusissimae, umbilicato-rugosae, glabrae. Squamae strob. foeminei subquadrangulae, obtusae.

Habitat in Africa australi.

Variat:

a. integerrimus; foliolis integerrimis.

ß. unidentatus; foliolis margine inferiore saepissime unidentatis, rarius nonullis ibidem bidentatis v. integerrimis. - Rgl. Труды l. с.

\section{Encephalartos Lehmanni Lehm. (v. v.)}

Lehm. pug. 6 p. 14. - Miq. mon. pag. 47. - Grtfl. 1865 p. 197. tab. 477. - D. C. prodr. XVI. II. 531. - Zamia Lehman- 
niana Eckl. et Zeyh. in 0lto et Dietr. Grtytg. 1833 p. 158. - Cycas glauca Van Royen miss. - E. mauritianus Miq. monogr. p. 48. - E. spinulosus Lehnm. et Vriese in Tijdsch. nat. Gesch. IV. 420 tab. VIII fig. B.? - De Vriese nov. spec. Cyc. p. 12 tab. III lig. B.? ") - E. elongatus Miq. in Bull. Necrl. 1838 p. 11. - Ejusd. comm. phyt. pag. 110 tab. 113. - De Vriese nov. spec. Cyc. pag. 11 tab. III. fig. A. - Lehm. et de Vr. Tijdsch. nat Gesch. IV, pag. 420 tab. VIII fig. A. - D. C. prodr. XVI, II 533.

Truncus initio ovatus, demum cylindricus, glaber. Folia circiter 1 m. longa, glauca, glabra. Petiolus rhachisque obtuse-tetragona v. teretia. Foliola multijuga, lineari-lanceolata, integerrima v. latere inferiore paucidentata, 14-18-nervia, pungenti-acuta, longiora 18-22 c. m. longa, $10-12 \mathrm{~m} \mathrm{~m}$. lata. Strobili masculi breviter pedunculati oblongi squamae inaequaliter rhomboideo-quadrangulares.

Habitat in Africa australi.

Variat:

a. typicus; foliolis integerrimis.

$\beta$. dentatus; foliolis latere inferiore 1-2 dentatis, dentibus pungenti-acutis.

E. Lehmanni $\beta$. spinulosus Rgl. in Труды Имп. Бот. сада III. II pag. 112 (nес E. spinulosus Lehm.).

\section{Encephatartos villosus Lem. (v. v.)}

Lem. ill. hort. 1867 p. 80 et 1868 tab. 557. - Rgl. in Труды Имп. Бот. сада III. II. p. 112. - Grtfl. 1875 p. 41.

Truncus apice dense cinereo-tomentosus. Folia 1-2 m. longa, multijuga, viridia. Petiolus et rhachis subteretia, initio cinereo subvillosa, demum glabrescentia. Foliola multijuga, elongato lineari-lanceolata, 12-16-plo longiora quam lata, nervis $20-25$ facile conspicuis percursa, recta v. subfalcata, pungenti-acuta, margine utrinque dentibus

*) Abgebildet ist ein Blatt. Es kaun das aber ebensowohl ein junges Blatt eines E. Lehmanni, als vielleicht von $\mathrm{E}$. villosus oder $\mathrm{E}$. Altensteinii,-oder selbst von einer Zamia sein. 
$3-5$ erectis pungenti-acutis satisque distantibus, 20 c. m. et ultra longa, $12-15 \mathrm{~m}$. m lata, inferiora sensim ad spinas partitas reducta. Habitat in Africa australi.

\section{Encephalartos Hildebrandti A. Br. et Bouché. (v. et s.)}

A. Br. in ind. sem. h. Berol. 1874 p. 18.

Truncus demum cylindricus, $1 \mathrm{~m}$. et ultra altus, perularum rudimentis dense vestitus. Folia prima juventute lanugine obducta, demum praeter basin rhachis glaberrima, $1 / 2-1 \mathrm{~m}$. longa. Rhachis latere in-

- feriore convexa, latere superiore carinata et juxta carinam utrinque sulco levi exarata. Foliola multijuga, (utrinque $36--50$ ), anguste lanceolata, 5-6-plo longiora quam lata, nervis $15-18$ difficile conspicuis percursa, pungenti-acuta, utrinque ad marginem dentibus $3-5$ erecto-patentibus pungenti-acutis armata, $8-10 \mathrm{c}$. m. longa, $14-16 \mathrm{~m}$. m. lata, laete viridia; inferiora sensim sensimque ad spinas palmatas $3-5$ fidas reducta. - Videtur varietas E. villosi.

Habitat ad oram Sansibar.

\section{Encephalartos Altensteini Lehm. (v. v.)}

Lehm. pug. IV. pag. 11, tab. 4 et 5.-Miq. mon. p. 51.-Linnaea XIX pag. 420, tab. 5. - D. C. prodr. XVI. II. 532. - E. Murumi Vriese Tijdschr. nat. Gesch. V, pag. 188. - Zamia spinosa Lodd. cat. - Z. spinulosaret spinosissima hort.

Truncus cylindricus, glaber v. apice tomentosus. Folia laete viridia, mox glabra, $3 / 4-1 \frac{1}{2} \mathrm{~m}$. longa. Petiolus et rhachis tereti-3-4gona. Foliola multijuga lanceolata, $5-7$-plo longiora quam lata, nervis 20 - 30 facile conspicuis percursa, pungenti-acuta, margine utrinque dentibus 1-6 pungenti-acutis erecto-patentibus armata v. interdum integerrima, $7-17 \mathrm{com}$. longa, $1 \frac{1}{2}-2^{1 / 2} \mathrm{c}$. m. lata, inferiora subito v. rarius sensim ad spinas palmato-partitas paucas $v$. nullas reducta. Squamae strobili masculi ovoideo-elongati patentes, quadrangulares et in conum truncatum sterilem desinentes, squamae superiores ovato-elongatae obtusae. Strobili foeminei squamae obovatae, extremitate omnium pubescente. - Habitat in Africa australi. 


\section{Variat :}

๙. typicus; foliolis usque $17 \mathrm{c.m}$. longis, utrinque $1-4$ dentatis $v$. rarius nonnullis integerrimis, inferioribus subito ad spinulas paucas $\mathrm{v}$. nullas reductis. - E. Altensteini et $\Lambda$ ltensteini $\beta$. angustifolia Miq. mon. p. 51 et 52 . - E. Mltensteini $\alpha$. typicus et $\gamma$. distans Rgl. in Труды III, fasc. I, pag. 114. - Rgl. in Grtfl. 1875 p. 40. - Zamia vernicosa h. Versch.

$\beta$. semidentatus; foliolis margine superiore v. margine inferiore $1-3$ dentatis v. utrinque integerrimis. Cetera ut praecedentis. - Miq. monogr. p. 52. - E. Altensteini $\beta$. paucidentatus Rgl. Труды et Grtfl. l. с. - E. Murumi Vriese l. с.

$\gamma$. spinosior; petiolo inermi; foliolis $5-10$ c. m. longis, $1^{1 / 2}$ -2 c. m. latis, utrinque $2-6$ dentatis. - E. Altensteini $\delta$. spinosior Grtfl. 1875 p. 40. - E. Altensteini o. parvifolius Rgl. Труды III. I. 114._Zamia elegantissima h. J. Versch. - Encephalartos Vromii h. J. Verschaff.

ঠ. macrophyllus; ; petiolo ad basin spinis palmato-partitis vestito; foliolis $10-12$ c. m. longis, usque $3 \mathrm{c.m}$. latis, utrinque $2-5$ dentatis. -- E. Altensteini $\varepsilon$. grandis et $\zeta$. macrophyllus Rgl. Grtfl. 1875 p. 40, 41. - E. grandis h. Haage et Schm. - Zamia Van den Heckei h. J. Versch. - Bombas Encephalartos h. Paullowsk.

ع. eriocephalus. De Vriese; trunco apice tomentoso. Cetera ut var. $\alpha$.

E. Altensteini var. eriocephala De Vriese descr. pl. nouv. Jard. Leyd. pag. 1, tab. 1 et 2.

8. Encephalartos septentrionalis Schweinf.

Schweinf. bot. Zeit. 1871 pag. 332. - Al. Br. in ind. sem. h. Berol. 1874 p. 18.

Tru neus plurima parte terra immersus, semper globosus. Folia 
pubescentia. Foliola utrinque dentibus 8 -10 magis erectis et minus pungentibus. Cetera ut praecedentis.

Habitat in Africae septentrionalis regione Niam-Niam.

\section{Encephalartos longifolius Lehm. (v. v.)}

Lehm. pug. VI, pag. 14, - Miq. mon. pag. 54. - Zamia longifolia Jacq. fragm. II, pag. 28 tab. 20.- E. longifolius D. C. prodr. XVI. II. 531. - Rgl. Труды III. I. 113. - Grtfl. 1875 p. 38.

Truncus crassus, cylindricus. Folia $1 \frac{1 / 2}{2}$. longa, juventute laxe tomentosa, mox glabra. - Petiolus inermis, obtuse tetragonus; rhachis teres. Foliola multijuga, viridia v: vix glancescentia, lanceolata, multinervia, stricta v. subfalcata, $12-16 \mathrm{c.}$. longa, $21 / 4-4 \mathrm{c}$. m. lata, integerrima v. margine inferiore $1-2$ obtuse dentata; inferiora pungenti-acuta, superiora obtusa v. apice ipso calloso-hamato obtuso. Strobili masculi sessilis cylindrici squamae usque ad $2 / 3$ longitudinis cuneatae, apice conico-quadrangulo fusco truncato terminatae.

Habitat in Africa australi.

Variat:

a. typicus; foliolis lanceolatis planis. Foliola $12-16 \mathrm{c.} \mathrm{m}$. longa, $2 \frac{1}{4}-3$ c. m. lata, saepissime integerrima. - E. longifolius $\%$ angustifolius et $\delta$. Hookeri D. C. prodr. XVI. II. 531. - E. caffer Hook. bot. mag. tab. 4903. — Zamia longifolia Jacq. l. c.

B. revolutus; foliolis lanceolatis, margine revolutis. D.C.l.c.

$\gamma$. latifolius; foliolis elliptico-lanceolatis, margine revolutis. Foliola 12-13 c. m. longa, 4 c. m. lata, margine inferiore obtuse grosseque 1-2 dentata, rarius integerrima.

E. longifolius $\gamma$. latifolius Rgl. in Труды III. I. pag. 113. — Grtfl. 1875 p. 39. - E. Almasianus h. Paullowsk.

\section{Encephalartos lamuginosus Lehm. (v. v.)}

Lehm. pug. VI pag. 14. - Miq. monogr. pag. 56. - D. C. prodr. XVI. II. 533. - Rgl. іn Труды Имп. Бот. сада III. I. 113. 
Grtfl. 1875 p. 39. - Zamia lanuginosa Jacq. fragm. tab. 30, 31. E. horridus $\beta$. lanuginosus Miq. in Ann. d. sc. nat. ser. II, tom. 10 pag: 367. - Enceph. latifrons Lehm. in de Vriese nov. spec. Cyc. p. 16, tab. 4 (IX) A. B.

Truncus crassus, humilis, demum subcylindricus, plus minus laxe albido-tomentosus. Folia saturate viridia, $1-1 \frac{1}{2} \mathrm{~m}$. longa. Petiolus inermis, tereti-subtrigonus, initio laxe tenuiterque tomentosus, mox glaber. Rhachis petiolo similis. Foliola multijuga oblongo- v. subelliptico-lanceolata, pungenti-acuta, margine inferiore dentibus $1-4$ grossis lobuliformibus patentissimis subito in acumen breve pungens acuminatis, multinervia, $12-16$ c. m. longa, $3-4$ c. m. lata.

Africa australis.

Foliis viridibus, foliolorum majorum dentibus in spinulam brevem subito acuminatis ab E. horrido, foliorum latiorum dentibus lobuliformibus pnngenti-acutis ab E. caffro dignoscitur.

\section{Encephatartos horridus Lehm. (v. v.)}

Lehm. pug. VI pag. 14. - Miq. mon. pag. 57. - D. C. prodr. XVI. II. 533 , excl. syn. $3 .-$ Rgl. in Труды III. I. 113. - Grtfl. 1875 p. 40, - Zamia horrida Jacq. fragm. tab. 27, 28. - E. nanus Lehm. in Lehm. et De Vriese Tijdschr. nat. Gesch. IV, pag. 414, 421 tab. VII fig. c - De Vriese nov. spec. Cyc. pag. 13 tab. III, fig. c.E. Van Hallii De Vriese in Lehm. et De Vr. Tijdschr. IV, p. 422, tab. $\mathrm{X}$ et De Vr. nov. sp. Cyc. pag. 14 tab. V. - E. horridus var. trispinosa Hook. bot. mag. 5371. - E. tricuspidatus hort. in Verh. z. Bef. Grtb. V, p. 186.

Truncus humilis, demum subcylindricus, glaber. Folia glauca, 40-80 c. m. longa. Rhachis petiolusque tereti-subtetragona, posterior inermis. Foliola lanceolata v. subelliptico-lanceolata, in spinam pungentem acuminata, multinervia, latere inferiore dentibus $1-3$ lobuliformibus in spinam sensim acuminatis saepissime simplicibus v. rarius bifidis, nunc horizontaliter nunc erecto- $\mathrm{v}$. divaricato-patentibus, $8-12$ c. m. longa, $2-4$ c. m. lata; foliola inferiora saepe integerrima. Strobilus masculus 
elongato-cylindraceus; strobilus foemineus ovatus; squamis pelta quadrangulari, fusca, utroque latere hamata terminatis.

Habitat in Africa australi.

\section{Species exclusae.}

Encephalartos pungens Lehm. = Macrozamia spiralis Miq. $-\mathrm{E}$. tridentatus Lehm. = Macrozamia tridentata Rgl.

\section{Lepidozamia RgI.}

(Rgl. Bull. de la Soc. de MIosc. 1857 I, p. 182 tab. IV fig. 20, 21. - Rgl. Grtfl. 1857 pag. 11 tab. 186 fig. 23 et 31. - Ibidem 1870 pag. 227 tab. 660 . - Ibid. 1875 pag. 42. - Ibidem 1876 p. 4.- D. C. prodr. XVI, II. 547.

Truncus demum elatus cylindricus, initio ovatus, perulis persistentibus (nunquam fibreso-laciniatis) onustus. Folia in verticillos terminales (nec unum post alterum) provenientia, vernatione recta imbricatave, pinnata; petiolus inermis. Foliola anguste lineari-lanceolata, integerrima longitudinaliter-nervosa, acutissima, numerosissima, basi neque articulata neque incrassata et ibidem deorsum ad rhacheos marginem decurrentia. Foliorum rhachis in latere superiore canaliculata.

Flores foeminei in conum subsessilem crassum maximum ovato-globosum dispositi. Carpophylla arcte imbricata, basi stipitata; stipite terminato pelta cordato-ovata, crassa et apice sensim in acumen planiusculum attenuata. 0vula pendula, utrinque ad peltae basin interiorem foveolae insidentia.

Patria: Nova Hollandia orientalis.

\section{Conspectus specierum.}

1. L. Peroffskyana; petiolis semiteretibus, latere superiore costa elevata subtriangulis, initio tenuiter eburneo-tomentellis, demum glabris; foliolis $10-14 \mathrm{~m}$. m. latis, $11-13$ nerviis. 
2. L. Denisoni; petiolis semitaretibus, supra planis et apicem versus subcanaliculatis, basi tenuiter fusco-tomentosis, caeterum glabris; foliolis circiter $10 \mathrm{~m}$. $\mathrm{m}$. Ialis, $11-15$ nerviis.

3. L. Hopei; petiolis ut antecedentis; foliolis usque $30 \mathrm{~m} . \mathrm{m}$. latis, nervis $20-30$ alteris validioribus alteris tenuioribus percursis.

\section{Ennmeratio specierum.}

1. Lepidozamia Peroffstyana Rgl. (v. v.)

Rgl. Bull. Mosc. et Gartenfl. 1. c. - D. C. prodr. XVI, II. 547. - Macrozamia Denisoni Moore et Müll. ex parte. - Zamia Macleayi h. Van Houtte. - Macrozamia Peroffskyana et Denisoni hort.

Folia incluso petiolo usque $2 \frac{1}{2} \mathrm{~m}$. longa, interiora erecto-patentia, intermedia recurvo-patentia, exteriora recurvo-dependentia. Petiolus circ. 70 c. m. longus. Foliola usque 100 -juga, anguste lineari-lanceolata, subfalcata, usque $30 \mathrm{c}$. m. longa et $12-14$ c. m. lata. Specimina juniora omnibus partibus minora foliolisque minus numerosis.

\section{Lepidozamia Denisoni Rgl. (v. v.)}

Rgl. Grtfl. 1845 p. 43. - Ibidem 1876. p. 5. - Macrozamia Denisoni Moore et Müll. fragm. austr. I. pag. 417. - D. C. prodr. XVI, II. 536. - Encephalartos Denisoni F. Müll. in Quart. Journ. pharm. Vict. II. 90.

Truncus demum elatus, cylindricus, usque 20 ped. altus. Folia teste Miquelio 7-12 pedes longa, petiolo $2-3$ pedali; foliolis usque 120 jugis, lineari-lanceolatis, falcatis, $12-15$ nerviis, usque 10 poll. longis et 6 lin. latis. Foliola speciminum juniorum cultorum incluso petiolo usque 110 c. m. longa, laete viridi-nitentia; petiolus usque 68 c. m. longus; foliola circiter 20 juga, 18 c. m. longa, 1 c. m. lata, 10-12 nervia. 
3. Lepidozamia Hopei Rgl. (v. v.)

Rgl. Grtfl. 1876. p. 6. - Katakidozamia Hopei h. Haage et Schm.

Dignoscitur foliolis $26 \mathrm{c.m}$. longis et $20-30 \mathrm{~m}$. m. latis, nervis longitudinalibus inaequalibus $20-30$ percursis.

\section{Dioon Lindl.}

Lindl. bot. reg. 1843 app. 59. - Miqu. epicr. pag. 289; in Linnaea XIX 414, XXI 576; in Verh. Ned. Inst. 1851 tab. 3 et 4. Lem. ill. hort. II pag. 91 cum tab. - Platyzamia Zucc. in Abh. Bayr. Ac. pag. 23. tab. 4.

Truncus initio ovatus, demum cylindricus, perulis persistentibus dense lanatis (nunquam fibroso-laciniatis) onustus. Folia in verticillos terminales (nec unum post alterum) provenientia, vernatione stricta imbricatave. Rhachis latere inferiore semiteres, latere superiore costa elevata semitereti. Foliola parallele nervosa, numerosissima, anguste linearilanceolata, rigida, apice spinescentia, basi non incrassata et ibidem deorsum decurrentia, utrinque ad costae basin insertae. Strobili squamae planae, imbricatae, obovato-cuneatae, apice sterili ovato inflexo extus lanato terminatae. Strobili foeminei squamae imbricatae, stipite trigono elongato suffultae, lamina lanceolata acuminata plana basi cordata terminata. Ovula pendula, utrinque ad stipitis apicem solitaria.

Arbores humiles regno mexicano indigenae.

\section{Dioon edule L. (v. v.)}

Lindl. Niiq. Lem. 1. c. - D. C. prodr. XVI, II p. 537. - Platyzamia rigida Zucc. 1. c. - Zamia Maeleni Miq. Linnaea XVIII. pag. 97. - D. imbricatum Niq. teste D. C. - D. aculeatum Lem.

Truncus demum 1-2 m. altus, apice lanatus. Folia circiter $1 \mathrm{~m}$. longa, glabra. Petiolus semiteres, inermis, latere superiore carina trigona, basi dense lanatus et paullo tantum dilatatus. Rhachis semiteres, latere superiore costa elevata semitereti. Foliola valde spinescentia, 
margine incrassato paullo revoluto, circiter 8-10 nervia, usque $11 \mathrm{c}$. m. longa, 4. $-6 \mathrm{~m}$. m. lata. Strobili foeminei elliptici squamis apice glabris, basi lanatis.

\section{Ceratozamia Brongn.}

Truncus abbreviatus, saepe decumbens et basi proliferus, rarius suberectus, perulis persistentibus (nunquam fibroso-laciniatis) onustus. Folia pinnata in verticillos terminales (nec unum post alterum) provenientia, vernatione circinata; petioli sparsim aculeati v. inermes, basi subvaginato-dilatata utrinque auriculati. Foliola parallele multinervia, lanceolata usque anguste lineari-lanceolata, integerrima v. rarius apicem versus denticulata, basi articulata, nascentia imbricata. Strobili cylindrici; squamae strobili masculi ultra medium obovato-cuneatac, superne steriles, apice bicornutae; squamae strobili foeminei stipite crasso utrinque ovulifero, peltatae, peltis transverse hexagonis e medio bicornutis.

Arbusculac regiones mexicanas incolentes.

\section{Conspectns specierum.}

A. Foliola 2-5 c. m. lata, lanceolata v. lineari-lanceolata, in statu vivo non transparente striato-nervosa.

1. C. mexicana Brongn, petiolo plus minus aculeato; rhachi inermi, foliolis integerrimis, $3-4^{1} / 3$ c. m. latis.

2. C. Katzeriana Rg?., petiolo aculeato; rhachi inermi; foliolis apicem versus spinescenti-dentatis, circiter $5 \mathrm{c.m}$. latis.

3. C. longifolia Miq., petiolo aculeato; rhachi saepe aculeolis raris armata; foliolis integerrimis, $17-30 \mathrm{~m}$. m. latis.

B. Foliola lanceolata, 3-5 c. m. lata, in statu vivo transparente striato-nervosa

4. C. robusta Miq., petiolo inferne dense aculeato; foliolis subito acuminatis, integerrimis.

5. C. Miqueliana H. Wencll, petiolo inermi r. basi vix aculeato; foliolis subito acuminatis, saepe sub apice dente unico magno obtuso. 
C. Fo'iola anguste lineari-lanceolata, circiter 1 c. m. lata. 6. C. Küsteriana Rgl.

\section{Linumeratio speciernm.}

\section{Ceratozamia mexicana Brongn. (v. v.)}

Brongn. in Ann. sc. nat. ser. III tom. 5 pag. 8 tab. 1. - Miq. prodr. Cyc. pag. 11 et 23. - D. C. prodr. XVI, II pag. 546. - C. brevifrons Miq. in Tijdschr. nat. Wet. I pag. 41. - C. mexicana et C. longifolia hort.

Truncus humilis, foliorum basibus perulisque acuminatis saltem apice cinereo tomentosis onustus. Folia speciminum juniorum $80-90$ c. m. longa, 2-3 juga; speciminum satis evolutorum usque $2 \mathrm{~m}$. longa, 7-16 juga, erecto-patentia et apice graciliter recurvata. Petiolus basi subvillosus, viridis, teres, a basi ad apicem v. inferne tantum aculeis sparsis raris brevibus armatus, quam lamina saepissime longior. Rhachis viridis, laevis, teres, supra leviter sulcata. Foliola lanceolata; recta v. leviter falcata, sensim v. subito acuminata, integerrima, 2035 nervia, $3-4^{1} / 2$ c. m. lata, $15-35$ c. m. longa.

\section{Ceratozamia Katzeriana Rgl. (v. v.)}

Zamia fusca h. Paullowsk.

Folia 8-10 juga. Petiolus teres, fuscus, aculeatus, initio leviter tomentosus, demum glaber. Rhachis inermis, fusca. Foliola lanceolata, leviter falcata, acuminata, margine a medio ad apicem dentibus spinescentibus erectis vestita, 5 c. m. lata usque $32 \mathrm{c.m}$. longa, multinervia, juniora e rubro fuscescentia, vetustiora obscure viridia, nitentia.

\section{Ceratozamia longifolia Miq. (v. v.)}

Miq. Wis. en Nat. Tijdschr. I. pag. 42. - Ejusd, prodr. Cyc. pag. 11 et 21. - D. C. prodr. XVI, II. 547. - C. intermedia Miq. mss. - C. longifolia b. minor. - Miq. prodr. 1. c. - C. mexicana et. C. robusta hort.

Truncus initio globosus, demum cylindricus flexuosus, foliorum basibus dilatatis perulisque onustus; perulae latissimac, in acumen patens 
strigoso-pilosum excurrentes. Folia patentissima, apicem versus graciliter recurvata, $1-2 \mathrm{~m}$. longa. Petioli teretes, $60-70 \mathrm{c}$. in. longa, virides, aculeolis brevibus raris armati. Rhachis teretiuscula, latere superiore bisulcata, $60-140 \mathrm{c} . \mathrm{m}$. longa, aculcolis rarissimis armata. Foliola 10 -multijuga, angustc lanceolata, recta v. subfalcata, 17-20 nervia, sensim attenuato-acuta, integerrima, $18-25$ v. rarius usque 30 m. m. lata, $22-35$ c. m. longa, utrinque lacte viridia.

\section{Ceratozamia robusta Miq. (v. v.)}

Miq. in Wis. en Nat. Tijdrschr. I p. 42. - D. C. prodr. XVI. II. p. 547 .

Truncus ut C. longifoliae. Folia crecto-patentia, apice leviter recurvata, $80-120 \mathrm{c} . \mathrm{m}$. longa. Petiolus teres, inferne aculeis diametrum dimidium petioli superantibus satis dense armatus, lutescente-viridis v. basin versus paullo purpurascens. Rhachis teretiuscula, supra bisulca, inermis. Foliola 13-multijuga, lanceolata, subito acuminata, recta v. subfalcata, in statu vivo eximie transparente-striato-nervosa, $3-4{ }^{1} / 2 \mathrm{c}$. m. lata, 16-22 c. m. longa, pallide viridia.

\section{Ceratozamia Miqueliana H. Wendl. (v. v.)}

H. Wendl. ind. Palm. p. 68. - Miiq. prodr. Cyc. pag. 11. 22. - D. C. prodr. XVI. II. 547. - C. latifolia Miq. Tijdr. I. c. I. pag. 206. - D. C. 1. c. p. 547. - C. mexicana et C. Ghiesbréchti hort.

Truncus ut C. mexicanae. Folia initio breviora, demum usque $1^{3 / 4}$ m. longa, erecto-patentia et apicem versus graciliter recurvata. Petiolus cylindricus, laevis $\mathrm{v}$. aculeis sparsis rarissimis armatus, initio purpurascens, demum luride virescens, basin versus saepissime albido-pruinatas, laminam aequans $\mathrm{v}$. ea longior. Rhachis laevis, teres, purpurascens v. viridis, supra leviter sulcata. Foliola 5-11 juga, opposita v. alterna, lanceolata, recta v. subfalcata, subito acuminata, integerrima v. sub apice dente satis magno obtuso aucta, supra atroviridia, subtus pallidiora, $35-40$-nervia, transparente striato-nervosa, $3^{1 / 2}-7 \mathrm{c}$. m. lata, $14-$ 32 c. in. longa. 


\section{Ceratozamia Küsteriana Rgl. (v. v.)}

Rgl. in Bull. Mosc. 1857 p. 187 cum iconc. et tab. III. fig. 6. tab. IV. fig. 22. - Rgl. Grtfl. - D. C. prodr. XVI. II. 546.

Truncus initio globosus, demum subcylindricus et basi plus minus ramoso-proliferus, foliorum basibus perulisque ovatis sensim acuminatis subglabris onustus. Folia erecto-patentia, apice leviter recurvata, $60-$ 80 c. m. longa. Petiolus teres, inermis, basi tomentosus, fusco-viridis, 20-25 c. m. longus. Rhachis teretiuscula, latere superiore bisulcata. Foliola multijuga (usque 40 juga), satis dense disposita, anguste linearilanceolata, sensim sensimque attenuato-acuminata, integerrima, 8-10 nervia, utrinque lacte viridia, recta v. leviter falcata, $11-13 \mathrm{~m} . \mathrm{m}$. lata, $15-25$ c. m. longa. Strobili masculi breviter pedunculati, subcylindrici, attenuato-acuti.

\section{Aulacophyllum Rgl.}

Truncus cylindricus, apice tantum perulis caducis onustus. Folia in verticillos terminales (nec unum post alterum) provenientia, pinnata. Petiolus sparsim aculeatus. Foliola lanceolata usque elliptico-lanceolata, praecipue apicem versus serrulata, multinervia, nervis latere superiore immersis et latere inferiore prominentibus v. utrinque prominentibus sulcata, basi articulata. Strobili foeminei cylindrici squamae pedicellatopeltatae; peltis hexagonis, externe convexis, transverse elongatis, in latere inferiore utrinque uniovulatae. Semina maxima, obovato-oblonga; matura rubra (an semper?).

Arbores humiles in Nova Granada, Panama et Ecuador indiginae, foliolis nervis immersis a generibus Zamia et Microcycas satis distinctae.

Cfr. Grtfl. 1876. p. 140.

\section{Dispositio specierum.}

A. Foliola oblongo-lanceolata.

a. Rhachis glabra. Foliola erecto-patentia.

1. A. Roczli.

b. Rhachis initio fusco-tomentella v. subhirsuta. Foliola horizontaliter patentia. 


\section{A. Lindeni.}

c. Rihachis glabra. Foliola horizontaliter-patentia.

3. A. montanum; foliolis 20-22-nerviis.

4. A. Ortyiesi $R g l$; foliolis $9-13$-nerviis.

B. Foliola clliptico-lanceolata $v$. elliptica.

5. A. Stimeri; foliolis sessilibus.

6. A. Wallisii; foliolis in petiolum attenuatis.

\section{Aulacophyllum Roezli. (v. v.)}

Zamia Roezli Rgl. in Linden. cat. 1873 n. 90. - Illustr. hort. 1873 tab. 133-134. - Rgl. Grtfl. 1874 pag. 55. - Aulacophyllum Roezli Rgl. Grtfl. 1876. p. 141.

Truncus cylindricus, $1-3 \mathrm{~m}$. altus, nudus, foliorum perularumque cicatricibus notatus. Folia pinnata, speciminum satis evolutorum usque $2 \mathrm{~m}$. longa, multijuga, speciminum juniorum duplo-quadruplo minora pauci-plurijuga. Petiolus glaber, speciminum non satis evolutorum teres inermis v. subinermis, specinninum satis evolutorum aculeis sparsis armatis teres et in latere superiore sulcatus. Rhachis aculeis sparsis raris armata, semiteres, in latere superiore costa prominente. Foliola erectopatentia, opposita v. rarius alterna, oblongo-lanceolata, acuminata, basi manifeste articulata, margine spinuloso-erectoque-dentata, basin versus integerrima, 12-18-nervia, laete viridia, 20-40 c. m. longa, 2-4 c. m. lata; nervis in latere superiore valde immersis, in latere inferiore costato-prominentibus.

Habitat in Nova Granada.

\section{Aulacophyllum Lindeni. (v. v.)}

Zamia Lindeni Rgl. in Linden. cat. 1875. - Linden et André Illustr. hort. 1875 tab. 195. - A. Lindeni Rgl. Grtfl. 1876. p. 141.

Petiolus rhachisque teretia, aculeis satis numerosis rigidisque armata, initio ferrugineo-tomentella v. subhirsuta, demum glabra. Foliola horizontaliter patentia, anguste lanceolata, nervis longitudinalibus 
minus profunde immersis 22 et ultra percursa, $20-25$ c. m. longa, $21 / 2-31 / 2$ c. m. lata. Cetera ut praecedentis.

Habitat in Ecuador.

\section{Aulacophyllum montanum. (v. v.)}

Zamia montana A. Br. in Monatsbericht. d. Ac. der Wiss. in Berl. 1875 pag. 376. - A. montanum Rgl. Grtfl. 1876. p. 141.

Pedunculi dense aculeati, basin versus fusco-tomentosi, caeterum rhachique glabri. Foliola horizontaliter patentia, 20-22 nervia, usque. $35 \mathrm{c.} \mathrm{m}$. longa et usque $4 \mathrm{c}$. m. lata. Çaeterum satis similis A. Roezli.

Habitat in Nova Granada.

\section{Aulacophyllum Ortgiesi (v. v.)}

A. Ortgiesi Rgl. Grtfl. 1876. p. 141.

Folia multijuga, glabra. Foliola basi articulata, horizontaliter patentia, anguste lanceolata, apicem versus attenuato-acuminata, 9-13-nervia, supra basin circ. $1 \mathrm{c.} \mathrm{m}$. lata, circiter $12 \mathrm{c.} \mathrm{m}$. longa, nervis utrinque prominentibus sulcata.

E Nova Granada a Cl. Wallisio introducta.

\section{Aulacophyllum Skinneri. (v. v.)}

Zamia Skinneri Warsczw. in 0tto et Dietr. Allg. Grtztg. XIX. pag. 146. - Hook. bot. mag. tab. 5242. - D. C. prodr. XVI. II. pag. 539. - A. Skinneri Rol. Grtfl. 1876. p. 143.

Truncus cylindricus, $1 \mathrm{~m}$. et ultra altus. Petiolus rhachisque teretia, aculeata, glabra. Foliola pauci-plurijuga (2-11 juga), ellipticolanceolata, acuminata, multinervia, superne spinuloso-dentata, $20 \mathrm{c.} \mathrm{m}$. et ultra longa, 4-8 c. m. lata, nervis immersis insigniter sulcata.

Habitat in Guatemala.

\section{Aulacophyllum Wallisi. (v. v.)}

Zamia Wallisii A. Br. Monatsb. der Berl. Ac. d. Wiss. 1875 pag. 376. - Aulacophyllum Wallisi Rgl. Grtfl. 1876. p. 143.

Truncus crassus, humilis, semisubterraneus. Petiolus teres, minute aculeatus, basi laxe tomentosus, caeterum rhachique glaber. Folia pauci- 
plurijuga ( $2-8$ juga). Foliola elliptico-lanceolata, basi in petiolum usque 4 c. 1 . longum attenuata, acuminata, superne denticulata, $12-45$ nervia, $35 \mathrm{c}$. m. et ultra longa, $9 \mathrm{c.m}$. et ultra lata, nervis immersis profunde sulcata.

Habitat in Nova Granada.

\section{Microcycas Miq.}

D. C. prodr. XVI. II. pag. 538.- Zamiae sectio Microcycas Miq. - Flore des serres VII. pag. 141.

Truncus cylindricus, demum nudus, foliorum perularumque deciduorum cicatricibus pictus. Folia pinnata in verticillos terminales (nec unum post alterum) provenientia. Petiolus inermis. Foliola anguste lineari-lanceolata, parallele nervosa, integerrima, basi insigniter articulata, nervis paullo immersis lineata. Squamae strobili masculi planae, crassiusculae, a basi ad mediam partem cuneatae et subtus antheriferae, a medio ovatae steriles. Squamae strobili foeminei laxe juxtapositae, axi perpendiculares, superiore majore parte drupam irregulariter sulcatam simulente, nempe ellipsoideo-costatae et sulcatae, extremitate truncata v. obtusa, inaequaliter bullata, basi in stipitem brevem angustata; stipite utrinque in apice semen ellipsoideum sessile gerente.

Arbusculus antillana.

Microcycas calocoma D. C. (v. v.)

D. C. prodr. XVI. II. pag. 538. - Zamia calocoma Miq. prodr. pag, 26. - Grish. cat. pl. Wright. pag. 217. - Rol. in Bull. Soc. Mosq. 1857. I. pag. 191.

Folia 60-90 c. m. longa, initio ubique pube tenui conspersa, demum (exclusa rhachi utrinque inter foliola villosula) glabra. Petiolus teres, demum glaber, usque 10 c. m. longus. Foliola multijuga, utrinque usque 80 , horizontaliter patentia, satis dense disposita $(5-10 \mathrm{~m}$. m. distantia), anguste lineari-lanceolata, in apicem obtusulum sensim 
attenuata, margine crassiora et revoluta, integerrima, nervis $9-14$ supra leviter immersis, infra leviter prominentibus, $9-18$ c. m. longa, 7-8 m. m. lata.

Habitat in insula Cuba et in insula Pinorum.

\section{Zamia L.}

Arbusculae humiles v. humillimae; trunco simplici subcylindrico $\mathrm{v}$. saepe pluri-multicipiti, nudo, cicatricibus perularum petiolorumque mox deciduorum ornato. Folia pinnata, unum post alterum provenientia. Petioli saepe sparse aculeati. Foliola linearia usque ovata, margine praecipue apicem versus denticulata v. rarius integerrima, omnia basi manifeste articulata, parallelinervia. Strobili masculi foemineique squamae pedicellato-peltatae; peltis hexagonis, transverse longioribus, adpressis; strobili masculi squamae in latere inferiore peltae et ad stipitem antheriferae, foeminei in latere inferiore peltae biovulatae.

\section{Conspectus specierum.}

I. Petioli aculeati.

A. Foliola longe linearia, acuminata, apice 3-4 denticulata, 7-10 nervia.

1. Z. spartea D. C.

B. Foliola lineari-lanceolata, apicem obtusum v. acutum versus denticulata.

2. Z. Loddigesii Miq., trunco 2-pluricipite, foliis $3-5$ jugis.

3. Z. Leiboldi Miq., trunco subcylindrico saepissime simplici; foliis 7-22 jugis.

C. Foliola lineari-lanceolata, integerrima $v$. apice obsolete denticulata.

4. Z. Chigua Seem.

D. Foliola oblongo-lanceolatu, acuminata, basi nuda.

5. Z. muricata Willd., foliolis 4-11 jugis, sub 40 nerviis. 
$6 Z$. Baraquiniana hort., foliolis $20-30$ jugis, sub 30 nerviis.

E. Foliola obovato-oblonga v. obverse lanceolata, obtusa $v$. subacuta, apicem versus denticulata, basi nuda.

7. Z. furfuracea Ait., foliolis multijugis.

8. Z. latifolia Lodd., foliolis paucijugis.

F. Foliola elliptica, acuminata, basi in petiolum manicatum attenuata.

9. Z. manicata Linden.

II. Petioli inermes.

A. Foliola plus quam 10-nervia.

a. Foliola lineari-lanceolata $v$. anguste lineari-lanceolata. 10. Z. Boliviana D. C., foliolis $10-18$ jugis, acuminatis. 11. Z. media Jacq., foliolis usque 24 jugis, acutis.

12. Z. tenuis Willd., foliolis plurijugis, obtusiusculis.

b. Foliola oblongo-obovata v. oblonga, obtusa.

13. Z. pumila L., foliolis $12-24$ jugis, oblongis v. obverse oblongis, integerrimis v. apice obsolete crenulato-serrulatis.

14. Z. Ottonis Miq., foliolis $3-6$ jugis, obovatis, apice crenulato-serrulatis. - Folia $30-90$ c. m. longa.

15. Z. pygmaea Sims., foliolis 3-10 jugis, oblongo-lanceolatis, a medio ad apicen crenato-serrulatis. - Folia 10 20 c. m. longa.

16. Z. Kickxii Miq., foliolis 24 jugis, oblongo-lanceolatis, a medio ad apicem crenato-serrulatis. - Folia $30-35$ c. m. longa.

c. Foliola lanceolata v. elliptico-lanceolata, acuta v. acuminata.

17. Z. pseudo-parasitica Yates., foliolis sinuoso-falcatis, integerrimis, cuspidatis.

18. Z. Pöppigiana Mart. et Eichl., foliolis falcato-lanceolatis, acutis, ab apice ultra medium argute serrulatis. 
19. Z. Fischeri Miq., foliolis lanceolatis, acutis, a medio ad apicem serrulatis.

20. Z. obliqua $A$. Br., foliolis elliptico-lanceolatis, caudatoacuminatis, a medio ad apicem spinuloso-serrulatis.

B. Foliola 3-10 nervia, linearia.

a. Foliola 46-61 juga.

21. Z. multifoliata $D$. $C$.

b. Foliola 2-24 juga.

22. Z. angustifolia Jacq.

\section{Ennmeratio specierum.}

1. Zamia spartea $A$. D. C.

DC. prodr. XVI. II. 539.

Petioli $4-5$ c. m. longi, crebre aculeati, teretes, pube demum evanescente vestiti, perulis lanceolatis $2-3 \mathrm{c} . \mathrm{m}$. longis fulvo-tomentosis mixti. Folia incluso petiolo circiter 30 c. m. longa, circiter 20 jugopinnata. Foliola longe linearia, acuminata, apice denticulis $3-4 \mathrm{mu}-$ nita, glabra, rigida, $7-10$ nervia, $5-30$ c. m. longa, $4-5 \mathrm{~m} . \mathrm{m}$. lata, margine revoluta. Strobili pedunculati; pedunculis $3 \frac{1}{2}-7 \mathrm{c} . \mathrm{m}$. longis, tomentosis.

Habitat in regno mexicano.

An varietas Z. angustifoliae Jacq. petiolis aculeatis?

\section{Zamia Loddigesii Miq. (v. v.)}

Miq. in Tijdschr. nat. Gesch. 10 pag. 73. - Miq. in Linnaea XIX. pag. 425 tab. 7, fig. b. c. - D. C. prodr. XVI. II. pag. 541 - excluso synonymo. - Z. Loddigesii $\alpha$. typica Rgl. Grtfl. 1856 pag. 14, tab. 186 fig. 26 (foliolum). - Z. serrulata et Z. carasana Lodd. cat. teste Miq. - Z. Loddigesii $\beta$. obtusifolia et $\gamma$. angustifolia Rgl. Grtfl. 1857 tab. 186 fig, 27, 28 et 29 (foliola). - Ceratozamia Miqueli h. Versch. - Z. eriolepis, Z. terrestris, Z. media, Z. debilis, Z. nigra hort. - Z. mexicana Miq. prodr. Cyc. pag. 13, 28. 
Truncus mox nudus, crassus, saepissime 2-pluriceps, Perulae e basi latiore acuminatae, fusco-tomentosae, mox caducae. Petioli teretes, glabri, parce aculeati v. rarius subinermes, rhachin inermem superantes, $12-2$ z̈ c. m. longi. Foliola $3-5$ juga, lineari-lanceolata, in apicem acutum v. obtusiusculum acuminata, a medio ad apicem spinuloso-denticulata, $20-25$-nervia, $10-20$ c. m. longa, $1 \frac{1}{2}-2$ c. m. lata.

Habitat in regno mexicano.

\section{Zamia Leiboldi Miq. (v. v.)}

Miq. in Linnaea XIX. pag. 427. - Z. Loddigesii 3 . Leiboldi DC. prodr. XVI. II. pag. 441 .

Truncus subcylindricus, usque $20 \mathrm{c}$. m. altus, saepissime simplex. Perulae fusco-tomentosae, e basi valde dilatata longe acuminatae, trunci nudi apicem coronantes. Petioli teretes v. latere superiore planiusculi, sparse aculeati $\mathrm{v}$. rhachique inermi v. aculeolis raris vestita tomento fusco demum evanescente vestiti, lamina breviores. Folia incluso petiolo 50-90 c. m. longa, 7-22 jugo-pinnata. Foliola valde variabilia, lineari-lanceolata v. anguste lineari-lanceolata, in apicem acutum v. obtusiusculum v. obtusum attenuata, a medio ad apicem spinuloso-serrulata, $20-32$-nervia, $1-2^{1} / 2$ c. m. lata, $15-30$ c. m. longa. Strobili breviter pedunculati, cinereo-tomentelli.

Habitat in India occidentali.

Variat:

a. typica; foliolis 14-22 jugis obtusis, $15-25 \mathrm{~m}$. m. latis, 25-30 nerviis. - Z. Leiboldi Miq. 1. c.

ß. latifolia; petiolo tereti; foliolis $7-12$ jugis, 25-32 nerviis, $15-25 \mathrm{~m}$. m. latis, acutis v. obtusiusculis.

$\gamma$. angustifolia; foliolis $10-16$ jugis, $10-12 \mathrm{~m}$. m. latis, 20-25 nerviis, acutis v. obtusiusculís.

\section{Zamia Chigua Seem. (v. v.)}

Seem. Bot. Herald. pag. 201 tab. 43. - DC. prodr. XVI. II. 539. - Zamia Lindleyi Warsz. in Otto et Dietr. Allg. Grtztg. XIX. 


\section{8}

pag. 146. - Miq. prodr. Cyc. pag. 24. - Zamia imbricata Roezl. (in hortis).

Truncus cylindricus, simplex, $12-30 \mathrm{c}$. m. altus. Folia usque 120 c. m. longa; petiolo crebre rhachi parce aculeatis, junioribus tomento tenui evanescenti-vestitis. Foliola pluri-multijuga ( $7-66$ juga), lineari-lanceolata, $10-16$ nervia, sensim in apicem subspinescentem attenuata, integerrima v. apicem versus obsolete denticulata, subhorizontaliter patentia, $12-20 \mathrm{c} . \mathrm{m}$. longa, usque $18 \mathrm{~m}$. m. lata. Strobilus masculus elongato-cylindricus, $13-16 \mathrm{c.} \mathrm{m}$. longus, tomentosus, pedunculatus.

Habitat in Panama et in insulis ostii fl. St. Juan isthmi Darien.

\section{Zamia muricata Willd. (v. v.)}

Willd. spec. IV. 847. - Miq. mon. p. 65 et 66 , tab. 7. - DC. prodr. XVI. fasc. II. pag. 541. - Karsten in Abh. Ac. Berol. 1856 tab. $1-3$.

Truncus subcylindricus, simplex v. divisus. Petiolus teres, basi tenuiter tomentosus, caeterum glaber, parce aculeatus v. rarius inermis. Rhachis inermis, teres, supra leviter sulcata. Foliola multinervia, 312 juga, lanceolata $\mathrm{v}$. oblongo-lanceolata, acuminata v. rarius singula obtusiuscula, a medio ad apicem spinuloso-denticulata, $12-25 \mathrm{c.} \mathrm{m}$. longa, $2-4 \mathrm{c} . \mathrm{m}$. lata. Strobili pedunculati, cylindrici, tomentosi, 8 -10 c. m. longi.

Habitat in America meridionali.

Variat:

3. picta; foliolis albo-maculatis. - Z. picta hort. - Z muricata $\beta$. picta Miq. in Wiss. Tijdschr. I. p. 198. - D. C. prodr. 1 c. p. 541 . - Folia incluso petiolo majis aculeata, $2 \mathrm{~m}$. et ultra longa. Foliola usque 25 juga et usque 40 c. m. longa. An species propria?

6. Zamia Baraquiniana hort. (v. v.)

Truncus cylindricus, simplex, usque $90 \mathrm{c} . \mathrm{m}$. altus. Folia usque $1 \frac{1}{4} \mathrm{~m}$. longa. Petiolus teres, paullo angulatus, sparsim aculeatus, basi 
fusco-tomentosus, caeterum glaber. Rhach is teres, latere superiore-sulco destituto, aculeis raris armata. Foliola 20-30 juga, anguste. lancelata, saepe falcata, acuminata, a medio ad apicem spinuloso-denticulata, usque 35 c. m. longa, circiter 3 c. m. lata, circiter 30 nervia.

Patria verosimiliter America tropica.

Trunco elatiore, rhachi aculeata, foliolorum angustiorum longiorumque jugis numerosioribus a Z. muricata typica dignoscitur.

\section{Zamia furfuracea Ait. (v. v.)}

Ait. hort. Kew. ed. I. tom. III. pag. 477. - Bot. mag. tab. 1969. - Miq. mon. pag. 66. - D. C. prodr. XVI. II. 540.Palmifolia fructu clavato polyspermo Trew. pl. sel. tab. 26. - Z. crassifolia hort. et Z. fusca latifolia hort.

Truncus cylindricus, apice foliis perulisque e basi valde dilatata lanceolato-acuminatis coronatus. Folia incluso petiolo $100-120 \mathrm{c.m}$. longa. Petiolus teres, aculeatus, $40-55 \mathrm{c} . \mathrm{m}$. longus, initio breviter tomentellus, demum glaber. Phachis $46-66 \mathrm{c} . \mathrm{m}$. longa, teres, inermis. Foliola 10-13 juga, obverse lanceolata, rigida, crassa, multinervia, basin versus attenuata, apice saepe rotundato-obtusa v. rarius subacuta, apicem versus crenulato-denticulata, saepe inaequilatera, $15-20$ c. m. longa, 4-5 c. m. lata. Strobili pedunculati, tomentosi, foemineus oblong 0 -0 voideus apice sterilis.

Habitat in Mexico.

\section{Zamia latifolia Lodd. (v. v.)}

Lodd. cat. n. 687. - Zamia muricata var. obtusifolia Miq. in Tijdschr. nat. Gesch. X. pag. 21 et in Linnaea XVII. pag. 733 et XIX pag. 425 tab. 7 fig. a. - Encephalartos latifolius Steud. nom. Z. latifolia D. C. prodr. XYI. II. 541.

Truncus crassus, saepe pluriceps, usque $20 \mathrm{c}$. m. altus. Petioli teretes, aculeis raris armati v. subinermes, juniores ut rhachis et foliorum pagina inferior fusco-pilosula, demum glabra. Foliola 2-4 juga, ob- 
ovato-oblonga, $25-35$ nervia, usque $8 \mathrm{c}$. m. longa et $1 \frac{1}{2}-2 \frac{1}{2} \mathrm{c}$. m. lata.

Habitat in regno mexicano.

\section{Zamia manicata Linden.}

Linden in horto Lindeano.

Truncus cylindricus. Petioli sparsim aculeati. Folia pauci-plurijugopinnata. Foliola elliptica, acuminata, undulata, apicem versus obsolete crenulato-denticulata, basin versus in petiolum annulo prominente manicatum attenuata.

10. Zamia boliviana $D$. $C$.

D. C. prodr. XVI. II. 540. - Ceratozamia boliviana Brongn. in Ann. sc. nat. ser. III. tom. V. p. 9. - Z. Brongniarti Wedd. in Ann. sc. nat. ser. III. tom. XIII. pag. 249 tab. 4. - Eichl. in Mart. fl. bras. tom. IV. pag. 413 tab. 108.

Truncus hypogaeus, cylindraceus. Perulae e basi latiore lanceolatae, sensim attenuato-acutae. Folia 35-60 c. m. longa. Petiolus inermis, $15-35$ c. m. longus, teres, juxta axillam tomentosus. Rhachis obtuse triquetra, supra leviter carinata, circiter petioli longitudine. Foliola 10 -18 juga, anguste lineari-lanceolata, subfalcata, circiter 12 nervia, sensim in apicem acutum attenuata, integerrima $\mathrm{v}$. apice utrinque obsolete $3-5$ denticulata, $15-25 \mathrm{c} . \mathrm{m}$. longa, circiter $8 \mathrm{~m}$. m. lata. Strobili pedunculati, cylindracei; masculi $7-9$ c. m. longi; foeminei quam masculi subduplo longiores et quadruplo crassiores, ferrugineo-virescentes, apice acuminati.

Habitat in Bolivia inque Brasilia.

Vix ac ne vix quidem a sequenti specie differre videtur.

\section{Zamia media Jacq. (v. v.)}

Jacq. hort. Schönbr. tab. 397 et 398. - Miq. monogr. pag. 68. - D. C. prodr. XVI. II. 542. - Z. integrifolia Rich. Conif. et Cyc. pag. 191 tab. 27 et 28. 
Perulae e basi valde dilatata in cuspidem acuminata. Folia glabra, incluso petiolo usque $60-70$ c. m. longa, 12-24 juga. Petiolus inermis, teres. Foliola anguste lineari-lanceolata, sensim in apicem acutum attenuata, integerrima v. apicem versus obsolete crenulata, $12-20$ c. m. longa, 8-16 m. m. lata, 12-24 nervia. Strobili pedunculati; masculi cylindrici et apicem versus attenuati (cfr. Jacq. tab. 398), circiter $11 \mathrm{c} . \mathrm{m}$. longi; foeminei subelliptici, 9-10 c. m. longi (cfr. Jacq. tab. 397), acuminati.

Habitat in India occidentali.

Perulis e basi valde dilatata triangulari subito in cuspidem elongatam attenuatis, strobilis masculis quam foeminei longioribus a praecedenti diversa videtur.

\section{Zamia tenuis Willd.}

Willd. spec. pl. IV. 846. - Miq. mon. pag. 72 et in Linnaea XIX. p. 428 tab. 6. - D. C. l. c. pag. 544.

Videtur varietas Z. mediae foliolis $6-7 \mathrm{~m}$. m. latis apice ipso obtusiusculis.

\section{Zamia pumila $L$. (v. v.)}

L. spec. pag. 1650. - Bot. mag. "tab. 2006. - Mliq. monogr. pag. 69. - D. C. prodr. XVI. II. 543. - Z. media Bot. mag. tab. 1838. - Z. integrifolia Ait. hort. Kew. ed. I. tom. I. pag. 478. Jacq. ic. pl. rar. II. tab. 635. - Bot. mag. tab. 1851. - Miq. mon. pag. 67. - D. C. prodr. XVI. II. 541. - Pursh. fl. am. II. pag. 648. - Rich. comm. Conif. et Cyc. tab. 27. - Z. debilis Willd. spec. pl. tom. IV. pag. 846. - Miq. mon. p. 71. tab. VIII. fig. b. - D. C. prodr. XVI. II. pag. 542. - Z. concinna h. Booth. - Encephalartos pumilus Steud. nom. - Z. cylindrica h. Booth.

Truncus humilis. Perulae e basi latiore lanceolatae, apicem versus sensim attenuatae tomentosae, saepe dentatae. Folia incluso petiolo 35 -70 c. m. longa, 6-16 juga, pinnata. Petiolus inermis, teres, su- 
pra leviter sulcatus, initio furfuraceo-tomentosus, demum glaber. Foliola oblonga v. lanceolato-oblonga v. obverse oblonga, 20-multinervia, integerrima v. apicem obtusum v. obtusiusculum versus minute denticulata, circiter $10-35 \mathrm{~m}$. m. inter se distantia, 7-20 m m. lata, 6-14 c. m. longa. Strobili pedunculati, fusco-tomentosi; masculi cylindrici, usque 11 c. m. longi; foeminei ellipsoideo-cylindrici, subaequilongi, apice steriles et ibidem rotundato-obtusi v. in conum obtusulum attenuati.

Habitat in India occidentali, idemque in Florida.

Z. pumila auct. foliolis angustioribus $7-10 \mathrm{~m}$. m. latis strobilisque obtusis, $-Z$. integrifolia Ait. foliolis latioribus usque $20 \mathrm{~m} . \mathrm{m}$. latis strobilisque foemineis cono sterili superatis dignoscuntur. Vidi specimina florentia in horto bot. Petropolitano foliolis usque $20 \mathrm{~m}$. m. latis strobilisque foemineis apice sterili conoideo v. obtuso.

\section{Zamia Ottonis Miq. (v v.)}

Miq. in Linnaea XVII. p. 740. - D. C. prodr. XVI. II. p. 544. - Niqu. Cye. quaedam am. pag. 4 tab. II. - Z. furfuracea Roezl. mss. -

Truncus humilis, crassus, simplex et subovatus v. biceps. Perulae e basi valde dilatata in cuspidem satis elongatam margine dentatam acuminatae, apicem versus fusco-tomentosae. Folia $30-90 \mathrm{c.} \mathrm{m}$. longa, 3-6 jugo-pinnata, initio füsco-furfuraceo-tomentella, demum glabra. Petiolus inermis, teres, supra leviter sulcatus. Foliola cuneato-obovata,superne rotundato-obtusa $v$. rotundata et in apicem obtusum producta, a medio ad apicem v. apicem versus tantum obsolete v. manifeste crenulata v. rarius sub apice crenis $2-3$ majoribus, multinervia, $5-13$ c. m. longa, $2 \frac{1}{2}-5$ c. m. lata, circiter, $2-3$-plo longiora quam lata; speciminum non satis evolutorum $3-5$ juca et satis dense disposita $(10-15 \mathrm{~m} . \mathrm{m}$. inter se distantia), speciminum satis evolutorum laxe disposita (usque 5 -13 c. m. inter se distantia). Strobili foeminei elliptici, acuminati, circiter $5 \mathrm{c.m}$. longi et $2^{3} / 4 \mathrm{c}$. m. lati.

Habitat in Guatemala unde in hortum Petropolitanum a Cl. Roezl introducta, idemque in Cuba. 


\section{Zamia pygmaea Sims. (v. v.)}

Sims. bot. mag. tab. 1741. - Miq. mon. pag. 70. - D. C. prodr. XVI. II. 543. - Z pumila hort.

Pygmaea, glabra. Folia incluso petiolo inermi $10-12$ c. m. longa, 3-10 jugo-pinnata. Foliola satis dense disposita, oblongo-lanceolata, obtusa, inaequilatera, a medio ad apicem crenato-dentata v. duplicato-crenato-dentata, $1^{1} / 2-4^{1} / 2 \mathrm{c}$. m. longa, $10-12 \mathrm{~m}$. m. lata. Strobili pedunculati, tenuiter fusco-tomentosi, masculi elliptico-oblongi, $21 / 2-3$ c. m. longi.

Habitat in India occidentali.

\section{Zamia Kikxii Miq.}

Z. Kikxii Miq. mon. pag. 71 tab. 8 fig. A. - D. C. prodr. XVI. II. pag. 542 .

Foliis usque $32 \mathrm{c} . \mathrm{m}$. longis, foliolis 24 jugis, $4 \mathrm{c}$. m. longis, 10 $-12 \mathrm{~m}$. m. latis a praecedenti differre videtur.

Habitat in insula Cuba.

\section{Zimia psendo-parasitica Yates.}

Yates in Seem. bot. Herạld pag. 282. - D. C. prodr. XVI. II. 543.

Truncus cylindricus. Foliola elongato-lanceolata, sinuoso-falcata, integerrima, glabra, apice acuminata, 18-nervia, 35-52 c. m. longa, $3-4$ c. m. lata.

Habitat in Panama et in latere orientali Andium Peruviae.

\section{Zamia Pöppigiana Mart. et Eichl.}

NIart. et Eichl. in fl. bras. IV. p. 414 tab. 109. - DC. prodr. XVI. II. pag. "340. - Zamia parasitica Pöpp. mss.

Truncus prostratus, radicans. Folia 12-14 jugo-pinnata. Petiolus inermis, acute triqueter, glaberrimus. Foliola falcato-lanceolata, apicem versus attenuato-acuta, utrinque ultra medium argute serrulata, $30-40$ nervia, usque $34 \mathrm{c}$. m. longa et circiter $4 \mathrm{c}$. m. lata. Strobili pedunculati; masculi cylindracei, $20 \mathrm{c}$. $\mathrm{m}$. longi et $4 \mathrm{~m}$. $\mathrm{m}$. in diametro.

Habitat in Peruvia orientali. 


\section{Zamia Fischeri Miq. (v. v.)}

Miq. in horto Van Houtteano pag. 20 et in Linnaea pag. 428 tab. VII. fig. d. - D. C. prodr. XVI. II. pag. 542.

Truncus humilis, crassus, multiceps. Folia usque $40 \mathrm{c.m}$. longa, 10-16 jugo-pinnata. Petiolus inermis rhachique initio laxe pilosus, demum glaber. Foliola lanceolata, acuta, a medio ad apicem argute serrulata, $10-16$ nervia, $4-6^{1} / 2 \mathrm{c}$. m. longa, $7-15 \mathrm{~m}$. m. lata. Strobili breviter petiolati, tenuiter fusco-tomentosi; masculi subcylindrici, obtusi, circiter $3^{1 / 2} \mathrm{c}$. m. longi; foeminei elliptici, $2^{1} / 2-2^{3} / 4 \mathrm{c} . \mathrm{m}$. longi, ex apice rotundato subito in conum brevem sterilem excurrentes.

Habitat in Mexico.

\section{Zamia obliqua $A$. Br. (v. v.)}

A. Br. in Monatsber. d. Ac. d. Wiss. Berl. 1875 pag. 376.

Truncus cylindricus. Petiolus inermis, teres, glaber. Foliola 26 juga, elliptico-lanceolata, basi in petiolum brevem attenuata, apice caudato-acuminata, a medio ad apicem spinuloso-denticulata, 25-30 nervia, $16-18$ c. m. longa, 5 c. m. lata.

Habitat in Nova Granada, unde a cl. Wallisio in hortum Veitchianum allata.

\section{Zamia multifoliata A. D. C.}

D. C. prodr. XVI. II. pag. 545. - Z. stricta Griesb. cat. pl. Wright. pag. 217.

Folia cum petiolo et rhachi pilis demum evanescentibus pilosa, 4361jugo-pinnata.Perulae sericeae, acuminatae. Petiolus inermis, semiteres, supra canaliculatus, $25-30 \mathrm{c}$. m. longus. Foliola anguste linearia, subaequilonga, 3 nervia, acuminata, integerrima $11-12 \mathrm{c.} \mathrm{m}$. longa, $1 \frac{1}{2}-2 \mathrm{~m}$. m. lata, rigida, patentia. Strobili pedunculati, tomentosi; masculi cylindrici, 6. c. m. longi, $1^{1} / 2 \mathrm{c} . \mathrm{m}$. in diametro; foeminei aequilongi et duplo crassiores, obtuse acuminati.

Habitat in Cuba orientali. 
22. Zamia angustifolia Jacq. (v. v.)

Jacq. coll. III. pag. 263. - Jacq. ic. pl. rar. III. tab. 636. Nliq. mon. pag. 73. - Ejusd. Cyc. quaed. am. p. 1, tab. I. fig. A.D. C. prodr. XVI. II. p. 544. - Z. angustissima Miq. Cyc. quaedam americ. pag. 4. tab. I. fig. 13. - D. C. prodr. XVI. II. 545. - Z. linifolia h. Pawl. -Z.floridana D. C. prodr. XVI. II. 544.-Z. Yatesii Mliq. Cyc. quaed. am. pag. 2. tab. I. fig. C.-D. C. I. c. pag. 545. Z. stricta Miq. Cyc. quaed. am. p. 3. - D. C. 1. c. p. 545.-Z. debilis Lodd. bot. cab. tab. 155. (?)

Truncus humilis, subcylindricus v. plantarum juniorum ovoideoconicus. Perulae e basi latiore in acumen villosum excurrentes. Folia glabra v. initio pilosa, $10-60 \mathrm{c.}$. longa, 6-24-jugo-pinnata. Foliola anguste linearia, 3-10-nervia, integerrima $v$. apice denticulis parvis v. dentibus $1-3$ manifestis, acuta v. obtusiuscula, $1 \frac{1}{2}-6 \mathrm{~m}$. $\mathrm{m}$. lata, 5-24 c. m. longa.

Species valde variabilis. Specimina juniora v. non satis evoluta foliolis paucijugis angustissimis 3 -nerviis integerrimis; specimina satis evoluta foliolis (foliorum interiorum) usque 24 jugis, $2-6 \mathrm{~m}$. m. latis, $3-10$-nerviis, apice minute denticulatis $v$. manifeste $2-3$-dentatis. Strobili pedunculati; masculi cylindrici usque $7 \mathrm{c}$. m. longi et $2 \mathrm{c.m}$. in diametro; foeminei duplo crassiores, elliptici, in acumen obtusum conoideum attenuati,

IIabitat in India occidentali et in Florida.

Variat:

a. typica; foliolis 4-20-jugis, 4-8-nerviis, apice obsolete denticulatis, $15-20 \mathrm{c} . \mathrm{m}$. longis, $3-4 \mathrm{~m}$. m. latis. Z. angustifolia Jacq. 1. c.

3. foridana; foliolis 14-jugis, apice 4-5-dentatis, 7-10nerviis, $8-9$ c. m. longis, $3-5 \mathrm{~m}$. m. latis. - Z. floridana D. C. 1. c.

\%. Yatesi; foliolis 5-7-jugis, apice obsolete 2-3-dentatis, 5-6-nerviis. -- Z. Yatesii Miq. I. c.

ঠ. stricta; foliolis $12-14$-jugis, apice $1-2$-dentatis, $3-5$ - 
nerviis, $4-12$ c. m. longis, $2 \mathrm{~m}$. m. latis. - Z. stricta IIiq.

ع. angustissima; foliolis 12 -jugis, 3-nerviis, integerrimis. Z. angustissima Miq. l. c.

\section{Bowenia Hook.}

Hook. bot. mag. tab. 5398. - F. Müll. fragm. phyt. austr. V. pag. 171. - D. C. prodr. XVI. II. pag. 524.

Arbusculae humiles, Novae Hollandiae indigenae. Truncus nudus, humilis, crassus, subcylindraceus, lenticellis cicatricibusque petiolorum (perularumque) mox caducorum vestitus. Folia bipinnatisecta, unum post alterum provenientia, longe gracileque petiolata; lamina circumscriptione suborbiculari; segmenta primaria $1-3$-juga, patentia, petiolata, simpliciter pinnata, inferiora bina usque quinata, superiora opposita; foliola pauci-plurijuga, parallelinervia, in petiolum brevem attenuata, cum rhachi non articulata. Strobili masculi parvi ovoidei squamae obovatocuneatae, vix stipitatae, apice dilatato-truncatae et tomentosae, subtus ad medium antheriferae. Strobili foeminei squamae deltoideo-rhomboideae, peltatae, longe stipitatae.

\section{Bowenia spectabilis Hook. (v. v.)}

Hook. l. c. - Dracontium polyphyllum A. Cunningh. in pl. exs.

Petiolus teres, ima basi lanuginosus. Foliola glabra, multinervia, subdimidiata, lanceolata v. elliptico-lanceolata v. elliptica, integerrima, basin versus sensim in petiolum brevem attenuata, acuminata, 8-16 $\mathrm{c}$. m. longa, 2-4 c. m. lata.

Petiolus laminam superans. Rhachis segmentorum primariorum 15 -30 c. m. longa. Foliola $5-7$-juga, nervis $15-30$ curvatis furcatoque ramosis percursa. 


\section{Macrozamia Miq.}

Truncus humilis, crassus, specierum elatiorum $1-1^{1} / 2 \mathrm{~m}$. altus, elliptico-cylindraceus, perulis persistentibus demum sacpissime fibrosis onustus. Petiolus basi dilatatus exauriculatus. Folia unum post alterum provenientia, pinnata. Foliola lineari-lanceolata v. linearia, integerrima v. apice paucidentata, parallelinervia, basi non articulata et in axilla plus minus calloso-incrassata, suprema basi decurrentia. Squamae strobili masculi subtus antherifcrae, apice acuminatae $\mathrm{v}$. acutac sterilesque. Strobili foeminēi squamae basi pedunculatae, medium versus incrassatae et utroque latere uniovulatae, superne subito in acumen corniforme acuminatae.

Arbusculae Novam Hollandiam incolentes.

\section{Conspectus specierum.}

A. Foliola integerrima, anguste lineari-lanceolata.

1. M. spiralis Miq., rhachi nunquam torta, foliolis 6-10nerviis.

2. M. Preissii Lehm., rhachi nunquam torta, foliolis 10-15. nerviis.

3. M. corallipes $h$. Bull., rhachi plus minus torta, foliolis $3-$ 6 -nerviis.

B. Foliola integerrima anguste linearia.

4. M. Paulli-Guilelmi E. MLïll., foliorum rhachi torta.

C. Foliola saepissime apice acute 2-3-dentata, linearia $v$. anguste lineari-lanceolata, 3-5-nervia.

5. M. tridentata Rgl.

1. Macrozamia spiralis Miq. (v. v.)

Miq. mon. pag. 36. tab. 4. 5. - D. C. prodr. XVI. II. 535.Zamia spiralis Salsb. prodr. pag. 401. - Encephalartos spiralis Lehm. pug. VI. pag. 13. - Mlacrozamia Oldfieldii D. C. prodr. XVI. II. pag. 535. - Enceph. Oldfieldii Miq. Cyc. Nieuw. Holl. pag. 8. - Macroz. 
Macdonnellii F. Müll. fragm. austr. II pag. 179. -D. C. prodr. XVI. II. 537. - Enceph. pungens Lehm. pug. 6. pag. 13. - Miq. monogr. pag. 42 et in Linnaea XIX pag. 419. tab. 4. - Zamia pungens Ait. teste Miqu. prodr. pag. 18. - Macrozamia Hillii, MI. eximia, MI. pulchra, M. cylindrica, MI. Fraseri, M. elegantissima, M. amabilis h. Bull.

Truncus humilis, initio ovatus v. ovato-conoideus, demum oblongosubcylindricus, perularum foliorumque rudimentis fibrosis persistentibus subtomentosus. Folia usque $1 \mathrm{~m}$. longa; petiolo rhachique subtus convexis, supra planiusculis, initio brevissime pilosis, mox glabris. Foliola multijuga (utrinque usque 30—60 et ultra), anguste lineari-lanceolata, integerrima, apice pungenti-acuta, basi in axilla plus minus calloso-incrassata, $12-30$ c. m. longa, 4-10 m. m. lata, 6-10-nervia, inferiora immutata v. rarius ad spinas reducta. Strobili glabri, masculi squamae cuspidato-acuminatae, foeminei squamae in acumen lanceolatum productae.

Habitat in Nova Hollandia australi et austro-occidentali.

Variat:

a. Hillii; foliolis 4-8 m. m. latis, 6-7-nerviis, basi viridilutescentibus. MI. Hillii h. Bull. - II. amabilis h. Bull.

ß. eximia; foliolis basi initio rubro-flavescentibus, demum viridi-flavescentibus. Cetera ut var. $\alpha$. II. eximia h. Bull.

$\gamma$. cylindrica; foliolis usque $10 \mathrm{~m}$. m. latis, 8-10-nerviis, basi flavo-viridibus. - II. cylindrica h. Bull. - II. elegantissima h. Bull.

o. Fraseri; trunco vix lanato, foliolis basi luteis. Cetera ut var. a. - Zamia Fraseri h. Van Houtte. - Macroz. pulchra h. Bull.

2. Macrozamia Preissii Lehm. (v. v.)

Lehm. in cat. horti Hambrg. 1842. - D. C. prodr. XVI. II. 535. - M. Fraseri Miq. mon. pag. 37. - Encephalartos spiralis Miq. mon. - Cycas Riedeli Gaudich. Freyc. p. 437. - Enceph. Preissii F. Müll. in Quart. journ. Pharm. Vict. II. p. 60. - Enceph. Fraseri 
Miq. Cyc. Nieuw. Holl. p. 6. - Macrozamia Preissii Heinzel in Nov. Act. nat. cur. XXI. I. 203. tab. 10-13. - Macrozamia grandis h. Bull.

Praecedenti simillima, differt tantum foliolis latioribus (usque 12 m. m. latis) 10-15-nerviis, strobilo masculo juniore fusco-lanato.

IIabitat in Nova Hollandia austro-occidentali.

\section{Macrozamia corallipes $h$. Bull. (v. v.)}

W. Bull. cat. 1873. cum icone. - Hook. bot. mag. tab. 5943.

Truncus crassus, ovato-conicus, lanatus. Petiolus rhachisque initio puberula, mox glabra. Rhachis plus minus torta; supra planiuscula, bisulca. Foliola glauca, late linearia, integerrima, spinescenti-acuta, usque 20 c. m. et ultra longa, $5-8 \mathrm{~m}$. m. lata, basi in axilla paullo callosoincrassata et ibidem rubra v. rubro-lutescentia; intermedia 6-nervia, inferiora 3-nervia. Strobilus masculus glaucus, glaber, cylindraceus, 13-18 c. m. longus, squamis basilaribus muticis, intermediis mucronatis, superioribus acumine suberecto rigido ornatis, omnibus latere inferiore antheriferis. Strobilus foemineus ovoideus $9-12 \mathrm{c.m}$. longus; squamis inferioribus acutis, superioribus subito longeque acuminatis.

Habitat in Novae Hollandiae provincia New South Wales.

\section{Macrozamia Paulli-Guilelmi F. Müll. (v. v.)}

F. Müll. fragm. phyt. austr. I. pag. 86. 243 et II. pag. 179. D. C. prodr. XVI. II. pag. 536. - II. plumosa h. Bull. - Enceph. Pauli Guilelmi F. Müll. in Quart. journ. pharm. soc. Vict. II. pag. 91. - Miq. Cyc. Nieuv. Holl. pag. 12.

Truncus ovato-conoideus, lanatus. Folia usque $1 \mathrm{~m}$. longa, glauca. Petiolus supra planus, basi lanatus. Rhachis spiraliter torta. Foliola multijuga, anguste linearia, pungenti-acuta, integerrima, usque $25 \mathrm{c.} \mathrm{m}$. longa, $2 \mathrm{~m}$. m. lata, saepissime 4 -nervia, rarius $3-5$-nervia. Strobili glabri; squamae strobili foeminei semilunato-reniformes, subito in acumen patens breve productae.

Habitat in Nova Hollandia austro-occidentali. 
5. Macrozamia tridentata Rgl. (v. v.)

Encephalartos tridentatus Lehm. pug. 6. pag. 13. - Miq. mon. pag. 45. tab. 6. - D. C. prodr. XVI. II. pag. 533. - Zamia tridentata Willd. spec. IV. 845. - Macrozamia Miqueli D. C. prodr. XVI. pag. 545. - Encephalartos Miqueli F. Müll. frag. phyt. austr. III. pag. 38 .

Truncus? Petiolus et rhachis teretia. Folia plantarum juniorum 40 -50 c. m. longa, plurijuga. Foliola basi vix callosa, linearia v. anguste lineari-lanceolata, subpungenti-acuta, $2-6 \mathrm{~m}$. m. lata, $6-10$ c. m. longa, 3-5-nervia, sub apice 2-3-dentata, dentibus subspinescenti-acutis. Folia speciminum satis evolutorum longiora, multijuga, foliolis usque $16 \mathrm{~m}$. m. latis et $25-40 \mathrm{c}$. m. longis (teste Müllero). Rhachis torta v. non torta. Foliola inferiora immutata v. ad spinas paucas reducta. Strobili masculi 6-10 poll. longi, 1-1 $1 / 2$-poll. lati, cylindrici, glabri; squamis inferioribus submuticis, mediis breviter cuspidatis, superioribus subito longeque cuspidatis.

Variat:

a. typica; foliolis late linearibus, 2-6 m. m. latis, 6-12 c. m. longis, 3-4-nerviis. - Zamia Miqueli et Ceratozamia Miqueli hortus Adelaidensis. - Macroz. tenuifolia hort.

§. oblongifolia; foliolis anguste lineari-lanceolatis, $4-5$-nerviis, 6-16 m. m. latis, $25-40$ c. m. longis. - M. Miqueli D. C. I. c.

\section{GENLRIS EVONONYII SPECIES FLORAII ROSSICANI INCOLENTES.}

A. Folia linearia.

1. E. nana $M . B$.

B. Folia lanceolata usque ovalia.

a. Rami laeves.

2. E. europaea $L$., capsula 4-v. rarius 3-v. 5-loba.

3. E. latifolia Scop., capsula 5-v. rarius quadrialata, alis latioribus quam latis. 
4. E. alata Thunbrg., capsula $1-3$ alata, alis oblongis plus duplo longioribus quam latis.

b. Rami verrucosi.

5. E. verrucosa Scop.

1. E. nana M. B. Cfr. Ledb. fl. ross. I. 499.

E. angustifolia hort.

2. E. europaea L. spec. 286.

a. typica: glabra v. subglabra; foliis lanceolatis v. ovato-lanceolatis v. rarius obovatis v. ovatis.

E. europaeus Ledb. fl. ross. I. 497. - E. vulgaris Gardn. dict. n. 1. - E. europaea angustifolia et macrophylla Rchb. ic. fl. germ. VI. tab. 360. - E. Maakii Rupr. Bull. Ac. Petr. XV. 358. - Maxim. prim. p. 75.

३. Semenovii; foliis lanceolatis, parvis, incluso petiolo 3-4 c. m. longis; pedunculis tenuibus post anthesin nutantibus. E. Semenovi Herder in pl: Semenov. n. 202.

$\gamma$. puberula; foliis laxe puberulis.

ঠ. velutina; ramis foliis pedunculis capsulisque dense puberulis.

E. velutinus Fisch. Mey. in Hoh. enum. Talüsch. p. 101. — Ledb. fl. ross. I. 497.

є. fimbrillifera; foliis subtus puberulis, florum disco margine interdum fimbriliifero.

E. fimbrillifera Fisch. NIey. 1. c. p. 102. - Ledb. 1. c. pag. 498 .

3. E. latifolia Scop.

Scop. fl. carn. I. pag. 165. - Ledb. fl. ross. I. 498. E. Sieboldianus Schmidt. fl. sachal. n. 99. (lusus foliis subtus laxe pilosis). - E. latifolius $\beta$. sacchalinensis Schmidt fl. sachal. n. 98. (lusus capsularum alis capsulam subaequantibus). - E. macropterus Rupr. pl. Maak. n. 24. (lusus capsularum alis capsulae diametro paullo longioribus). 
4. E. alata Thbrg.

Thbrg. fl. jap. p. 98. - Maxim. prim. fl. amur. p. 73.Rgl. fl. uss. pag. 487. - E. Thunbergiana Blume Bjdr. 1147.

5. E. verrucosa Scop.

Scop. fl. carn. I. 166. - Ledb. fl. ross. I. 498.

\section{RHAINI SPECIES IMPERIUII ROSSICUH INCOLENTES.}

Rhammus cathartica L. $\gamma$. coriacea.

Frutex humilis, ut videtur $1 / 2-3$ pedalis, spinosissimus, ramis patentissimis rigidis. Folia cuneato-spathulata, acutiuscula v. saepissime rotundato-obtusa, argute serrulata, nervis lateralibus utrinque $2-3$ arcuato sub ad apicem adscendentibus percursa, demum coriacea, glabra, excluso petiolo $10-17 \mathrm{~m}$. m. longa, serraturis glandula subulata terminatis.

Calyx tubo campanulato, latiore quam long 0 ; limbo quadrifido. Druparum immaturarum exsuccarum subglobosarum pyrenae cartilagineae, dehiscentes, facile a druparum tegumento secedentes; druparum maturarum nigro-carnosarum pyrenae carne seminibusque adglutinatis. Semina oblonga, sulco lato longitudinali aperto.

Habitat in alpibus turkestanicis, $2000-12000^{\prime}$ alt. supra mare.

Um die in Rede stehende Form des R. cathartica L. mit Sicherheit festzulegen, habe ich eine genaue Revision aller der nah verwandten Rhamnus Asiens und Europas vornehmen müssen. Dabei bin ich zu dem Resultate gekommen, dass fast alle gemeiniglich zur Unterscheidung der Arten dieser ausserordentlich schwierigen Gattung benutzten Charaktere entweder durchaus wandelbar, oder so künstlicher Natur sind, dass durchaus gleichartige Formen durch dieselben zu versehiedenen Arten getheilt werden.

- Die Rhamnus nehmen je nach Standort und Klima verschiedene Gestalten an. So z. B. ist R. cathartica auf gewöhnlichem nahrhaften Boden und freiem Standort ein hoher Strauch, dessen Aeste in Dornen ausgehen. Auf üppigem Waldboden und zwischen andern Sträuchern wachsend ver- 
lieren sich die Durnen. Auf magerm felsigen Boden und freiem Standort unter dem Einfluss der trockenen heissen Sommer des südlichen Europas und des mittlerı $\Lambda$ siens, bleibt der Strauch klein, bekommt ein sehr sparriges Wachsthum und viele starre Dornen, - und die Alpen hinaufsteigend sinkt er bis zum z.wergigen Strauch hinab. Einen ähnlichen Unterschied im Wachsthum zeigt R. alpina unter gleichen Einflüssen, nur dass diese Art nie Dornen trägt und auf den Alpen bis zum niederliegenden Strauch herabsinkt.

Die Blätter geben einen guten sichern Charakter, der die ächten Rhamnus von den Frangula-Arten unterscheidet. Bei den ächten Rhamnus steigen die Seitennerven nämlich bogig aufwärts fast bis zur Spitze des Blattes, bei den Frangula verlaufen sie parallel und schief nach dem Blattrand und anastomisiren da. Die Blattform ist dagegen sehr wechselnd und geht z. B. bei R. cathartica und R. alpina von der lanzettlichen oder keilförmig-spathelförmigen Gestalt, bis zur ovalen oder rundlichen Form über. Dagegen habe ich die lineare oder schmal länglichlineare Gestalt der Blätter von Rhamnus Erythroxylon und verwandten Arten, nicht zu der breitern Blattform übergehen sehen, ebenso dürfte der niclitgezähnte Blattrand einen guten Unterschied gegenüber dem gezähnelten Blattrand gewähren. Die Behaarung der Blätter wechselt bei den Formen des R. alpina sehr bedeutend. Das gleiche ist bei dieser vielgestaltigen Art mit der Grösse der Blätter der Fall, die bei den Formen der Iochalpen nur einige Centimeter lang, während sie im Garten und unter dem Einfluss des warmen feuchten Climas bis 18 C. MI. lang werden.

Die Blumen bieten keine haltbaren Charaktere. In der Form der Kelchröhre, ob dieselbe breiter als lang oder wie bei R. tinctoria W. et K. mehr kreiselförmig und länger als breit, glaubte ich erst einen guten Unterschied gefunden zu haben, später überzeugte ich mich aber, dass das selbst beim gleichen Exemplare nicht constant ist.

Als der wichtigste Charakter zur Unterscheidung der Arten, gilt gemeiniglich die Vier-oder Fünfzahl der Blumen und ob der Griffel vorn in Aeste getheilt oder die Griffel bis zur Spitze lose mit einander verwachsen und sonach der Griffel ungetheilt erscheint. 
Leider können wir auch in diesen Charakteren keine Unterschiede für die Arten erkennen. Denn die Rhamnus sind meist polygamisch, die unvollkommen ausgebildeten Fruchtknoten tragen auch bei R. cathartica ungetheilte Griffel uud die 4 und 5 Theilung der Blume wechselt bei den ganz übereinstimmenden Formen von R. alpina. So unterscheidet unser scharfer deutscher Diagnostiker Koch, R. rupestris Scop. durch 5-zählige Blumen von R. alpina und R. pumila. Scopoli selbst beschreibt aber seinen R. rupestris mit 4-5-zähligen Blumen und charakterisirt denselben nur durch Blattform und Behaarung. Wie bei Primula, 0xalis und andern, finden sich in Bezug auf Zahl und Theilung des Griffels dimorphe Formen bei ganz der gleichen, vom Standort und Klima bedingten Form.

Noch auffallender war es. mir, dass ein anderer noch auffallenderer Charakter, durchaus unbeständig ist. Fischer hat eine hochwachsende grossblättrige Form des Caucasus von R. alpina, nach der Grösse der Blätter, besonders aber dadurch unterschieden, dass dieselbe nicht einblumige in den Blattachseln gehäufte Blüthenstiele, sondern von besonderm allgemeinen Blüthenstiel getragene Blüthendolden besitzt. Aber auch das hält nicht Stand. Wir besitzen ganz genau die gleiche Form aus dem Caucasus mit einblumigen gehäuften achselständigen Blüthenstielen, während an andern Exemplaren, ein entweder sehr kurzer oder längerer deutlicher allgemeiner Blüthenstiel, die bündelförmigen Blüthenstielchen als Dolde emporträgt.

Die Samen der Rhamnus besitzen eine Längsfurche, die entweder geschlossen, oder etwas oder stärker geöffnet ist und zuweilen noch einen kurzen flügelartigen durchgehenden oder unterbrochenen Rand trägt. Hiernach hat Koch mehrere Arten von R. cathartica zu unterscheiden gesucht. Es ist mir aber nicht gelungen hierin einen andern als einen rein künstlichen Charakter zu finden, der natürlich zusammen gehörige Formen wieder scheiden würde.

C. Maximowicz hat in seiner höchst exacten und genauen Arbeit über die Phamnus 0stasiens, noch auf einen andern auffallenden Unterschied in der Frucht der Formen von R. cathartica aufmerksam gemacht. 
Es wächst näınlich von Dahurien an durch China bis zu den Hochgebirgen 0stindiens, eine mit unserm gewöhnlichen R. Cathartica übereinstimmende Form. Die uns vorliegenden nicht ganz gereiften Früchte sind trockeı. Die Früchtchen lösen sich leicht aus der Fruchthülle und springen mit einem Längsspalt auf und auch die Samen lösen sich leicht aus den Früchtchen heraus, während bei unserer R. cathartica, die Fruchthülle mit den Früchtchen (pyrenae) ziemlich verwachsen, so dass sie shwer loszulösen und die Früchtchen auch nicht aufzuspringen scheinen. Maximowicz unterscheidet diese erstere Form Asiens als $R h$. virgata Roxbrg. und auch ich glaubte, dass man hiernach und wie es schien, darnach dass die Früchte derselben nicht fleischig würden, diese R. virgata trotz ihrer ausserordentlichen Aehnlichkeit mit der gemeinen R. cathartica, dennoch spezifisch unterscheiden müsse. Die ron mir oben beschriebene Form Turkestans, hat mich eines anderen belehrt, denn es liegen mir von derselben Exemplare mit nicht ganz reifen Früchten vor, die sich ganz verhalten wie die Früchte von $R$. virgata und solche mit reifen Früchten, die sich verhalten wie die Früchte von R. cathartica.

Nach diesen vorausgesendeten Bemerkungen lassen wir die Uebersicht der Rhamnus-Arten der Flora des Russischen Reiches folgen, wobei wir die dazu gehörigen Formen Europas und Nordamerikas berücksichtigt haben. Um Missrerständnisse zu vermeiden, erkläre ich, dass ich dagegen nichts einzuwenden habe, wenn andere Botaniker die von mir aufgeführten Formen für gute Arten annehmen, meine persönliche Ueberzeugung ist es aber, dass R. cathartica und R. alpina zu denjenigen Planzenarten einer sehr weiten Verbreitung gehören, die bei ihren Wanderungen von den Alpen durch verschiedene Zonengebiete, eben jene grosse Zahl von Formen gebildet haben.

\section{Conspectus speciernm Rhamni Imperium rossicnm incolentium.}

A. Foliorum nervi laterales arcuato sub ad apicem forii adscendentes.

1. $R$. cathartica $L$., foliis oblong0-spathulatis usque ovatis v. subrotundis. 
2. R. Erythroxylon Pall., foliis oblongis usque linearibus.

B. Foliorum nervi laterales oblique paralleli et ante marginem anastomosantes.

3. R. Frangula $L$., foliis integerrimis.

4. $R$. alpina $L$., foliis margine serrulatis.

\section{Enumeratio specierum generis Rhamni.}

1. R. cathartica (L. spec. 2\%9.)

Frutex humilis v. pygmaeus usque ad 15 pedes altus, ramis ramulisque spinescentibus $v$. rarius inermibus. Folia elliptica v. ovato-subrotunda usque oblongo-spathulata, apice saepe acuminata v. rarius obtusa, utrinque nervis $2-6$ lateralibus arcuato sub ad apicem adscendentibus percursa, serrulatis, initio breve laxeque pilosulis, demum glabris; serraturis obtusis v. glandula subulata terminatis. Calyx quadrifidus. Stylus florum fertilium apice 2-4 fidus. Drupa globosa, baccata, nigra, 2-4-pyrena.

\section{Conspectus varietatum Rh. catharticae.}

A. Frutices saepissime spinosi, 10-15 pedes alti.

a. Folia ovato-subrotunda usque lanceolata.

* Pyrenae ad drupae integumenta adhaerentes, indehiscentes.

a. typica; foliis utrinque $3-4_{-}$-nerviis.

ß. intermedia; foliis utrinque 4-6-nerviis.

* Pyrenae cartilagineae, a drupae integumentis facile secedentes, rima longitudinali dehiscentes.

$\gamma$ virgata; foliis utrinque 4-6-nerviis.

B. Frutices inermes, 10-15 pedes alti. Folia elliptica v. oblongo-elliptica, utrinque 4-6-nervia.

o. dahurica.

C. Frutices humiles 1-5-pedales, divaricato-ramosi, spinosissimi $v$. spinis rarioribus armati. 
a. Calycis tubus campanulatus, latior quan longus. Pyrenae ad drupae integumenta adhaerentes, indehiscentes.

E. infectoria; foliis oblongo-ellipticis usque ovatosubrotundis, utrinque 2-4-nerviis.

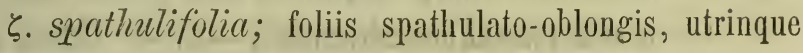
3-4-nerviis.

b. Calycis tubus campanulatus, latior quam longus. Pyrenae cartilagineae, a drupae integumentis facile secedentes, rima longitudinali dehiscentes.

n. parviflora; foliis ellipticis v. ovatis, acuminatis, utrinque 3-4-nerviis.

Э. coriacea; foliis cuneato-spathulatis, saepissime rotundato-obtusis, utrinque 2-3-nerviis.

c. Calycis tubus turbinatus, longior quam latus.

1. saxatilis; foliis lanceolatis usque ovatis, utrinque 2-4-nerviis.

\section{Ennmeratio varietatum Rh. cathartici.}

R. cathartica $\propto$. typica (IIaxim. Rhamneae orientali-asiaticae pag. 8).

Frutex $10-15$ pedes altus, saepissime valde spinosus. Folia elliptica v. ovato-rotundata v. rarius lancoolato-elliptica, saepe acuminata, utrinque $3-4$ nervia. 'Calycis tubus campanulatus, latior quam longus. Pyrenae druparum integumento seminibusque adhaerentes, indehiscentes. Semina sulco clauso v. anguste aperto.

Habitat in Europa et in Asia media.

R. cathartica L. et auct. - Ledb. fl. ross. I. pag. 508. - DC. prodr. II. p. 24. - Guimpel deutsche Holzgew. tab. 13. - Engl. bot. tab. 1629. - Lam. encycl. tab. 128. - Fl. dan. tab. 850 etc. R. Wihhor Lucé fl. os. p. 62. (R. Wikklius hort.)-R. spinosus Gilib. fl. lithuan. V. p. 132. - R. solutivus Erndt. virid. waraw. pag. 104. - R. petiolaris Boiss. et Balansa. 
Folia majora $5-7$ c. m. excluso petiolo longa, omnia simpliciter v. duplicato crenato-serrulata, serraturis saepe mucrone glanduliformi brevi fuscescenti v. nigrescenti inverso terminatis.

$\beta$. intermedia (Ilaxim. l. c.). Folia elliptica usque ovata v. rotundato-ovata, majora excluso petiolo usque $9 \mathrm{c} . \mathrm{m}$. longa; nervis lateralibus utrinque $4-6$. - Cetera ut praecedentis.

Habitat in regione amurensi.

$\gamma$. virgata. Folia elliptica usque rotundato- ovata; lamina usque 7 c. m. longa, nervis lateralibus $4-6$ percursa. Pyrenae cartilagineae, a drupae integumentis facile secedentes, rima longitudinali dehiscentes. Semina libera, sulco apice clauso a medio hiante. Cetera ut var. $\alpha .-R$. virgata $\alpha$. sylvestris R. Rhamn. pag. 13. - Rh. virgatus Roxb. fl. ind. II. 551. teste Mraxim.-R. globosus Bnge. enum. Chin. p. 14. - R. polymorpha Turcz. fl. baic. dah. I. p. 269. ex parte. - R. davurica var. Turez. pl. exs. dah.

Habitat in regione amurensi, in China et India orientali.

Habitu foliorumque statura etc. omnino cum var. $\alpha$. congruit.

o. davurica (Ilaxim. Rhamn. pag. 9). Inermis. Folia oblongoelliptica v. rarius elliptica, saepissime acuminata, utrinque nervis lateralibus 4-6 percursa, saepissime acuminata, majora usque $9 \mathrm{c.} \mathrm{m}$. longa.

Habitat in Sibiria transbaicalensi, in Dahuria, in regio amurensi et in China boreali.

R. davurica Pall. it. III. app. n. 77. - Ejusd. fl. ross. II. 24 tab. 61. - D. C. prodr. II. 24. - Ledb. fl. ross. I. tab. 502 .

ع. infectoria. Frutex 3-5-pedalis, spinosissimus, divaricatoramosissimus. Folia elliptica, oblongo-elliptica v. ovato-subrotunda, obtusa v. acuta v. breviter acuminata; lamina $8-23$ m. m. longa, utrinque nervis lateralibus $2-4$ percursa. Cetera ut var. $\alpha$.

Habitat in Europa australi, in Caucaso et in Oriente. 
R. infectoria L. mant. 49. - D. C. prodr. II. p. 24. Ledb. fl. ross. I. 502. - R. minor Mill. dict. n. 2. - R. tinctoria Guimpel fr. Holzgew. tab. 97. - R. saxatilis Guimpel 1. c. tab. 98 .

ऊ. spathulifolia. Frutex $4-5$-pedalis, spinis raris armatus. F0lia oblongo-spathulata v. oblongo-lanceolata, basin versus cuneata, acuta $\mathrm{v}$. obtusa; lamina $1 \frac{1}{2}-6$ c. m. longa, nervis lateralibus utrinque $3-4$ percursa. Cetera ut var. $\alpha$.

Habitat in Caucaso.

R. spathulaefolia Fisch. et Mey. ind. sem. h. Petr. IV. p. 46. - Ledb. fl. ross. I. 502.

n. parviflora. Frutex humilis, valde spinosus. Folia elliptica v. ovata v. ovato-subrotunda, acuminata v. acuta v. rotundatoobtusa, utrinque $3-4$-nervia, excluso petiolo $1-3 \frac{1}{2} \mathrm{c} . \mathrm{m}$. longa, crenulato-serrulata; serraturis glandula mucroniformi brevi saepissime terminatis. Calycis tubus campanulatus, latior quam longus. Drupa ut var. $\gamma$. Semina libera, sulco plus minus hiante.

Habitat in Dahuria et in China boreali.

R. parvifolia Bnge. enum. Chin. p. 14. - Maxim. Phamnus p. 16. - R. virgata $\beta$. aprica Mlaxim. Rham. p. 14. R. polymorpha Turcz. fl. baic. dah. I. 269 ex parte.

ๆ. coriacea $R g l$. Cfr. supra. Dignoscitur a varietate praecedenti foliorum demum coriaceorum cuneato-spathulatorum serraturis glandula subulata terminatis, seminibus sulco lato aperto.

'. saxatilis. Frutex humilis, spinosissimus, divaricato ramosus. Folia lanceolata v. anguste lanceolata v. rarius ovata, utrinque $3-4$-nervia. Calycis tubus turbinatus, longior quam latus. Cetera ut var. $\varepsilon$.

Habitat in Europa media et australi.

R. saxatilis L. spec. 1671. - D. C. prodr. II. 24. - R: tinctoria W. et K. pl. hung. rar. III. tab. 255. - R. longifolia Mill. gardn. dict. n. 3. - R. infectoria Guimpel fr. Holzgew. tab. 99. 


\section{R. Erythroxylon Pall.}

Pall. it III. app. p. 72. n. 78. tab. T. fig. 1. - Ledb. fl. ross. I. 503. - Pall. fl. ross. II. pag. 26. tab. 43. - R. Pallasii Fisch. Mey. ind. sem. h. Petr. IV. pag. 46. - Ledb. fl。 ross. I. 503. R. lycioides Pall. it. III. pag. 591.

Habitat in Caucaso et in Sibiria australi.

Foliis linearibus v. oblongo-linearibus serrulatis eximia. R. lycioides L. et $R$. velutina Boiss. foliis integerrimis facile dignoscuntur.

\section{R. Frangula $L$.}

L. spec. 280. - D. C. prodr. II. p. 26. - Ledb. fl. ross. I. 503. - Guimpel deutsch. Holzg. tab. 14. - Schrank fl. monac. tab. 109. - Fl. dan. tab. 278. - Engl. bot. IV. tab. 250.

Eabitat in Europa et in Sibiria.

\section{R. alpina (L. spec. ed. I. pag. 193).}

Frutex polymorphus, inermis, nunc 4-8-pedalis erectus, - nunc pygmaeus ramis terram appressis. Folia lanceolata usque late ovata v. ovato-subrotunda, margine serrulata, glabra v. praecipue subtus ad nervos plus minus fusco-pilosa, utrinque nervis oblique parallelis $5-30$ ante marginem anąstomosantibus percursa. Pedunculi saepissime uniflori et in foliorum axillis fasciculati, — rarius flores in pedunculorum solitariorum axillarium apice in umbellas pauci-pluriflores collocati. Calyx tubo campanulato, limbo $4-5$ fido. Petala staminaque tot, quot calycis segmenta. Stylus apice indivisus v. $2-3$-fidus. Semina sulco clauso. Foliis serrulatis a R. Frangula differt.

\section{Variat:}

a. pygmaea. Frutex pygmaeus, glaber, ramosissimus, dense caespitosus; ramis terram adpressis; foliis lanceolatis v. elliptico-lanceolatis, utrinque 4-6-nerviis. Folia $1-4 \mathrm{c.m}$. longa. Pedunculi uniflori.

Habitat in alpibus Eurapae occidentalis.

R. pumila L. mant. 49 ex parte. 
$\beta$. rupestris. Frutex humilis, ramosissimus, usque 2 pedes altus; foliis ovatis v. ovato-subrotundis, sacpissime obtusis, 2 $-31 / 2 \mathrm{c} . \mathrm{m}$. longis, utrinque $4-7$-nerviis, junioribus subtus ad nervos dense brevitcrque ferrugineo-pilosis, demum saepe glabrioribus.

Habitat in alpibus austriacis.

R. rupestris Scop. fl. carn. p. 164. tab. 5. - R. rumeliaca Friv. in Fl. XVIII. 332.

$\gamma$. pumila. Frutex humilis, ramosissimus, usque 2 ped. altus; foliis ovatis v. oblongo-ovatis, saepissime acutis, utrinque 6 -9-nerviis. - Folia subtus glabra v. ad nervos ferrugineohirtula, usque $4^{1} / 2 \mathrm{c}$. m. longa.

Habitat in alpibus Europae australis et in Caucaso.

R. pumila L. mant. I. 49. - Wulff in Jacq. collect. II. 141. tab. 11. - R. Wulffeni Sprgl. syst. I. 768. - Frangula Wulffeni Rchb. fl. exc. II. 488. - R. rupestris Vill. hist. dauph. II. 531. - Ledb. fl. ross. I. 503 et herb. - R. Villarsii Sk. Handb. II. 120. - Frangula rotundifolia Mill. dict. n. 3 .

ס. alpina. Frutex 4-6 ped. altus; foliis ovatis v. oblongo-ovatis, saepe paullo acuminatis, rarius obtusis, $4-13$ c. m. (excluso petiolo) longis, utrinque $9-16$-nerviis, subtus v. omnino v. ad nervos tantum breviter ferrugineo-pilosis r. demum glabris; pedunculis unifloris.

Habitat in montibus Europae mediae et australis, idem in Caucaso.

R. alpina L. spec. I. 193 et auct. - Frangula latifolia Mill. gardn. dict. n. 3. - Alaternus alpinus Ilœnch. meth. 344. - R. cornifolia Boiss. et Hoh., R. libanotica Boiss., R. fallax Boiss., R. Sibthorpiana D. C. (cfr. Boiss. fl. or. II. p. 19 et 20 , et R. Crini 0rph. pl. exs. mea sententia varietates plus minus dense pubescentes $\mathrm{v}$. tomentellas exhibent. 
ع. grandifolia. Frutex $6-8$ pedalis; foliis maximis usque 18 c. m. longis, ovatis v. oblongo-ovatis, utrinque $15-30$-nerviis, subtus saepe pubescentibus; pedunculis unifloris, glomeratis v. pedunculo solitario apice umbella pauci-pluriflora terminato. - Folia subtus totidem v. ad nervos tantum pilosa.

Habitat in Caucaso, in insulis azoricis et in America boreali. R, grandifolia Fisch. Mey. in Hoh. enum. Talüsch. p. 99.Ledb. fl. ross. I. 504. - R. latifolia secrt. angl. V. tab. 8. - R. Purshiana DC. prodr. II. 25. - R. alnifolia Prsh. fl. am. septr. I. 166.

\section{REVISIO SPECIBRUII VARIETATUIIUE GENERIS FUNKIA.}

\section{Funkia Sprgl.}

(Baker Journ. of Linn. Soc. XI. pag. 366.)

A. Bracteae geminatae, bractea interiore minore.

1. F. subcordata Sprgl.

B. Bracteae solitariae.

2. F. Sieboldiana Hook., foliis late cordato-ovatis, glaucis, coriaceis.

3. F. ovata Sprgl., foliis e basi rotundata v. subcordata ovatis v. late ovatis, viridibus, herbaceis.

4. F. lancifolia Sprgl., foliis lanceolatis, basin versus sensim attenuatis, viridibus, herbaceis.

1. Funkia subcordata Sprgl. Cfr. Baker 1. c.

2. Funkia Sieboldiana Hook. bot. mag. tab. 3663. - Bot. reg. 1839. tab. 50. - Hemerocallis Sieboldiana Bot. cab. tab. 1869 .

a. typica, floribus pallide violaceis, $5-5^{1 / 2}$ c. m. longis, tubo limbum aequante. - Folia late cordato-ovata v. basi rotundata, infra ad nervos laevia v. scaberula. - F. Sieboldiana hort. - F. glauca hort. - F. grandiflora hort. 
ß. Fortunei; floribus albidis, $3-3^{1} / 2$ c. m. longis, tubo quam limbus breviore. - Folia rotundato-cordata, pruina alba eximie glauca. - F. Fortunei h. Leichtl. - F. Sieboldiana $\beta$. Fortunei Grtn. tab 867.

3. Funkia ovata Sprgl. syst. II. 40. - Hemerocallis coerulea Andr. bot. rep. tab. 6. - Bot. mag. tab. 894.

a. typica; foliis viridibus, e basi rotundata ovatis, utrinque 5-6-nerviis; floribus violaceis. (Bot. nnag. tab. 894:)

ß. latifolia; foliis viridibus, e basi cordata v. subcordata late ovatis v. subcordatis, plus minus undulatis, utrinque 7-9nerviis.

$\gamma$. aureo-variegata hort. Sieb., foliis var. $\beta$. similibus sed flavo-viridi - pictis $\mathrm{v}$. flavo-viridibus et atroviridi striatis.

o. albo-marginata; foliis ut var. $\beta$. attamen margine anguste argenteo-marginatis.

ع. latemarginata; foliis maximis, e basi rotundata ovatis, valde undulatis, utrinque latere 9-nerviis, late argenteomarginatis.

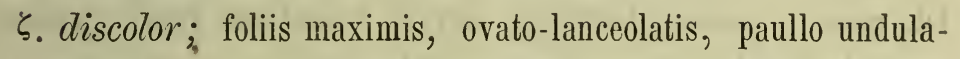
tis, utrinque 9-10-nerviis, flavo-viridibus et atroviridi pictis.

4. Funkia lancifolia Sprgl. syst. II. 41.

a. typica; foliss lanceolatis v. undulatis, viridi-nitentibus.

$\beta$. lutescens; foliis lanceolatis, vix undulatis, viridibus, luteoviridi pictis.

$\gamma$. albo-marginata; foliis ut var. $\alpha$. attamen anguste argenteomarginatis.

F. albo-marginata Hook. bot. mag. tab. 3657. - F. cucullata albo-marginata h. Haage et Schm.

o. undulata; foliis ut var. $\alpha$., valde undulatis autem striaque intermedia latissima argentea percursis.

F. undulata 0tto et Dietr. Gartzt. 1833. pag. 120. Knth. enum. IV. 592. 
ع. angustifolia; foliis anguste-lanceolatis, viridibus, planiusculis, sensim ad petioli basin angustatis.

\section{DESCRIPTIONES PLANTARUII IN IIORTO BOTANICO PLTROPOLITANO CULTARUI.}

\section{Anthurium cristallinum Linden.}

A. regale Linden et André in Lind. cat. 1873 n. 90. - Illustr. hort. 1873 tab. 128.

Caudice crasso, brevissimo; petiolis e basi vaginante teretibus, laminam subaequantibus, apice geniculo paullo incrassato cylindrico curvato; lamina ampla, cordato-ovata, paullo acuminata, basi sinu angusto saepissime clauso, palmato 7-9-costata; costis supra prominentibus; costa intermedia utrinque nervis tribus lateralibus non prominentibus; costis basilaribus mox a margine remotis, simplicibus, non prominentibus; scapo folia plus duplo superante; spatha lineari-oblonga, acuminata, viridi, reflexa; spadice cylindrico, basi stipitato, a basi ad apicem obtusum paullo attenuato.

A. regale Linden cat. 1866 (n. 20) pag. 2, foliorum sinu basilari late aperto, costae intermediae nervis lateralibus supra prominentibus, costis basilaribus sinum marginantibus latisque unilateraliter nervosis, nervis supra prominentibus facile dignoseitur.

2. Begonia (Rosmannia) Roezli Rgl.

Caule crasso, erecto; ramis paucis, apice foliatis; foliis oblique cordato-ovatis, angulato-sublobatis, palmato 8-nerviis, petiolum glabrum superantibus, margine irregulariter-dentatis, utrinque glabris dentibus in pilum brevem excurrentibus; pedunculo folia superante, glabro, apice iterato-trichotomo; floribus masculis sepalis duobus reniformi-subrotundis, petalis nullis; antheris oblongis, truncato-obtusis, -filamenta subaequantibus; floribus foemineis dipetalis, petalis reniformi-subrotundis; stylis tribus, profunde bifidis; ramis linearibus, spiraliter flexuosis, fascia stigmatosa marginali continua. - Folia supra laete viridia, basi ad petioli insertionem macula rubra. Flores ex albido carnei. - Semina misit el. Rœzl e Peruvia. 


\section{Calathea undulata.}

Rgl. Grtfl. 1876 tab. 852. - Maranta undulata Linden et André in Linden cat. № 87 anno 1871 pag. 4.

Herba perennis, pumila, caespitesa. Folia petiolata; petiolus apice latere interiore puberulus, caeterun glaber, $4-5 \mathrm{c} . \mathrm{m}$. longus, a basi supra medium in vaginam ampliatus; lamina oblongo-elliptica v. subelliptica, obtusa, undulata, glabra, inacquilatera, supra nitida, viridis et ad costam mediam alba, infra purpurascens, $8-10$ c. m. longa, 4 c. m. et ultra lata. Spicae pedunculus pallide viridis, basi puberulus, caeterum glaber, 5-7 c. m. altus. Spica terminalis, solitaria, obconoidea, capitata, circiter $1^{1 / 2} \mathrm{c} . \mathrm{m}$. longa. Bracteae circiter 5 , vaginantes, glabrae, limbo patente ovato-subrotundo acutiusculo. Flores gemini, ad bractearum basin interiorem inserti, basi bracteolis crebris albidis involuti. Bracteola exterior vaginata, dorso bicarinata, interiores ovatae usque lineares. Sepala 3, anguste lanceolato-linearia, acuta, corolla subduplo breviora. Petala cum staminodiis in tubum angustum glabrum sepalis paullo longiorem connata, glabra, alba, ovato-oblonga, acuta. Staminodium externum lanceolatum, interna cum stamine fertili connata.

\section{Habitat in Ecuador.}

Affinis C. micanti Körnck. et C. microcephalae Körnck. Prior foliis minoribus angustioribus acutis $\mathrm{v}$. acuminatis, bracteis ad basin capitularum tantum duabus atque non vaginantibus, - altera foliis concoloribus superne breviter acuminatis, - dignoscuntur. Calathea micans (IIaranta cinerea Linden cat. n. 87 anno 1871 pag. 22) species adhuc indescripta, cui species nostra valde similis, differt «foliis stria intermedia destitutis striisque pallidioribus lateralibus ornatis, brevissime obsoleteque puberulis v. supra in nervo medio pilositate barbata, bracteis tribus ad basin capitulorum, vaginatis, pilosis».

\section{Calochortus vemustus Denth.}

Benth. in hort. trans. nov. ser. I. 412 , tab. 15. fig. 3. Lindl. bot. reg. tab. 1669. - Knth. enum. IV. 233.-Flore d. serr. II. Mai tab. 1 (tab. 40) fig. 3. - Baker in Journ. of Linn. Soc. XIV. pag. 310 . 
§. brachysepalus; sepalis interioribus sepala exteriora 1/3 superantibus, supra basin fusco-purpure0-pictis, superne carneo-albidis macula purpurea destitutis. - California. Cfr. Grtfl. tab 865 .

\section{Choisya grandiflora Rgl.}

C. ternata H. B. Knth., filamentis subulatis, quam petala duplo brevioribus.

C. grandiflora; filamentis carnosis, lineari-lanceolatis, acuminatis, quam petala plus quadruplo brevioribus.

Frutex ramosus, ramulis teretibus petiolis pedunculisque breviter puberulis. Folia opposita, petiolata, ternata. Foliola subsessilia, obovato-oblonga, obtusa, basi cuneata, penninervia, margine et in nervo medio breviter puberula, caeterum glabra, glanduloso-punctulata, petiolo communi subaequilonga. Pedunculi in ramorum apice axillares, subverticillati, simplices v. medio paullo ramosi, basi bractea unica v. bracteis oppositis suffulti, medio bracteolis nonnullis vestiti. Flores erecti. Sepala 5, elliptica, submembranacea, mox caduca, quinquenervia, glanduloso-punctulata, apicem versus ciliolata. Petala 5, alba, 'oblonga, circiter 20 c. m. longa, nervis tribus ramosis percursa. Stamina 10 , hypogyna, 5 exteriora longiora, 5 interiora subduplo breviora. Filamenta alba. Antherae biloculares, cordato-subrotundae, luteae. Discus glandulosus nullus. Stylus unicus; ovarium subglobosum, 5-loculare, ovulis in quolibet loculo 2, axi centrali affixis. Stylus unicus, terminalis, stigmate capitato quinquelobo terminatus. Capsula quinquesulcata, quinquerostrata.

\section{Dorstenia erecta Vellozo.}

(Flor. flum. I. tab. 142. - DC. prodr. XVII. 267.)

ঠ. variegata; caule apicem versus petiolis pedunculis foliisque molliter pilosis; foliis oblongo-ellipticis, margine repandocrenato-denticulatis, supra utrinque ad nervum medium argente0 pictis. - D. nervosa h. Berol. - D. urceolata $\beta$. variegata L. cfr. Bureau in DC. prodr. XVII. pag. 266. 


\section{Hibiscus insignis Mart. (ex horto Municensi).}

Fruticosus, breviter denseque hirtulus. Folia longe petiolata, cordata, saepissime profunde v. rarius breviter triloba, rarissime subintegra, inaequaliter crenato-dentata; sinu inter lobos rotundato; lobis e basi angustiore ovato-cuspidatis, cuspide integerrima. Involucellum brevissimum, breviter 8-dentatum, quam calyx multoties brevius. Calycis dentes lanceolati, erecti.

Corolla maxima, lutescens, apicem versus roseo-suffusa, supra basin macula annulari purpurea. Capsula ovata, conica, polysperina, hirsuta. - Brasilia. (Cfr. Gartenfl. tab. 368).

\section{Meconopsis quintuplinervia Rgl.}

Patentim hispido-pilosa ; seapo unifloro, setis horizontaliter v. erectopatentibus vestito; foliis omnibus radicalibus, lanceolatis, quintuplinerviis; pistillo staminibus breviore.

Folia lanceolata, in petiolum attenuata, integerrima, nervis 5 longitudinalibus percursa, setis subferrugineis patentissimis hispida, circiter 6 c. m. longa. Scapus humilis usque spithamaeus, erectus, uniflorus, setis subhorizontaliter patentibus hispidus. Flos nutans. Calyx disepalus, extus hispidus, ante anthesin deciduus. Petala, breviter unguiculata, rhombeo-orata, subacuta v. subemarginata, pallide violacea, concava, erecto-patentia, circiter $3^{1 / 2} \mathrm{com}$. longa et $2^{1 / 2} \mathrm{cc}$ m. lata. Stamina pluriserialia, numerosa, exteriora breviora, interiora subduplo longiora, quam petala breviora. Pistillum staminibus brevioribus brevius. 0 varium ovato-oblongum, setis erecto-patentibus dense vestitum, stylo brevi terminatum. Stigma capitatum, 8 radiatum. Capsula?

Mandshuria occidentali-australis (Przewalski).

\section{Sempervivum patens Griseb. a. typicum.}

S. patens; foliis rosularum obovato-oblongis, abrupte cuspidatomucronatis, margine dense minuteque ciliatis, utrinque hirtulis v. subglabris, caulinis oblongo-lanceolatis acutis semiamplexicaulibus; cyma densa; petalis 6, ochroleucis, oblongis, hirtis, apice tridentatis, dento 
intermedio in mucronem excurrente; calycis hirti lobis lanceolatis, acutis, petalis subduplo brevioribuis; squamis hypogynis brevibus, ovatis, apice truncatis.

๙. typicum; foliis glaucis, ex apice rotundato subito acuminatomucronatis, utrinque hirtis. (Cfr. Gartenfl. tab. 858).

S. patens Griseb. it. Hung. p. 315. - Boiss. fl. or. II. p. 797. - S. hirtum Sm. prodr. fl. graec. pag. 235 non L. - S. Reginae Amaliae hort.

अ. Heuffelii; foliis viridibus, superne cuneato-attenuatis, apice ipso in mucronem acuminatis, utrinque glabris v. sparse hirtulis.

S. Heuffelii Schott. Oestr. Wochenbl. 1852 pag. 18.

\section{Sida glochidiata Rgl.}

Fruticosa, glabra v. pilis minutissimis stellatis asperula. Rami teretes. Folia breviter petiolata, ovata, acuminata, duplicato-crenato-dentata. Stipulae parvae, subulatae, vix puberulae. Pedunculi axillares, solitarii, continui, folium subaequantes v. paullo superantes. Involucelli sub ad basin partiti laciniae obverse lineari-oblongae, calycem paullo superantes. Corolla aurea, calycem plus duplo superans. Carpella 5, rostro dorsali binisque lateralibus basilaribus glochidiato-pilosis vestita.

Sida carpinifolia hort.

\section{LEGUHINOSARUII GENUS NOVUVI AUGTORE A. BUNGE.}

\section{Smirnowia Bnge.}

Calyx bilabiato-quinquefidus bibracteolatus? Vexilli lamina valde resupinata, basi ecallosa. Carina obtusa. Stamina diadelpha. Ovarium brevissime stipitatum, multiovulatum, ovulis biseriatis? Stylus subulatus, inflexus, apice dorso dense barbatus. Stigma terminale, subcapitatum. Legumen vesicarium utrinque ventre profundius sulcatum, sutura dorsali convexa ventralem in dissepimentum incompletum productam rectam multo superante, polyspermum. Semina complanata reniformia laevia.

Frutex ramosissimus, ramis longissimis filiformibus sparse foliosis. 
Folia exstipulata, basi articulata, decidua, unifolúsata Racemi breves? pauciflori. Flores ... ? Legumina magna inflata. Genus styli stigmatisque structura cum Eremosparto fere congruum et habitu praews folia omnino evoluta simillimum, sed distinctum legumine poly- nec submu nospermo, utrinque sulcato neque utrinque compresso carinate, brevissime quidem at distincte stipitato nec omnino sessili, praesertim vero sutura ventrali intus in dissepimentum fere 2 lineas latum producta. Longius distat a Colutea et Sphaerophysa, a priore stigmate terminali et stylo tereti nec ventre sulcato, ab utraque barba styli dorsali, ut in Eremosparto, nec ventrali.

Species hucusque nota unica.

\section{Smirnowia turkestana.}

Habitat in arenosis deserti transaralensis Kisil-kum (Smirnow!).

Plantae curiosissimae specimina incompleta collecta *), floribus jam omnino orbata et leguminibus omnibus delapsis, fere sine inflorescentiae vestigiis; floris rudimenta perpauca fructibus adhaerebant. Frutex erectus, bi-tripedalis, virgato-ramosissimus, trunco recto, circiter crassitiae pennae anserinae, tecto cortice tenui glabrescente stramineo lucido; rami graciles ramulique longissimi simplices fere filiformes teretes, molliter breve-villoso-canescentes. Folia sparsa, omnino exstipulata, unifoliolata, basi articulata, decidua, breviter petiolulata, cuneato-obovata vel obcordata, apice nempe vel truncato-rotundata, vel leviter emarginata, fere carnosula, utrinque pube brevi simplici basifixa patula villoso-canescentia, cum petiolulo vix unquam $4^{\prime \prime \prime}$ excedentia, superne $2^{\text {"' lata. }}$ Inflorescentiae bractearumque vestigia vix ulla. Calyx albo-tomentosus, turbinatus, longitudine 3 "' parum excedens; dentes duo superiores paulo profundius sejuncti fere triangulares acuti, tres inferiores paulo "altius connati angustiores, medio paulo magis producto. Vexillum ex ungue complicato 2 "' longo subito dilatatum, lamina 4 "' alta et explanata 5 "' lata; callorum vestigia ad basin vix ulla. Alarum rudimenta deerant. Carina circiter 5'", longa, unguibus tenuibus $3^{\prime \prime \prime}$ longis. Laminae dorso con-

*) Omnia attuli specimina quae inveni. Smirnow. 
vexo-curvatae, apise víx productae, obtusae, ventre concavae. Stylus et stigma genpris. Legumen longiuscule pedicellatum, intra calycem brevissimudcrasse stipitatum, stipite vix calycis tubum aequante, vesicarium, oblongum, tenue, membranaceum, molliter dense breve patulo - villosulum, ad suturam dorsalem multo longiorem convexum, leviter sulcatum, apice adpresse-inflexum, stylo incurvo in sulco obscondito terminatum, ad suturam ventralem breviorem rectam profunde sulcatum, sutura intus in dissepimentum duplex placentigerum fere duas lineas latum producta. Nervus suturae dorsalis impressus, a legumine macerato facile solutus, 3 -pollicaris, sutura ventralis $16^{\prime \prime \prime}$ longa. Semina numerosa, reniformia, complanata, radicula rimalis cotyledonum dimidio brevior.

In der Gattung Eremosparton enthält das 0varium gewöhnlich $8 \mathrm{Sa-}$ menknospen, die einander paarweise gegenüberstehen. Letzteres scheint auch für die viel zahlreicheren Samenknospen von Smirnowia der Fall zu sein, weshalb, besonders da bei Smirnowia auch die Bauchnaht in eine schmale Scheidewand nach innen vordringt, diese beiden Gattungen den Astragaleen beizuzählen sein möchten. Sie stehen der Abtheilung Pogonophace zunächst. 


\section{$\frac{30 \text { Janvier }}{11 \text { Février }} 1879$.}

\section{Enumeratio Salsolacearum omnium in Mongolia hucus- que collectarum. Auctore Al. Bunge, membro ho- nario Academiae Petropolitanae etc.}

\section{Clavis diagnostica tribuum.}

1. Embryo periphericus cyclicus vel hippocrepicus albumen cingens, rarissime plicatus exalbuminosus. 2.

Embryo spiralis exalbuminosus vel albumine parco laterali. 6 .

2. Flores glomerati in paniculas vel spicas dispositi. 3 .

Flores simpliciter spicati. 5 .

3. Folia plana herbacea, saepius sinuato-dentata. 4.

Folia linearia integerrima............. III. Camforosmeae.

4. Flores homomorphí plerumque omnes hermaphroditi

I. Chenopodeae.

Flores heteromorphi sexu distincti ........ II. Atripliceae.

5. Folia linearia herbacea planiuscula.. ..... IV. Corispermeae.

" nulla vel squamaeformia, rarius carnosa. V. Salicornieae.

6. Seminum saltem praecociorum testa semper crustacea, albumen laterale parcum...... VI. Suaedeae.

Seminum omuium testa membranacea, albumen nullum $7 \ldots \ldots \ldots \ldots \ldots \ldots \ldots$.

7. Semen horizontale................ VII. Salsoleae.

" verticale.................. VIII. Anabaseae.

\section{Clavis diagnostica generum.}

1. Chenopodeae: Semen horizontale ............ Chenopodium.
)
verticale..
Blitum.

2. Atripliceae: 1. Seminis testa crustacea vel coriacea, albumen copiosum. Embryo albidus. 2. 
Seminis testa tenue membranacea, albumen parcum. Embryo viridis. 3 .

2. Calyx floris feminei tripartitus in fructu scariosus ......... Axyris.

Calyx floris feminei bifidus a dorso compressus, increscens lobis liberis vel plus minusve connatis.. Atriplex.

3. Calyx $f$. feminei semibifidus bicornis villosissimus........... Eurotia.

Calyx fl.feminei cuneatus compressus biaristatus............. Ceratocarpus.

3. Camforosmeae: 1. Semen verticale; flor.quadridentati Camforosma.

Semen horizontale, calyx plerumque 5-dentatus. 2.

2. Calyx fructifer exappendiculatus lana involutus ............. Londesia.

Sepala dorso in alam vel in aculeum excrescentia.............. Kochia.

4. Corispermeae: Semen e pericarpio aperto seorsim deciduum ................. Agriophylum.

Semen cum pericarpio clauso deciduum ................. Corispermum.

5. Salicornieae: 1. Folia opposita, caulis articulatus. 2.

Folia alterna, caulis continuus... Kalidium.

2. Embryo plicatus exalbuminosus, herba annua.............. Salicornia.

Embryo hippocrepicus albumen cingens, frutex............ Halostachys.

6. Suadeae: Ovarium basi calyci adnatum..... Schanginia. " liberum, stąmina subhypogyna................... Suaeda.

7. Sodeae: $\quad$ Staminodia nulla.............. Salsola.

Staminodia 5. cum filamentis plus minusve connata ........... Haloxylon.

8. Anabaseae: 1. Folia opposita. 2.

Folia sparsa. 4.

2. Staminodia distincta, fruticulosae vel caudice lignoso. 3.

Staminodia nulla, planta annua, folia elongata ............. Petrosimcnia.

3. Calyx fructifer alatus.......... Anabasis. " " immutatus exalatus Brachylepis.

4. Herbae annuae, sepala in fructu late alata ................ Halogeton. Fruticulosae. 5. 


\section{$-277-$}

5. Sepala exalata, flores tunc demum distincti................. Nanophytum.

Sepala alata, flores in capitulum conferruminati............ Sympegma.

Enumeratio Salsolacearum omnium hucusque in Mongolia collectarum.

\section{Cyclolobeae.}

Trib. I. Chenopodieae.

\section{Chenopodium L.}

Clavis specierum.

1. Embryo perfecte annularis. 2.

) hippocrepicus. 6.

2. Folia integra et integerrima .......... Ch. acuminatum. "sinuato-dentata. 3 .

3. Semina margine acuta laevissima. 4.

» margine obtusa. 5 .

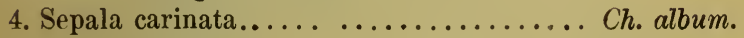

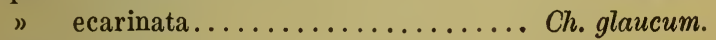

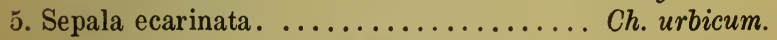

" carinata, semina laevigata........ Ch. opulifolium.

6. Folia lanceolato-linearia glabriuscula in-

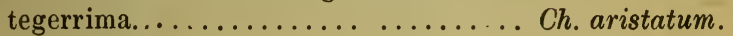

Folia sinuato-pinnatifida glanduloso-pubescentia...................... Botrys.

1. Ch. acuminatum Willd. Led. fl. ross. III. p. 694 . Maxim. Ind. mongol. p. 484.

Hab. in lapidosis vallis Irtysch nigri in montibus Kitschkene-Tau, 27. Juni. 76. (Potanin), prope Kiachta (Basilewski), in jugo Han-hai, in collibus arenosis vallis fluvii Schuryk, 23. Juli 1877. (Potanin), in siccis ad tractum mercatorium (Bunge, Kirilow. 1831.)

2. Ch. opulifolium Schrad.? Fl. ross. 1. c. p. 696.

Hab. in Mongoliae australis terra Ordos, in valle fl. Hoangho, solo argilloso frequens. 5. Sept. 71. (Przewalski). 
Fructu nondum maturo haud rite determinandum, nec tamen ad aliam speciem amandandum.

3. Ch. album L. Led. 1. c. p. 697 . Ind. mong. l. c.

Hab. in Mongolia boreali: secus fl. Kungess, affluentem Ili, sub finem mens. Aug. et ad medium Septbr. 1877. (Przew.), in valle Irtysch nigri ad fortalitium Saissan 27. Juli 76, in via inter Kinderlyk et Assu Syr-bulak. 4. Aug. 76, in campis Dürbeldjin, 24. Aug. 76 (Potanin), Arschain-gol et Bogdyn gol in lapidosis jugi Han-hai, Urten-gol Altai australis 2. Juli 1877. Forma pygmaea (Potanin), in Mongolia australi : Siwan-tse prope Chalgan (Pat. Artselaer, 1876), inter Thianschan et murum magnum, in ipsa urbe Ssu-tscheu (Piassezki).

Speciei polymorphae formae variae collectae, certis characteribus haud limitandae, omnes calyce 5 -costato, fructifero firmiter clauso, seminibusque laevissimis margine acutis inter se convenientes.

4. Ch. glaucum L. fl. ross. l. c. p. 700.

Hab. in Mongolia (Turczaninow, Piassezki.)

5. Ch. urbicum L. fl. ross. p. 701. Ind. mong. 1. c.

Hab. in Mongolia boreali ad Irtysch nigrum (Potanin) et orientali ad tractum mercatorium (Tatarinow. 1840.)

6. Ch. aristatum. L. Teloxys aristata Moq. Led. fl. ross. l. c. p. 693. Ind. mong. 1. c.

Hab. in siccis Mongoliae borealis: ditione jugi Tannuola, ad lacum Schar-nor in ripa fl. Tess, 1 Novbri 1877. Mongolis "Ssoli», cibo inservit. (Potanin.), ad tractum mërcatorium (Kirilow, Bge.), nec non parte australi: Siwan-tse prope Chalgan(Pater Artselaer). 
Teloxys nulla re a Chenopodiis sectionis Botryois distincta; iterum Chenopodiis associanda. 7. Ch. Botrys L. Led. fl. ross. 1. c. p. 704.

Hab. Mongolia boreali-occidentali, in desertis ad $\mathrm{fl}$. Kungess inferiorem et Ili superiorem, Juni-Juli 1877. (Przewalski), ad Irtysch nigrum, in montibus .Kitschkene-tau in lapidosis. (Potanin 27. Juli 1876.)

\section{Blitum Tourn.}

8. Bl. virgatum L. Led. Al. ross. 1. c. p. 706 .

Mongolia borealis: in montosis Altyn-tschetsche, inter Chobdo et fines Sibiriae (Kalning), Altai australi, in alveis siccis rivulorum Ssakssa et Tatal, 7. et 8. Juli 1877 (Potanin) et in valle Bogdyngol jugi Han-hai 7. Aug. 77 (Potanin), in Mongolia (Piassezki.)

Trib. II. Atripliceae.

\section{Axyris L.}

Erecta, foliis ovatis ................ amarantoides. Diffusa, foliis obovatis................. prostrata.

9. A. amarantoides L. Led. fl. ross. III. p. 713. Ind. mong. 1. c.

Hab. in Mongolia boreali, jugo Han-hai, ad fl. Schuryk, 23. Juli 77. (Potanin), ad tractum mercatorium (Bunge, Kirilow 1831, Tatarinow 1840), in Mongolia austro-orientali: Siwan-tse pr. Chalgan (Pat. Artselaer, 1876).

10. A. prostrata L. Led. 1. c. p. 714 . Ind. mong. 1. c.

Hab. in lapidosis tractus mercatorii Mongoliae orientalis (Bunge, Kirilow 1831.) 


\section{Atriplex L.}

1. Folia subintegerrima ovato-lanceolata, virentia....................... lenticulare.

Folia sinuato-dentata, subtus albida. 2.

2. Flores feminei fructificantes cuneato-subglobosi muricati................ sibiricum.

Flores feminei fructificantes sessiles rhombei vel triangulari-subhastati margine dentati ..................... laciniatum.

11. A. laciniatum L. Led. l. c. p. 718.

Hab. in Mongolia boreali: ad Irtim nigrum, 15. et 26. Aug. 1876 (Potanin), in desertis ad fl. Tekess ditione Kungess, locis olim habitatis, 3. Juli 1877. (Przewalski). Mongolia australis: deserto inter Anssi-tscheu et Hami, 20-22. Aug. 75. (Piassezki.) 12. A. lenticulare C. A. M. ex Turcz. Cat. Baical. n. 958. Obione fera Moq. Led. 1. c. p. 733. Ind. mong. l. c.

Hab. in Mongoliae orientalis salsis (Bunge, Kirilow, 1831.)

13. A. sibiricum L. Led. fl. alt. IV. p. 315. Obione muricata Gärtn. in Led. fl. r. 1. c. p. 734. Ind. mong. l. c.

Hab. in Mongolia boreali: ditione jugi Tannu-ola, ad lacum Schar-nor in ripa fl. Tess, 1 Novbr. 1877. incolis: “Chamgul» (Potanin), in valle fl. Kran, 28. Aug. 76. (Potanin), ad tractum mercatorium orientalem, frequens (Bunge, Kirilow, 1831., Tatarinow 1840.), in ditione Ordos australis inter Porobalgassun et Wousjen, a muro magno et urbe Ninghia-fu orientem versus, autumno 1877 (Pat. Verlinden), nec non in valle fl. Hoang-ho, in solo arenoso frequens, 24. Aug. 1871.(Przewalski), in Mon- 
goliae occidentali-borealis terra Chalcha, 20. Aug. 1873. (Przew.)

\section{Eurotia Adans.}

14. E. ceratoides L. Led. fl. ross. 1. c. p. 738 . Ind. mong. l. c. Axyris rosmarinifolia Turcz. Ind. mong. l. c. Axyris sericea Turcz. pl. exs.

Frequens per Mongoliam orientalem (Bunge 1831, Kirilow 1840., Tatarinow), in Mongoliae australis montibus Alaschan, in valle fl. Hoang-ho, in arena mobili, 16. Aug. 1871 (Przewalski), in Mongolia boreali ad Irtin nigrum (Potanin).

Ceratocarpus Buxb.

15. C. arenarius L. Led. fl. ross. l. c. p. 739.

In Mongolia boreali-occidentali in desertis ad $\mathrm{fl}$. Tekess ditione Kungess, vulgaris, Juli 1877. (Przewalski).

Tribus III. Camforosmeae.

Londesia F. et M.

16. L. eriantha Fisch. et Meyer. Led. fl. ross. III.

p. 745 .

Hab. in Mongolia boreali-occidentali, in itinere ad Chobdo (Kalning).

\section{Camforosma L.}

17. C. ruthenicum M. Bieb. Led. fl. ross. 1. c. p. 743 . Hab. in desertis vallis fl. Irtysch nigri prope fortalitium Saissan, 1876. Julio (Potanin).

1. Annuae. 2.

Kochia Roth.

Perennis basi lignosa suffruticosa, calyx alatus........................... prostrata.

2. Calyx in alas 5 minutas tuberculiformes excrescens....................... scoparia.

Calyx in spinas 5. excrescens. 3. 
3. Spinae calycis fructiferi apice hamato inflexae.................... hyssopifolia. Spinae calycis fructiferi apice rectae. 4.

4. Molliter patentim villosa ........... $K$. mollis.

Pube adpressa sericeo-villosa ......... $K$. divaricata.

18. K. scoparia Schrad. Led. fl. r. 1. c. p. 746. Ind. mong. l. c.

Hab. in ditione Ordos australi inter Poro-balgassun et Wousjen, autumno 1877. (Pater Verlinden, Mongolis: (Sapan» audit); ibidem, in valle fl. Hoangho, medio Julio 1871. (Przewalski), in Mongolia austro-orientali: Siwan-tse prope Chalgan (Pater Artselaer 1876.) et alibi in locis subarenosis $(1831$. Bunge, Kirilow, forma humilis subsimplex). Var. $\gamma$. in Mong. occ. terra Ordos, in valle fl. Hoang-ho in uliginosis limosis rara (Przew.)

19. $K$. prostrata Schrad. Led. fl. ross. l. c. p. 747. Ind. mong. l. c.

In Mongoliae borealis aridis in faucibus Dzussylyk Altai australis, 29. Juni 77.(Potanin), in siccis ad tractum mercatorium, frequens (Bunge, Kirilow 1831. Kirilow 1841).

20. K. hyssopifolia (Salsola) Pall. Led. fl. ross 1. c. 751 (sub Echinopsilo.)

In urbe Ssu-tscheu inter murum magnum et Hami, ad vias, 2. Aug. 75. vixdum florens (Piassezki). 21. $K$. dasyphylla F. et M. in Schrenk Enum. I. p. 12 in adnot. Echinopsilon divaricatus Kar. et Kir. Led. fl. ross. l. c. p. 752 .

In borealibus, ad lacum Uliungur, ad Salburta, 17. Aug. 76. (Potanin.) Huc etiam spectare videntur duo specimina valde juvenilia a cl. Piassezki collecta; tum in terra Ordos in valle fl. Hoangho in 
arenosis frequens, et in regione Chalcha, in alveolis arenosis exsiccatis vallium frequens, Aug. 73. florere incipiens (Przewalski).

22. $K$. mollis Bge. F. et M. l. c. Echinopsilon mollis Fenzl. in Led. fl. ross. l. c. p. 754 .

Hab. in arena mobili in medio deserto Gobi pr. Chadatu, Schara-budurghana et Durma (Bunge 1830 et 1831), in itinere ad Chinam (Tatarinow 1840), in Mongoliae occidentalis montibus Alaschan (Przewalski 1871), in Ordos australi, inter Poro-balgassun et Wousjen, Autumno 1877 (Pater Verlinden: Plante médicinale dans les accouchements difficiles, "Patang-hambei " en Mongol).

Praecedenti proxime affinis et forsan aptius cum illa specie jungenda. Discrimina a cl. F. et M. 1. c. allata ex parte ab aetate pendent, nam $K$. dasyphyllam juniorem tantum observabant, cum fructus omnino maturos alterius a m. collectos cl. Fischero communicaveram. Habitus tamen tantisper discrepans. Indumentum in illa densius fere adpressum, caulis rarius a basi atque laxius ramosus, in hac dense ramosissimus in globum excrescens. Spinae calycis fructiferi in illa tenuiores, in utraque vero occurrunt calyces fructiferi quorum sepalum unum praeter spinulam insuper in alam spinula breviorem lateralem excrescit, ita ut discrimen inter Kochiam et Echinopsilon omnino nullum, annuente etiam cl. Fenzl. in fl. ross. l. c. p. 751 .

Tribus IV. Corispermeae.

Agriophyllum M. Bieb.

Fructus ala sensim in rostrum attenuata angusta dentata ................. arenarium.

Fructus ala apice dilatata lacera........ A. gobicum. 
23. A. gobicum Bge. pl. exs. in hb. Acad. et Horti petrop. Przewalski it. I. 157. Agr. arenarium Ind. mongol. 1. c.

A. foliis sessilibus lanceolatis $5-7$ nerviis pungentibus, spiculis axillaribus numerosissimis, bracteis rigidis pungentibus squarroso-reflexis, fructu basi anguste apicem versus latius alato, ala superne dilatata lacera stigmatibus erectis saepius hinc dente auctis.

Hab. in arenosis Mongoliae mediae australioris prope Durma (Bunge) et Kobur (Tatarinow!, Kirilow); in ditione Ordos: in valle fl. Hoang-ho in arena mobili vulgare et gregarium, etiam in montibus Alaschan vulgatissimum, a Mongolis «Ssulchir» dictum, e cujus seminibus farinam parant, 16 Aug. 1871.(Przewalski), ejusdem regionis parte australi, "sauvage et cultivée, Soulkhir en Mongol»(Pater Verlinden). Valde affine Agr. arenario, nec ab illo nisi fructu maturescente distinguendum; sub anthesi omnino congruum, sed fructus major superne latius alatus, ala apice dilatata lacera; stigmata etiam in Agr. arenario hinc inde lateraliter dente aucta.

24. Agriophyllum arenarium M. B. - Led. fl. ross. III. p. 756 .

A. foliis sessilibus lanceolatis $5-7$ nerviis pungentibus, spiculis axillaribus numerosissimis, bracteis rigidis pungentibus squarrosis, fructu anguste alato, ala apicem versus attenuata denticulata, stigmatibus junioribus divaricatis, saepius hinc dente auctis.

Hab. in arena mobili ad fl. Irtysch nigrum (Potanin, 1876.), deserto ab urbe Gutschen et jugo 
Thianschan boream versus, 18. Sept. 1875. (Piassezki.)

\section{Corispermum L.}

1. Fructus villosulus exalatus........... C. Gmelini.

" glaberrimus. 2.

2. Fructus apterus................ orientale.

” in alam distinctam expansus. 3.

3. Fructus apice integer stylorum basi biden-

ticulatus..................... C. hyssopifolium.

Fructus apice emarginatus; sepala nulla. C. Marschalli.

25. C. orientale Lam. Led. fl. ross. 1. c. p. 758. Corispermi spec. Ind. mong. l. c.

Hab. parte orientali ad tractum mercatorium (Tatarinow), parte australi, ditione Ordos, in valle fl. Hoang-ho, in arenosis Kusuptschi dictis, 1. Sept. 1871. florens, nec non in montibus Alaschan, Sept. 71. fructificans (Przewalski).

Planta a Przewalskio collecta distincta foliis latioribus carnosulis, bracteis fructum tegentibus latissimis, sed ob flores pentandros et fructum omnino immarginatum convexo-concavum huc spectans. An C. Stauntoni, mihi ignotum?

26. C. Marschallii Steven. Led. l. c. p. 762.

Hab. in Mongoliae terra Ordos australi (Pat. Verlinden, autumno 1877.)

27. C. hyssopifolium Juss. Led. 1. c. p. 759.

Hab. in Mongolia boreali: ad ripam fl. Irtysch nigri, nec non ad fl. Kran, 28. Aug. 1876. fructif. (Potanin); jugo Han-hai, in collibus arenosis vallis $\mathrm{fl}$. Schuryk fl., 20. Juli 77. (idem).

28. C. Gmelini $\mathrm{m}$. in hb. Acad. petrop.

C. elongatum divaricato-ramosum, junius canescens, fructiferum rubens; foliis oblongo-linearibus, spi- 
cis elongatis tenuibus laxis, bracteis ovatis acuminato-cuspidatis, floribus monosepalis $1-3,4$-andris, fructu pube stellata pubescente oblongo immarginato 0 "vel ala angustissima cincto.

Hab. in Mongoliae terra Ordos australi, autumno 1877 fr. maturo (Pat. Verlinden), nec non in Chinae occidentalis prov. Kansu, 23. Juli 1875., florens et c. fr. immaturo (Piassezki).

Ab omnibus speciebus notis, praeter C. Redowskii et ulopterum, facile distinctum fructu pube stellata canescente, $a b$ his vero fructus ala nulla vel angustissima integra. - Planta a Piassezkio lecta junior tota canescit, serius, ut in speciminibus Verlindenianis, calvescit, caule ramisque intense rubescentibus. Elatior, fere pedalis, cum C. Redowskii semper humile vidi. Folia in caule primario saepe $8^{\prime \prime \prime}$ longa, basi attenuata, supra medium usque ad $3^{\prime \prime \prime}$ lata, obtusa, ramealia minora. Bracteae inferiores sub anthesi oblongo-lanceolatae, superiores breviores ovatae herbaceae, denique fructu maturo marcescentes, fere ex toto membranaceae, pungenti-mucronatae. Sepalum unicum oblongum apice rotundatum hyalinum. Stamina saepius plura, filamenta sepalum multo superantia, nec tamen illo duplo longiora, antherae mox caducae, suborbiculares, didymae. Fructus immaturus pube stellata densa tectus, canus, denique rufescens et in dorso saepe calvescens, tenuiter papulosus, $1,6^{\prime \prime \prime}$ longus, $3 / 4$ l' latus, oblongus acutus, vix ac ne vix quidem marginatus, apice acutus vel basi stylorum persistente biapiculatus, facie interna convexus.

C. Gmelini dixi, quia frustulum in herbario Aca- 
demiae Petrop. asservatum verosimiliter e herb. Gmeliniano ortum est.

Tribus V. Salicornieae.

Salicornia Moq.

29. S. herbacea L. Led. 1. c. p. 767. Ind. mong. 1. c. Hab. in salsis Mongoliae orientalis (1831. Bunge, Kirilow), in Mongoliae australis montibus Alaschan, in lutoso-salsis ad ripam lacus Zagan-nor vulgaris, 21. Sept. 1871. (Przewalski)

\section{Kalidium Moq.}

1. Folia subnulla, seu potius foliorum lamina libera brevissima. 2.

Foliorum lamina libera elongata ...... $\boldsymbol{K}$. foliatum.

2. Flores in spica ternatim dispositi....... $\boldsymbol{K}$. caspicum.

" " solitarii.............. $K$. gracite.

30. $K$. gracile Fenzl. in Led. fl. ross. 1. c. p. 769 in adnot. Ind. mong. 1. c.

Hab. in Mongoliae orientalis deserto Gobi pr. Chailassutu, Boroldshi etc. (Bge. 1830, 31., Tatarinow. 1840. Kirilow. 1841), in Mongoliae australis terra Ordos et ad montes Alaschan in desertis aridissimis boream versus, in argilloso-salsis vulgare et gregarium, camelorum pabulum gratissimum. Augusto 1873. (Przewalski)

31. K. caspicum L. Ung. Sternb. in Atti del Congr. Firenz. p. 317. K. arabicum Ind. mong. 1. c. Led. fl. ross. 1. c.

Hab. in Mongolia orientali (Bunge, 1830) et boreali, in salsis ad lacum Uliungur, 11. Aug. 1876. (Potanin), Var. $\gamma$. cuspidata: in Mongoliae australis 
terra Ordos, in valle fl. Hoang-ho, locis arenosolutosis vere inundatis vulgare et gregarium, 2 . Aug. 1871. (Przewalski).

32. $K$. foliatum Pall. Led. fl. ross. III. p. 770. Ind. mong. l. c.

Hab. in Mongolia orientali (Bunge, 1831. Kirilow, 1841) et boreali, regione Chalcha, in limoso-salsis, quoad formam simile $K$. gracili, quocum iisdem locis crescit, 20. Aug. 1873. (Przewalski), var. brevifolium in Mongoliae borealis ditione Urot, in deserto Golbyn-Gobi sparse, solo argilloso-lapidoso (idem), nec non ad lacum Uliungur, 15. Aug. 1876. et ditione Tannu-ola, ad lacus Schar-nor et Ubsa, 1., 7. Novbr. 1877. (Potanin.)

Halostachys C. A. Mey.

33. H. caspia Pall. Ung. Sternb. l. c. p. 334. Id. Versuch eines Syst. d. Salicorn. p. 77-79. Halocnemum caspicum Fenzl. in fl. ross. 1. c. p. 772 .

Hab. in Mong. austro-occid. in desertis ad fl. Tarym superiorem, haud procul a Lob-nor, Nov. et Decbr. 1876. (Przewalski) et boreali, ad lacum Uliungur (Potanin.)

\section{Spixolobeae.}

Tribus VI. Suaedeae.

Schanginia C. A. Mey.

34. S. linifolia Pall. in Led. fl. ross. 1. c. p. 755.

Hab. in Mongolia boreali, in pratis ad fl. Kran, affl. Irtin, 29. Aug. 76. (Potanin.)

\section{Suaeda.}

1. Fruticosa, foliis elongatis, calyce fructifero inflato....................... physophora. 
Annuae herbaceae. 2.

2. Florum glomeruli petiolares vel subpetiolares. 3.

Florum glomeruli exacte axillares. 4 .

3. Erecta elata, foliis filiformibus confertis, seminibus praecocibus globosis granulatis, serotinis horizontalibus in calyce depresso. S. glauca.

Prostrata, foliis carnosis spathulatis, seminibus praecocibus globosis laevissimis, serotinis in calyce globoso-inflato verticalibus..................... S. ampullacea.

4. Folia lineari-teretia. 5.

„ obovata carnosa, semina planiuscula

tenuissime striata................. S. Przewalskii.

5. Sepala apice tuberculata in calycem substellatum excrescentia............. S. corniculata.

Sepala ecarinata rotundata. 6

6. Folia acuta vel in setam terminata......S. setigera. ) obtusa. 7 .

7. Semina granulata vel punctato-striata..... S. maritima. ") laevissima nitida ............ S. salsa.

35. S. physophora Pall. in Led. fl. ross. 1. c. p. 777. Hab. in Mongolia boreali: in deserto salso ad fl. Tekess infer., frequens, $1 \frac{1}{2}-21 / 2$ ped. alta, $7 \mathrm{Juli}$ 1877. (Przewalski) et prope Kertsch ad rivulum Tschakyrta, ditionis Irtysch nigri, 5. Aug. 1876. (Potanin).

Praeeunte cl. Fenzl. 1. c. Chenopodinam Moq. Tand. non solum, sed et plurima genera ab illo constituta a Schoberia C. A. M. sejuncta, ad genus Suaedam reducenda censeo; seminum nempe et fructuum fabrica in omnibus his plantis tam variabilis, ut nullos certos fines inter illas invenire possim. In plurimis semina serotina a praecocibus omnino diversa, haec testa crustacea albumineque praedita, illa vero testa membranacea albumineque nullo; semina fere omnium tum horizontalia tum verticalia, calycis structura aeque varia unde Scho- 
beria, Brezia, Calvelia et Belowia nullo modo a Chenopodinis, quibuscum habitu optime congruunt, removendae. Denique et Helicilla Moq., infauste ad Sodeas relata, nil nisi Suaeda (Schoberia) glauca m., vel si mavis Suaeda Stauntoni Moq.

36. S. Przewalskii n. sp.

S. annua a basi divaricato-ramosa, foliis carnosulis omnibus obovatis obtusissimis, floribus exacte axillaribus glomeratis, sepalis laevibus ecarinatis clausis, pericarpio semini arcte adhaerente, semine horizontali tenuissime striato-granulato planiusculo nec turgido.

Hab. in Mongoliae australis regione Alaschan, ripa limoso-salsa lacus Zagan-nor, vulgaris et gregaria 21 Sept. 1871. (Przewalski), nec non in prov. Kansu Chinae occidentalis, 23. Juli 1875. (Piassezki.)

Affinis S. maritimae, sed facillime distincta foliis omnibus obovatis, pericarpio semini arcte adhaerente et semine planiusculo supra concavo, subtus convexo. Viva laete virens, exsiccata flavescens, caulis a basi solutus in ramos ut videtur prostratos, ad summum 10-11-pollicares, saepius multo breviores. Folia infima maxima ex parte emarcida $4-5^{\prime \prime \prime}$ longa, subfloralia $2^{1} / 2$ '" longa, sub apice $1{ }_{2}^{\prime \prime \prime \prime}$ lata, basi cuneiformia, subarcuato-surrecta, summa minora. Glomeruli exacte axillares 5-7flori, flore primario vel tribus fertilibus, lateralibus sterilibus vel fructum serotinum maturantibus. Sepala convexa arcte conniventia carnosula, in flore fructificante planiuscula. Antherae minutae flavae inclusae (?). Styli duo brevissimi. Semen 
vix $3 / 4$ "' in diametro, nigro-brunneum, difficillime a pericarpio solvitur, planiusculum, sed margine obtusum, tenuiter concentrice punctato-striatum. Fructus serotini desunt. Planta Piassezkii omnino congrua, sed vix florens.

37. S. ampullacea n. sp.

S. annua, a basi in ramos soluta; foliis carnosis spathulatis obtusissimis glabris, glomerulis subpetiolaribus paucifloris, floribus primariis hermaphroditis semen horizontale crustaceum turgidum a pericarpio facile solutum gerentibus, sepalis floris serotini (feminei?) ampullaceo-inflatis clausis tenerrimis, pericarpio ovato tenue membranaceo semine multo ampliore, seminis verticalis exalbuminosi testa tenue membranacea, rostello infero.

Hab. in Mongolia occidentali, deserto Gobi, ad austrum urbis Hami, 28. Aug. 75. (Piassezki.)

Planta singularis, cujus unicum specimen collectum autumnale, habitu foliisque omnino simile S. Przewalskii, sed quamvis jam Augusto mense collecta, tamen fructus nisi serotinos ferens, seminibus primariis crustaceis in calyce haud ampliato perpaucis jam a caule solutis, magnitudine, forma et superficie ab illis $S$. Przewalskii omnino distinctis. Folia inferiora lineari-clavata $6^{\prime \prime \prime}$ vix longiora, $3 / 4$ '" crassa, carnosa, superiora subfloralia paulo latiora et breviora, obtusissima. Flores e rudimentis in glomerulo pauci fere axillares. Bracteolae ovatae acutae scarioso-hyalinae. Flores primarios hermaphroditos perpaucos superstites rite examinare haud licuit. Semen in illis majusculum tur- 
gidum nitide nigrum laevissimum. Calyces fructiferi florum ut videtur femineorum, nam staminum ne vestigium quidem detegere potui, ampullacei, usque ad $4^{\prime \prime \prime}$ ampli, tenuissime membranacei, videntur omnino clausi. Pericarpium amplum, videtur inflatum, exsiccatione vero compressum, fere $3^{\prime \prime \prime}$ longum totidemque latum, fovet semen multo angustius, in diametro vix ultra lineam magnum, testa tenue membranacea rufescente. Embryon exalbuminosum rostello lutescente, cotyledonibus brevioribus viridibus. Plumula vix conspicua.

38. S. salsa Fenzl in Led. fl. ross. III. p. 785, excl. syn. Pall. ill. p. 46., quoad descriptionem.

Hab. in Mongolia orientali (Tatarinow 1840), boreali-occidentali, in terra Urot, in luto salso humido arenoso, 10. Aug. 1873. (Przewalski), Mong. australi, in valle Hoang-ho, ad pedem m. Muniula, Julio 1873. (Idem.)

Icon Pallasiana tab. 39. forsan huc spectat, non vero descriptio, quae disertis verbis sequentem speciem indicat: "Calyces facti e foliolis quinis carnosissimis viridibus, supra semen arcte conniventibus, apice gibbis, extrorsumque angulo insigni prominulis, unde substellati apparent", quod certe ad amussin in Schoberiam corniculatam C. A. M. quadrat, non vero in Sch. salsam. Nec credibile, plantam characteribus his insignem et in regionibus ab oculatissimo Pallasio perlustratis frequentem illum effugisse. Quid sit Salsola salsa L., qui plantam prope Astrachan collectam hoc nomine insignivit, vix eruendum. $S$. salsa C. A. M. a S. maritima abunde diversa vi- 
detur caule robustiore elato, ramis elongatis fastigiatis, colore glauco seminibusque minoribus laevissimis nec punctulatis, a Pallasio forsan ut a Biebersteinio pro forma proceriore $S$. maritimae sumta est.

39. S. corniculata (Schoberia) C. A. M.

Hab. in Mongoliae orientalis salsuginosis ('Tatarinow 1840.)

40. S. glauca (Schoberia) Bge. Enum. chin. n. 310. Helicilla altissima Moq. in DC. prodr. XIII. p. 170. Suaeda Stauntoni Moq. Chenop. Enum. p. 31.

Hab. in Mongoliae australis terra Ordos, frequens in pratis vere inundatis vallis fl. Hoangho, $21 \mathrm{Juli}$ 1871 fl. incip. (Przewalski).

Ambigit inter Suadam et Schanginiam, nam calyx basi ovarii, quamvis breviter, adnatus vel adhaerens. Habitus vero omnino specierum annuarum Suaedae, facile vero ab omnibus notis distinguenda: caule elato foliosissimo, erecto, glomerulis petiolaribus, floribus polygamis, et seminis testa subtiliter at eleganter granulata.

Annua. Caules stricte erecti, parce fastigiato-ramosi, aetate provectiores $3-5$ pedes alti. Folia filiformia $12-15^{\prime \prime \prime}$ longa, $1 / 3$ '"' crassa, praesertim versus apicem ramorum sterilium conferta, erecta, glauca, acutissima. Glomeruli primarii 5-7 flori, petiolo supra basin inserti, sessiles, flore medio hermaphrodito, lateralibus multo minoribus abortu femineis, in summo caule et in ramulis supremis flores subsolitarii omnes abortu feminei, staminibus cum antheris effoetis brevissimis squamulaeformibus ad basin ovarii subperigynis; ex his in- 
feriores fructiferi parum depressi obtuse pentagoni, profunde 5-sulcati, quinquedentati, dentibus invicem marginibus dilatatis obtusissimis incumbentibus et arcte cohaerentibus, nec tamen vere connatis, ita ut foramen tantum minutum stylo stigmatibusque perforatum remaneat. Sepala dorso convexa omnino ecarinata, denique in floribus summis in cornicula subalaeformia carnosula stellatim patentia excrescunt. Semina horum florum inferiora testa crustacea, summa serotina testa membranacea praedita, haec omnino exalbuminosa. Haec tantum cl. Moquin investigavit, neglectis inferioribus. 41. S. maritima Dumort? Led. fl. r. 1. c. p. 786. Schoberia glauca Turcz. pl. exs. Ind. mong. 1. c. Hab. in Mongolia orientali (Turcz. pl. exs. a Kirilow an. 1831 collectae.)

Specimina nimis juvenilia, vix florentia, nec rite determinanda.

42. Suaeda setigera Moq. Led. fl. ross. l. c. p. 783. Hab. in Mongolia boreali, inter fines Sibiriae et oppidum Chobdo (Kalning 1870.)

Hujus quoque specimen valde juvenile et incompletum collectum, ob folia acuminata huc relatum. Collecta insuper specimina vel nondum florentia, vel primos flores expandentia, ideoque indeterminabilia, a Przewalskio sub № 249 in regione Urot, ad fontem uliginosum, in luto salso humido, et omnino similia ad fl. Tschakyrta prope Kertsch, a D. Potanin, 5. Aug. 1876 ; a D. Kalning in itinire ad Chobdo sub № 180 , nec non aliud in montibus Alaschan in deserto aridissimo boream versus frequens (Przewalski № 229. a. 1873.) 
Tribus VII. Sodeae.

Salsola Gaertn.

1. Annuae. 2.

Fruticosae. 12.

2. Folia ramique sparsi. 3.

" " oppositi, antherae appendiculatae....................... S. brachiata.

3. Folia spinuloso-mucronata rigescentia. 4. " mutica vel submutica carnosa. 7.

4. Styli breves stigma simplex mentientes, flores remote glomerati............... S. ulicina.

Stigmata elongata filiformia, flores subsolitarii. 5 .

5. Flores superiores feminei, sepalum anticum alatum, caetera dorso gibba.......... S. monoptera.

Flores omues hermaphroditi, sepala omnia alata vel dorso gibba. 6 .

6. Sepala basi membranacea dorso gibba, alis nempe minutis spongiosis........... S. collina.

Sepala basi indurata omniaalata, alis membranaceis.................... S. Kali.

7. Antherae omnino exappendiculatae. 8.

" appendiculatae vel saltem apice pictae. 10.

8. Stigmata brevissima, calyx fructifer apertus, utriculus baccatus............. S. clavifolia.

Stigmata subulata elongata, utriculus siccus. 9.

9. Alae reniformes membranaceae........ S. rosacea. " subnullae transverse carinaeformes. . S. Soda.

10. Antherae appendicula distincta membranacea. 11.

Anthera vix apiculata, nervo apice viridipicto......................... S. spissa.

11. Alae reniformes imbricatae, antherae appendicula subulata acuta............ S. affinis.

Alae obovatae sinu rotundato interstinctae, anth. app. ovata obtusa............. S. scleranth $\alpha$.

12. Virides, folia elongata linearia. 13. Cana, prostrata, folia brevia semiamplexicaulia ....................... gemmascens.

13. Folia basi membranaceo marginata, axillae villosae ......................... abrotanojdes.

Folia basi in petiolum brevem angustata, axillae glabrae..................S. Arbuscula. 
43. S. ulicina (Horaninowia) F. et M. in Led. fl. ross. 1. c. p. 794 .

Hab. in Mongolia boreali-occidentali. (Piassezki 1875.)

44. S. monoptera 11 . sp.

S. annua, ramosissima, brevissime patulo-hispidula, dense foliosa; foliis subulato-triquetris spinulosoacuminatissimis basi tenuissime dentato-spinellosis,

- floralibus florem axillarem solitarium longe superantibus, floribus polygamis inferioribus $\Varangle$ superioribus femineis, sepalo calycis fructiferi antico minute alato, caeteris immutatis, artheris vix apiculatis.

Hab. in Mongolia orientali australiore (Tatarinow 1840.)

Caulis circiter pedalis crassitie fere pennae anserinae, ut videtur prostratus, dense ramosus, ramis patentissimis, imo inferioribus reversis semipedalibus, iterum ramulosis, undique setulis patulis hispidus. Folia triquetra basi parum dilatata subulata apice in spinulam tenuem pungentem producta versus basin muriculato ciliolata subsemipollicaria. Flores fere in omnibus axillis ramulorum minutissimi, folio subflorali, bracteisque geminis occulti, illisque multo breviores, inferiores hermaphroditi, superiores mere feminei. Bracteae e basi oblonga membranaceo dilatata, in cuspidem triquetrum pungentem contractae, $2^{1} / 2^{\prime \prime \prime}$ longae. - Flos vix linea dimidia amplior 5-partitus, sepala nempe 5 basi breviter connata membranacea acuta, exterius anticum in fructu in alam minutam subcartilagineam interdum bilobam excrescens, 
apice in fructu utriculum tegens; caetera, quamvis etiam uninervia, immutata, vel medio gibbere minuto (an forsan serius ctiam in alam excrescente?) aucta. Discus hypogynus inconspicuus cum basi calycis et ovarii breviter coalitus. Stamina 5 vel pauciora perigyna, filamentis exsertis filiformibus enerviis. Antherae oblongae vix apiculatae concolores. Ovarium globosum, stylus brevis, stigmata duo elongata filiformia papillosa. Utriculus suburceolatus. Semen horizontale. Embryo spiralis subturbinatus. Flos etiam fructifer vix auctus.

Ob flores polygamos, et sepalum unum tantum in alam excrescens olim generice hanc speciem a veris Salsolis sejungendam esse credidi, Monopterygium minutiflorum illam nuncupans; ob affinitatem vero proximam cum Salsola collina potius in genere retinendam esse censeo.

45. S. Kali L. Led. fl. r. l. c. p. 797.

$\mathrm{Hab}$. in Mongolia orientali frequens (Bunge, Kirilow, Tatarinow, Rosow, alii), australi: in valle fl. Hoangho in lotis lutoso-arenosis terrae Ordos frequens, 24. Aug. 1871., in montibus Alaschan, in desertis aridissimis boream versus, frequens, 26. Juli 1873 (Przewalski) occidentali (Piassezki), boreali: rara in lutosis humidis in terra Chaicha, 31. Aug. 1873 et ibidern in parte australi frequens, 29. Aug. 1873 . (Przewalski), ad lacum Uliungur, 16. Aug. 76., Bulun -tochoi in arvis derelictis, 19. Aug. 76., ad fl. Urungu in pratis, 21. Aug. 76., ad fl. Irtysch nigrum, 28. Aug. et 27. Juni 76. Han-hai, ad fl. Schuryk, 23. Juli 77, ad fl. Telgir-morin, 19. Sept. 1877 (Potanin). 
46. S. rosacea L. Led. fl. r. 1. c. p. 801.

Hab. Mongolia boreali, in lapidosis pr. Djurbeldshin ad fl. Irtysch nigrum, 24. Aug. 1876. (Potanin.)

47. S. collina Pall. Led. fl. r. 1. c. p. 800 .

Hab. in locis subarenosis ad tractum mercatorium orientalem (Turcz. pl. exs. a Kirilow collectae, Bge, 1831., Kirilow, 1841., Tatarinow, 1840), in Mongoliae meridionalis deserto ad pedem australem jugi Muni-ula, in agris Sinensium vulgaris, 22.Juli 1871. (Przewalski), ditione Ordos australis, inter Poro-balgassun et Wousjen, autumno 1877. Mongolis "Sapan" (Pater Verlinden), boreali in arvis derelictis pr. fortalitium Saissan, nec non prope Djurbeldshin (Potanin, 1876.)

48. S. clavifolia Pall. Led. fl. r. l. c. p. 802 , non Ind. mong. 1. c.

Hab. in Mongolia boreali occidentali (Piassezki.)

49. S. Soda L. Led. fl. r. l. c. p. 803.

Hab. in Mongolia boreali prope Kertsch ad fl. Tschakyrta (Potanin.)

50. S. affinis C. A. Mey. Led. fl. ross. 1. c. p. 805.

Hab. in Mongoliae borealis valle fl. Kran, 29. Aug.

76. (Potanin), in Mongolia occidentali (Piassezki).

51. S. brachiata Pall. Led. fl. ross. 1. c. p. 806 .

Hab. in Mongolia boreali prope Djurbeldshin et ad fl. Kran (Potanin).

52. S. sclerantha C. A. M. Led. 1. c. p. 807.

Hab. in Mongolia occidentali (Piassezki.)

53. S. spissa M. B. Led. fl. ross. l. c. p. 808.

Hab. in Mongolia boreali ad lacum Uliungur prope Salburta (Potanin.) 
54. S. gemmascens Pall. Led. 1. c. p. 815. Halimocnemis microphylla Turcz. pl. exs. Mong. Salsola Passerina Bge. in Linn. 1843. pag. 4.

Hab. in salsis Mongoliae orientalis mediae deserto Gobi (Bunge, Kirilow 1830. Kirilow 1841.), boreali: in deserto Golbyn-Gobi in terra Urot, in lapidosis rarius, 14. Aug. 1873. (Przewalski), australi: in montibus Alaschan, in planitiebus argillosis trans arenas Tyngeri sitis gregaria (Przewalski).

55. S. abrotanoides n. sp.

S. fruticosa humilis tortuoso-ramosa glabriuscula glauca; foliis sparsis sessilibus teretibus obtusis vel mucronatis, axillis villosis, floribus in ramis terminalibus gracilibus confertim spicatis, bracteolis flore brevioribus, sepalis ovatis obtusis membranaceo-marginatis, (tunc demum supra medium alatis) glabris, antheris minute obtuse apiculatis mox deciduis, filamentis brevissime exsertis hyalinis; fructu?

Collecta specimina pauca valde juvenilia in valle deserta secus pedem borealem jugi Thian-schan expansa, solo limoso circa vicum Adak, 17. Juni 1877. et ad fl. Koschöty, in deserto salso boream versus a montibus Taischir-ola Altai australis sito, 16. Juli 77. (Potanin.)

S. Arbusculae affinis, attamen diversissima. Fructu ignoto locus in systemate dubius. Villi crispati in axillis foliorum affinitatem cum nonnullis Anabaseis, sed ovarii conformatio et ovuli situs semen horizontale Sodcarum indicant.

Truncus saepe digito multo crassior nigricans, dis- 
torte breviter ramosus, ramulis hornotinis aliis foliigeris, aliis mere florigeris gracilibus, illis sub anthesi ad summum tripollicaribus. Folia teretiuscula carnosa $3-5^{\prime \prime \prime}$ longa, exsiccata vix ${ }^{1 / 3^{\prime \prime \prime}}$ crassiora, vel saepius obtusissima, vel rarius juniora mucronulata, recta vel curvata, in axilla crispato-villosula, basi non in petiolum angustata, ut in $S$. Arbuscula, sed saepius anguste membranaceo dilatata, in axillis subinde fasciculata. Rami floridi sub anthesi $1 / 2-1 \frac{1}{2}$ pollicares graciles, laxi nec rigidi, recti ut in $S$. Arbuscula; sub anthesi dense imbricato-florigeri, floribus contiguis. Folia subfloralia caulinis similia, at sensius breviora, summa flore breviora. Flores solitarii. Bracteolae ovatae minutae flore breviores. Sepala 5 late ovata late hyalino marginata obtusa, medio intense viridia, jam supra medium alarum vestigia ostendunt, nec infra medium ut in S. Arbuscula. Stamina 5 filamentis linearibus extus cyathulo minutissimo insertis, parum supra sepala prominulis, hyalinis, nec ut in S. Arbuscula fuscescentibus. Antherae cordatae ad mediam fissae, apice minutissime obtuse apiculatae. Ovarium ovatum in stylum attenuatum, stigmata mox recurva nigricantia. Semen.....?

56. S. Arbuscula Pall. Led. fl. ross. 1. c. p. 816. Halimocnemis laricifolia Turcz. pl. exs. Ind. mong. 1. c.

Hab. in montosis lapidosis Mongoliae borealioris mediae (Bunge, Kirilow, 1831., Kirilow 1841), in regione Chalcha, in lutosis lapidosis rara, 29. Aug. 1873. (Przewalski), in sabulosis ad lacum 


\section{$-301-$}

Uliungur, 15. Aug. et ad fl. Kran, 28. et 29. Aug. 1876. (Potanin), in Mongolia occidentali (Piassezki.)

Valde polymorpha, sed facile recognoscenda in omnibus formis foliorum structura, quae semper versus basin in petiolum brevem albidurn attenuata, supra illum facile rupta, ipso petiolo maxima parte adnato-decurrente et basi in gibbum minutum incrassato persistente. Sepalorum parte infra alas sita vix indurata haec species distinguitur a $S$. subaphylla, glauca et affinibus.

\section{Haloxylon Bge.}

Folia brevissima in cupulam connata opposita, rami articulati..............H. Ammodendron. Folia elongata sparsa, rami continui..... H. Regelii.

57. H. Ammodendron C. A. M. (sub Anabasi) Led. fl. alt. I. p. 373 . Led. fl. ross. l. c. p. 820.

Hab. in Mongolia australi: in montibus Alaschan borealibus, 1. Juni 1872. (Przewalski: "Arbor " $10-14$ pedalis, trunco vix 5 pedes longo, sed in"terdum ultra pedem crasso, tortuoso, ligno fragili, "cortice albido laevi cum fossulis longitudinalibus; "florere dicitur A prili,floribus luteis, fide incolarum" Prz. in schedula). In Mongolia boreali: in trajectu inter Kenderlyk ad Assu-ssary-bulak, 7.Aug., Semis-tschij, 10. Aug., in litore austro-orientali lacus Uliungur, 15. Aug., in valle Kran, 29. Aug. 1876., deserto Gobi inter Thian-schan et Altai, fauce Gaschiun-dsuch, 23. Juni 77. (Potanin) et ibidem occidentem versus (Piassezki.)

58. H. Regelii n. sp. 
H. fruticulosum, caudice brevi crasso lignoso ramosissimo, ramis hornotinis ramosis, foliis fere omnibus sparsis carnosulis lineari-clavatis, floribus axillaribus solitariis minutissimis, staminodiis 5 . brevibus carnosulis, filamentis sepala aequantibus, stylo brevissimo, stigmatibus duobus divaricatis.

Hab. Altai australi, in deserto lapidoso inter lacum salsum Burá et fl. Tugurjuk, 5. Juli 77. (vix florere incipiens), in deserto Gobi inter Altai et Thian-schan sito, septentrionem versus a vico Nom, 21. Juni 77. (vix florens); in itinere a Hami versus trajectum jugi Thian-schan, in limite australi deserti sterilissimi limosi, 4. Juni 77. nondum florens sed vegetius (Potanin.)

Specimina nondum vel vixdum florida in nostris regionibus collecta, plantae distinctissimae, nec tamen rite definiendae, nisi in regionibus conterminis a cl. Alb. Regel sine ulla dubitatione eadem planta fructificans collecta esset, quae de affinitate illius dubia solvere licuit. Quamvis habitus a caeteris Haloxylis longe abhorreat, attamen certe huic generi adnumeranda, mediantibus $H$. Griffithii et H. Thomsonii m.

Caudices saepe pollice crassiores tortuosi fusci ramosi abbreviati. Rami hornotini graciles incipiente anthesi 3-6 pollicares, rarius pedales, nec fructiferi longiores, in parte lignescente cortice laevi tecti, foliosi, foliis sparsis exsiccatione nigricantibus. Folia carnosula clavata $2-3^{1} /{ }_{2}^{\prime \prime \prime}$ longa, rarius in planta vegetiore nondum alabastra ferente semipollicaria, juniora exsiccata vix ultra $1 / 3^{\prime \prime \prime}$ crassa, tunc demum paulo crassiora, glaberrima 
patentissima teretiuscula obtusa, plerumque apice paulo crassiora. Flores in axillis superioribus exacte sessiles solitarii minutissimi, incipiente anthesi vix ultra ${ }_{2}^{1}{ }_{2}^{\prime \prime \prime}$ magni, bibracteolati. Bracteolae flore breviores crassiusculae, breviter ovatae membranaceo marginatae obtusae. Sepala 5 suborbiculata concava latiuscule membranaceo marginata obtusissima, ima basi connata. Staminodia 5 rotundata carnosula margine glandulosa. Filamenta brevia inter ovarium et staminodia inserta et brevissime cum his connata inclusa. Antherae cordato-reniformes obtusissimae vix exsertae. Ovarium subglobosum in stylum brevissimum attenuatum, stigmatibus 2 vel 3 brevibus divaricatis. Sepala fructigera longe supra medium alata, parte inferiore concava latiuscula, parte supra alam sita brevi incurva, alis tenuibus flabellatis patulis $2{ }_{4}{ }^{\prime \prime \prime}$ latis et $11_{2}^{\prime \prime \prime}$ altis. Pericarpium carnosulo-coriaceum nigrum, tenuissime subpapulosum, a semine facile solutum. Seminis horizontalis integumentum fuscescens membranaceum. Embryo spiralis exalbuminosus, rostello flavicante, cotyledonibus multo brevioribus intense viridibus. Plumula vix conspicua.

Tribus VIII. Anabaseae.

Anabasis L.

1. Caules annui herbacei a trunco articulatosecedentes ..................... cretacea.

Caules basi persistente lignescentes. 2 .

2. Sepala tria tantum alata, folia obsoletissima truncata...................... aphylla.

Sepala 5 omnia alata, folia distincta apice setigera ...................... brevifolia.

59. A. cretacea Pall. Bge. Anab. rev. p. 36. 
Hab. in Mongolia boreali, prope Kok-bucha, 10. Aug. 1876. (Potanin.)

60. A. aphylla L. Bge. l. c. p. 40.

Hab. in Mongolia boreali, in trajectu inter Kenderlyk ad Assu-Ssary-bulak, 4. Aug. 1876 et prope Kran, 28. Aug. 1876. (Potanin), in Mongolia occidentali (Piassezki.)

61. A. brevifolia C. A. M. Bge. 1. c. p. 42. Ind. mong. 1. c.

Hab. in deserto Gobi Mongoliae orientalis mediae (Bge., Tatarinow, Kirilow), Mongolia australi, in arenosis montium Alaschan frequens, 25. Sept. 1871. et in desertis ad boream montium horum, in argillosis rarius, 28. Juli 1873., boreali: in terra Chalcha, ad rupes et in lutosis lapidosis vulgaris, 25. Aug. 1873. (Przewalski), in rupestribus pr. Kran, 29. Aug., pr. Kok-bucha, 10. Aug. 76 ; Altai australi, inter lacum Burá et fl. Tugurjuk, 5. Juli 77., et pr. Zagan-derissu, 2. Juli 77. (Potanin.)

Brachylepis C. A. Mey.

62. B. salsa C. A. M. Bge. l. c. p. 48.

Hab. ad litus austro-orientale lacus Uliungur, 15. Aug. 76, et pr. Kertsch ad fl. Tschakyrta, Mongoliae borealis (Potanin.)

\section{Nanophytum Less.}

63. N. erinaceum Pall. Bge. 1. c. p. 51.

Hab. in Mongolia boreali, prope Assu-ssary-bulak, in argilloso-salsis, 5. Aug. 76. et prope Kertsch ad fl. Tschakyrta (Potanin), in Mongolia occidentali (Piassezki.) 
Petrosimonia Bge.

64. P. sibirica Pall. Bge. 1. c. p. 60.

Hab. in Mongolia boreali in itinere a fl. Ulasty ad fl. Tumandy, 7. Aug. 76 et ad fl. Tschakyrta, 5. Aug. 76. (Potanin.)

IIalogeton C. A. Mey.

Semen verticale................. H. glomeratus. " horizontale................... arachnoideus.

65. H. arachnoideus Moq. Bge. 1. c. p. 98. Ind. mong. 1. c.

Hab. in Mongoliae orientalis australioris arenosis (Bunge, 1831., Tatarinow, 1840., Kirilow 1841), et australi, in montibus Alaschan, Sept. 71. (Przewalski fructif.), boreali: in ditione Chalcha, lapidosis nudis deserti aridissimi Golbyn-gobi frequens, 15. Aug. vix florens (Przewalski), in litore austroorientali lacus Uliungur prope Salburta (Potanin), in Mong. occid. (Piassezki).

Collecta insuper in terra Chalcha, 20. Aug. 73, specimina duo sub N. 267 a. $D^{\circ}$ Przewalski, quae forsan ad speciem novam pertinent; distincta habitu multo robustiore, caule pedali annuo quidem sed lignescente, cortice alutace 0 -albo, flores saltem medii in glomerulo pentandri, sed staminodia detegere haud potui, fructu deficiente seminum situs haud eruendus; affinis etiam $H$. tibetico $\mathrm{m}$.

66. H. glomeratus M. B. Bge. 1. c. p. 95 .

Hab. in Mongolia boreali, pr. Kertsch ad fl. Tschakyrta, 5. Aug. 1876. (Potanin) et occidentali (Piassezki). 


\section{Sympegma Bge.}

67. S. Regelii Bge. Salsol. turkest. ined.

Hab. in Mongolia boreali: in trajectu Udsjur-Mingan, montibus Altai parallelo, ad fontem Tomibulyk, 28. Juni 77. (Potanin), occidentali (Piassezki.)

(Tiré du Bulletin, T. XXV, pag.349-371.) 


\title{
DESCRIPTIONES PLANTARUM
}

\section{NOVARUM ET MINUS COGNITARUM.}

\author{
Fasciculus V.
}

5.

\author{
AUCTORE
}

E. REGEL.

\section{C.-ПЕТЕРЕУРГЪ.}

Типографія Братьевъ ІІумахеръ, Вас. Остр., Загпбенинъ пер., di 1. 



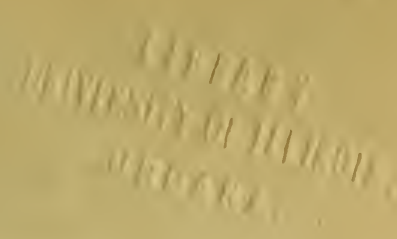

A. PLANTAE REGIONES TURKESTANICAS INCOIENTES, SECUNDUM SPECIMINA SICCA

A REGELIO ET SCHIMALHAUSENIO DETERMINATAE. auctore F. Regel.

5.

\section{Ranunculaceae *).}

.. Anemone biflora D. C. prodr. I. p. 19. - Rgl. et Herd. pl. Semenov. n. 11. - R. Gortschakowi Kar. et Kir. enum. pl. song. n. 14. - Ledb. fl. ross. p. 727.

B. parviflora; flore duplo minore, sepalis 5-6 Mm. longis. In Turkestaniae montibus Arganakatty-tau. (Kuschakewicz.) Ranunculus $L$.

Sectio. Euranunculus. (Flores lutei, calyx 5-sepalus, carpella inflata v. plano-compressa).

Subdivisio I. Grumosae. (Radix perennis, e fibris fasciculatis incrassatis grumosis constans).

Cohors I. Dissecti longirostri. (Folia pinnati- v. bipinnatisecta v. iterato-trisecta. - Carpella in rostrum carpello ipso longius desinentia, basi in appendicem compressam producta).

*) Die Beschreibungen der neuen von Frau Olga Fedtschenko gesammelten Pfanzen werden im Bulletin der Gesellschaft der Freunde der Naturkunde, Anthropologie und Ethnographie in Moskau gedruckt, durch welche Gesellschaft auch die Fortsetzungen der Flora Turkestan's erscheinen werden. 
2. R. orientalis $\mathrm{L}$., carpellis sensin in rostrum recurvatum lineari-lanceolatum desinentibus. - Folia subpinnatisecta. - L. spec. 781. a. typicus; adpresse villosus.

Hab. in Caucaso, in Asia minore, Persia.

$\beta$. villosus; patule villosus.

In Turkestania leg. Sewerzow *).

3. R. linearilobus Bnge; pube adpressa v. ad caulis basin paullo patenter villoso-canescens; foliis trisectis lobatisque v. iterato-trisectisv. segmento terminali magis elongato pinnatisecto bipinnatisectis; carpellis demum in spicam cylindricam dispositis, subito in rostrum filiforme recurvatum v. apice hamatum desinentibus.- Stolones nulli Caulis humilis v. spithamaeus usque pedalis, plus minus ramosus. Fr ${ }^{\prime}$ radicalia trisecta v. iterato-trisecta v.bipinnatisecta(in uno eodem s cimine occurrunt folia trisecta et bipinnatisecta), caulina decresc tia minus dissecta; foliorum segmenta linearia v. rarius oblons integra v. bi-trifida. Sepala patula, extus patule villosa. Carpelı saepissime glabra v. basi vix pubescentia.

R. linearilobus Bnge. in reliq. Lehm. n. 22. - Rgl. in pl. Semenov. suppl. II. n. 206. (Bull. soc. mosq. 1870 n. 2). - Boiss. fl. or. I. pag. $\left.33^{* *}\right)$.

In Turkestania satis frequens occurrit. tinet

*, R. orientalis $\beta$. heterophyllus Boiss. ad R. oxyspermum Willd. per-

**) Boissier in seiner exakten Bearbeitung der Pflanzen des Orients (Flora orientalis l. c.) stellt diese Pflanze zu den Arten mit kurzem Schnabel. Wahrscheinlich sah derselbe vou dieser, nur in Turkestan an den verschiedensten Standorten häufig vorkommenden Art, nur ein unvollkommenes Exemplar, wie solche von Lehmann vorliegen. Unsere Planze stimmt mit dem Original von Bunge genau überein. Im Habitus stimmt unsere Pflanze mit R. dasycarpus Stev. ïberein, der aber rauh behaarte Früchtchen besitzt, die allmälig in den Schnabel verschmälert sind. Die Formen mit wiederholt 3-theiligen Blättern kommen R. platyspermus Fisch. nahe, deren Früchtchen ein kurzes rostrum besitzen. 
4. R. Sewerzowi Rgl., patule villosus; foliis trisectis lobatisque v. iteratotrisectis v. pinnatisectis; segmentis late obverse oblongis, apice bi- $\mathrm{v}$. trifidis v. bi- trilobis v. rarius integris; carpellis demum in spicam cylindricam dispositis, subito in rostrum gracile apice hamatanı excurrentibus. - Basi stolonibus filiformibus radicantibus. Caulis elatus, $1-2$ pedalis. Carpella glabra, rostro glabro v. sub lente vix hirtulo. - Cetera ut praecedentis.

Habitat in Turkestania.

Sewerzow legit in montibus karatavicis Kcharli-tau et Mogol-tau; Korolkow in montibus alatavicis Kumsana $\left(3000^{\prime}\right)$; - 0. Fedtschenko prope Taschkent, et in valle fluvii Sarawschan $\left(3-4000^{\prime}\right)$; A. Regel in montibus Karatau.

5. R. Meinshauseni Schrenk.

Schrenk in Bull. Ac. Petrop. III. 309. - Trantv. in Bull. Mosc. 1860 p. 65 . - Affinis R. linearilobo, differt: caule basi patule, apicem versus adpresse villoso; foliis patule villosis; floribus iis affinium specierum majoribus; carpellis in capitulum ovatum v. subglobosum collectis, apice in rostrum tenue filiforme apice recurvatum carpellum subaequans $\mathrm{v}$. superans desinentibus. - Carpella glabra v. hirtula.

R. Meinshauseni Schrenk in Bull. Ac. Petr. III. 309.-Trantv. in pl. Schrenk. n. 25 in Bull. Nosc. 1860 I. p. 64. Hab. in Turkestania.

Subdivisio II. Nivales. Radix perennis fibrosa. Folia radicalia integra v. lobata v. $3-5$ secta; caulina palmato partita. Caules uni- vel rarius biflori.

6. R. altaicus Laxm., caule unifloro v. rarissime bifloro; foliis radicalibus cuneiformibus usque suborbiculatis, saepissime apice tantum incisis, rarius subcircum grosse crenatis $\mathrm{v}$. ad ${ }^{2} / 3$ longitudinis trilobis; caulinis palmatifidis, lobis oblongis integerrimis v. minus profunde incisis; pedunculis versus apicem calycisque saepissime fusco-villosis v. rarius albido-subhirsutis; calyce patulo, quam corolla 
duplo breviore; carpellorum rostro tenui lineari recto $\mathrm{v}$. apice recurv0 carpello glabro subito imposito, quam carpellum circiter duplo breviore.

Affinis $R$. nivali Gunn. et R. sulphureo Soland. (Fries summa veg. I. p. 142). Posterior cui cl. Trautvetter plantam altaicam adjunxit: «carpellis in rostrum porrectum carpellum aequans sensim attenuatis» dignoscitur.

R. altaicus Laxm. in nov. comm. Ac. Petr. XVIII. p. 533 tab. 8. (1774). - Ledb. fl. ross. I. p. 37. - Variat :

a. typicus; foliis radicalibus cuneatis v. ovatis v. subrotundis, apice tantum grosse crenatis $\mathrm{v}$. varie inciso-lobatis ; pedunculis apicem versus calycibusque extus insigniter fusco-villosis.

R. sulphureus var. altaica Trautv. pl. Schrenk. (Bull. Mosq. 1860 pag. 69. n. 33. - R. altaicus Laxm. 1. c. - Ledb. fl. ross. I. 37. - R. frigidus Willd. spec. II. p. 1312. - D. C. prodr. I. 37. - Rgl. pl. Radd. n. 64.

Habitat in Sibiria altaica et baicalensi et in provinciis turkestanicis.

$\beta$. pubescens; pedunculis apicem versus calycibusque extus albido-pubescentibus. Cetera ut praecedentis.

Hab. in Turkestaniae montibus Alatau (Kuschakewicz) et Thianschan (Kaulbars).

$\gamma$. fraternus; foliis radicalibus ovatis v. subrotundis, suprabasin ad apicem grosse crenatis; pedunculis apicem versus calycibusque extus fusco- v. albido-villosis.

R. fraternus Schrenk enum. pl. nov. I. p. 103. - R. sulphureus var. fraterna Trautv. pl. Schrenk. Bull. Mosq. 1860 p. 70. In montibus Turkestaniae satis frequens.

ঠ. trilobus; foliis radicalibus subreniformibus, ad medium trilobis, lobis apice grosse dentatis. - Cetera ut var. $\alpha$.

R. sulphureus var. triloba Trautv. I. c.

Hab. in montibus Tarbagatai. 
7. Rununculus lasiocarpus C. A. Meyer.

C. A. MI. in Ledeb. fl. alt. II. 323. - Ledeb. II. ross. I. p. 37 .

Satis affinis R. altaico, differt autem: foliis radicalibus trisectis, segmentis breviter petiolatis varie lobatis, carpellis pubescelltibus rostro brevi apice uncinato.

Pedunculi calycesque saepissime fusco-villosi.

Satis frequens in montibus editioribus alatavicis $\left(8-10000^{\prime}\right)$. (Kuschakewicz et Korolkow.)

8. Ranunculus Alberti Rgl. et Schmalh.; caule simplici unifloro v. supra basin bifido bifloro; foliis radicalibus reniformibus v. subrotundis, grosse crenato-dentatis; folio caulino inferiore saepissime petiolato, ovato, crenato-lobato v. palmato- 3 - 5-fido, lobis oblongis; caulino supremo sessili palmatifido, lobis $3-5$ lineari-oblongis; pedunculis calycibusque glabriusculis v. vix pilosulis; receptaculo glabro; carpellis glabris, subrotundis, rostro brevi hamato coronatis.

Glaber. Caulis humilis usque spithamaeus, tenuis, erectus v. adscendens, simplex v. supra basin bifidus, ramis subaequilongis unifoliis unifloris. Flos parvus, magnitudine R. auricomi, aureus.

Caule simplici v. bifido gracili, foliis pedunculis calycibusque glabris, foliis caulinis saepissime 2 minusque incisis, floribus minoribus, carpellorum rostro breviore a R. altaico facile dignoscitur. R. auricomus L. differt caule elatiore multifloro, foliis caulinis digitato-partitis, carpellis velutinis.

In T'urkestaniae montibus Alatau in valle Karakol et in trajectı Kumbel $\left(6-9000^{\prime}\right) \operatorname{leg}$. A. Regel.

9. R. songoricus Schrent; radice fasciculata, fibrosa; caule glabro, humili usque pedali, simplici v. bifido, ramis simplicibus unifloris; foliis glabris: radicalibus supra basin v. ad basin tripartitis: segmentis obovatis, intermedio trilobo, lateralibus in latere exteriore varie lobatis dentatisque; foliis caulinis superioribus palma. 
tim in lobos $3-5$-lineares oblongos divisis; pedunculo apicem versus calyceque patulo latere exteriore pilosis v. subglabris; carpellis glabris subito in rostrum breve porrectum apice hamato-recurvum desinentibus.

Affinis species R. polyrhizos Steph. differt: radicis fasciculatae fibris crassioribus, caule $1-5$ floro, carpellis rostro brevissimo subito a carpelli apice uncinato-recurvo. R. lasiocarpus C. A. M. pedunculo apicem versus calyceque ferrugineo-villosis, floribus duplo majoribus, foliis magis dissectis, carpellorum pubescentium rostro brevissimo apice uncinato facile dignoscitur.

R. songoricus Schrenk. enum. pl. nov. II. p. 67.

Habitat in montibus editioribus Turkestaniae.

10. Trollius patulus Salisb. o. sibiricus Rgl.

Rgl. et Tiling fl. ajan. p. 38. - Tr. americanus Mühlbrg. et Gaissh. in Donn. cat. h. cantabr. - D. C. prodr. I. p. 46. Ledb. Il. ross. I. p. 734. - Rgl. et Tiling fl. ajan. p. 34. - Tr. pumilus D. Don. fl. nepal. p. 195.

In montibus editioribus prope Wernoje (Kuschakewicz), - Alatau in montibus Alexander in trajectu Kumbel $\left(9000^{\prime}\right)$ leg, A. Regel, in valle Sarawschan in angustiis Saratat $\left(7-12,000^{\prime}\right) 0$. Fedtschenko.

Specimina turkestanica pygmaea $21 / 2-7 \mathrm{Cm}$. alta, foliis caulinis saepissime $1-2$ sessilibus $v$. in vagina petioli sessilibus, rarius petiolatis.

Wir haben in der Flora ajanensis Tr. americanus Mühlbg. et Gaissh. in Berücksichtigung des Vaterlandes, von der in Rede stehenden Form, unterschieden. Seitdem haben wir uns aber sowohl durch Beobachtung an cultivirten, wie an den zahlreich wild gesammelten Exemplaren überzeugt, dass die in Rede stehende, im 0sten Sibiriens und in den Hochalpen Turkestans und Chinas wachsende Form, von der Amerika's gar nicht verschieden ist.

11. Eranthis longistipitata Rgl. (Plantae Semenov. suppl. II. p. 8 n. 39 b. (Bull. Mosq. anno 1870 *).

*) Bei Beschreibung dieser Art lagen uns seiner Zeit nur wenige Exemplare vor, so war dieselbe nach den damals vorliegenden Exemplaren mit einem Blüthenstiel, der länger als die Involucralblätter und 5 Kelchblätterı 
Turkestaniae in montibus Karatau (prope Bugun et in Mogol-tau) leg. Sewerzow et Krause, prope Taschkent, Tschupanata (0. Fedtschenko), prope Timir-Kabuk inter Taschkent et Karak-ati (Korolkow).

12. Delphinium rugulosum Boiss., in Ann. sc. nat. 1841. p. 361.Ejusd. fl. or. I. p. 76. - D. camptocarpum \% rugulosum Bnge. reliq. Lehm. n. 37 in Mem. Ac. Petr. VIl (1854). - Rgl. pl. Semenov. suppl. II. 11. 44 b. in Bull. Mosq. anno 1870.

Foliis floralibus florem superantibus, floribus in spicam laxam foliosam dispositis, capsulıs villosis subsessilibus v. pedunculo quam capsula plus duplo breviore suffultis, facile a D. camptocarpo dignoscitur.

Capsulae elevato-rugulosae. .

In regionibus turkestanicis frequens.

13. Delphinium barbatum Bnge. (reliq. Lehm. n. 38 in Mem. Ac. Petr. VII. 188). — Variat: Puberulum v. pedicellis tantum glan-

beschrieben, Charaktere, welche nach den uns jetzt vorliegenden Exemplaren keinen Werth, haben. Wir geben daher im Nachstehenden die Charaktere der Eranthis-Arten Mittelasiens :

a. Flores fructusque sessiles.

1. E. hiemalis Salisb.

Carpella breviter stipitata, oblongo-elliptica, deman horizontaliter patentia. Involucri foliola palmatim in lobos lineari-oblongos integros v. apice paucidentatos divisa, stylo recto coronati.

b. Flores breviter, fructus longius pedunculati.

* Carpella oblongo-elliptica breviter stipitata.

2. E. sibirica D. C., carpellis erecto-patentibus, stylo recto coronatis.Involucri foliola in lobos paucos integros $v$ parce dentatos divisa.

3. E. uncinata Turcz., carpcllis maturis horizontaliter patentibus, stylo apice plus minus uncinato coronatis. - Involucri foliola palmatim lobata v. dentata v. rarius ad medium in lobos lineari-oblongos partita. ** Carpella lineari-oblonga, demum longe stipitata.

4. E. longistipitata $\mathrm{Rgl}$.

Pedunculi floriferi involucro breviores v. rarius longiores, fructiferi involucrum superantes. Carpella erecto-patentia, in statu maturo stipite circiter $15 \mathrm{Mm}$. longo suffulta, stylo recto v, recurvato coronata. - Involucri foliola iterato palmatilobata, lubis lineari-oblongis. Flos 6- v. rarius 5-sepalus. 
duloso-villosis v. breviter puberulis. Proxime accedit ad D. divaricatum Ledb., sepalis apice barbatis, calcari breviore apice paullo inflato obtuso parceque recurvo bene distinctum.

In regionibus turkestanicis frequentissime occurrit.

14. Delphinium hybridum W. . sulphureum, racemo elongato densiusculo v. laxo, calcari sepalis glabris longiore, floribus sulphureis. In regionibus turkestanicis satis frequens.

15. Delphinium longipedunculatum Rgl. et Schmalh.

Perenne; caule subdivaricato-ramoso, basi foliisque hirtis, apicem versus glabro; foliis cordato-subrotundis, palmatilobatis, lobis incisis, lobulis late oblongis obtusis; racemis laxis; pedunculis quam flores duplo-pluries longioribus; floribus azureis; petalis superioribus breviter bilobis, glabris, in calcar glabrum rectum ad apicem sensim attenuatum sepala demum superans abeuntibus; petalis inferioribus bilobis, unguiculatis, barbatis; carpellis saepissime tribus, glabris. Affine D. hirto, caule subdivaricato-ramoso, pedunculis elongatis flores 2-pluries superantibus, foliis palmatilobatis (nec palmatisectis) etc. satis differt.

In montibus Karatau inter Turkestan et Tschemkent legit A. Regel.

\section{Berberideae.}

16. Berberis heteropoda Schrenk. enum. pl. nov. p. 102. - Ledb. fl. ross. I. 742. - Rgl. Berberis in Acta h. Petr. II. 418. B. sphaerocarpa Kar. et Kir. enum. pl. alt. n. $46 .{ }^{*}$ )

Variat: $\alpha$. typica; baccis magnis globosis v. ovato-subglobosis, atropurpureis, immaturis pruina glauca vestitis, maturis epruinosis. - B. heteropoda Schrenk. 1. c. - Kar. et Kir. 1. c.

*) Haec species a B. vulgari facile dignoscitur : „fuliis migis coriaceis; racemis corymbosis, ex alabastro 2-plures egredientibus, alio plurifloro, altero v. alteris 1-3 floris; baccis cacruleis v. e caeruleo atropurpurcis, sacpissime glauco-pruinosis". 
ILabitat in montibus alatavicis cisiliensibus (Schrenk, Kar. et Kirilow) et in montibus thianschanicis (Scharnhorst).

ß. caerulea; baccis magnis, globosis v. ovato-globosis, caeruleis, glauco-pruinosis. - B. heteropoda Rgl. l. c.

Hab. in montibus alatavicis prope Wernoje (A. Regel, Kuschakewicz) et in Kokania (0. Fedtschenko).

$\gamma$. elliptica; baccis ellipticis glauco-pruinosis.

Kokania, in valle fluvii Sarawschan (0. Fedtschenko), in montibus alatavicis cisiliensibus in valle fluvii T'schotkal ( $\Lambda$. Regel).

ঠ. oblonga; baccis elliptico-oblongis, caerulescenti-atropurpureis, glauco pruinosis v. epruinosis.

In Turkestaniae montibus alatavicis transiliensibus in valle Tschotkal, 4-6000' alt. (A. Regel).

$\varepsilon$. densiflora; racemis valde densifloris, ex alabastro saepissime pluribus egredientibus, alteris unifloris; baccis minoribus, globosis, ex atropurpureo caeruleis, initio glauco-pruinosis. Turkestaniae, in faucibus MIagian. (0. Fedtschenk0).

\section{Berberis integerrima Bnge.}

(Cfr. Rgl. Berb. in Acta h. bot. Petr. II. 418).

A specie affini B. vulgaris L. differt: "ramis floriferis junioribus teretibus laevibus v. vix sulcatis; foliis subcoriaceis subtus reticulatovenosis, integerrimis v. vix spinuloso-serratis; baccis subglobosis».

Variat: $\alpha$. typica; baccis globosis $\mathrm{v}$. ovato-subglobosis, atropurpureis, glauco-pruinosis. - Racemi folia aequantes usque duplo superantes, nunc laxi nune densi, breviter v. Ionge pedunculati.

B. integerrima Bnge. reliq. Lehm. n. 44 (lusus racemis densifloris breviter pedunculatis). - B. densiffora Boiss. et Buhse Aufz. d. Pí. Transc. und Pers. in Mem. soc. Mosq. XII. p. 9, tab. III. fig. 2 (lusus racemis densifloris sub anthesi folia subaequantibus). - B. nummularia Bnge. reliq. Lehm. n. 45 (lusus racemis laxifloris longe petiolatis folia subduplo superantibus). 
Specimina ab 0. Fedtschenko et Kuschakewicz in Turkestaniae regionibus occidentalibus collecta ad lusum racemis pedunculatis laxifloris folia paullo-duplo superantibus pertinent.

ß. pyrocarpa; baccis minoribus, globosis v. ovato-subglobosis, rubris. - Racemi pedunculati, laxi, folia paullo usque duplo superantes.

In Turkestaniae regionibus orientalibus. (Kuschakewicz, A. Regel). *)

\section{Papaveraceae.}

18. Roemeria hybrida D. C.

D. C. syst. II. 93. - Ejusd. prodr. I. 122. - Ledb. fl. ross.

I. 92. - Chelidonium hybridum MI. B. fl. taur. cauc. II. 3. Glaucium violaceum II. B. l. c. III. 363.

Hab. in Tauria, in Caucaso, in Oriente et in provinciis turkestanicis ubi frequentissime in variis formis occurrit.

Variat:

" Folia bi-tripinnatisecta, laciniae sailtem foliorum caulinorum lineares. (Calyces glabri v. plus minus hispidi).

a. typica; capsulis setis sparsis hispidis, caeterum glabris v. pube minima vestitis; pedunculis rectis.

R. hybrida D. C. et auct.

$\beta$. refracta; pedunculis fructiferis demum recurvis. Cętera ut praecedentis.

R. refracta D. C. syst. II. 93. - Ejusd. prodr. I. 122. Ledb. fl. ross. I. 92.

$\%$ bicolor; capsulis setulis erectis dense hispidis.

R. bicotor Rgl. pl. Semenlov. suppl. 2. 1. 57 c. (Bull. soc. Hosq. 1870).

*) Die erneuerte Vergleichung der zahlreichen in Central-Asien vorkommenden Formen von Berberis, lässt es mir jetzt fast richtiger erscheinen, anch B. integerrima und B. sinensis noch zu dem Formenkreis von B vulgaaris zu stellen. (E. R.) 
j. rhoeadiflora; capsulis glabris. - Ludit pedunculis fructiferis rectis v. plus minus recurvis, petalis $14-50 \mathrm{Cm}$. longis.

In regionibus turkestanicis frequentissime occurrit.

R. rhoeadiflora Boiss. diagn. ser. I. fase. VI. p. 7. Ejusd. fl. or. I. p. 119.

* Folia 1-3 pinnatisecta, segmentis ovato-oblongis.

$\varepsilon$. orientalis siliquis setis sparsis hispidis.

R. orientalis Boiss. in Ann. sc. nat. 1841, p. 374 . Ejusd. fl. or. I. p. 118. ")

\section{Cruciferae.}

Diptychocarpus Trautv. (pl. Schrenk. n. 116 in Bull. Mosq. 1860 p. 108) $\left.{ }^{* *}\right)$.

*) Schon bei der Aufstellung von $\mathrm{R}$ bicolor sprachen wir es aus, dass wahrscheinlich diese und die andern Roemeria-Arten, richtiger als Formen von R. hybrida betrachtet werden müssten. Die zahlreichen, uns aus Turkestan vorliegenden Formen bestätigen diese Ansicht vollkommen.

Nach Grösse der Blumen, Auftreten eines kurzen Flaumes zwischen den Borsten der Schote, abstehender oder theils angedrückter bald starker, bald schwacher Beharung, könnte man die Zahl der Formen noch bedeutend vermehren.

**) Die Gattung Diptychocarpus unterscheidet sich von Malcolmia durch die unteren Schoten, welche fast stielrund sind und so verkorken, dass die Klappen derselben schwierig sich ablösen, so dass man die Schoten leichter in Stücke brechen als die Klappen trennen kann. Letzteres ist jedoch in allen mir vorgekommenen Fällen möglich, so duss dieselben nicht zu wirklichen Gliederschoten werden. Ausserdem sind die oberen Schoten flach gedrückt und stimmen vollständig mit Malcolmia überein, zu welcher Gattung auch die Art, nach der von Trautvetter die Gattung aufgestellt ward, von Bernhardi gerechnet worden ist. Man könnte daher Diptychocarpus auch als Untergattung zu Matthiola ziehen, wenn nicht alle hierher gehörigen Arten schon darum eine ganz abweichende Tracht besässen, dass sie niemals die angedrückte weisse dichte Behaarung zeigen, welche die Arten der Gattung Matthiola auszeichnen. Junge Exemplare mit noch nicht entwickelten Früichten zeigen vielmehr d̀en Habitus von Chorispora, zu welcher Gattung denn anch Fischer den $\boldsymbol{D}$. strietus und ich selbst den D. hispidus gestellt hatten. 
Conspectus specierum florae turkestanicae.

D. strictus Trautv. Pilis simplicibus saltem basin versus molliter villosus; pedicellis calyce duplo brevioribus; petalis linearioblongis; rostro siliqua glabra $3-6$-plo breviore.

D. hispidus Rgl. Pilis simplicibus longioribus minutisque glanduliferis hispidus; pedicellis calycem subaequantibus; petalis oblongis; rostro glabro, siliqua hispida $3-6$-plo breviore.

D. sarawschanicus Rgl. et Schmalh. Pilis simplicibus satis laxe dispositis subhispidus; pedicellis calyce duplo brevioribus; petalorum lamina obverse oblonga; rostro siliqua glabra v. hirtula multoties breviore.

D. Olgae Rgl. et Schmalh. Pilis simplicibus dense hispidovillosus; pedicellis calyce subduplo brevioribus; petalorum lamina lineari; rostro conico, brevissimo, siliqua multoties breviore.

19. Diptychocarpus strictus. Trautv. 1. c.

Chorispora stricta Fisch. et Mey. ind. sem. hort. Petr. I. p. 24.Matthiola Fischeri Bernh. ind. sem. h. Erfurt. anno 1835. - Ledb. fl. ross. I. p. 110. - Raphanus strictus MI. Bieb. fl. taur. cauc. III. 452 .

In Turkestania frequentissime occurrit. -.. Folia linearia v. linearioblonga, dentata v. grosse sinuato dentata.

20. Diptychocarpus hispidus Rgl.

Chorispora hispida Rgl. pl. Semenov. suppl. II n. 93. 6. (Bull. Mosq. 1870.)

Annuus v. biennis. Caules erecti, $20-40 \mathrm{Cm}$. alti, basin versus ut folia hispido-pilosa pilis minutis glanduliferis intermixtis, apice minute glanduloso-hirtuli v. glabri. Sepala plus minus glandulis breviter stipitatis munita, apice saepissime hispido-barbata. Petala pallide rubra. Siliquae plus minus dense hispidae. Stigma bilobum, lobis secus stylum decurrentibus.

In Turkestaniae montibus Karatau prope Boroldai legit Korolkow. 


\section{Diptychocarpus sarawschanicus Rigl. et Schmalh.}

Radix annua v. biennis, caulem unicum v. plures crectos basi v. a basi ad medium foliatos simplices $v$. ramosos pilis simplicibus sparsis subhispidos vestitos, protrudens. Folia oblongo-lanceolata, dentata usque runcinato-pinnatifida, pilis simplicibus subhispida. Pedicelli plus minus hispidi, calycem dimidium sparse hirtum vix aequantes. Petalorum lamina obverse oblonga, ut videtur pallide rubra, calycem vix duplo supcrans. Siliquae strictae, sparse hirtulae $\mathrm{v}$. glabrae, usque $10 \mathrm{Cm}$. longae, 1'/2 -2 $\mathrm{Mm}$. latae, valvis superiorum planis nervo medio prominente percursis; rostro 2-6 $\mathrm{Mm}$. long0. - Stigmatis lobi arcte conniventes, secus rostrum decurrentes. Semina complanata, circum alata.

In Kokaniae valle fluvii Sarawschan leg. 0. Fedtschenko.

(Ex Bull. Имп. Общ. Люб. естеств. антр. и этног. hic, iterum publicatum.)

\section{Diptychocarpus Olgae Rgl. et Schmalh.}

Perennis multicaulis, caulibus foliis pedicellis calycibusque dense villoso-hispidis. Folia oblonga, petiolata; radicalia runcinato-dentata v. sinuato- v. subruncinato-pinnatifida, lobis oblongis integerrimis $\mathrm{v}$. obtuse dentatis; caulina pauca, runcinato-dentata. Caules erecti, humiles, florum racemo terminati, incluso racemo $5-10 \mathrm{Cm}$. alti, basi tantum foliati. Pedicelli satis robusti, erecto-patentes, densissime albo-villosi, siliquae diametro circiter triplo longiores, calyci basi subbisaccato plus duplo breviores. Petalorum unguiculatorum lamina exserta, lineari-oblonga, ut videtur lurido-purpurea, calycem dimidium circiter aequans. Stigmatis lobi erecti, secus stylum decurrentes. Siliquae erecto-patentes, lineares, pilis simplicibus hirtae, stylo conico siliquae diametro duplo longiore terminatae, $4-5 \mathrm{Cm}$. longae, $1 \frac{1}{2}-2-2 \mathrm{Mm}$. latae; valvis nervo medio elevato percursis. Semina complanata, ala scariosa circumdata; cotyledones accumbentes.

Habitu Hesperidi secundiflorae affinis.

Habitat in Kokaniae valle Sarawschan. (0. Fedtschenko.)

(Ex Bull. Имп. Общ. Люб. естеств. антр. п этног. hic iterum publicatum.) 
23. Aralis (?) Korollkowi Rgl. et Schmalh. Annua v. biennis; caule humili usque subspithamaeo, simplici, glabro; foliis glabris, inaequaliter repando-dentatis; radicalibus obovato-oblongis, in petiolum attenuatis; caulinis $2-4$, sessilibus, e basi cordata oblongis v. elliptico-oblongis, supremis margine laxe piloso-ciliolatis; pedunculis florem aequantibus $v$. paullo superantibus calycibusque laxe patule pilosis; petalis unguiculatis, lineari-oblongis, calycem subduplo superantibus, albis, circiter $4 \mathrm{Mm}$. longis.

Folia latere inferiore saepe purpurascentia. 0varium lineare. Stylus brevis, stigmate indiviso punctiformi coronatus. Specimina fructifera desunt. Affinis A. hirsutae, habitu alieno, caule humili flexuoso 2-4 folio, foliis majoribus cauleque glabris, diversa.

In Turkestaniae arenosis inter Taschkent et Karak-Ati in itinere ad Chiwam leg. Korolkow.

\section{Parrya R. Br.}

(Conspectus specierum imperium rossicum incolentium *).

I. Perennes, rhizomate subterraneo ramoso multicipiti; ramulis epigaeis nunc brevissimis, nunc magis elongatis ad basin folius emortuis persistentibus dense vestitis.

A. Florum racemi nunc pedunculati, nunc nidulantes, aphylli; pedicelli elongati pedunculos radicales unifloros aemulantes. Folia oninia radicalia.

a. Racemi nidulantes (Pedicelli subradicales uniflori).

P. excapa C. A. M., calyce glabro.

$P$. eriocalyx Rgl. et Schmalh., calyce lanato.

*) In der Enumeratio plantarum in regionibus cis- et transiliensibus a Cl. Semenovio collectarum, supplementum II sub n. 71 a (in Bull. Soc. Mosq. 1870), habe ich eine Uebersicht der Arten dieser Gattung gegeben. Mehrere neue Arten, die mir jetzt aus Turkestan vorliegen, veranlassten mich zu einer erneuerten Durchsicht dieser Gattung, wobei ich auch die früher von mir eingezogene P. stenocarpa Kar. et Kir. wieder herstelle, da sich diese durch die viel längeren und schmäleren Schoten von $P$. nudicaulis gut unterscheidet. 
b. Racemi pedunculati, muli, radicales $v$. ex rhizomatis $r a$ mulis egredientes.

* Folia integerrima $v$. dentata $v$. irregulariler runcinatolobata.

$P$. nudicaulis $L$., petalorum ungue calycem aequante v. paullo usque sesqui superante; siliquis lineari-lanceolatis, irregulariter constrictis, 5-8-plo longioribus quam latis.

I. stenocarpa Kar. et Kir., petalorum ungue calycem sesqui-duplo superante; siliquis elongato linearibus, multoties longioribus quam latis.

* Folia regulariter runcinato-pinnatificla.

P. pinnatifida Kar. et Kir.

II. Perennes, rhizomatis ramulis omnibus brevissimis. Caulis humilis pauci-plurifolius, simplex, florum racemo v. corymbo composito terminatus.

P. microcarpa Ledb., foliis oblongo-lanceolatis, integerrimis, setis bipartitis adpressis strigosis; racemis simplicibus; siliquis glabris, brevibus, 5-6-plo longioribus quam latis.

P. Ermani Ledb., foliis cuneato-obovatis, apice crenis $3-5$, utrinque tomentosis; racemis simplicibus; siliquis glabris.

P. flabellata $R g l$., foliis cuneato-obovatis, apice crenatis v. flabellato-incisis, siliquisque utrinque tomentosis; racemo ramoso, corymboso.

III. Fruticuli humiles ramosi, ramis nudis, ramulis hornotinis foliatis, foliis hieme caducis.

P. fruticulosa Rgl. et Schmalh.

24. Parrya excapa C. A. M. in Ledb. fl. alt. III. p. 28. - Ledb. ic. pl. fl. ross. tab. 86. - Ejusd. fl. ross. I. 132. - Rgl. pl. Semenov. suppl. II. 11. 71 a. - Hook. et Th. fl. of brit. Ind. p. 131. 
Dense caespitusa. Folia omnia radicalia, petiolata; petiolo glabro v. rarius laxe ciliato; lamina cuneato-oblonga usque subrotunda, rotundato-obtusa, integerrima v. obtuse dentata, glabra. Racemus sessilis v. breviter pedunculatus, nudus, saepissime glaber v. rarius laxe pilosus. Pedicelli graciles, florem paullo-pluries superantes. Calyx glaber v. apice barbulatus. Petalorum unguis calycem aequans v. superans. Siliquae late lineares, compressoplanae, glabrae, usque $8 \mathrm{~cm}$. longae et $6 \mathrm{Mm}$. latae, stylo brevi apiculatae; valvae nervo intermedio prominente notatae. Semina compresso-plana, ovata, immarginata v. margine angusto circumdata.

Habitat in alpibus altaicis, turkestanicis et tibetanis.

25. P. eriocalyx Rgl. et Schmalh.

Humilis, dense caespitosa. Folia omnia radicalia, spathulatolanceolata, in petiolum latum attenuata, integerrima, praecipue ad petiolum pilis setosis horizontaliter patentibus ciliata. Pedicelli radicales, graciles, flores pluries superantes, setis sparsis vestiti, folia aequantes v. superantes. Calyx bisaccatus, albido-setoso-villosus. Petala obovata, apice rotundata, ungue calycem aequante v. paullo superante. Antherae lineari-elongatae. Pistillum lineare. Siliqua ignota *).

In T'urkestaniae tractu Terekti legit Kaulbars.

25. P. nuclicaulis (Arabis) L. spec. p. 913. - P. macrocarpa R. Br. in Parry voyag. I. app 270. - Hook. et Thomps. fl of brit. Ind. p. 131. - P. Linneana et P. macrocarpa Ledb. fl. ross. I. 131. - P. arctica R. Br. in Parry 1. voyag. app. tab. 13. Hesperis arabidiflora D. C. syst. II. 454. - Neuroloma arabidiflorum D. C. prodr 1. 156. - Arabis grandiffora W. spec. III. p. 534. -

") Wir haben diese Art, von der wir nur ein blïhendes Exemplar besitzen, nach dem Habitus hierher gestellt, vielleicht gehört dieselbe zu'einer andern Gattung, doch spricht auch die Bildung des Pistills für Parrya. 
Arabis nudicaulis D. C. syst. II. 240. - Hesperis scapigera D. C. syst. II. 454. - Neuroloma nudicaule et scapigerum D. C. prodr.

I. 156. - Cheiranthus scapiger Adams in Mem. Mosq. V. 112. -

P. nudicaulis (exclusa P. stenocarpa Rgl.) in pl. Semenov. suppl.

II. sub. 71 a.

Habitat in America et Asia boreali et in montibus editioribus Asiae mediae et in alpibus tibetanis himalaicisve.

27. P. stenocarpa Kar. et Kir. enum. pl. song. n. 70. - Ledb.

fl. ross. I. p. 751. - P. nudicaulis $\varepsilon$. stenocarpa Rgl. in pl.

Semenov. suppl. II. sub n. 71 a et 71 b.- P. stenoloma Schrenk.

in ind. sem. h. Petr. VIII. p. 19.

Hab. in alpibus turkestanicis.

28. P. pinnatifida Kar. et Kir. enum. pl. song. n. 69. - Ledb.

fl. ross. I. 751. - Rgl. pl. Semenov. suppl. II. sub n. 71 a.

Dense caespitosa, rhizomatis ramis subterraneis demum subnudis, epigaeis abbreviatis $\mathbf{v}$. magis elongatis et iterato breviter denseque ramulosis, ramis ramulisque ad basin foliis emortuis dense vestitis. Folia petiolata, lineari-oblonga, regulariter runcinato-pinnatifida, glabra v. sub lente setulis brevissimis glanduliferis hispidula. Pedunculi folia superantes ut pedicelli saepissime glandulis stipitatis hispiduli. Petalorum purpureorum obovatorum unguis calycem sesqui usque subduplo superans. Siliquae lineares, strictae v. curvatae, stylo siliquae latitudinem superante coronatae, $3-4^{1} / 4 \mathrm{Cm}$. longae, $3 \mathrm{Mm}$. latae, juniores interdum glandulis breviter stipıtatis hispidulae, maturae semper glabrae. Semina margine scarioso transparente lato circumdata.

Habitat in alpibus turkestanicis (Karelin et Kirilow, Schrenk, 0. F(dtschenko).

29. P. microcarpa Ledl. fl. ross. I. p. 132. - Rgl. pl. Semenor. suppl. II. sub 11. 71a. - Draba grandifloraC. A. MI. in Ledb. fl. alt. III. p. 74. - Ledb. ic. fl. ross. 1. 267.-Eutrema piliferum Turcz. cat. baic. - Pachyneurum grandiflorum Bunge ind. sem. h. Dorp. anno 1839. 
Dense caespitosa. Caules erecti, $3-5 \mathrm{Cm}$. alti, foliis $4-5$ alternis vestiti. - Racemus corymbosus. Antherae ovatae. Siliquae glabrae, $1-1 \frac{1}{2} \mathrm{Cm}$. longae, $1 \frac{1}{2}-2 \mathrm{Mm}$. latae, stylo bre vissimo diametro siliquae duplo usque pluries breviore coronatae. Stigma subcapitatum, hreviter bilobum. Semina ovata, immarginata.

Habitat in alpibus altaicis.

30. P. Ermani Ledb. fl. ross. I. 132. - Rgl. pl. Semenor. suppl. II. sub. n. 71 a.

Humilis, dense caespitosa. Folia caules calycesque pilis simplicibus stellatisque dense albo-tomentosa, siliquae glabrae. Folia radicalia obovato-cuneata, apice grosse 3-5-crenata; caulina angustiora, nunc subtrifida lobis lineari-oblongis, nunc integerrima obverse oblonga. Racemus lanatus, simplex, initio corymbosus, demum magis elongatus. Flores pro genere parvi, ut videtur albidi. Siliquae glabrae, stylo brevissimo latitudine siliquae pluries breviore coronatae, $8-10 \mathrm{Mm}$. longae, $1 \frac{1}{2}$ -2 Mm. latae. Semina ovata, immarginata.

Ilabitat in montibus editioribus Kamtschatkae.

31. P. flabellata Rgl. in pl. Semenov. suppl. II. n. 71 c.

Caespitosa, ubique pilis simplicibus stellatisque cinereo-tomentosa, multicaulis, caulibus e basi procumbente adscendentibus, foliatis. Folia cuneato-obovata, apice grosse crenata v. crenato-lobata v. flabellatoincisa. Flores in racemum dense lanatum corymbosum simplicem $v$. saepissime ramosum densum congesti. Petalorum caerulescenti-roseorum obovatorum ungues calycem circiter sesqui superantes. Siliquae tomentosae, lineari-oblongae, rectae v. subfalcatae, stylo brevi latitudine siliquae circiter duplo breviore coronatae, $4-5 \mathrm{Cm}$. longae, $3-31 / 2 \mathrm{Mm}$. latae; valvae nervo intermedio nervisque lateralibus prominentibus notatae. Stigma capitatum, breviter bilobum. Semina ovata, immarginata (nec marginata).

Habitat in alpibus kokanicis Dshaman-Daban (Sewerzow), in tractu Dschiptik et Karakasuk (0. Fedtschenko). 
32. P. fruticulosa Rigl. et Schmalh.

Ubique glabra. Fruticulus humilis, ramosus, vix spithamaeus usque pedalis et ultra; rami nudi; ramuli hornotini foliati. Folia caduca, linearioblonga, v. rarius lineari-lanceolata, integerrima v. paucidentata v runcinato-pinnatifida. Pedunculi folia superantes, racemo trifloro v. rarius 1-2 floro terminati. Pedicelli flore breviores. Calyx bisaccatus, purpurascens. Petala obcordata, ut videtur pailide rubri, ungue calycem circiter aequante. Antherae lineari-elongatae. Siliquae juniores linearielongatae, stylo brevi coronatae; stigma breviter bilobum.

Variat: $\alpha$. subintegra; foliis lineari-oblongis, integerrimis v. paucidentatis.

In Kokania, in valle fl. Sarawschan $3-7000^{\prime}$ in monte Aksai. ( 0 . Fedtschenko.)

3. runcinutu; fuliis lineari-lanceolatis, grosse runcinato-dentatis v. runcinato-subpinnatifidis.

Kokania, in valle fl. Sarawschan in tractu Kadschraga (10900') leg. 0. Fedtschenko.

Glabritie omnium partium, caule fruticuloso, ramis nudis (nec f0liis emortuis dense vestitis), foliis caducis, petalorum ungue calycem aequante, stylo breviore a P. pinnatifidae varietatibus ramulis epigaeis magis elongatis dignoscitur.

(Ex Bull. Имп. Обществ. антроп. ІІ этног, hic iterum publicatum).

\section{Draba Alberti Rigl. et Schmalh.}

Dense caespitosa, caudiculis valde elungatis procumbentịbus ramosis, usque $10-14 \mathrm{Cm}$. longis, apicem versus foliis deuse vestitis. Folia obverse oblonga, integerrima, obtusa, pilis minoribus majoribusque stellatis intermixtisque simplicibus dense tomentoso-canescentia. Scapi nudi, incluso racemo fructifero $3--4 \mathrm{Cm}$. alti, pedicellisque pilis mollioribus ramosis tomentosi. Racemus abbreviatus, corymbosus. Siliculae ellipticae v. elliptico-lanceolatae, circiter $7 \mathrm{Mm}$. longae, $3 \mathrm{Mm}$. latae, stylo tenui $1-1^{1} / 2 \mathrm{Mm}$. longo coronatae. Stigma capitatum. Siliculae loculi (ut videtur) utrinque 5-6 ovulati. 
In Turkestaniae montibus Alexander, in tractu Karabura 8-10000' alt. leg. A. Regel.

Anmerkung. Die oben beschriebene Art liegt uns nur mit Fruchtständen, deren Fruchtklappen und Samen schon abgefallen sind, vor. In der Tracht gleicht dieselbe einer in breiten grossen Rasen wachsenden Aretia glacialis. Dieselbe scheint der Draba glacialis Adams zunächst zu stehen. Im ersten Bande der Aufzählung der Pflanzen 0st-Sibiriens, Band I. (Bull. Mosq. anno 1861, sub n. 204) in einer Anmerkung über die Abtheilung Chrysodraba, haben wir die Russischen Arten dieser Section besprochen. Nach erneuerter Durchsicht bei Bearbeitung der Pflanzen Turkestans, haben wir aber uns überzeugt, dass von den zu $\mathrm{Dr}$. pilosa Adams gerechneten Formen, die Dr. polytricha Ledb. und von den zu Dr. glacialis Adams gerechneten Formen, die Dr. mollisima Steven als gute Arten zu betrachten sind.

34. Draba nemorosa L. \%. Hueti. (D. Hueti Boiss. diagn. ser. II. fasc. V. p. 31. - Ejusd. fl. or. I. p. 302).

Pedicellis siliculam subaequantibus dignoscitur, transiit ad Dr. nemorosam hebecarpam Ledb. (D. nemorosa genuina Boiss. l. c.).

In Turkestania prope Dschasyl-kul leg. Kuschakewicz.

\section{Ghorispora D. C.}

Sectio I. Flores purpurascentes. (Cfr. Rgl. pl. Semenov. suppl. II. sub n. 92 in Bull. Mosq. 1870.)

Ch. Bungeana Fisch. et Mey. Perennis, acaulis v. subcaulescens.

Ch. tenella $D$. C. Annua, petalorum lamina obverse elliptico-oblonga, siliquis glabris, in rostrum iis paullo brevius abeuntibus. - Saepissime glandulis breviter stipitatis hispidula v. rarius pilisque simplicibus adspersa.

Ch. stenopetala Rgl. et Schmalh. Annua, petalorum lamina lineari, ovario glabro rostrum aequante. - Glaberrima *).

*) Ch. hispida Rgl. ad Diptychocarpum pertinet. 
35. Chorispora tenella I). C. (syst. II. 435 -Ledb. fl. ross. I. 169.)

๙. typica; caule foliis pedicellis siliquisque glandulis breviter stipitatis plus minus dense vestitis.

ß. pilosa; caule pedicellisque glandulis breviter stipitatis raris pilisque elongatis simplicibus vestitis, siliquis glandulis breviter stipitatis raris.

Inter Taschkent et Karak-ati leg. Korolkow,

36. Chorisp a stenopetala Rgl. et Schmalh. Annua, glaberrima. Caulis erectus. Folia inferiora lineari-oblonga, superiora anguste linearia. Petala linearia, calycem subduplo superantia, e roseo violacea. Ovarium glabrum, stylo rostriforme ovarium subaequante terminatum.

Specimina nostra caule simplici 8-10 Cm. alta. Flores terminales solitarii v. in racemum foliosum 2-3 florum dispositi.

In hortis prope Taschkent, sponte (Krause).

37. Chorispora macropoda Trautv. (pl. Schrenk. n. 119).

Nil nisi varietatem Ch. songoricae Schrenk (enum pl. nov. II. 97) pedicellis longioribus floribus majoribus sistere mihi videtur.

In Kokania, Ktschi-Alai et in tractu Psfairam (0. Fedtschenko), in Turkestaniae montibus Thian-Shan $8-12,000^{\prime}$ alt. (Kuschakewicz).

38. Malcolmia africana L. $\%$ intermedia. (Cfr. Rgl. pl. Semenov. suppl. II. sub. n. 95 in Bull. Mosq. 1876. - II. intermedia C. A. Mey. ind. cauc. p. 186. - Ledb. fl. ross. I. 170.)

Variat foliis omuibus subintegerrimis $v$. dentatis $v$. inferioribus runcinato-dentatis. Basi tantum pube $2 \rightarrow 3$-fida hispidula v. exclusis siliquis omnino plus minus dense hispidula.

Satis frequens in regionibus turkestanicis occurrit.

39. Malcolmia Bungei Boiss.

(Boiss. fl. or. p. 222. - Rgl. in pl. Semenov. suppl. II. sub. n. 95.) - Dontostemon grandiflorus Bunge reliq. Lehm. n. 98. 
In regionibus turkestanicis satis frequens.

a. typica; siliquis glabris.

$\beta$. lasiocarpa; siliquis pilis ramosis simplicibusque hirtis.

M. Bungei $\beta$. lasiocarpa et $\%$. macrantha R.gl. l. c.

40. Sisymbrium (Arabidopsis) hirtulum Rgl. et Schmalh.

Annuum, erectum. Caulis, folia, pedunculus, pedicelli, calyces et siliquae pilis stellatis hirtula. Caulis simplex v. apice ramosus, foliatus, usque pedalis. Folia elliptico-oblonga v. elliptica, sinuato-dentata v. sinuato-pinnatifida, radicalia in petiolum attenuata, caulina basi cordatosagittata sessilia. Racemus congestus, simplex vel basi ramosus. Flores parvi, petalis calycem sesqui superantibus, albis. Pedicelli florem circiter aequantes, siliquis $3-4$-plo breviores. Siliquae dense hirtulae, flexuosae, stigmate subsessili capitato coronatae, valvis convexis trinerviis.

Affine S. kokanico Rgl. et Schmalh. (cfr. Bull. Имп. Обц. естеств. l. с.) caule unico erecto usque pedali, foliis latioribus, racemo corymboso etc. dignoscitur.

In Kokania prope Samarkand et Tschupanata leg. 0. Fedtschenko.

41. Sisymbrium (Arabidopsis) Korolkowi Rgl. et Schmalh.

Pube ramosa ubique (siliquisque) satis dense pubescens. Caules plures e collo simplici egredientes, erectiusculi, circiter spithamaei, foliati. Folia radicalia caulinaque oblongo-lanceolata, dentata, radicalia in petiolum attenuata, caulina exauriculata, basin versus attenuata. Florum racemi initio corymbosi, post florescentiam elongati laxi. Flores albi. Petala calycem duplo superantia. Pedicelli erecti, flore breviores. Siliquae erectae, breves, pedicellum 2-4-plo superantes, teretes, molliter pubescentes, stylo brevi glabro terminatae; stigmate bilobo.

S. contortuplicatum D. C., cui species nostra valde affinis, siliquis stigmate sessili integro petalisque roseis dignoscitur.

In Turkestaniae tractu Dolon legit Korolkow. 


\section{Braya Sternbrg. et Hoppe.}

Calyx clausus v. patulus. Siliqua brevis, lincaris v. lineari-conica v. subelliptica, teres v. a dorso v. a latere subcompressa, valvulis convexis herbaceis non transparcntibus, rigidis, uninerviis $v$. enerviis. Stigma obtusum. 0vula in quovis loculo 4- vel plura. Semina 1-2 serialia. Stamina libera, edentula.

Taphrospermum C. A. II. siliquis abbreviatis lineari-tetragonis, valvulis membranaceis pellucidis trinerviis dignoscitur.

42. Braya rosea Bnge. in Ledb. fl. ross. I. 195. - Variat foliis linearibus $\mathrm{v}$. lineari-oblongis in petiolum attenuatis.

a. typica; scapo canescenti-puberulo v. villoso-canescente, foliis plus minus pilis simplicibus furcatisque ciliatis v. adspersis.

B. rosea et B. aenea in Ledb. fl. ross. I. 195.

ß. glabra; foliis scapisque glabris.

In Turkestania in tractu montium Thian-Schan Terekti (Kaulbars).

\section{Braya Scharnhorsti Rgl. et Schmalh.}

Perennis, caespitosa, ubique pilis simplicibus hirto-incana. Folia linearia, integcrrima, radicalia rosulata, caulina sparsa. Florum racemus initio corymbosus, demum laxus elongatus. Calycis patuli sepala viridia et late hyalino-marginata, dorso hirsuta. Petala ungue cuneato rubro calycem subaequante, limbo exserto ovato-subrotundo lutescente. Siliqua conica, teretiuscula, a latere compressa, utrinque $2-3$-sperma; valvis convexis, enerviis, hirtis. Septum lineari-lanceolatum, hyalinum, stylo brevi glabro coronatum. Stigma breviter bilobum.

In Turkestania, in valle montium Thian-Schan Jak-'Tama ct in tractu Sujuk, Sart et Baskaun, 6-1200' alt. leg. Scharnhorst. ")

*) Eine ausgezeichnete Form, welche durch die kurzen Schoten mit wenigen Samen in den Fächern und wegen des abstehenden Kelches, an Taphrospermum angränzt und gleichsam eine Mittelform swischen Taphrospermum und Braya darstellt. Am nächsten steht sie der Br. glabella Richards., die aber durch schwächere Beharung, von dem Rücken zusammengedrückte Schoten und von einem Mittelnerven durchzogene Klappen, sowic auch angedrückte Kelchblattchen, welche der breiten häutigen durchsichtigeu Umrandung entbehren, leicht zu unterscheiden ist. 


\section{Capsella Bursa pastoris Mönch.}

Variat subglabra usque villoso-hispida, foliis radicalibus subintegris usque duplicato-runcinato-pinnatifidis, siliculis cuneato-triangularibus usque late obcordatis.

Vulgatissima in omnibus provinciis turkestanicis, in montibus editioribus usque ad $10,000^{\prime}$ altitudinem adscendens.

45. Lepidium karataviense Rgl. et s'chmalh. Caespitosum, humile Folia hirtulo-cana; radicalia congesta, pinnatisecta, laciniis distantibus subulato-linearibus oppositis v. alternis; caulina saepissime integra, subulato-linearia, distantia. Caulis tenuis, ramosus, vix spithamaeus et ultra, glaber. Pedicelli erecto-patentes, filiformes, glaberrimi, floribus paullo, siliculis subduplo brevioribus. Calyx patulus; sepala viridia apice albo-marginata, petalis obovatis albis subduplo breviora. Siliculae ovato-subrotundae, apice leviter emarginatae, glabrae; stylus brevissimus, emarginaturam vix superans.

Affine $\mathbf{L}$. caespitoso Desv. et L. Meyeri Claus. (Localfloren der Wolgagegenden in Beiträge z. Kenntn. d. Russ. Reichs, 8. Lief. p. 286. Primum, foliis radicalibus integris, caule simplici, siliculis ovatis acutis reticulatis stylo emarginaturam superante coronatis, - alterum foliis glabris, pedicellis pubescentibus, siliculis subcordato ovatis acutis stylo brevi apiculatis dignoscuntur.

In Turkestania, in montibus Karatau, Balakschi-ata (leg. A. Regel).

\section{Eruca sativa Lam.}

Variat papilloso-hirta v. glabrescens, siliquis glabris v. rarius setoso-pilosis, rostro quam siliqua 2-3-plo breviore, floribus pallide luteis v. sulphureis.

E. sativa Lam. fl. fr. II. 496. - E. cappadocica Reut. h. Genev. 1857 (lusus floribus sulphureis rostro saepe breviore).

In regionibus turkestanicis vulgatissima.

47. Stroganovia paniculata Rgl. et Schmalh.

Glabra. Folia caulina oblongo-lanceolata, integerrima v. crenatodenticulata; inferiora in petiolum attenuata, nervo intermedio apicem 
versus trifido percursa; superiora angustiora, sessilia. Caulis paniculatoramosissimus. Pedicelli graciles, florem siliculasque superantes, in apice ramulorum corymbosi. Silicula obovata, glabra, apice rotundato stigmate sessili coronata; valvulis uninerviis, carinato-convexis, loculis monospermis. Semina ovata cotyledonibus conduplicatis.

Ab omnibus speciebus Stroganoviae (Stroganovia Kar. et Kir. enum. pl. fl. alt. n. 123. - Ledb. fl. ross. I. 770) stigmate sessili diversa. Species proxime affinis $\mathrm{S}$. intermedia Kar. et Kir. foliis caulinis semiamplexicaulibus, floribus in ramulis racemosis styloque brevi dignoscitur.

In Turkestaniae valle fl. Sarawschan (specimen dubium ante anthesin collectum) 0 . Fedtschenko, in valle fluvii Tschirtschik (specimina fructifera) A. Regel 8-9000' alt.

48. Crambe Sewerzowi Rgl. (Rgl. in pl. Semenov. suppl. II. n. 120). Caulis elatus, paniculatus, pedunculis pedicellisque pilis sparsis setiformibus hirsutis. Folia petiolata, utrinque et praecipue subtus hirta, petiolis hirsutis;inferiora cordato-reniformia; superiora rhombeo-ovata v. ovato-oblonga; omnia repando-sublobata crenatoque dentata; panicula ramosissima. Ovarium biarticulatum; articulo inferiore post anthesin articulum superiorem subaequante. Silicula globosa, glabra, articulum inferiorem pluries superans.

Petala alba, obovata, $4-5 \mathrm{Mm}$. longa.

In Turkestaniae promontorio Kcharli-tau (Karatau) leg. Sewerzow, in deserto inter fluv. Syr-darja et Taschkent, in valle fluvii Sarawschan satis frequens, inter Karakasuk et Schagimardan. (0. Fedtschenko, Korolkow).

Foliis utrinque petiolis pedunculis pedicellisque hirtis v. hirsutis, ovarii articulo inferiore post anthesin articulum superiorem subaequante a C. cordifolia Stev. dignoscitur.

49. Crambe palmatifida Rgl. et Schmalh. Caulis elatus, paniculatus, laxe hirsutus. Folia caulina (radicalia desunt) petiolata, petioloque utrinque hirta v. subhirsuta, palmatilobata, lobis brevibus breviter acuminatis duplicato-dentatis. Pedunculi, pedicelli calycesque 
hirsuti. Flores albi, pro genere maximi, in ramorum apice corymbos densos formantes. Petala obovata, usque $12 \mathrm{Mm}$. longa. Ovarium glabrum, biarticulatum, articulo inferiore post anthesin quam superior sesqui longiore.

Affinis Cr. Kotschyanae Boiss. (diagn. ser. I. fasc. VI. p. 91.fl. or. I. 406), diversa autem: foliorum caulinorum cordatorum utrinque hirtorum lobuli breviter acuminati (nec rotundati), panicula hirsuta (nec glabra), ovarii articulo inferiore longiore.

In Turkestania, ad fluvium Ters in montibus Abraschan leg. Krause.

\section{Sileneae.}

50. Dianthus Seguieri Vill. $\beta$. sylvaticus (Cfr. Rgl. pl. Radd. n. 275).

Lusus $\gamma$. macrosepalus; caule humili $3-5$ pollicari, uni v. paucifloro; squamis calycinis exterioribus calycem sesqui superantibus.

In montibus Alatau, Suok-dschailaju, leg. Kuschakewicz.

51. Dianthus crinitus Sm. (act. soc. Linn. II. p. 300. - Ledb. fl. ross. I. 283. - Boiss. fl. or. I. 496). Caules simplices v. ramosi.

Variat.: $\alpha$. scaber; caule foliisque plus minus scabris.

$\beta$. glaber; caule foliisque glabris.

In regionibus turkestanicis vulgatissimus.

52. Dianthus Tabrisianus Bienert (in Bunge pl. Pers. exs. 1859.Boiss. fl. or. 1. 496).

Petalis saepe profundius laciniatis a planta persica differt.

In valle fluvii Tschirtschik (Sewerzow), in valle fl. Talas (A. Regel), Alatau transiliensis (Kuschakewicz), in regionibus kokanicis Alai (0. Fedtschenko), Karatau prope Boroldai (A. Regel).

53. Dianthus Kuschakewiczi Rgl. et Schmalh. Glaber, multicaulis. Caules e basi procumbente adscendentes, flexuosi v. geniculati, plus minus ramosi, ramis unifloris. Folia linearia, flaccida, triner- 
via, integerrima, basi in vaginam brevissimam connata. Squamae 4 , adpressae, exteriores oblongo-ellipticae, interiores ellipticae, omnes in aristam squamam subaequantem $v$. superantem excurrentes, calycem dimidium subaequantes. Calyx cylindricus, $3 \mathrm{Cm}$. et ultra longus, ad $4 \mathrm{Mm}$. latus, dentibus lineari-subulatis. Petalorum lamina glabra, oblonga, in lacinias capillares latitudine areae multo longiores multifida.

Caulibus adscendentibus geniculato-flexuosis ramosis, foliis latioribus flaccidis, squamis longioribus in aristam excurrentibus, ab affini specie D. crinito facile dignoscitur.

Alatau transiliensis, in angustiis montium borealium Kastek (Kuschakewicz legit, .

54. Gypsophila fastigiata L. (am. III. p. 23. - G. fastigiata L. et G. altissima L. et auct.).

a. typica; foliis linearibus. - Flores paniculato-corymbosi.

k. cephalotes; foliis lineari-oblongis v. obverse lineari-oblongis $\mathbf{v}$. lineari-lanceolatis, $1-3$-nerviis; florum panicula e corymbis glomeratis paucis-multis composita. - G. congesta Turcz. in herb. h. Petrop. - G. fastigiata $\beta$. cephalotes Schrenk. enum pl. nov. I. p. 92. - G. fastigiata Trautv. pl. Schrenk. n. 200. - G. altissima Kar. et Kir. enum. pl. alt. n. 137.

In alpibus alatavicis transiliensibus (Kuschakewicz, A. Regel), in alpibus kokanicis (U. Fedtschenko).

$\%$ altissima; foliis lineari-oblongis $\mathrm{v}$. obverse lineari- $\mathrm{v}$. lanceolato-oblongis, $1-3$-nerviis; floribus corymboso-paniculatis.

G. altissima L. spec. pl. ed. II. p. 582 et auct.

In desertis uralensibus (E. Borszczow).

Die obigen Formen zeigen Uebergänge von der einen zur anderen. Linné unterschied G. fastigiata und G. altissima nur durch die Breite der Blätter. Fenzl in seiner ausgezcichneten Bearbeitung der Sileneen in Ledebours Flora rossica, usterscheidct ausserdem dicse beiden Arten noch durch die Länge der Blïthenstielchen im Verhältniss zum Kelche, einem 
vor und nach der Blüthezeit am gleichen Exemplar sehr wechselnden Charakter, der aber doch unsere beiden habituell sehr verschiedenen Formen $\beta$. und $\gamma$. unterscheidet. Wollte man Breite der Blätter und Länge der Blüthenstielchen als unterscheidende Charaktere benutzen, so müssten aus G. fastigiata und G. altissima sogar 4 Arten aufgestellt werden, während wir vollständig überzeugt sind, dass es nur Formen der einen weit verbreiteten Art sind.

55. Saponuria Sewerzowi Rgl. et Schmalh. Caulis erectus, humilis, nanus, a basi dichotome ramosus, angulatus, glaber, florum corymbo coarctato glanduloso-hirto terminatus. Folia glabra, semiamplexicauli-sessilia, integerrima, e basi subcordata lanceolata v. lanceolato-oblonga, acuta, nervo intermedio apicem attingente nervisque lateralibus tenuioribus e folii basi egredientibus et apicem non attingentibus utrinque $1-2$ instructa. Pedicelli erecti, calyce breviores. Calyx cylindricus, fructifer anguste oblongus, dentibus oblongis obtusis. Petala cuneato-lineari-oblonga, calycem duplo superantia, apice rotundato-obtusa, integra, nuda, in unguem sensim angustata.

Pedunculi pedicelli et calyces dense glanduloso-hirti. Calyx 15-nervius, nervis obscure areolato-anastomosantibus.

Habitus G. viscosae satis affinis, caule ramisque angulatis foliisque glabris, foliis 3-5-nervis semiamplexicauli-sessilibus, calycis dentibus oblongis sessilibus, petalis nudis integris - facile dignoscitur.

Karatau, in promontorio Kcharli-tau legit Sewerzow.

56. Silene Kuschakewiczi Rgi. et Schmalh. Perennis, basi suffruticosa. Caules spithamaei usque pedales, simplices, adscendentes, geniculato-flexuosi, pilis brevissimis retrorso-puberuli. Folia obverseoblonga, acuta, integerrima, pilis brevissimis rigidis asperula, ramulorun sterilium in petiolum ima basi ciliatum attenuata, caulina basi ipsa tantum connata. Flores in cymam bifidam v. trifidam paucifloram dispositi, initio subsessiles, demun longe pedicellati. Pedunculi pedicelli calycesque nilis tenuibus albis, confervoiden- 
crispis eglandulosis dense albido-villosuli. Calyx cylindrico-clavatus, albido-membranaceus, nervis 10 purpurascentibus apicem versus lateraliter anastomosantibus instructus, 20-25 $\mathrm{Mm}$. longus, limbi dentibus elliptico-lanceolatis, obtusis, late albo-marginatis. Petala alba unguibus calycem circiter aequantibus; lamina circiter 6-8 Mm. longa, late-obovata, bifida, lobis obovato-oblongis obtusis, appendicibus binis emarginatis. Carpophorum capsula 2-3-plo longius.

Affinis S. depressae M. B. et ejusdem varietatibus (Ledb. fl. ross. I. 321. - Rorb. mon. p. 133. - S. depressa et S. Meyeri Boiss. fl. or. I. p. 622 et 623 ), differt autem caulibus altioribus, pedicellorum calycumque indumento, floribus majoribus, cyma 3-pluriflora. Prope Wernoje legit Kuschakewicz.

Acanthophyllum C. A. M. (Benth. et Hook. gen. I. 145).

Calyx tubulosus, 5-nervius, 5-dentatus v. rarius apice truncatus integerrimus. Petala 5, lamina esquamata. Stamina 10. Ovarium 1-loculare, 4-ovulatum; ovulis erectis in columellae apice affixis; styli 3. Capsula obortu $1-2$ sperma, nunc indehiscens, nunc apice $2-4$ valvis dehiscens.

Sect. I. Euacanthophyllum. Folia acerosa, apice in spinam desinentes.

57. Acanthophyllum pungens Boiss.

Bunge in Ledb. fl. alt. II. 132 sub Saponaria. - A. pungens et squarrosum Boiss. in fl. or. I. 561, 562.-- A. spinosum C. A. M. ind. cauc. p. 210 . - Ledb. fl. ross. I. pag. 333.

Variat ubique crispule puberulum v. caule glabro corymbis parce hirtulis v. omnino glabrum (A. Stocksianum Boiss. diagn. ser. II. fase. 1. pag. 81), petalorum lamina oblongo-elliptica v. oblongo-lanceolata (A. squarrosum Boiss. diagn. ser. II. fasc. I. pag. 81), obtusa vel subacuta.

Die zahlreichen Exemplare, welche wir von dieser Art aus der Flora Turkestans besitzen, gehen in den oben genannten Charakteren in 
einander über. Es giebt sehr dicht kurzbeharte, weniger dicht und noch kürzer beharte, solche mit kahlem Stengel und schwach behartem Blüthenstande und endlich ganz kahle Formen. Die Kelchzähne bieten gar keinen Unterschied und die Platte der Blumenblätter ist bald etwas breiter, bald etwas schmäler und länger, bald deutlich stumpf, bald spitzlich oder deutlich spitz. Boissier sagt von A. pungens, dass es rotho Blumen und dass A. squarrosum weisse am Schlunde rothe Blumenblätter besitze. Nach den uns vorliegenden trockenen Exemplaren sind die Blumen entweder anfangs schön roth und bleichen nach dem Abblühen immer mehr aus oder sie sind blassrosa und bleiben später am Schlund rosa oder bleichen auch hier allmälig aus, - oder sie sind endlich vom Aufblühen an rein weiss. Wir unterscheiden hiernach 4 Formen.

a. typicum; undique crispule puberulum, floribus roseis v. persicinis. - Petula obtusa v. acuta.

ß.glabriusculum; caule glabro, corymbis glabris v. parce puberulis. A. Stocksianum Boiss. 1. c.

\%. squarrosum; undique crispule-puberulum, floribus initio pallide roseis, demum albis fauce roseis v. totidem albidis.

A. squarrosum Boiss. ex parte.

ठ. album; undique crispulo-puberulum, floribus albis.

Sect. II. Allochrusa Bunge (in Boiss. flor. or I. 559.) Folia inermia.

58. A. versicolor $F$. et $M$. Pubescenti- v. hirto-glandulosum. Folia obverse oblongo-linearia. Flores racemosi v. racemoso-paniculati. Petalorum lamina obovata.

A. versicolor F. et II. ind. sem. horti Petrop. p. 31. - Ledb. fl. ross. I. 334. - A. versicolor et persica Boiss. fl. or. I. p. 559 et 560 .

Habitat in Caucaso.

59. A. Bungei Trautv. Patule pubescens. Folia obverse lineari-oblonga v. oblong 0 -spathulata. Flores in paniculam simplicem terıninalem laxam dispositi. Petalorum lamina obovata. 
Allochrusa Bungei Boiss. fl. or. 1. 560. - Acanthophylling gei Trautv. $\beta$. latifolium Trautv. in act. h. Petrop. II. p. 511.

Hab. in Persia et in provinciis caucasicis.

61. A. paniculatum Rgl. Puberulo-hirtulum. Folia linearia, stricta. Flores in caulis ramorumque apice cymosi, in paniculam simplicem rauci-plurifloram dispositi. Calycis canescenti- lirtuli dentes acuti immarginati. Petalorum lamina obverse oblonga.

A. paniculatum Rgl. pl. Sem. n. 135. tah. II. fig. 1 et 2. (Bull. NIosq. ant10 1866.).

In Turkestania, Alatau transiliensis prope Sary-bulak (Semenow); in valle fluvii T'schirtschik (Krause).

62. A. gypsophiloides Rgl. (Cfr. Rgl. in Bull. Имп. Общ. естеств.).

Glaberrimum. Folia anguste linearia, subfalcata. Flores in paniculas effusas ramosissimas multifloras dispositi. Calycis dentes acutiusculi, albo-marginati. Petalorum lamina obverse oblonga.

In desertis inter Taschkent et fluvium Syr-Darja (0. Fedtschenko, Korolkow), in valle fluvii Sarawschan, in angustiis prope Oalinsk et in montibus Daschti-kasi (0. Fedtschenko), in montibus Karatau prope Boroldai et in valle fluvii Tschirtschik (A. Regel).

63. A. Korolliowi Rgl. et Schmalh. Fruticulus erectus, ramosus; caules primarii demum glabri, foliorum enortuorum nervis intermediis persistentibus spiniformibus oppositis restiti.

Rami cum foliis minute derseque hirtulo-glandulosi ; florum corymbo denso, e corjmbulis tribus brevitar pedunculatis composito. Folia ramorum sessilia, lineari-oblonga, obtusa, setulis glanduliferis brevissimis basi tuberculum insidentibus scabra. Pedunculi dense hirtoglandulosi. Bracteae ad basin florum oppositae, late ovatae, obtusae, minute puberulae, late albido-scarioso marginatie, calycem dimidium superantes. Calyx cylindricus, 6-costatus, apice truncatus et obsolete :-dentatus, minute glandulosu-hirtulus, 5 Hm. longus. Petalia cibverse 
lineari-oblonga, obtusa, calycem sesqui superantia, trinervia; nervis petalorum apicem non attingentibus; nervo medio sub apice furcato te cum lateralibus anastomosante.

Inter Chalati et Amu-Darja ad lacum Sardeba-kul in arenosis (Korolkow).

Speciem valde affinem (A. Alexandrae Smirnow) ad fluvium AmuDarja legit Smirnow. Foliis latioribus minus asperis, ramis corymbis ternis terminatis, pedunculis corymbulos superantibus differre videtur.

Anmerkung. A. Bunge unterscheidet in Boissier's Flora orientalis I. p. 559 die Gattung Allochrusa durch nicht in Stacheln ausgehende Blätter und Staubfäden, die nicht lang vorsehen, von Acanthophyllum. Der letztere Charakter findet sich wohl bei A. versicolor, nicht aber bei A. paniculatum, gypsophiloides und Korolkowi. Unter den von uns zur Section Allochrusa gezogenen Arten, sind Acanthophyllum paniculatum und A. gypsophiloides RgI. sehr nahe verwandt. Ausser der charakterischen Beharung von Acanth. paniculatum, trägt dasselbe auf der Spitze der Stengel nur einfache armblumige Blithenrispen, während gegentheils A. gypsophiloides in seinem Habitus der Gypsophila paniculata ähnlich ist, denn die Stengel desselben sind stark verästelt und die auf der Spitze aller Zweige stehenden Blüthenrispen überspinnen den ganzen grossen dichten Busch mit einer leicht gebauten Blüthenmasse, ähnlich wis das bei Gypsophila paniculata der Fall ist. Die Fruchtknoten enthalten dagegen nur 4 Eier und so muss auch diese Art, trotz ihrer habituellen Achnlichkeit mit Gypsophila zu Acanthophyllum gerechnet werden.

\section{Alsineae.}

64. Arenaria Meyeri Fenzl. (Ledb. fl. ross. I. 368). Differt caule ramosissimo suffruticoso, sepalis acuminatis ab A. capillari Poir. vccurrit dense caespitosa $v$. caespites laxiores formans, foliis erectis v. patentibus, $10-25 \mathrm{Mm}$. longis semiteretibus v. Inargine inflexis subteretibus, margine scabris v. glabris.

IIuc A. Ledebouriana Fenzl. in Russeg. Reise II. I. p. 89.

In valle fluvii Sarawschan (0. Fedtschenko), in montibus Alatau (Korolkow, $\Lambda$. Riegel). 
65. Stellaria humifusa Rotyb. in act. Ac. hafn. X. 447 † Fenzl. in Ledb. fl. ross. I. p. 384.

o. caespitosa; caudiculis abbreviatis, ramosis, dense caespitosis; foliis oblongis internodia subaequantibus v. superantibus.

Lus. amblyosepala; sepalis obtusis.

Kokaniae in tractu Kawuk (0. Fedtschenko).

Lus. oxysepala; sepalis acutis.

Karatau, in montibus Alexander 9000' alt. (A. Regel).

66. Cerastium davuricum Fisch. in Sprgl. pug. pl. minus cogn.

II. p. 65. - Sprgl. in Ledb. fl. ross. I. pag. 401.

a. glabrum; glaberrimum v. caule basi tantum pilis sparsis vestito.

In Turkestania (Kuschakewicz, Scharnhorst).

ß. pilosum; caule ramisque pilis patentibus hirsutis v. subhirsutis, pedicellis sparse pilosis, calycibus glaberrimis.

Karatau in tractu Karakia leg. A. Regel.

\section{Stellaria rigida Bunge.}

Dense glanduloso-hirta. Caules angulati, simplices v. apice parcedichotomo-ramosi, in cymam pauci-plurifloram soluti. Folia copiosa, oblongo-lanceolata usque subcordato-ovata, sessilia, bractealia herbacea caeteris similia, omnia carnosula cinereo-glaucescentiae. Calycis laciniae ovatae, obtusae v. subacutae, quam corolla duplo breviores, plus minus purpurascentes. Petala semibifida, lobis oblongis obtusis. Capsula 5sperma. Semina compressa, subrotunda, laevia.

Stellaria dichotoma $\varepsilon$. rigida Bunge Verz. der Pfl. des Altai pag. 34. - Fenzl. in Ledb. fl. ross. I. 380.

St. dichotoma facile dignoscitur caule tereti a basi dichotomo-ramosissimo in cymam multifloram soluto, calycis laciniis lanceolatis acutissimis viridibus, petalis calycis lacinias subaequantibus $\mathrm{r}$. paullo superantibus, seminibus obtuse granulatis. 
๙. typica; foliis oblongo-lancedatis.

In regione altaica ad Tschugam superiorem legit Bunge.

3. latifolia; foliis ovatis v. subcordato-0vatis.

In Kokania prope Dschiptyk et Karakasuk legit 0. Fedschenko.

\section{Geraniaceac.}

68. Geranium collinum Steph. Willd. spec. pl. III. 705. - Ledb. fl. ross. I. 467. - Trautv. pl. Schrenk. 11. 260.

Pedunculis elongatis ex foliorum axillis saepissime a basi ad apicem caulis egredientibus pedicellisque post florescentiam refractis ab affinibus speciebus dignoscitur. In regionibus turkestanicis satis commune et in innumeris varietatibus occurrit.

๙. eglandulosum Ledb.; caule petiolis pedunculis pedicellisque pilis brevibus adpressis deorsum versis pubescenti-subcanescentibus; calycibus puberulis. - Flores satis inigni, violacei v. albidi. Variat caule humili usque bipedali, foliis plus minus dissectis.

G. Londesi Fisch. in Lk. enum. h. Berol. II. 196. et auct. G. longipes D. C. prodr. I. 642. - G. collinum eglandulosum Ledb. fl. ross. 1. 468. - Trautv. pl. Schrenk. 11. 260. - G. rectum villosulum Herder pl. Semenor. - G. saxatile Kar. et Kir. enum. pl. song. p. 195. — Ledb. fl. ross. I. 195.

3. glandulosum Ledb.; caulibus petiolisque pilis brevibus adpressis v . recurvis eglandulosis; peduıculorum pedicellorumque pilis patentibus brevibus glandulosis; calyce munc pilis adpressis sparsis eglandulosis, nunc magis patentibus glanduliferis eglandulosisque vestito. - Flores violacei.

G. collinum glandulosum Ledb. fl. ross. 1. c. - Trantv. 1. c. G. longipes $\beta$. adenotrichum Schrenk. pl. nov. 1. p. 90. - G. collinum b. C. prodr. 1. 642 .

$\%$ saxatile; caule petiolis pedunculisque pilis adpressis eglanduIosis; pedicellis pilis patentilus glanduliferis; calyce ut praecedentis. 
G. saxatile Kar. et Kir. pl. exs. ex parte.

o. Tirsutum Trautv. ; caulis petiolorum pedunculorum pedicellorumque pilis patentibus, plerisque glanduliferis.

G. collinum hirsutum Trautv. 1. c.

¿. viscosum; ubique pilis mollibus patentibus glanduliferis dense subvilloso-viscosum. - Humile, vix spithamaeum. Vidi specimen unicum aCl. Sewerzowio in montibus prope Wernoje, alterumque a Cl. Semenovio in trajectu Kurmety (Alatau) lecta.

G. sixatile Herder in pl. Semenov. n. 189.

ร. alpinum; caulibus nullis v. brevibus, foliis parvis minus divisis. - Irdumentum valde variabile, ad varietates $\alpha . \beta . \gamma$. accedens.

In alpibus turkestanicis altitudine $6-11,000^{\prime}$ satis frequens.

Anmerlung. Die letztere Form ist genau genommen, die Alpenform der Varietäten $\alpha$-ò, obgleich solche als fast stengellos und durch die kleineren weniger getheilten Blätter sehr verschieden erscheint.

Das $G$. collinum mit seinen Formen ist oft von den angrenzenden Arten schwer zu unterscheiden. Unter diesen ist G. rectum Trautv. durch den aufrechten Wuchs und nach der Blïthe gerade aufgerichtete Blüthensticle und Blüthenstielchen, sowie durch das Auftreten langer driisenloser Haare verschieden. G. palustre $L$., scheint mir gar nicht verschieden zu sein, so dass ich gegen eine Vereinigung beider Arten nichts einzuwenden lätte, G. sylvaticuın L., G. pratelsse L. und G. affine Ledb. (letzteres von $G$. pratense kaum spezifisch zu scheiden) unterscheiden sich nur durch den auf der Spitze der Stengel mehr bouquetartig vereinigten Blitithenstand.

\section{Geranium erectum Trautv.}

Trautr. pl. Schrenk. n. 261.

๙. glabratum Trantv. (l. c.); caule glabro, pedunculis pedicellisque deorsum adpresse pilosulis, calycibus glabris v. albovillosis.

Prope Weruoje leg. Kuschakewicz.

3. villosulum Traute.; caule albo-villosulo r. rilloso. Ceterd ut praecrdentis. 
Prope Wernoje (Kuschakewicz), in valle superiore fluvii Talas (A. Regel).

$\%$ villosum; caule pedunculis pedicellis calycibusque patente albo villosis.

Dschasyl-kul, Alatau, leg. Kuschakewicz.

\section{Umbelliferae.}

70. Peucedanum dasycarpum Rgl. et Schmalh.

Caule tereti, stricto, sulcato, hirtulo; foliis radicalibus caulinisque inferioribus bipinnatisectis, superioribus simpliciter pinnatisectis, omnibus glabris: segmentis ovatis v. ovato-lanceolatis, lobulatis dentatisque v. praecipue apicem versus irregulariter et subduplicato-dentatis, lateralibus basi dimidiato-cordatis $\mathrm{v}$. dimidiato-subcuneatis, terminali basi cuneata decurrente cum lateralibus plus minus confluente; vaginis inflatis, omnibus foliiferis; involucri polyphylli foliolis lineari-lanceolatis v. lanceolatis acuminatis, erecto-patentibus, hirtulis; umbellae radiis teretibus, sulcatostrictis, hirtulis; fructibus omnino hirtulis.

Caulis robustus, ramosus, usque $1-1^{1} / 4 \mathrm{MI}$. altus, basi circiter $1 \mathrm{Cm}$. in diametro. Radicis perpendicularis simplicis collum fibris foliorum emarcidorum vestitum. Umbella multiradiata, radiis $3-5^{1} / 2 \mathrm{Cm}$. longis. Umbellulae multiradiatae densae; involucellum polyphyllum; foliolis lanceolatis v. lineari-lanceolatis, hirtulis, umbellulae radiis adpressis, eos subaequantibus, hirtulis, dorso viridibus, late albido-marginatis, $5-7 \mathrm{Mm}$. longis. Calycis margo manifestus. Fructus a dorso compressus, ovatus, $4 \mathrm{Mm}$. longus, $3 \mathrm{Mm}$. latus; mericarpiis margine lato diaphano; valleculae univittatae; commissura 4 -vittata.

Dignoscimus a specie proxime affine P. latifolio D. C. «caule radiis fructibusque dense hirtulis, foliorum vaginis omnibus foliiferis».

In Turkestaniae valle fluvii Karakol legit A. Regel.

\section{Lonicereae.}

71. Lonicera turcomanica Fisch. et Mey. Foliis ovato-ellipticis, obtusis v. acutis, basi rotundatis, glabriusculis v. subvillosis; pedun- 
culis petiolo duplo brevioribus, quan flores pluries brevioribus; corollis basi aequalibus; baccis distinctis.

Frutex erectus. Ramuli glabri v. apicen versus brevissine puberuli. Petioli puberuli v. subvillosi. Folia glabra v. parce flosculoso-puberula v. pubescentia. Baccae parvae, nigrescentes, apice nudac.

Pedunculis petiolo brevioribus, baccis duplo minoribus a $\mathrm{L}$. Xylosteo L. dignoscitur.

L. turkomanica F'. et M. in Bull. Mosc. 1839. II. 156 (sine descriptione). - Trautv. in Act. h. Petr. I. 274. - L. nummularia Fisch. et Ney. Bull. Mosc. l. c. - L. Xylosteum $\beta$. Inacrocalyx Rgl. et Herd. pl. Semenov. n. 472.

Var. a. typica; petiolis pedunculisque breviter puberulis, foliis subglabris v. parce floccoso-puberulis.

3. subvillosa; petiolis pedunculis foliisque subvillosis. - L . Xylosteum $\beta$. Rgl. et Herd. l. c.

Habitat in Turcomania (Karelin et Kirilow), in Turkestaniae montibus Alatau (Semenow, A. Regel).

\section{Compositae.}

72. Tunacetum trichophyllum Rigl. et Schmalh.

Radicis verticalis simplicis collo dense lanato; caule recto simplici, solido, lanato-villoso; foliis inferioribus ambitu elongato-oblongis, lanatovillosis, bi-tripinnatisectis, segmentis lineari-setaceis, confertissimis, mucronato-acutis ; corymbo composito, umbelliformi; pedunculis pedicellisque bracteis filiformibus lanato-villosis vestitis, caeterum glabriuseulis; capitulis hemisphaericis, satis magnis; involucri foliolis dorso virescentibus, late albo-hyalino marginatis, villosulo-ciliatis, caeterum glabris, exterioribus obovato-oblongis obtusis, interioribus angustioribus acutis; receptaculo elevato-hemisphaerico, punctato, nudo; floribus tubo elongato filiformi glanduloso, limbo omnium campanulato 5-dentato; acheniis linearibus, curvatis, $4-5$ costatis, glanduloso-tuberculatis, apice nudis. 
Caulis usque $20 \mathrm{Cm}$. altus, foliosus; foliis decrescentibus, inferioribus medio $10-12 \mathrm{~cm}$. latis, superioribus sensim sensimque ad bracteas desinentibus. Involucrum circiter $1 \mathrm{Cm}$. in diametro. Foliorum laciuulae confertissimae, $1-2 \mathrm{Mm}$. longae.

Facie Achilleam trichophyllam referens, affine Tanaceto (Pyrethro) umbellifero Boiss. Prima receptaculo nudo, capitulis subglobosis, acheniis apice margine membranaceo-denticulato coronatis, - alterum caule pedunculisque fistulosis, foliorum laciniis lanceolatis, rhachi spinulosa, capitulis minutis, floribus marginalibus limbo 3-dentato, - facile dignoscuntur.

Habitat in Turkestaniae inontibus Karatau prope Boroldai. Legit 1. Regel.

\section{Echinops karatavicus Rgl. et Schmalh.}

Caule plus minus laxe albo-tomentoso; foliis subcoriaceis, pinnatifidis, supra glandulis breviter stipitatis hirtulis, infra albo-tomentosis, lobis in spinam satis rigidam luteolam cuspidatis spinosoque dentatis; involucri partialis penicillo quam involucri squamae intimae $4-5$-plo breviore; squamis glabris, e viridi amethystinis, infimis 8-10 parvis penicillum vix aequantibus, e basi panciciliata in apicem triangulari-spathulatum spinuloso-denticulatum dilatatis; superioribus $15-20$, omnibus liberis, lineari-lanceolatis, canaliculatis, spinoso-acutis, setoso-ciliatis; acheniis lineari-subclavatis, setis appressis dense vestitis; pappi setis in coronam brevem membranaceam margine ciliolatam connatis.

Caulis robustus, $60-80 \mathrm{Cm}$. altus, foliis decrescentibus vestitus. Folia inferiora ambitu elliptico-lanceolata v. lanceolata, $15-25 \mathrm{~cm}$. longa. Capitula uniflura, in glomerulum globosum terminalem collocata. Involucrum circiter $20 \mathrm{~cm}$. longum, florem solitarium circiter aequans.

Lchinops chantavicus Trautv. sect. Ritro (Trautv. pl. Schrenk. n. 645), cui species nostra satis affinis, differt «foliis supra glabris v. paullo scabridis (nunquam glandulosis), involucri squamis inferioribus penicillum subduplo superantibus ex apice spathulato in cuspidem satis elongatam excurrentibus». E. sphaerocephalus L. «caule canescente setulosoque glanduloso, foliis mollibus, penicilli setis dimidio involucro sublongioribus, involucri squamis viscido-puberulis etr. longe distat. 
In 'Turkestania iu valle fluvii 'T'schirtschik prope Saylik 3-5000' alt. leg. A. Regel.

\section{Cousinia Trautvetteri Rigl.}

Cousinia, series A. (receptaculi setae lacvissimae).

Subseries I. (achenia ecostata laevia v. striata apice rotundato minute areolata edentula v. obsolete marginulata). $\$ \$ 2$. Serratuloideae (capitula mediocra v. majuscule multiflora, involucri phylla numerosa) ** (phylla saltem inferiora squarroso-patentia v. reflexa). Boiss. fl. or. III. pag. 459.

Perennis; caulc elato, simplici v. paullo ramoso, araneoso-albo-lanato, nudo; foliis oblongo-lanceolatis, utrinque attenuatis, coriaceis, sinuatopinnatifidis dentatisque lobis dentibusque omnibus in spinam rigidam excurrentibus, supra laxe araneoso-lanatis, infra dense niveo-tomentosis; radicalibus caulinisque inferioribus in petiolum attentatis, caulinis superioribus decrescentibus, basi angusta sessilibus; capitulis maximis, subnutantibus, plus 200 -floris, subsessilibus, depresso-globosis; involucri squamis numerosissimis, exterioribus reflexis, interioribus imbricatis erectis, glabrescentibus $v$. laxe villosis, e basi lanceolata margine fimbriatolacera (praecipue squamarum interiorum) in spinam subulatam rectam denudatam virescenti-luteam exeuntibus; acheniis obovato-oblongis, complanatis, laevibus, striatis; pappi setis numerosis, pro genere elongatis, flores subaequantibus, sub lente scabris, basi in fasciculis coalitis mox caducis; styli ramis angustis, brevibus.

Habitu, capitulis maximis, pappo elongato Carduorun, - caule nudo, antherarum caudis setosis, pappi setis nunquam in annulum connatis ad Cousiniam pertinere videtur Cousinia Chamaepence Boiss. cui species nostra proxima, differt foliis caulinis basi subcordata sessilibus, capitulis pedunculatis 70 — 80 -floris, involucri squamis e basi dense lanata ill spinam denudatam purpurascentem excurrentibus, pappo flore quadruplo breviore.

Habitat in Turkestauiae valle fluvii Karakol in tractu Karakia montium dlexander. Legit $\mathrm{A}$, Regel. 


\section{Campanalaceac.}

75. Cylindrocarpa Rgl.

Calycis tubo cylindrico, limbo 5-fido. Corolla tubo brevissimo; limbo 5-partito; laciniis lineari-oblongis, initio cohaerentibus, demum liberis erecto-patentibus. Stamina 5 ; filamentis brevissimis, ovato-triangularibus, in filum brevissimum excurrentibus; antheris elongato-linearibus, filamento multo longioribus, liberis, erectis. Stylus apice 2-3tidus. Capsula lineari-cylindrica, apice in collum constricta, 2-3locularis, sub apice poris dehiscens.

Radix perennis, collo multicauli. Caules foliosi, ramosi, ramulis filiformibus apice flore solitario terminatis. Habitus Campanulae, corolla Phyteumatis, capsula Speculariae.

\section{Cylindrocarpa Sewerzowi Rgl.}

Glabra, radice perenni, collo multicauli; caulibus simplicibus $\nabla$. plus minus ramosis, erectis v. adscendentibus, teunibus, foliatis; ramis simplicibus v. simpliciter v. iterato ramosis; ranıulis filiformibus, flore solitario terminatis; foliis lineari-lanceolatis, decrescentibus, remote denticulatis, basin versus sensim attenuatis; calycis tubo lineari-cylindrico, limbi lobis linearibus erectis, tubo plus duplo brevioribus; corolla caerulea, supra basin quinquefida, lobis demum inter se liberis, anguste oblongis, erecto-patentibus, quam calycis lobi circiter triplo longioribus; antheris elongato-linearibus, quam corollae lobi paullo brevioribus, filamento basi triangulari-dilatato in filum brevissimum excurrente sufiultis; stylo filiformi, stigmatibus linearibus $2-3$-coronato; capsula linearicylindrica, apice in collum constricta, sub apice poris dehiscens. Caules $1 / 2-1 \frac{1}{2}$ pedales. - Calycis tubus $5-6 \mathrm{Mm}$. longus, $1-1^{1 / 2}$ latus. Capsula 12-18 Mm. longa, $3 \mathrm{Mm}$. lata. Calycis lobi $3 \mathrm{Mm}$. longi. Corolla $10 \mathrm{Mm}$. longa, lobis $1-1^{1} / 2 \mathrm{Mm}$. latis. - Phyteuma Sewerzowi Rgl. pl. Semenov. n. 671.

Ilabitat in Turkestaniae montibus Karatau prope Dschie, intrr Kultschuk et Dschaman-Tasch - Llatau, ad fluv. T'schotkal $\left(4-6000^{\circ}\right.$ alt.), Kara-T'schok (A. Regel). 


\section{Borragincae.}

76. Arnebia guttata Bnge.

Bnge. ind. sem h. Dorp. 1840 p. 7. - Ledb. fl. ross. III. 139. - Flores flavi, fauce maculis purpureis 5 ornati.

Radice perenni, caulibus ramosis $2-4$ pollicaribus, calyce fructifero tubo ecornuto, calycis lobis linearibus folia floralia (bracteas) superantibus, coryopsibus in conum acuminatis subspinuloso tuberculatis ab A. cornuta Fisch. et Mey., cui proxima facile dignoscitur.

Ad montium declivibus prope Kutmaldy ad lacum Issikkul et in montibus alatavicis prope Dschil-Aryk leg. A. Regel.

\section{Plumbagineae.}

77. Statice alatavica Rgl. et Schmalh.

Foliis oblongo-lanceolatis, in petiolum attenuatis, acutis, viridibus, subcoriaceis, margine planis, glabris, $15-25 \mathrm{Cm}$. longis ; scapo erecto, paniculato, $40-60 \mathrm{Cm}$. alto, glabro; ramis angulatis, patule hirtis ; florum fasciculis $3-4$ floris, confertis, in spicas breves dispositis; bracteis membranaceo-marginatis, exterioribus late ovatis, in mucronem cuspidatis, interioribus obcordatis ex emarginatura in mucronem rigidum aristiformem excurrentibus; calycis tubo patule hirto, limbo explanato quinquelobo scarioso, lobis acuminatis nervo excurrente breviter mucronatis.

Affinis St. speciosae L. et St. Sewerzowi Herder. Prima differt foliis obovatis acuminato-mucronatis, ramis ancipitibus triquetrisve alatis glabris v. glabriusculis, bracteis interioribus totis membranaceis obtusis v. acuminatis, calycis limbo obsolete obtuseque quinquelobo; - altera scapi ramis glabris $\mathrm{v}$. ramulis basi vix hirtulis, spiculis in spicas elongatas imbricatis, bractea intima obtusa, calycis tubo basi hirtulo, limbo obtuse quinquelobo.

In Turkestaniae montibus Alatau legit A. Regel.

78. Statice Höltzeri Rgl.

Glabra; caulibus pluribus, erectis, divaricato-ramosis ; ramis filiformibus, teretibus, inferioribus sterilibus, superioribus apice floriferis; foliis radicalibus oblongo-spathulatis, obtusis, in petiolum attenuatis, caulinis 
ad squamas lanceolato-deltoideas apice scariosas reductis; florum fasciculis $2-3$-floris, in corymbos capituliformes terminales congestis; bracteis ovato-orbiculatis, exterioribus dorso rubro-fuscis margine lato membranaceo-hyalino cinctis, interioribus totis hyalinis; calycis tubo ad nervos piloso-hirtulo, limbo quinquefido, initio carneo-roseo, demum albidohyalino, laciniis oblongo-lanceolatis, leviter crenulatis.

Rhizoma crassum, multiceps. Caules ramosissimi, $14-20 \mathrm{Cm}$. alti. Folia radicalia $2-2^{1} \frac{2}{\mathrm{Cm}}$. longa, sub apice $2-21 / 2 \mathrm{Mm}$. lata.

St. congesta, cui species nostra proxime affinis, differt caulibus adscendentibus oligophyllis, ramis sterilibus paucis, florum fasciculis in spicas breves congestis.

Habitat ad Turkestaniae fluvium Tschu prope Tokmak et prope Dschil-Arik inter Tokmak et lacum Issyk kul. Legit A. Regel.

Dedicavimus plantarum perennium horti botanici Imperialis Petropolitani' cultivatori eruditissimo H. Höltzer.

\section{Irideac.}

\section{Iris L. Sect. III. Barbatee.}

Perigonii laciniae exteriores intus barba instructae.

79. I. Alberti Rgl.

Caulis pluriflorus, foliis ensiformibus glaucis brevior v. ea subaequans. Spathae ovato-lanceolatae, perigonii tubum superantes, a basi ad medium herbaceae, apicem versus scariosae. Perigonii tubo ovarium vix aequante; laciniis exterioribus juxta costam barbatis, cacterum glabris; laciniis interioribus exteriorum longitudine, obovatis, sensim in unguem attenuatis: filamentis antheram subaequantibus; stigmatibus bilobis, lobis apice rotundatis crenulatis, marginibus sese tegentibus.

Rhizoma I. germanicae. Perigonii laciniae $4-4{ }^{1 / 2} \mathrm{Cm}$. longae, saturate caeruleae, basin versus lutescentes.

In Turkestania prope Wernoje et in valle fluvii Almatinka $\left(4000^{\prime}\right)$. Legit A. Regel.

Iris germanica, cui specics nostra affinis, differt: caulc foliis longiole, perigonii laciniis subito in unguem contractis. stigmatis lobis divaricatis acutis, florihus majoribus. 


\section{Liliaceae.}

80. Orithyja dasystemon Rgl.

Bulbi oblongo-conici tunicac pallide fuscae, intus pilosae. Caulis glaber, incluso flore $15-18 \mathrm{Cm}$. altus, diphyllus. Folia alterna v. subopposita, glabra, acutiuscula, inferiore lanceolato v. lineari-lanceolato, superiore sublineari. Perigonii phylla erecto-patentia, lanceolata usque lineari-lanceolita, exteriora glabra intus lutea extus virescentia, interiora lutea apice basique puberula. Stamina inclusis antheris pistillum superantia; filamenta e basi lanceolata in apicem subulatum glabrum excurrentia, hirsuta. Pistillum in stylum germen subaequans sensim attenuatum; stigma capitatum.

Filamentis basi hirsutis ab ommibus speciebus hujus generis facile dignositur.

In montibus prope Wernoje ad fluvium Almatinka 5500-6000, (A. Regel).

\section{B. PLANTAE REGIONES TURKESTANICAS ET CHNTRO- ASIATICAS INCOLENTES,}

SECUNDUM SPECIMINA VIVA IN HORTO BOTANICO IMPERIALI PETROPOLITANO CULTA DESCRIPTA. auctore $\mathbf{E E G}$. REL.

1. Allium globosum Redouté. (Cfr. Rgl. Allium pag. 197.)

7) albidum; spatha umbellam paucifloram vix superante, pedicellis perigonium vix superantibus, perigonii phyllis albidis nervo viridi percursis.

Legit A. Regel in Turkestaniae montium Alexauder tractu Karabura.

2. Allium stramineum Rgl. (Grtfl, 1876, tab. 886).

Bulbis solitariis, ovatis; tunicis membranaceis, exterioribus parallele larimiate-tibrosis. alhidis; caule inferme $3-4$-folio, foliis tistulusis bre- 
viore v. subaequilongo; umbella globosa v. hemisphacrica, multiflora, capsulifera; spathae valvis quam flores brevioribus; pedicellis perigonio brevioribus usque paullo longioribus, basi nudis; sepalis exterioribus ovato-lanceolatis, eximie carinatis, quam interiora oblonga $1 / 4$ brevioribus, laevissimis, nitido-stramineis; filamentis perigonio paullo brevioribus, subulatis, simplicibus, ima basi in annulum connatis.

Glaberrimum. Caulis teres, $25-30 \mathrm{Cm}$. altus, usque ad quartam partem vaginis foliorum involutus. Folia e viridi-glaucescentia, lineåria v. filiformia, bulborum sterilium teretia, bulborum fertilium semiteretia, supra eximie canaliculata. Umbella densa. Spatha in valvas duas ovato-subrotundas subscariosas apice subacutas v. laciniatas rumpens. Flores eximie trigoni. Sepala erecta; exteriora carinato-navicularia, ovatolanceolata, subacuta, uninervia, $5-6 \mathrm{Im}$. longa, apice tantum patentia. 0varium ovatum, basi sacculis tribus immersis, apice stylo subulato ovario subaequilongo coronatum; stigmate punctiformi.

Semina Cl. Prczewalsky ex Mandschuria occidentali-australi attulit.

\section{Crocus alatavicus Semenov et Regel *).}

Vernalis, tunicis membranaceis demum a basi bulbi ad medium in fibras tenues parallelas superne anastomosantes discedentes; foliis linearibus, glabris, medio stria alba ornatis, corollae tubum aequantibus usque florem superantibus; spatha diphylla, membranacea; perigonii fauce glabri phyllis oblongis, obtusis, antheras lineares subduplo superantibus; stigmatibus erectis, subclavatis, quam antherae subduplo brevioribus. Corolla intus alba, basi crocea; sepala exteriora extus colore plumbeo dense tenuissimeque striolata, margine luteola. - Affinis C. reticulato et L. verno. Primus tunicarum radicalium structura, alter tunicis bulborum demum a basi ad apicem in fibras solutis sepalisque latioribus dignoscuntur.

*) Cr. alatavicus Rgl. et Semenov. in Rgl. pl. Semenovianae 1V. n. 1036 (Bull. de Mose. 1869). Die citirte Beschreibung ist theils nach nicht gut getrockneterı Exemplaren gemacht, theils durch Druckfehler entstellt, weshalb wir dieselbe hier nach lebenden Exemplaren, die wir durch A. Regel's Verurittclung erhielten und die kürzlich im Botanischen Garten blüheten, im Obigen wiederholten und verbesserten. Eine Abbildung findet sich Giurtentlora 1877 tab. 9ut. 


\section{Liis (Xiphion) Kolpakowskiana Rigl.}

Tunica bulborum fibroso-reticulata, fibris satis crassis lutescentibus. Scapus brevissimus, humilis, uniflor'us, teres, simplex, basi vagina solitaria scapum superante. Folia glauca, linearia, erecta, supra canaliculata, subtus carinata v. rarius subtricarinata, florem superantia. Flos vaginis duabus oppositis floris tubum superantibus involucratus, caeruleus. Perigonii tubus limbum subaequans; phylla exteriora elliptico-oblonga, ex apice rotundato obtusa, subito in acumen lineare excurrentia, ungue margine caeruleo, in mediano croceo nervo medio virescente, apice albo, variegato, lamina caerulea; phylla interiora exterioribus longiora, caerulea, cuneato-oblonga, ad tertiam partem bifida, lobis subdivergentibus, longe cuspidatis. Filamenta antheras aequantia. Stigmata biloba, lobis oblongis integerrimis. Ab umuibus speciebus sectionis Xiphion, perigonii laciniis interioribus cuspidato-bifidis diversa.

Prope Wernoje in Turkestania legit Fetisow.

Wir erhielten von dieser ausgezeichneten Art einige Zwiebeln, welche im Kalthause im März zur Blüthe kamen. Im freien Lande dürfte diese Art gleich I. reticulata zu den ersten Blumen des Frühjahrs gehören.

Wir nennen diese schöne neue Art nach dem Hern General Kolpakowski, Gouverıeur des Semiretschinskischen Gebietes, der alle Unterıehmungen zur Erforschung der östlichen Gebiete Turkestans init allen ihm zu Gebote stehendenden Mitteln und mit dem lebhaftesten Interesse für die Naturwissenschaften befördert und unterstützt.

5. Sedum umbilicoides Rgl.

Folia carnosa, glauca; radicalia dense rosulata, oblongo-lanceolata, acuta, utrinque convexo plana, margine sub lente ciliolata, ceterum glabra; caulina sparsa, obiongo-linearia, utrinque convexa, glabra v. cileolis paucis munita, basi soluta, acuta v. obtusiuscula. Caulis adscendens v. decumbens, glaber, infra foliorum rosulam erumpens, apice in cymam biradiatam paucifloram transiens. Flores pedicellati, initio terminales, demum in axillis foliorum floralium solitarii, pedicellis breviores, heptameri. Calycis 7-partiti sepala lanceolata, mucronato-acuta. Petala 7, calycem duplo superantia, lanceolato-elliptica, mucronato-acuta, 
intus alba, extus alba rubroque striolata, basi inter se subconnata, apice patentia. Stamina 14, petalis breviora. Carpella 7, capsularia, polysperma, conniventia. Squamae hypogynae 7, parvae, semicirculares.

Species insignis, Umbilici Crassulaeque habitu affinis.

In Turkestaniae valle superiore fluvii Tschotkal $5-6000^{\prime}$ alt. in montibus alatavicis legit A. Regel.

\section{Tulipa Alberti Rgl. *)}

Pertinet cum subsequentibus ad sectionem generis Tulipae «sepalis ima basi glabris, supra basin macula magna nigrescente notatis, staminibus glabris, pedunculo sub lente minute puberulo, bulbi tunicis intus pilis appressis strigoso-pilosis, Rgl. act. h. Petr. II. 438».

T. Greigi $R g l$., foliis virescentibus maculatis; sepalis omnibus acutis, a basi $\mathrm{v}$. a medio $\mathrm{v}$. apice tantum patentibus; filamentis antheris pollineque flavis; stylo sub authesi antheris duplo breviore. - T. Greigi RgI. Grtfl. 1873 tab. 773. - Acta h. Petrop. II. p. 428 et 448.

a. typica; sepalis sub authesi a basi v. a medio patentibus. (Cfr. Grtfl. tab. 773.)

ß. campanulata; sepalis sub antliesi apice tantum patentilus.

Variat floribus plus minus intense purpureis v. lutescentibus.

T. Alberti R.gl., foliis glaucis (pruina albida vestitis), immaculatis; sepalis exterioribus acutis v . acuminatis v. subito in cuspiden excurrentibus, interioribus conniventibus rotundato-obtusis $\mathrm{v}$. saepissime emarginatis $\mathrm{v}$. mucrone minimo inflexo in emarginatura; filamentis antheris pollineque fla-

*) Von den zahlreichen von Herrn A. Regel in dem Alatau gesammelten Zwiebeln von Tulipa, die alle in gänzlich verblühtem Zustande gesammelt worden sind, kamen in diesem Frühjahre viele in Biüthe und lieferten uus den Beweis, dass gerade dieser Theil Central-Asiens, die Heimath einer zahlreichen Menge von Arten dieser Gattung ist. Tulipa Greigi ist dort in zalılreichen Formen vertreten. Zwei andere verwandte Arten sind uns seitdem bekannt geworden, die eine in der Umgegend Baku's heimische, ward vou mir (Acta h. Petrop. III I. p. 156) als T. Eichleri beschrieben, die andere ward jetzt nebst T. Kaufmanni von A. Regel im Alatau gesammelt und unterscheidet sich durch nicht gefleckte blauweiss bereifte Blätter und mehr glockig urnenförmige Blumen mit inneru zusammen neigenden stumpfin Binmenblialtern. 
vis; stylo sub anthesi antheris paullo breviore. - Caulis brevis usque pedalis, triphyllus, sub lente minute puberulus. Folia anguste lanceolata usque elliptico-lanceolata, attenuato-acuta, plus minus undulata, florem superantia, hyalino-marginata. Flores coccinei v. purpurei v. e coccineo flavescentes.

In montibus Alatau fluvium T'schirtschik adjacentibus legit A. Regel.

T. Eichleri Rgl.; filamentis antherisque atroviolaceis, polline violaceo; stylo sub anthesi antheras subaequante. - Rgl. in Acta horti Petropolitani III. I. p. 156. - Grtfl. tab. 799.

\section{Tulipa Kaufmanniana Rgl.}

Bulbi tunicae intus praecipue apicem versus appresse strigoso-pilosae. Caulis diphyllus. Folia erecta, immarginata, lanceolato-oblonga v. elliptico-lanceolata, florem circiter aequantia, superius inferiore angustius. Pedunculus sub lente minutissime puberulus. Perigonii foliola campanulato-conniventia, elliptico- v. anguste elliptico-oblonga, obtusa v. interiora emarginata, omnia basi apiceque glabra. Filamenta antheras subaequantia, totidem glabra. Antherae lineares; loculis ab apice ad basin sensim dehiscentibus. 0varium brevissimum, filamentis duplotriplo brevius, stigmate sessili trigono.

Circiter $20 \mathrm{~cm}$. alta. Folia glabra, glaucescentia. Variat sepalis albis, intus basin versus croceis, exterioribus dorso rubris, - vel sepalis pallide flavis intus infra medium macula carminea notatis, exterioribus dorso rubris, - v. sepalis omnino purpureis.

In Turkestaniae montibus fluvium 'Tschirtschik adjacentibus, legit A. Regel.

Affinis T. suaveolenti et altaicae, ab ambabus ovarii constructione, praeterea caule bifolio a T. suaveolente, foliis immarginatis petalis obtusis a T. altaica diversa.

Blühet im freien Lande früher als alle andern Tulpen, kommt mit weiss und gelbgrundigen Blumen vor, deren äussere Blätter auf dem Rücken roth und mit weissem oder gelbem Rand, innen an Grunde gelb und der gelbe Fleck oben häufig roth gesäumt, oder die Blumen sind ganz purpur und nur im Grunde gelb. 


\section{Tulipa Kolpakowskiana Rgl.}

Bulbi tunicae intus apicem versus strigoso-pilosae, fuscae. Caulis triphyllus, uniflorus. Folia erecto-patentia v. patentia, undulata, obsolete cartilagineo-marginata, margine laevia v. scaberula, inferiora anguste-lanceolata v. lineari-lanceolata, superiora sublinearia. Pedunculus glaber. Perigonium erectum; sepala patentia, elliptico-lanceolata, usque lanceolata, omnia acuta v. rarius obtusiuscula flava, exteriora dorso saepissime rubescentia $\mathrm{v}$. virescentia $\mathrm{v}$. in varietate omnia purpurea, apice basique glabra. Stamina glabra. Filamenta antheris breviora v. eas subaequantia, omnino glabra. Pistillum filamenta subaequans v. iis brevius, stigmate parv0 capitato vix trilobo coronatum.

Species proxime affinis T. Gesneriana L., differt caule 3-4phyllo, foliis iminarginatis latioribus, perigonii phyllis campanulato-conniventibus saepissime obtusis, pistillo filamenta superante $\mathrm{v}$. antheras subaequante usque superante, stigmate magno trilobo.

In Turkestania prope Weruoje et in valle fluvii Alınatinka. (A. Regel).

\section{PLANTARUM IN HORTO BOTANICO IMPERIALI PETROPOLITANO CULTARUM DESCRIPTIONES, auctore E. REGEL.}

1. Allium Elwesi Rgl.

Glaberrimum. Bulbi depresso-globosi tunicis membranaceis, integerrimis, reticulo cellularum minuto regulari; caule spithamaeo, adscendenti, tereti, supra basin bifolio ; foliis linearibus, succulentis, supra canaliculatis, subtus convexis, caulem superantibus; umbella capsulifera, hemisphaerica, pluriflora; spatha membranaceo-hyalina, irregulariter bifida; spathae valvis late ovatis, breviter acuminatis, pedicellos superantibus; pedicellis initio flores aequantibus demum superantibus, basi nudis; sepalis 
ovatis, obtusis, roseis, stamina 1/3 superantibus; filamentis $\mathrm{A}$, basi latiore subulatis, simplicibus, inter se aequalibus, basi inter se et cum sepalorum basi in annulum brevem coalitis.

Caulis usque $17 \mathrm{Cm}$. altus. Umbella circiter 15-flora. Sepala 10-12 Mm. longa, exteriora $6 \mathrm{Mm}$. lata, interiora angustiora. Capsula globosa, loculis apice biapiculatis.

Recepimus ex horto Cl. Elwes. Patria verosimiliter Californiae alpes.

A. nevadensi Wats. (Rgl. All. p. 113) simillimum, differt autem "bulbi tunicis rete minuto regulari, caule bifolio, sepalis ovatis obtusis, filamentis basin versus magis dilatatis.»

2. Arabis lilacina Schrad. in ind. sem. h. Gött. 1832 p. I. (et in herb. Schraderi). (Foliis caulinis lineari-lanceolatis, sagittato-amplexicaulibus, serratis, glabris, glaucescentibus; racemis subsecundis; siliquis reflexis; seminibus subbiserialibus. Schrad. 1. c.)

Biennis. Folia radicalia lanceolata, in petiolum attenuata, canescentia, integerrima v. paucidentata. Folia caulina glabra, plus minus serrata. Semina siliquarum juniorum subbiserialia, maturarum uniserialia. - Huc pertinent.

Turritis retrofracta Hook. fl. bor. am. I. pag. 41. - Torr. et Gray fl. of N. Am. I. 79. - Arabis Turczaninowii Ledb. fl. ross. I. pag. 123. - Habitat in America boreali et in Sibiria orientali.

3. Begonia metallica (in G. Smith Floral Magazine Febr. 1876. tab. 197).

Caule erecto, ramoso, pilis setosis albis hirsuto; stipulis persistentibus, ovato-lanceolatis, acuminatis. sulbtus margineque setosis; foliis longe petiolatis, oblique cordato-ovatis, palmato-5-nerviis, irregulariter lobato-dentatis, utrinque petioloque hirsutis, supra metallice olivaceonitentibus, subtus purpurascentibus; pedunculis quam folia longioribus, puberulis; cyma dichotoma, multiflora; bracteis scariosis, persistentibus, setoso-fimbriatis hirsutisque; florum masculorum sepalis rotundato-ovatis, supra carneis, subtus ad basin setis purpureis barbatis hirsutisque;

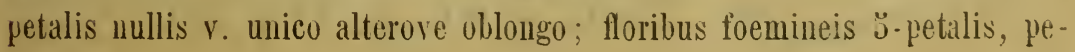


talis obovatis, ciliolatis; ovario inaequalier 3 -alato, fusco-hirsuto; alis duabus brevissimis, tertia elongato-ovato-oblonga, omnibus hirsutis.

A. specie proxime affini B. (Gireoudia) sericoneura Liebm. (D. C. prodr. XV. I. 336) foliis quinquenerviis, pedunculis puberulis, sepalis flor. masc. subtus fusco-barbatis etc. facile dignoscitur. - Patria ignota sed verosimiliter ex America tropica in hortos Angliae introducta.

\section{Calathea leopardina (Maranta) h. Bull.}

Calathea Körn. in mon. Marant. prodr. pars altera p. 111. sect. 3 .

Grandiflorae. Flores magni, staminodia duo extima maxima; spicae subbasilares.

C. leopardina (Rgl. Grtfl. 1877 p. 35. tab. 893), acaulis; foliis acuminatis; spicis sessilibus, subovatis; bracteis imbricatis, glaberrimis, e basi ovato-oblonga subvaginata in apicem patulum lanceolatum herbaceum excurrentibus; floribus in bractearum axilla saepissime binis, glaberrimis; corollae tubo gracili, bracteolam dorso bicarinatam paullo superante; staıninodiis externis petaloideis, flavis, ovato-subrotundis, apice emarginatis. - Folia elliptico-lanceolata v. elliptica, acuminata, glaberrima, nitentia, supra laete viridia, fasciis a nervo medio lateralibus atroviridibus lanceolatis acuminatis picta. Petiolus a basi sub apicem vaginatus, apice geniculo tereti terminatus. Staminodium intimum cucullatum, auricula subrostriformi. Appendix petaloidea staminis parva; anthera adnata. Stylus curvatus, stomatis truncati margo inferne non productus. - Maranta leopardina cat. horti W. Bull. 1876 p. 46. cum. icone. - II. concinna h. Bull.

Affinis C. excapae Koern. (Ph. excapum Poepp. Nova Gen. p. 18. tab. 25), quae foliis abrupte acuminatis, bracteis puberulis, stylo villoso etc. facile dignoscenda.

Variat: $\propto$ typica; foliis elliptico-lanceolatis. (M. leopardina h. Bull.)

ß. concinna; foliis ellipticis. (M. concinna h. Bull.)

Habitat in Brasilia.

5. Epidendrum Allardti Rgl. ( $\$ 6,0$ smophytum Lindl. in bot. reg. 1839 misc. 135. - Rchb. in Müll. ann VI. p. 354 ). 
Pseudobulbis subcompressis, laevibus, elongato-bblongis, apicem versus attenuatis, apice $2-3$-phyllis; foliis lanceolatis, obtusis v. s sabacutis, racemum terminalem 5-6-florum circiter aequantibus; floribus pedicellatis; sepalis petalisque horizontaliter patentibus, obverse lanceolatis, acutis, virescenti-flavidis, basi punctis sparsis purpureis notatis; labello adnato, late cordato, acuminato, albo, medio tantum purpureo striato.

Affine E. radiato, cochleato et lancifolio, - pseudobulborum figuratione, labello acuminato, sepalis petalisque angustioribus ab E. radiato, - petalis sepalisque horizontaliter patentibus nunquam acuminatis ab E. lancifolio, pseudobulborum configuratione, sepalis petalisque latioribus horizontaliter patentibus, labello acuminato ab E. cochleato, facile dignoscitur.

Patria verosimiliter Mexico.

Accepimus nomine E. tigrino ex horto Allardtiano.

\section{Homalonema Schott. (Schott Melet. 20).}

\section{A. Euhomalonema.}

Herbae caulescentes Indiam orientalem incolentes.

(Homalonema Schott. 1. c. - Endl. gen. pl. pag. 238. - Knth. enum. IV. 56. - Schott. prodr. Ar. p. 308).

Huc pertinent exceptione H. Wendlandi species ommes a Cl. Schottio I. c. enumeratae.

\section{B. Curmeria.}

Herbae acaules Americam tropicam incolentes.

(Curmeria Linden et André in ill. hort. 1873. p. 45 tab. 121). a. Folia cordato-hastata.

1. H. Wendlandi Schott. (prodr. Ar. p. 308); petiolo tereti, puberulo, vaginam plus duplo superante.

2. H. picturata (Curmeria picturata Linden et André 1. c.); petiolo supra canaliculato, dense ferrugineo-tomentoso, vaginam aequante $\mathrm{v}$. subaequante.

๖. Folia elliptica, basin versus attemuata. 
3. H. Roezli (Curmeria Roezli Masters in Gardn. Chron. 1874. II. p. 804 , fig. 159,160$)$; foliis acuminatis, basi acutis et ibidem in petiolum breviter decurrentibus; petiolo vaginam superante. - Glabra.

4. H. Wallisii Rgl. (Grtfl. 1876. p. 320); foliis breviter apiculato-acuminatis, in petiolum non decurrentibus, basiu versus rotundatis et ima basi subemarginatis; petiolo vagina breviore. - Curmeria Wallisii Bull. cat. 1877. p. 4 cum. xyl. - Masters gardn. Chron. 1877. p. 108 cum. xyl.

In Venezuela legit Wallis.

\section{Lilium concolor Salsb.}

(Salsb. Parad. tab. 47. - Knth. enum. IV. 259. - Bot. mag. tab. 1165. Baker in Journ. of Linn. Soc. XIV. 237.)

\section{Variat:}

๙. typicum; bulbis solitariis; foliis oblongo-lanceolatis, obscure 7-nerviis, $10-15 \mathrm{Mm}$. latis; sepalis intus obscure coccineis immaculatis, extus pallidioribus, apice paullo recurvis.

L. concolor cfr. auct. supra cit. - L. sinicum Lindl. in Paxt. fl. gard. II. tab. 193. - Lem. ill. hort. tab. 100. - L. concolor var. sinica Bot. mag. tab. 605. - Hab. in Japonia.

в pulchellum; bulbis solitariis; foliis late linearibus, $5-8$ IIm. latis, 3- v. obscure plurinerviis; sepalis coccineis, intus plus minus punctatis, apice vix recurvis.

L. pulchellum Fisch et Lallem. in ind. sem. h. Petr. 1840. pag. 56. — Grfl. tab. 284. — Ledb. fl. ross. IV. 152. - Turcz. cat. baic. n. 1134. - Knth. enum. IV. 266. 676. - L. Buschianum Lodd. bot. cab. tab. 1628. - L. concolor Buschianum Baker in Journ. of Liun. soc. XIV. 236. - L. concolor pulchellum Baker 1. c. 237. - Hab. in Dạuria et Mandschuria.

$\%$ partheneion; bulbis demum caespitosis; foliis anguste lanceolatis, 5-7 nerviis, 8-10 Mm. latis; sepalis pallide coccineis $v$. flavo-variegatis, intus punctatis. 
L. partheneion Sieb. et de Vriese in Tuing. 11. II. 1. 341 culn iv. Varietas culturae.

o. Coridion; sepalis acuminatis, sulphureis, intus purpure0punctatis. Cetera ut praecedentis.

L. Coridion Sieb. et De Vr. 1. c. p. 341. cum ic.

Varietas culturae.

ع. luteum; bulbis demum caespitosis; foliis lineari-lanceolatis, 5-7 Mm. latis, 3-nerviis; sepalis obtusis v. apice submarginatis, luteis, intus purpureo-maculatis.

L. concolor luteum Maxim in herb. Petrop. - Grtfl. 1876. tab. 885. - L. concolor pulchellum flaviflorum Baker in Journ. of Linn. soc. XIV. 237. - Habitat in China et Japonia.

8. Niphaea Roezli Rgl. (Grtfl. 1877. Gesneriaceae).

Caule humili, ramoso, nunc albido, nunc rufescenti hirsuto; propagulis cylindricis, squamis imbricatis glandulosis vestitis; foliis petiolatis; petiolis albido-hirsutis; lamina ovata, obtusa v. subacuta, basi rotundata, margine simpliciter crenata, supra rugosa, dense breviter pilosa, saturate viridis, subtus subvillosa, nervis elevatis plus minus rubescentibus reticulata; pedunculis in axillis petiolorum superiorum aggregatis, folium superantibus, glanduloso-pilosis, purpureis; calycis hirsuti tubo brevi purpureo, lobis oblongis viridibus; corollae parrae albidae lobis ovatis, apice rotundatis.

$A b$ affine specie «N. rubida» caule petiolisque viridibus, foliis margine simpliciter crenatis (nec grosse duplicato-crenatis), corollae plus duplo minoris lobis apice rotundatis, facile dignoscitur.

Roezl misit semina ex America tropica.

\section{Torenia exappendiculata Rgl.}

T. exappendiculata; hirtula, caule erecto ramisque diffusis quadrangularibus; foliis petiolatis, e basi subcordata ellipticis, acutis, nerris lateralibus latere superiore insigniter immersis subplicatis, dentatis; dentibus breviter mucronatis; fluribus in apice ramorum umbellato-fasciculiformibus: calycibus ovato-oblongis, subarqualiter quinquecostato-alatis, 
basi obtusis, bilabiatis; labio superiore apice breviter $2-3$-dentato, labio inferiore integerrimo v. apice breviter bidentato; corolla calyce circiter duplo longiore; filamentis exappendiculatis.

Corolla alba, circiter $22 \mathrm{Mm}$. longa, limbi vix $15 \mathrm{Mm}$. lati lobis lateralibus caeruleis, lobo antico albo, lobo inferiore leviter caerulescente fauce lute0. -

Affinis T. asiaticae et hirsutae, calyce quinquealato ovato-oblongo, corolla plus duplo minore, filamentis anticis basi exappendiculatis facile dignoscitur. -

Nomine T. ciliatae ex horto Parisiensi accepimus. Patria verosimiliter India orientalis.

10. Pentas carnea Benth. (in Bot. reg. XXX. tab. 32.)

a. typica; filamentis brevissimis antherisque tubo inclusis; stylo exserto. (Benth. l. c.)

3. macrostemon; filamentis elongatis e tubo exsertis; stylo incluso.

Semina legit Hildebrandt in insula St. Johanna Africae borealiorientalis.

11. Zamia muricata Willd. (Cfr. Acta h. Petr. IV. pag. 308.)

$\gamma$. Katzeri; petiolis aculeis crebris armatis, rhachibus basi parce aculeatis, perulis lanceolatis in acumen elongatum attenuatis, strobilis masculis acutis. - Ceratozamia Katzeriana Rgl. Acta h. Petr. IV. p. $298^{*}$ ).

*) Die von uns am angezogenen Orte beschriebene Pflanze hat jetzt gcblüht und Herr Katzer hatte die Freundlichkeit das betreffende Exemplar uns zuzusenden. Dasselbe blühete mit 5 männlichen Zapfen, welche diese Pflanze als eine Zamia dokumentirten, die in den Formenkreis von Zamia muricata gehört und namentlich mit der im Jahrgang 1856 der Verhandlungen der Berliner Academie der Wissenschaften von Karsten gegebenen Abbildung gut übereinstimmt, jedoch mit den oben in der Diagnose festgestellten Abweichungen. Auch der jetzt besser entwickelte Stamm stimmt mit dem Gattungscharakter von Zamia vollständig überein. 


\section{DESCRIPTIONES PLANTARUM}

NOVARUM ET MINUS COGNITARUM.

Fasciculus VI.

AUCTORE

E. RE GE L.

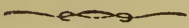

PETROPOLI.

18\%8.

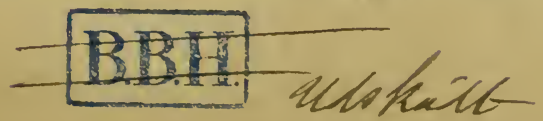





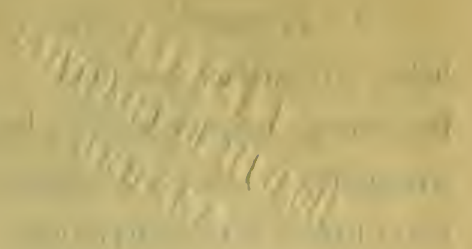

\section{A. PLANTAE REGIONES TURKESTANICAS INCOLENTES, SECUNDUM SPECIMINA SICCA \\ A REGELIO ET SCHMALHAUSENIO DETERMINATAE,}

\section{auctore E. Regel.}

\section{Rosaceae.}

1. Geum (Sieversia) karatavicum Rgl. et Schmalh.

Caules adscendentes, pedales et ultra, pilis brevibus intermixtisque longioribus subpubescentes, apice simpliciter v. iterato dichotomo-ramosi, floribus alaribus terminalibusque. Folia pubescentia v. subhirsuta; radicalia lyrato-pinnata; foliolis lateralibus paucijugis, subsessilibus, cuneatoobovatis $\mathrm{v}$. subcordato-ovatis $\mathrm{v}$. subrotundis, superne sublobatis duplicatodentatis: terminali maximo, cordato-ovato, sublobato, duplicato-dentato; caulina pauca, foliolis lateralibus foliorum radicalium similia $\mathrm{v}$. inferiora petiolata foliis radicalibus similia. Flores ignoti. Calyx fructifer extus pubescens, tubo turbinato, lobis elongatis lineari-lanceolatis acutis integris v. paucidentatis, bracteolis similibus minoribus. Achaenia 10-15, carpophoro stipitato tubo calycis breviore insidentia, linearioblonga, in rostrum rectum subulatum achaenium subduplo superans excurrentia, a basii ad medium patenter hirtula, medio glabra, apice setis reflexis dense barbata.

Habitat in Turkestaniae montibus Karatau (Scwerzow), prope Karagus in montibus karataricis (A. Regel). 


\section{Leguminosae.}

2. Trigonella orthoceras Kar. et Kir., annua; florum umbellis axillaribus sessii bus v. pedunculatis, 1-4-floris; leguminibus linearibus, compressiusculis, longis, rectis v. saepius plus minus arcuatis, irregulariter reticulato-areolatis, areolis longitudinalibus, apice stylo brevi paullo curvato terminatis.

T. orthoceras Kar. et Kir. in Bull. Mosq. XV. 339. - T. incisa Benth. in Royl. ill. Him. 197. - T. geminiflora Bunge in reliq. Lehm. p. 247 n. 306 . - T. Noëana Boiss. diagn. ser. II. fasc. II, p. 11. - T. monantha C. A. MI. ind. cauc. p. 137. - T. dicarpa C. A. MI. in herb. h. Petrop. -T. anatolica Boiss. diagn. ser. II, fasc. VI, p. 46. - Satis frequens in regionibus turkestanicis.

3. T. polycerata $L$, areolis leguminis transversis a praecedenti dignoscitur.

In Turkestaniae regionibus orientalibus.

4. Psoralea drupacea Bnge.

Bnge. reliq. Lehm. n. 320. - Boiss. fl. or. II. p. 187.

Perennis, herbacea, (nec fruticosa) caulibus 2-3-pedalibus, simplicibus v. apice parce ramosis. Folia simplicia v. trifoliata, foliolo superiore majore.

In regionibus turkestanicis satis frequens, inter Katta-kurgan et Pentschakent (Lehmann), in montibus karatavicis prope Boroldai et in deserto prope Taschkent (A. Regel), - in deserto inter fluvium SyrDarja et Taschkent, prope Samarkand (0. Fedtschenko), - in deserto inter Taschkent et Toi-Tiube (Korolkow).

Dhipelta Rgl. et Schmalh. (Genus novum).

Calycis campanulato-tubulosi dentes subulati, superiores minores. Petala unguiculata; vexillum erectum, apice bilobum, lobis rotundatis; alae oblongae; carina recta, obtusa, mutica, alas paullo superans, vexillo brevior. Stamina 10, vexillare liberum, caetera connata. Ovarium stipitatum, 4-ovulatum. Stylus filiformis, ovarium superans, stigmate capitato terminatus. Legumen didymum, stipite filiformi suffultum, sub- 
5

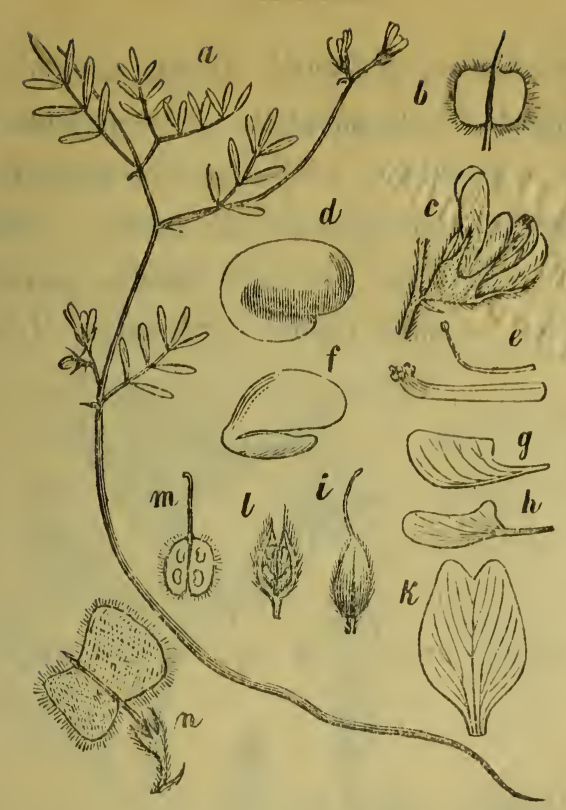

compresso-planum, septo angusto duplicato e sutura dorsali intruso in loculos duos ovato-subquadratos bispermos divisum; valvis navicularibus, quadrato-ovatis, compressis, nunc subaequalibus, nunc inaequalibus, margine integris, a legumine maturo saepe secedentibus et deciduis. Semina reniformia, compressa; cotyledones planae, radicula rimali adscendenti accumbentes.

Herba annua, pusilla, ramosa, pilis subadpressis simplicibus strigoso-hirta. Folia simpliciter impari-pinnata. Flores racemosi.

Habitu Astragali speciebus annuis affinis «leguminibus aequaliter v. inaequaliter didymis, compressis, loculis demum delapsis» insignis.

5. D. turkestanica.

Caulis crectus $\mathrm{v}$. adscendens, $5-7 \mathrm{Cm}$ altus, ramosus. Folia 3-juga cum impari, foliola lineari-oblonga, obtusa, utrinque strigosohirta. Stipulae liberae, srhulatae. Racemi axillares, folia superantes, pauciflori. Flores subsessiles, parvi, 3-4 NIm. longi, bracteola subulata suffulti. Calycis pilis nigrescentibus hirti dentes tubum plus duplo superantes, quain carina breviores.

Ilabitat in Turkestaniae montibus karatavicis prope Karagus. (A. Regel). 
Sewerzowia Rgl. et Schmalh. (Genus novum).

Calycis tubulosi dentes subulati, ad faucis latus inferius congesti. Petala longiuscule unguiculata; vexillum erectum, apice truncatum; alae oblongae; carina recta, obtusa, alis paullo brevior. Stamina 10 , vexillare liberum, caetera connata. 0varium sessile, pluriovulatum. Stylus brevis, crassiusculus, stigmate capitato terminatus. Legumen ellipticum,

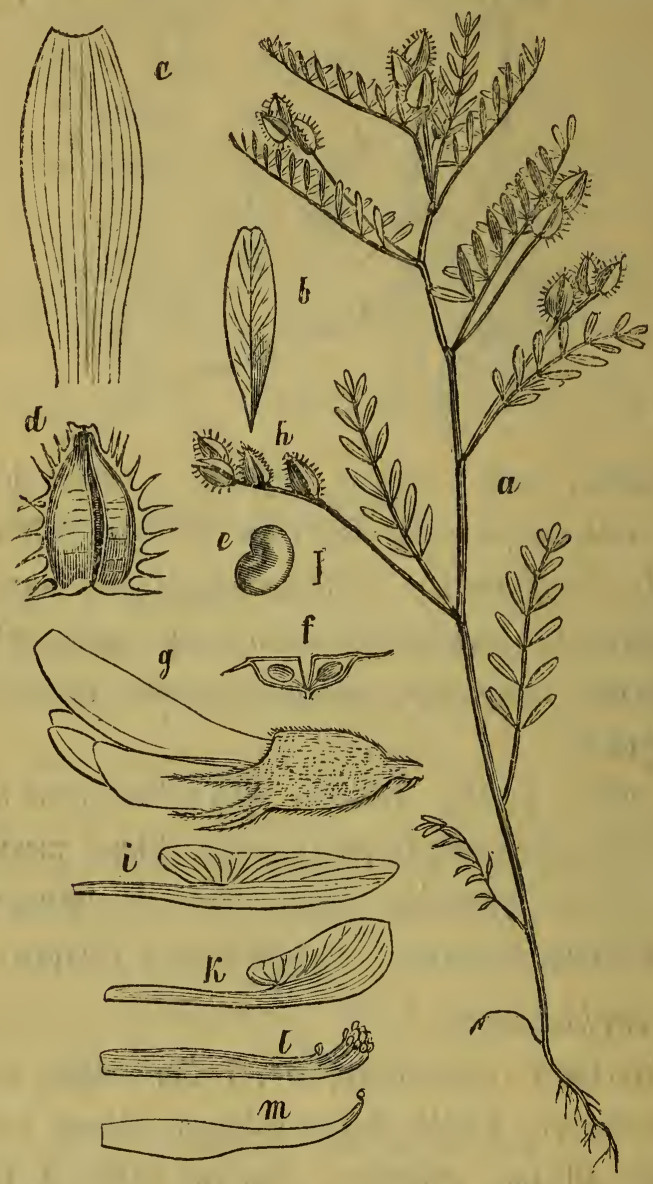

trigonum, dorso planum, ventre carinatum, intus septo duplicato e sutura dorsali intruso in loculos duos longitudinaliter divisum; septi membranae initio arcte connatae, in fructu maturo a sutura dorsali secedentes; valvis navicularibus, carinis (leguminis margines mentientibus) dentibus spinosis ciliatis. Semina compressa, reniformi-ovata. 
Herba annua, erecta. Folia impari-pinnata, alterna, stipulata; stipulae liberae subulatae; foliola exstipulata. Flores parvi, in racemos axillares, panci-plurifloros dispositi.

Genus novum, calycis leguminisque structura ab Astragalo et Biserrula facile dignoscendum.

\section{S. turkestanica Rgl. et Schmalh.}

Puberula. Caulis erectus, simplex v. basi ramosus, spithamaeus usque $40 \mathrm{Cm}$. altus. Foliola 8-10-juga, lineari-oblonga, apice truncato-emarginata. Racemi pedunculati, folium subaequantes v. superantes.

1 In regionibus turkestanicis ad fluvium Tschajan leg. Sewerzow, in deserto Kisilkum et in deserto inter Taschkent et fluvium Syr-Darja legit 0. Fedtschenko.

7. Alhagi camelorum Fisch. (ind. h. gorenk. 1812. p. 72.Ledb. fl. ross. I. pag. 715). - A. kirghisorum Schrenk enum. pl. nov. p. 84 .

$\alpha$. typica; omnino glabra.

$\beta$. canescens; caule foliisque utrinque v. foliis subtus tantum pilis brevibus adpressis subcanescentibus.

In regionibus turkestanicis satis communis.

Variat foliis angustioribus v. latioribus, spinas subaequantibus v. paullo superantibus v. iis duplo-pluries brevioribus, calyce manifeste $\mathbf{v}$. obsolete dentato.

\section{Pomaceae.}

\section{Pyrus heterophylla Rgl. et Schmalh.}

Fruticosa, glabra, ramis divaricatis v. horizontaliter patentibus, demum saepe in spinam brevem v. elongatam mutatis. Gemmae glabrae. Folia petiolo gracili filiformi suffulta, nunc integra v. bi- v. trifida, basi in petiolum plus minus decurrentia, nunc impari-pinnatifida v. subpinnatisecta; foliola $1-3$ juga, nunc omnia basi confluentia, nunc inferiora ad basin sessilem libera, superiora basi confluentia, omnia lanceolata v. linearilanceolata v. linearia crenato-serrulata; crenis glandula acuta demum 
decidua terminatis. Flores ignoti. Fructus terminales, pomacei, ut videtur satis duri, calyce persistente cupuliformi coronati, 5-loculares; loculis 2 -spermis, endocarpio cartilagineo. Fructus basi in petiolum apice incrassatum subattenuati, usque $2 \mathrm{Cm}$. longi, $2 \frac{1}{2} \mathrm{Cm}$. in diametro transversali.

In regionibus turkestanicis satis frequens occurrit.

In Kokania in trajectu Kindir-daban, in valle fluvii Sarawschan in montibus Aksai et inter Dscham et Aksai (0. Fedtschenko); in montibus alatavicis Turkestaniae, ad fluvium Maili (Krause), ad fluvium Tschirtschik (Sewerzow, Kuschakewicz), ad fluvium Tschotkal (A. Regel); in montibus karatavicis prope Bugun (Sewerzow), prope Boroldai et Kultschek (A. Regel).

\section{Tamariscineae.}

9. Tamarix polystachya Ledb. (fl. ross. II. 132) var. cerifera.

Ramuli juniores, folia et praecipue racemorum pedunculi rhaches et pedicelli globulis minutis ceraceis dense asperata.

Inter Taschkent et Karak-ata ad montes Manam-djan (Korolkow).

\section{Tamarix Korolkowi Rgl. et Schmalh.}

Glauca, glabra, cortice rufescenti-fusca. Folia ovata, subsemiamplexicaulia, acuminata, ramulorum imbricato-adpressa. Racemi in ramulis hornotinis creberrimi, solitarii, terminales racemosique, longissimi, gracillimi, latitudine sua multoties longiores. Bracteae lanceolatae, coloratae, pedicellum subaequantes v. eo breviores. Pedicelli calycem superantes. Flores pentandri; petalis roseis, ovatis v. ovato-oblongis, calycem triplo superantibus, mox deciduis; filamentis filiformibus, exsertis; antheris exapiculatis; disco quinquelobo. Ovarium e basi latiore in collum sensim sensinque attenuatum, stylis 3 obovatis patentibus coronatum.

T. leptostachys cui planta nostra habitu proxima, differt: «bracteis herbaceis e basi latiore subulatis calycem (incluso pedicello) aequantibus v. superantibus, petalis calycem duplo superantibus.

- In regno chivensi ad fluvium Amu-Darja prope Chasar-aspa in sepulcreto frequentissima (Korolkow). 


\section{Crassulaceae.}

\section{Umbilicus paniculatus Rgl. et Schmalh.}

Perennis, glaberrimus. Caulis erectus, simplex. Folia plana; radicalia rosulata, spathulato-obovata v. spathulato-oblonga, saepissime acuta; caulina sparsa, spathulato-oblonga v. lanceolata, acuta. Flores in paniculam spiciformem v. subpyramidatam terminalem dispositi, pedicellis florem subaequantibus v. eo brevioribus suffulti. Calycis 5-partiti laciniae ovato-lanceolatae, acutae, corolla circiter triplo breviores. Corollae ad medium 5 -fidae laciniae lanceolatae, acuminatae, nervo supra basin trifido percursae. Caulis. inclusa panicula $20-35 \mathrm{Cm}$. altus. Paniculae rami breves, pauci-pluriflori, floriferi patentes, fructiferi erecti. Bracteae lanceolatae v. lineari-lanceolatae, pedunculo pedicellisque breviores. Corolla circiter $6 \mathrm{Mm}$. longa, ut videtur pallide flava nervis rubicundis picta. Folia exsiccata eximie reticulato-nervosa.

Species proxime affinis U. platyphyllo Schrenk «foliis caule calycibusque pilis crassiusculis ubique adspersis, floribus racemoso-corymbosis, calycis corollaeque laciniis obtusis» facile dignoscitur.

In Kokaniae valle fluvii Sarawschan inter Varsaminor et Peti, $4500-60 n 0$ ped. alt., in montibus prope Daschty-Kasy, 4000 ped. alt. prope Van Sarvada, 6300 p. alt. (0. Fedtschenk0), - in Turkestaniae montibus alatavicis in valle fluvii Tschirtschik, 4-6000 ped. alt., et in valle fluvii Tschotkal, 4- -6000 ped. alt. (A. Regel).

12. Sedum Rhodiola $L$. var. linifolia. Foliis lineari-lanceolatis subintegerrimis v. plus minus grosse argute serratis, floribus purpureis.

Valde affine S. Rhodiolae var. Stephani, dignoscitur autem foliis minus profunde argute serratis $\mathrm{v}$. subintegerrimis, floribus purpureis.

In montibus alatavicis prope Wernoje leg. Kuschakewicz et Sewerzow.

13. Ribes heterotrichum C. A. Meyer. (Cfr. Ledb. fl. ross. II. 197).

\section{Variat:}

a. typicum Rgl. et Schmalh.; foliis suborbiculato-renifor- 
mibus, subtus petiolis racemisque setuloso-pilosis glandulosisque.

In Turkestaniae montibus Alexander (A. Regel), in montibus thianschanicis Jak-tasch 12000 ped. alt. (Scharnhorst).

ß. glabriusculum Rgl. et Schmalh.; foliis e basi rotundata v. rarius subcordata subrotundis, glabriusculis, eglandulosis, petiolis racemisque setuloso-pilosis.

In montibus alatavicis ad fluvium Almatinka prope Wernoje, in trajectu Karakia 8000 ped. alt., in montium Alexander trajectu Karabura 8000 ped. alt. (A. Regel).

\%. cuneatum Rgl. et Schmalh.; foliis e basi cuneata subrotundis. Cetera ut praecedentis. - Habitus R. saxatilis, inerme autem et indumento $R$. heterotrichi var. $\beta$.

In Kokania prope Isphairan (0. Fedtschenk0).

14. Ribes rubrum $L$. (Cfr. Maxim. diagn. pl. decas VI in Bull. Ac. Petr. 1873 tom. IX. p. 233).

Var. intermedia Rgl. et Schmalh., sepalis minute ciliatis, stylo cylindrico.

Stylo cylindrico (nec conico) solummodo a R. petraeo differt.

In regionibus turkestanicis et kokanicis satis frequens occurrit.

\section{Saxifragaceae.}

15. Saxifraga Alberti Rgl. et Schmalh.

1.1. Caudiculi suffruticulosi, foliis densissime vestiti, columniformes, caespitem densum magnum efformantes. Caules floriferi pilis glanduliferis hirtuli. Folia caudiculorum dense imbricata, lingulato-oblonga, supra concava, infra convexa et subcarinata, subaequilata, in apicem obtusiusculum attenuata, fere horizontaliter patentia, apice juxta marginem serie fovearum $3-5$ minutissimarum v. subobsoletarum notata v. peltis calcareis nonnullis foveas tegentibus instructa, sub lente a basi supra medium denticulato-ciliolata, caeterum glabra; folia caulium floriferorum sparsa, pilis setiformibus glanduliferis ciliata, lineari-lanceolata, apicem versus sensim attenuata. Flores in racemum corymbiformem $4-5$-florum ter- 
minalem glanduloso-hirtum collocati. Bracteae bracteolaeque lineares, pedicellum superantes. Calycis tubus late campanulatus, brevissime glanduloso-hirtulus; lobi tubum superantes, corolla plus duplo breviores; ovato-oblongi, coriacei (nec transparentes), dorso glandulis paucis breviter stipitatis hirtuli, margine vix glanduloso-ciliati. Petala obovata, obtusa, trinervia, ut videtur alba. - Caulis floriferus circiter $2 \mathrm{Cm}$. altus.

Affinis S. valdensi D. C. et $S$. ramulosae Wall., una differt, "foliis caudiculorum basi erectis, a medio recurvis, margine et in disco foveis numerosis, calycis laciniis apicem versus dorso glabris transparentibus, altera foliis caudiculorum oblong0-spathulatis juxta marginem 5-9 fovearum serie satis conspicuarum notatis, foliis caulium floriferorum apicem versus spathulato-dilatatis, floribus in caulium apice solitariis vel rarius binis».

In Turkestaniae montibus Alexander in tractu Karabura 8000 ped. alt. leg. A. Regel.

\section{Umbelliferae.}

\section{Carum chaerophylloides Rigl. et Schmalh. ")}

Glaberrimum. Bulbus depresso-globosus. Folia bi-tripinnatisecta; laciniis linearibus $\mathrm{v}$. anguste lineari-lanceolatis, acutis. Umbella pluriradiata, involucro involucelloque nullo. Flores albi, petalis acumine inflex0 obcordatis. Fructus lineari-cylinłrici.

\section{*) Carum Koch.}

Conspectus specierum in Imperio Rossico crescentium.

A. Involucrum uullum v. 1-2-phyllum.

a. Involucellum nullum.

1. C. Carvi $L$., radice fusiformi, fructibus ovato-oblongis.

2. C. chaerophylloides Rgl. et Schmalh., bulbo depresso-globoso, fructibus lineari-cylindricis $\mathrm{v}$. cylindricis.

b. Involucellum 1-4-phyllum.

3. C. atrosanguineum $K a r$. et $K i r$, foliis radicalibus pinnatisectis v. bipinnatisectis, foliolis oppositis sessilibus $\mathbf{v}$. breviter petiolatis; umbellae radiis valde inaequalibus; involucelli phyllis oblongolanceolatis; stylis recurvis stylopodio brevioribus. - Variat:

a. typicum; foliolis sessilibus trisectis, segmentis lateralibus laciniatis, terminali pinnatifido-5-1obo

C. atrosanguineum Kar. et Kir. enum. pl. song. n. 362 . 
Caulis 1-2-pedalis, plus minus ramosus, teres, laevis, striatus. Folia radicalia longe petiolata, trisecta; segmentis petiolatis, bipinnatisectis; foliorum caulinorum petiolis a basi ad apicem in vaginam inflatam margine scariosam mutatis. Umbella 10-16 radiata. Involucrum nullum v. monophyllum. Involucellum nullum. Calyx nullus. Fructus linearicylindricus, pedicello filiformi brevior, maturus ab apice ad basin partitus;

$\beta$. alpestre; foliolis brevissime petiolatis v. sessilibus, pinnatisectis, segmentis inferioribus 2-5-lobis. - C. indicum $\beta$. alpestre Herder in pl. Semenov. n. 433.

In montibus alativicis in salto Tubulgaty (Semenov), in angustiis Sulu-kastek prope Wernoje (A. Kuschakewicz).

$\gamma$ kokanicum; foliolis omnibus petiolatis. Cetera ut praecedentis.

In regionibus kokanicis prope Alui (O. Fedtschenko).

4. C. lomatocarum Boiss., foliis radicalibus bipinnatisectis; foliolis petiolatis, segmentis integris v. Jobatis, laciniis linearibus; umbellae radiis subaequalibus; involucelli phyllis capillaribus; stylis recurvis stylopodium superantibus. - Seseli alpinum M. B. fl. taur. cauc. I. p. 236. - Lomatocarum alpinum Fisch. et Mey. ind. sem. h. Petrop. VI. p. 17. - Carum lomatocarum Boiss. fl. or. II. p. 879 .

c. Involucellum polyphyllum.

5. C. heterophyllum Rgl. et Schmalh., foliorum caulinorum laciniis capillaribus; involucelli phyllis capillaribus ; stylis recurvatis stylopodio vix longioribus. - Habitat in regionibus kokanicis (Cfr. pl. Fedtschenkoanae).

6. C. elegans Fenzl., foliorum laciniis capillaribus; involucelli phyllis oblongis, scarioso-marginatis; stylis erectis $\nabla$. patulis, stylopodio 3-pluries longioribus. - C. elegans Fenzl. pug. n. 54. - Ledb. fl. ross. II. p. 883. - In Turkestaniae montibus karatavicis in promontorio Kcharli-tau (Sewerzow); prope Karnak (A. Regel), in Kokaniae valle fluvii Sarawschan inter Ulus et Dscham $(0$. Fedtschenko).

B. Involucrum et involucellum 4-polyphyllum.

a. Involucelli phylla late scárioso-marginata, uninervia.

C. apiculatum Kar. et Kir. enum. pl. song. n. 360. - Ledb. fl. ross. II. 260. - Foliorum bipinnatisectorum laciniis ovatooblongis in mucronem acuminatis, involucri involucellique phyllis oblongis acutis. Fructus maturi compressi ala cincti, ideo justa ratione $\mathrm{Cl}$. Trautvetter hanc speciem generi Peucedano sub nomine I. rapiferi adnumeravit.

7. C. trichophyllum Sclvenk. (Ledb. fl. ross. II. 250); radice globosa; 
mericarpia semicylindrica, 5 -juga; jugis filiformibus prominentibus albis; valleculis vitta unica lata fusca; commissura concava. Styli recurvi stylopodio paullo longiores. Carpophorum bipartitum.

A. C. Carvi L. bulbo depresso-globoso fructuumque configuratione aliisque notis facile dignoscitur. Valde affine etiam Chaerophyllo bulboso, differt autem : semine non sulcato, involucri involucellique defectu.

foliorum supradecompositorum laciniis setaceis acutis; involucri involucellique plyllis oblongis obtusis; fructibus elliptico-oblongis.

In Turkestaniae montibus alatavicis in valle fluvii Talas (A. Regel)

8. C chaerophylloides $R g l$. et Schmalh., ridice lignosa crassa subcylindrica, foliorum oblongorum tripinnatisectorum laciniis setaceis brevibus in acumen tenue excurrentibus, involucri involucellique phyllis lineari-oblongis, fructibus (immaturis) cylindricis quadruplo longioribus quam latis.

In Kokaniae valle fluvii Sarawschan, alt. $4000^{\prime}$ (O. Fedtschenko).

9. C. Sewerzowi $R g l$., radice (ut videtur) cylindrica, foliorum oblongorum supradecompositorum laciniis lineari-setaceis brevibus in callum tumidum acuminatum excurrentibus, involucri involucellique phyllis oblongis v. ovato-oblongis, fructibus immaturis oblongis duplo longioribus quam latis*).

b. Involucri involucellique phylla ovata, obtusissima, late scarioso-marginata, plúinervia.

11. C. bupleuroides Schrenk. (Cfr. Ledb. fl. ross. II. 250).

c. Involucri involucellique phylla subulata usque lineavi-lanceolata, herbacea, immarginata $v$. vix scarioso-marginata.

12. C. Bulbocastanum L. (Cir. Ledb. fl. ross. II. 2ł8), foliis trisectis, segmentis pinnati- v. bipinnatisectis, laciniis remotis anguste lineari-lanceolatis v. lineari-oblongis; pedicellis fructiferis erectis quam fructus lineari-oblongi subaequilongis $v$. longioribus.

13. C. buriaticum Turcz. (cfr. Ledb. fl. ross. II. 249); foliis bipinnatiusque tripinnatisectis, laciniis linearibus; pedicellis fructiferis erectis v. patentibus fructu ovato-oblongo duplo-pluries longioribus.

14. C. cylindricum Boiss., foliis bi-tripinnatisectis, laciniis linearibus brevibus. - C. cylindricum Boiss. et Hoh. diagn. ser. I. fasc. 10. pag. 23. - Boiss. fl. or. II. 885. - Chaerophyllum tuberosum C. A. M. in herb. lhorti Petrop.

15. C. setaceum Schrenk. (Cfi. Ledb. fl. ross. II. p. 249); foliorum supracompositorum laciniis setaceo-capillaribus.

*) Species n. 8 et 9 adhuc fructibus immaturis tantum notac. 
In Turkestaniae montibus karatavicis in promontorio Mogol-tau et prope Jani-kurgan (Sewerzow), inter Taschkent et Keles, in hortis urbis Taschkent (0. Fedtschenk0 et Krause), in Kokaniae valle fluvii Sarawschan, in deserto Karak, prope Samarkand (0. Fedtschenk0).

Species nostra cum C. cylindrico Boiss., sectionem intermediam inter genera Carum et Chaerophyllum sistere videtur; fructibus figuratione Chaerophylli, albumine esulcato ut in Caro.

\section{Carum Sewerzowi Rgl.}

Glabrum. Foliorum 3-pinnatisectorum laciniis lineari-subulatis, apice callo tumido acuminato terminatis; involucris involucellisque polyphyllis, phyllis albido-scariosis; involucri phyllis ovato-oblongis, acutis v. obtusis, uninerviis v. basi tantum trinerviis; involucelli phyllis oblongolanceolatis, acutis, uninerviis.

Radix ignota, collo fibris foliorum emortuorum vestito. Caulis e basi ramosissimus, $1-2$ pedes altus. Folia caulina saepe ad vaginas reducta. Umbellae 10-multiradiatae. Flores albi, petalis ovato-subrotundis, in caudam involutam productis. Fructus juniores elliptico-oblongi, stylis recurvis stylopodio longioribus terminati. Nericarpia jugis 5-linearibus. Fructus maturi ignoti.

Carum bupleuroides Herd. pl. Semenov. n. 432 ex parte.

In Turkestaniae montibus karatavicis in promontorio Mogol-tau, legit Sewerzow.

18. Conopodium allioides Rgl. et Schmalh. (Scaligeria sect. II. Elaeostica).

Glabrum. Bulbus depresso-globosus. Caulis erectus, ramosus, teres, foliosus, albido-striatus, $1 \frac{1}{2}-2 \frac{1}{2}$ pedes altus. Folia tripinnatisecta; laciniis lineari-setaceis, petiolo brevi vaginato suffulta. Umbella pluriradiata, radiis $1-1 \frac{1}{2} \mathrm{Cm}$. longis. Involucra involucellaque polyphylla. Involucri phylla lineari-lanceolata, acuminata, albido-scariosa, medio $3-5$-nervia, initio radios circiter aequantia, demum iis breviora. Involucelli phylla $5-6$, demum conniventia, flores superantia et post anthesin occultantia, lanceolata v. ovato-lanceolata v. ovata, cuspidata, albido- 
hyalina et saepe roseo tincta, medio 1-3-nervia, florem Allii aemulantia, $4-5^{1} / 2 \mathrm{Mm}$. longa. Flores numerosi, breviter pedicellati, quain involucelli phylla subduplo-breviores; petala late ovato-subrotunda, acumine inflexo subemarginata, alba v. rosea. Fructus parvi, ovato-oblongi, sub lente minute hirtuli, stylis recurvis stylopodio paullo longioribus terminati; mericarpia dorso convexa, 5-juga; jugis filiformibus; valleculac vittaeque obsoletae; commissura profunde sulcata. Carpophorum bipartitum. Semen facie profunde sulcatum, sulco leviter bisulcato.

Affine Conopodio glaucescenti (Bunium glaucescens D. C. - Scaligeria glaucescens Boiss. fl. or. II. 877. - Butinia glaucescens Boiss. in Ann. sc. nat. 1844. pag. 61. - Elacosticta glaucescens Boiss. diagn. ser. I. fasc. 10. pag. 51), differt autem toto coelo «bulbo depressogloboso, involucelli phyllis demum conniventibus (nec reflexis) flores fructusque occultantibus, pedicellos duplo superantibus, fructibus sub lente hirtulis». - Carum bupleuroides Schrenk, cui planta nostra similis est, non solum semine non sulcato, sed etiam radiis involucro duplo triploque longioribus, involucelli phyllis obtusis demum reflexis flores fructusque circiter aequantibus, fructibus glabris oblongis, facile dignoscitur.

In Turkestaniae montibus alatavicis inter Bugun et Boroldai, in montibus alatavicis prope Kokschar $\left(6-7000^{\prime}\right.$ alt.), prope Aischmara in valle fluvii Tschotkal $\left(6000^{\prime}\right.$ alt.) leg. A. Regel.

19. Deverra Korolkowi Rgl. et Schmalh. (Deverra sect. II. Pithuranthus Viv. cfr. D. C. prodr. IV. 144).

Caulis erectus, ramosus, foliosus, teres, striato-subangulatus, sub lente minutissime laxeque viscido-hirtulus, demum glaber. Folia minute viscido-hirtula, inferiora bipinnatisecta, superiora decrescenti-minora pinnatisecta, laciniis lineari-subulatis. Umbellae 8-16 radiatae; radiis subaequalibus, patentibus, involucro $2-\frac{1}{4}$-plo longioribus, sub lente minutissime laxeque viscido-hirtulis. Involucrorum involucellorunque 5 -6-phyllorum phyllis viridibus, lineari-lanceolatis, viscidis. Pedicelli involucellum circiter aequantes. Fructus ovatus, a latere compressus. Mericarpia tuberculis squamuliformibus omnino vestita; jugis 5 , filifor- 
mibus, paullo elevatis; valleculis univittatis; commissura plana, bivittata. Styli duo, recurvi, stylopodio paullo longiores. Carpophorum bivittatum. Semen teres.

Radix et folia radicalia ignota. Flores albi; petala subrotunda, acumine inflexo emarginata. Calycis dentes obsoleti. Fructus sapore eorum Pimpinelli Anisi.

In hortis urbis Chiva cultum sub nomine Mumuk. (Korolkow).

20. Angelica songorica Rgl. et Schmalh. (Sectio III. Archangelica) *).

Caulis cavus, glaber, elevato-striatus. Folia pinnatisecta v. bipinnatisecta, v. tripinnatisecta, foliolis e basi subcordata v. rotundata v. cuneata ovatis v. late ovatis v. subrotundis, obtusis v. acutis, crenatodentatis, supra glabriusculis $v$. hirtulis, subtus praecipue ad rete venarum hirtulis, inferioribus saepe breviter petiolatis, superioribus sessilibus vix v. non decurrentibus, omnibus integris v. terminalibus confluentibus et plus minus lobatis. Umbella multiradiata, involucrum nullum. Umbellula multiflora, hirtula; involucelli polyphylli phyllis lineari-subulatis, pedicellos subaequantibus, hirtulis. Calycis margo obsoletus. Petala oblongolanceolata, acuminata, acumine incurvato, dorso plus minus hirtula. Stylopodii plano-depressi margo elevatus, undulatus, subcrenatus. Styli

*) Angelica $\mathbf{L}$.

(Vittae pericarpii endocarpio instructae).

SECTIO I. Euangelica. Endocarpium pericarpii stratis exterioribus adhaerens. Valleculae univittatae.

A. montana Schleich., A. pachyptera Lallem., A. sylvestris L., A. saxatilis Turcz., A dura C. Koch., A. ursina Rupr., A. refracta F. Schmidt.

SECTIO II. Mesangelica.

Endocarpium semini adhaerens, a pericarpii stratis exterioribus dissolutum, vittis 4 instructum, quae valleculis oppositae sunt.

A. tornata Rgl. et Schmalh.

SECTIO III. Archangelica.

Endocarpium semini adhaerens, a pericarpii stratis exterioribus dissolutum, vittis multis instructum.

A. decurrens Ledb., A. officinalis Hofm., A. songorica Rgl. et Schmalh. 
demum recurvi stylopodium superantes. Fructus ovato-oblongus, a dorso subcompressus. Mericarpii jugis alatis, marginalibus latioribus, sub hiantibus. Endocarpium semini adhaerens, a pericarpii stratis exterioribus dissolutum, vittis numerosis iustructum. Semen dorso convexum, latere interiore commissurae opposito subreniformi excavatum. - Caulis 8-35 Cin. altus.

Foliola $4-10 \mathrm{Cm}$. longa, $3-6 \mathrm{Cm}$. lata. Petioli foliorum caulinorum basi v. totidem saccato-inflati.

Archangelica decurrens $\beta$. alpina Herder in pl. Semenov. n. 452. Angelica (Archangelica) decurrens Ledb. cui species nostra proxima, «foliorum laciniis oblongis $\mathrm{v}$. ovato-oblongis acuminatis longe decurrentibus terminali trilobo, petalis ellipticis acuminatis, stylopodio conico» dignoscitur *).

a. ovalifolia; foliis pinnatisectis $\mathrm{v}$. bipinnatisectis, foliolis ovatis obtusis $\nabla$. acutiusculis, $\breve{b}-10 \mathrm{Cm}$. longis.

In promontoriis jugorum Tarbagatai et Alatau (Schrenk), in jugis montium Alexander in trajectu Karabura $8000^{\prime}$ alt. (A. Regel), in montibus Thianschan in valle fluvii Kok-djar, 8000' alt. (Semenow).

$\beta$. rotundifolia; foliis bi- $v$. tripinnatisectis, foliolis omnibus subrotundis obtusis, $1 \frac{1}{2}-6 \mathrm{Cm}$. longis.

In Kokania inter juga Isphairan et glacies Tentis-bai, 8-11,000 alt., ad glacies Tschzurowski, 8-10,000' alt. et in trajectu Dschiptik, $8-12,000^{\prime}$ alt. (0. Fedtschenko).

\section{Ferula penninervis Rgl. et Schmalh. **)}

Glabra. Caulis elatus, crassus, teres, medulla farctus, apice paniculato-ramosissimus. Folia maxima, decrescentia; inferiora et intermedia

*) Ledebour nennt den Kelchrand bei Archangelica 5-zähnig, es ist hier aber kein Kelchrand vorhanden, sondern offenbar der stark wellige und meist etwas aufgerichtete Rand des Stylopodiums dafür genommen worden.

**) Ferula L.

SECTIO I. Ferulae legitimae.

Foliorum lobi v. foliola angusta, linearia v. lineari-lanceolata.

a. Vittae in valleculis solitariae. Calycis margo olsoletus.

F. penninervis Rgl. et Schmall. 
petiolo tereti elongato basi vagina amplexicauli suffulta; superiora petiolo totidem vaginato instructa, suprema petiolo vaginato aphylla. Foliorum inferiorum lamina trisecta; segmentis petiolatis, $4-5$ tuplicato-pinnatisectis; laciniis planis, anguste lineari-lanceolatis, utrinque attenuatis margine repando-subcrenatis, eximie penninerviis, $1 \frac{1}{2}-5 \mathrm{~cm}$. longis, 3-4 Min. latis. Umbellae multiflorae, in caule ramisque terminales; centrales breviter v. longiuscule pedicellatae, foemineae, sub apice proliferae; laterales longius pedunculatae, saepissime 2, masculae. Involucrum nullum. Involucellum umbellularum mascularum polyphyllum, phyllis parvis, mox deciduis, umbellularum foeminearum nullum. Unbellula multiflora, pedicelli fructum aequantes $v$. paullo superantes.

b Vittae in valleculis solitariae. Calycis margo dentatus.

F. Karatavica Rgl. et Schmalh.

F. ceratophylla Rigl. et Schmalh.

F: Olgae Rgl et Schmalh. (Cfr. pl. Fedtsch.).

F. Schair Borszcz.

c. Vittae in valleculis $2-5$.

F. Karelini Bnge.

SECTIO II. Asa foetida. (Foliorum laciniae amplae lanceolatae usque ovatae).

A. Scorodosma Bnge.

Fructus vittis numerosis minutissimis oculo forte armato tantum conspicuis $\nabla$. subobsoletis instructus.

F. foetida Bnge. (Reliq. Lehm. n. 549. - Borszczow über die Asa foetida Pflanzen in Mem. Ac. Petrop. ser. VII. tom. III. tab. 1 et 2$)$; foliorum laciniis integerrimis, umbellulis villosis, petalis umbellarum foeminearum magnis albis obtusis, diu persistentibus, mericarpii dorso puberuli alls semine paullo tantum angustioribus, vittis numerosis oculo forte armato tantum conspicuis. Turkestania.

F. Asa foetida Boiss. (Fl. orient. II. p. 994 exclusis synonymis); foliorum foliolis integerrimis; petalis luteis mox deciduis, pedicellis villosis brevissimis demum incrassatis, fructu ovato v. suborbiculato puberulo v. glabrescente, ala dimidio semine sublatiore cinctis, mericarpii vittis numerosis oculo forte armato tantum conspicuis. Persia.

F. alliacea Boiss. (Fl. orient. II. p. 995); foliorum cinereo-tomentellorum foliolis obtuse dentatis, pedicellis brevissimis incrassatis, fructus ovatooblongi margine semine quintuplo angustiore, mericarpii vittis obsoletis indistinctis. - F. Assa foetida Boiss. et Buhse Autzählnng pag. 100 (mihi ignota). - Persia.

F. rubricaulis Boiss. (Fl. orient. II. 995); differt secundum adumbrationem Cl. Boissieri solummodo "pedicellis fructiferis vix incrassatis (an glabris), mericarpii vittis numerosis tenuissimis" a F. Asa foetida Boiss. - Persia. 
Calycis margo obsoletus. Petala ovato-oblonga, acuminata, apice incurva, lutea Stylopodium carnosum, cyathiforme, margine crenulatum. Styli recurvi stylopodium paullo superantes. Fructus ovato-oblongus, alá semen dimidium subaequante cinctus. Nericarpia plano-compressa, dorso 3 -juga; jugis filiformibus vix elevatis; commissura plana; vallecularum vittae latae solitariae; commissura vittis duabus latis maximis, alae vittis duabus parvis.

Gigantea; caulis inclusa panicula 5-6-pedes altus, basi usque $4 \mathrm{Cm}$. in diametro, striatus. Folia inferiora incluso petiolo usque 3-pedes longa.

Affinis species Ferula songorica Pall. differt, «caule minus robusto

\section{B. Euferula.}

Mericarpia vittis vallecularum dorsalium 1-3-jugis evittatis, cummissura 6-vittata. Umbellae in uno eodem specimine aut omnes terminales pedunculatae, aut centralis sessilis foeminea lateralibus e basi v. infra basin umbellae centralis egredientibus pedunculatis polygamis.

$F$. foetidissima $R g l$. et Schmalh., foliorum minute hirtulorum foliolis simpliciter v. duplicato, crenato-serratis, pedicellis brevibus glabris non incrassatis, fructus ovato-oblongi foetidissimi ala semine quadruplo breviore. Turkestania.

\section{Ferulago.}

Mericarpii valleculae 4-5-vittatae; commissura 12-14-vittata, vittis dorsalibus pericarpio tectss, commissuralibus superficialibus.

F. Kokanica Rgl. et Schmalh., foliorum laxe hirto-scabrorum foliolis serratis. Kokania.

\section{Juga vittata:}

Mericarpii valleculae jugaque univittata, vallecularum vitta diametro longitudinali suo semini parallela, jugorum vitta diametro longitudinali in semine perpendiculari.

Ferula diversivittata $R g l$ et Schmalh., foliorum foliolis integerrimis: Turkestania.

\section{E. Doremoides}

Mericarpii valleculae 3 -4-vittatae. Umbellae terminales pauciradiatae, umbelluiae laterales plus minus numerosae briviter pedunculatae in racemum dispositae.

F. Tschzurowstiana Rgl et Sclemall. *)

In Kokaniae montibus.

*) Ad honorem praesidis societatis mosquensis amicorum scientiarum naturalium viri illustris 'Tschzurowski eam nominavimus. 
humiliore, foliorum laciniis angustioribus $1-1 \frac{1}{2} \mathrm{Mm}$. latis uninerviis (nec fenninerviis) margine integerrimis, umbellulis foemineis masculisque involucello polyphyllo fultis.

In Turkestàniae montibus karatavicis prope Karagus, in montibus alatavicis in valle fluvii Tschirtschik $4-6000^{\prime}$ alt. (A. Regel).

\section{Ferula karatavica Rgl. et Schmalh.}

Glabra. Caulis elatus, teres, laevis, glaber, paniculato-ramosus, ramis saepe verticillatis. Folia inferiora ainpla, biternato-supradecomposita, petiolata; petiolus teres, basi vaginatus; segmenta primaria et secundaria petiolata; secundaria oblonga, bipinnatisecta; laciniae lineari setaceae, marginibus involutis teretes, elongatae, mucronatoacutae; folia caulina intermedia minus dissecta, petiolo inflato-vaginato amplexicauli v. brevi tereti vagina inflata insidente; folia superiora ad vaginam inflatam amplexicaulem reducta. Paniculae aphyllae rami ramulique verticillati, oppositi v. alterni. Umbellae $6-10$-radiatae, omnes pedunculatae, centrales pedunculo paullo breviore suffultae. Involucrum nullum. Umbellulae multiflorae; involucelli pleiophylli phyllis minimis brevissimis late triangulari-ovatis demum obsoletis; pedicellis fructu 3-plo longioribus. Calycis margo 5 -dentatus, dentibus brevissimis subobsoletis Stylopodii depressi margo undulatus elevatus. Styli recurvi stylopodium superantes. Fructus ovato-oblongi, plano-compressi. Mericarpia jugis tribus dorsalibus carinatis, lateralibus obsoletis in marginem dilatatum abeuntibus; valleculae vitta solitaria magna instructae; commissura plana $4-6$-vittata.

Planta perennis, 3-4-pedes alta, basi foliata, superne valde paniculato-ramosa, nuda. Foliorum laciniae teretes, $1-1^{1} / 2 \mathrm{Cm}$. longae, $1 / 3-1 / 2 \mathrm{Mm}$. latae. Umbella centralis fertilis, pedunculo $5-8 \mathrm{~cm}$. longo suffulta; umbellae laterales $2-3$, longius pedunculatae, masculae v. polygamae. Pedicelli fructifcri circiter $2 \mathrm{Cm}$. longi. Fructus 7 Min. longus.

F. anatolicae Boiss. ut videtur valde affinis, secundum descriptionem $\mathrm{Cl}$. Boissieri diversa videtur: «ramis inflorescentiae basi nudis 
(nec basi vaginatis), involucelli phyllis brevissimis late ovato-triangularibus (nec lineari-lanceolatis), calycis dentibus brevissimis subobsoletis (nec triangulari-subulatis)». Fructus F. anatolicae ignotus.

In Turkestaniae montibus karatavicis prope Boroldai. (A. Regel).

\section{F'erula ceratophylla Rgl. et Schmalh.}

Glabra. Caulis 2-3-pedes altus, paniculato-ramosus, teres, striatus, medulla farctus, basi fibris foliorum emortuorum vestitus, usque ad florum paniculam nudam foliatus. Folia rigida; inferiora iterato-trisecta, petiolo communi tereti supra medium in vaginam inflatam amplexicaulem mutatu; superiora minus dissecta, in vaginae amplexicaulis inflatae apice sessilia; suprema ad vaginam reducta; foliorum segmenta petiolo semitereti suffulta; lobi lineares, canaliculato-carinati, apice ipso saepissime dentibus corniformibus tribus v. rarius duobus, caeterum integerrimi v. sub apice dentibus similibus nonullis. Umbellae 4-10-radiatae; centralis sessilis, fertilis; laterales pedunculatae, saepissime 2 , masculae $\nabla$. polygamae. Involucra involucellaque nulla. Calycis dentes florum masculorum ovati, satis conspicui, reflexo-patentes, florum foemineorum minuti. Petala flava, ovata, incurva Stylopodium depresso-conicum, parvum. Styli recurvi, breves, stylopodium subaequantes. Fructus glabri, elliptico-oblongi, plano-compressi; mericarpia jugis dorsalibus tribus filiformibus vix elevatis, lateralibus obsoletis in marginem dilatatuin abeuntibus. Valleculae univittatae; commissura 4-6-vittata; vittis latis, in sectione trar sversali lineari-oblongis.

Species foliorum forma insignis. Folia et vaginae valde rigida, coriacea, glauca, nervis albis prominentibus parallelis striata. Foliorum lobi $1 / 2-3 \mathrm{Cm}$. longi, $1 \frac{1}{2} 2-2 \mathrm{Mm}$. lati, a basi ad apicem corniformidentatum aequilati. Umbellarum radii $2-3 \mathrm{~cm}$. longi, patentes. Pedunculi umbellarum lateralium $4-5 \mathrm{~cm}$. longi. Pedicelli florum foemineorum masculorumque $2-4 \mathrm{Nm}$. longi. Fructus $1 \mathrm{Cm}$. et paullo ultra longus et $3 \frac{1}{2} \mathrm{HIm}$. latus.

In Turkestaniae montibus Karatau prope hultschek et ad montem liara-Tschokla prope Bala-kschiata, 5000' alt. (A. Regel). 
Es ist diese ausgezeichnete Art auch noch dadurch interessant, dass sie an den Blättern und zwischen den Blüthendolden, einen durchsichtigen, dem Gummi galbanum ähnlichen Gummi ausscheidet.

24. Ferula Schair Borszcz. (Borszczow in Mem. Ac. Petrop. ser. VII. tom. III. Abhandl. n. 8 pag. 37 tab. VII.)

Diese in der Wüste Kisil-Kumi, Karaksk, Tschardara etc. von 0. Fedtschenko und in den Steppen auf der Reise nach Chiwa von Korolkow gesammelte Pflanze, weicht von Borszczow's Beschreibung nur dadurch ab, dass sie blaugrün und nicht wie der Autor sagt purpurviolett ist, ferner sind die Blattlappen unserer getrockneten Exemplare flach und nicht medio sulcata wie Borszczow angiebt. Auf der Abbildung giebt Fig. 8 c. Borszczow den Durchschnitt einer Frucht, der vom Rücken zusammengepresst oval und oline seitliche flache Flügel und deren vittae im Durchschnitte rundlich sind. Bei unserer Pflanze sind die Früchte ziemlich flach zusammengepresst und die vittae im Querdurchschnitt länglich und viel weniger geöffnet. Da aber Borszczow's Beschreibung gerade mit der Form der Frucht und der vittae übereinstimmt, wie solche sich bei unserer Pflanze vorfinden, so scheint hier ein Versehen des Zeichners der sonst vorzüglich guten Tafeln vorzuliegen und wir zweifeln nicht, dass die uns vorliegenden Exemplare die ächte Ferula Schair Borszcz. darstellen.

25. Ferula Karelini Bnge. (reliq. Lehm. n. 544).

Fructuum valleculae $3-5$-vittatae, commissura $6-10$-vittata.

In deserto aralensi in regione fluvii Syr-Darja (Borszczow), in desertis arenosis inter Orsk et Taschkent, Karak et Kisil-kum (0. Fedtschenk0), in deserto inter Karak-ati et Adam-kirullan in exped. ad Chiwam (Korolkow), prope Orenburg (A. Regel).

26. Peucedanum Renardi Rgl. et Schmalh. *) Sectio. Eupeucedanum. (Boiss. fl. or. II. 1014. Foliorum laciniae planae.

*) Dedicavimus hane speciem Cl. viro «Renard Societatis Scientiarum naturalium Imperialis Mosquensis praesidi sccundo. 
Hericarpia anguste alata. Valleculac univittatae. involucrum oligophyllum v. nullum).

Glabrum. Radix perennis, pluricaulis, collo fibris foliorum emortuorum vestito. Caules $30-40 \mathrm{~cm}$. alti, ramosi. Folia petiolata; petiolus foliorum inferiorum basi vaginatus, foliorum supremorum in vaginam linearem v. anguste lineari-lanceolatam (nec inflatam) foliiferam v. supremorum aphyllam mutatus. Folia inferiora trisecta; segmenta petiolata, bipinnatisecta; intermedia trisecta, segmentis pinnatisectis; suprema ad vaginam reducta; foliorum laciniae anguste lineari-lanccolatae, in mucronem attenuatae, 5-8 Mm longae, 1-2 Mm. latae. Involucra et involucella nulla. Umbellae 6-10-radiatae, polygamae; radiis inaequalibus. Umbellulac pluriflorae; pedicelli fructu sesqui-duplo longiores. Petala flava, subrotunda, acumine incurvo. Fructus planocompressi, ala angusta quam semen quintuplo angustiore cincti. Calycis laciniae lanceolatae, satis conspicuae. Stylopodii cyathiformis margo erectus, crenatus. Styli recurvi, stylopodium vix aequantes. Hericarpia jugis dorsalibus tribus filiformibus, apicem versus tantum prominentibus. Valleculae univittatae; juga evittata. Commissura apice tantum bivittata, a basi sub apicem evittata. Vittae omnes superficiales.

Peucedanum transiliense Herd. pl. Semenov. n. 455, cui species nostra proxima «caule $40-90 \mathrm{Cm}$. alto, foliis glaucis, vaginis foliorum superiorum inflatis et imprimis stylopodii depresso-conici margine deflexo nec erecto», facile dignoscitur.

P. Meyeri Boiss. (fl. or. Il p. 1018. - P. pancifolium Ledb.) cui P. Renardi habitu proximum, differt, «involucello polyphyllo, valleculis univittatis, jugis univittatis, jugorum vitta magna orbiculari supra fasciculum vasorum posita, fructu ala semine triplo angustiore cincto,

Peucedanum Meyeri Boiss. ist im Habitus unserer Pflanze sehr ähnlich. Wir haben die Analyse der Frucht desselben sowohl nach von Boissier, als von Ledebour stammenden Originalexemplaren gemacht. Beide Antoren erwähnen nichts von der grossen vitta in jeder Rippe, die oberhalb des kleinen Gefässbündels liegt. Boissier sagt von der Zahl der vittae in jedem Thälchen nichts, und Ledebour giebt $2-3$ vittae für jedes Thälchen an, während stets nur eine vitta vorhanden ist. 
commissura ab apice ad basin bivittata, stylopodii conici margine deflexo (non erecto), calycis dentibus subobsoletis».

In Turkestaniae montibus A'lexander in trajectu Karabura $8,000^{\prime}$ alt.

\section{Peucedanum karataviense Rgl. et Schmalh.}

Radix perennis. Caules glabri, a basi ramosi, teretes, laeves, $10-15 \mathrm{~cm}$. alti Folia radicalia petiolo brevi basi vaginato suffulta, dense cano-hirta, trisecta; segmentis tripinnatisectis; laciniis linearioblongis, acutis, 2-4 Mm. longis, vix $1 \mathrm{Mm}$. latis; folia caulina nunc omnia ad vaginam inflatam cano-puberulam v. demum glabram reducta, nunc folium $v$. folia infima radicalibus multo minora et minus dissecta, petiolo inflato-vaginato cano-puberulo suffulta. Involucra involucellaque nulla. Umbellae 3-6-radiatae glabrae radii subaequilongi, tenues, circiter $2-2 \frac{1}{2} \mathrm{Cm}$. longi. Umbellulae pluriflorae, pedicellis petala subduplo superantibus. Calycis laciniae lanceolatae, satis conspicuae. Stylopodii conici margo cyathiformi-erectus, dentatus. Petala lutea, glabra, acumine ovato-inflexo. Styli recurvi, stylopodium plus duplo superantes. Fructus immaturus subturbinatus, glaber. - P. vaginatum Ledb. cui species nostra proxima "foliis glabris, involucello pleiophyllo» dignoscitur. Fructus maturi iguoti.

In Turkestaniae montibus karatavicis prope Ischtübe, legit A. Regel.

\section{Pastinaca dasycarpa Rgl. et Schmalh.}

Perennis. Caulis gracilis, teres, striatus, glaber, subsimplex, 30-40 Cm. altus. Folia glabra, pinnatisecta; foliolis ovatis, reticulatovenosis, duplicato-dentatis, dentibus in mucronem attenuatis. Umbella 8-12-radiata. Involucra involucellaque polyphylla, pubescentia; phyllis involucri demum caducis, quam radii pluries brevioribus; involucelli phyllis persistentibus, anguste lineari-lanceolatis, pedicellos puberulos circiter aequantibus. Fructus plano-compressus, teuuiter tomentosopuberulus, ala angusta cinctus. Calycis margo conspicuus, undulatus, obsolete dentatus. Stylopodii conici margo deflexus crenatus. Styli recurvi, stylopodium subduplo superantes. Mericarpia jugis 5, vix prominentibus. Vallecularum vittae solitariae, latae. Commissura bivittata. 
Pastinaca armena, cui species nostra proxima ccaule angulato, foliis plus minus pubescentibus, involucro nullo v. oligophyllo, umbella 5-7-radiata, involucelli phyllis lineari-sctaceis caducis, fructibus glabris v. vix hirtulis, calycis margine obsoleto» facile dignoscitur.

In Turkestaniae montibus Alexander in trajectu Karabura, 8,000' alt. (A. Regel).

\section{Daucus Golickeanus Rigl. et Schmalh.}

Caules erecti, ramosi, teretes, canaliculato-costati, glabri v. ad costas minute scaberuli. Folia caulina petiolo brevi basi vaginatosemiamplexicauli suffulta, glabra, circuitu oblonga, bi-tripinnatisecta; laciniis anguste-linearibus, in mucronem acuminatis, usque $5 \mathrm{Mm}$. longis, vix $1 / 2 \mathrm{Mm}$. latis. Umbella multiradiata; radiis inaequalibus, minutissime scaberulis. Involucra et involucella polyphylla; phyllis involucri valde inaequalibus, nunc omnibus lineari-setaceis quam radii brevioribus, nunc nonullis modo foliorum pinnatisectis $\mathrm{v}$. subbipinnatisectis radios subaequantibus; phyllis involucelli saepissime omnibus lineari-subulatis, integris, pedicellos floriferos minute hirtulos subaequantibus v. superantibus, - v. nonullis apicem versus parce dentatis. Calycis dentes lanceolati, acuminati, satis magni. Petala alba, omnia aequalia, obovato-subrotunda, lobulo inflexo emarginata. Stylopodium conicum basi crenatum. Styli erecti, stylopodium superantes. Ovarium latius quam longum, a latere compressum. Ovarii mericarpia semiteretia, dorso jugis tribus secundariis magis prominentibus, bifariam aculeolatis, jugis primariis 4 aculeolis minoribus. Fructus ignotus.

Habitu D. bessarabico D. C., crinito D. C. et gracili Steinh. affinis, quorum unus «involucro nullo, foliis ternato-supradecompositis», - alter «caule radiisque retrorso-asperis, involucri phyllis aequalibus apice multifidis, ovarii jugis setis elongatis hispidis», - posterior "foliorum vaginis longe ciliatis, involucri phyllis omnibus pinnatisectis, floribus radiantibus» facile dignoscuntur.

Ad fluvium Syr-Darja legit Golicke 
30. Torilis heterotricha Trautv. (pl. Schrenk. n. 513).

Folia petiolo lineari vaginato brevi suffulta, glabra, trisecta; segmenta tri- $\mathrm{v}$, bisecta; laciniae lineari-filiformes.

$\mathrm{Cl}$. Trautvetter hanc speciem in regionibus turkestanicis satis vulgarem secundum specimina fructifera foliis delapsis descripsit. In Turkestaniae montibus karatavicis (Sewerzow et A. Regel), in desertis Karak Ati et Adam Kirullan (Korolkow), in deserto inter Taschkent et fluvium Syr-Darja, in deserto Fisil-kumi, in deserto Karask, prope Kieless et in valle fluvii Sarawschan. (0. Fedtschenko).

\section{Torilis Borszczowi Rgl. et Schmalh.}

Biennis, glabra. Caules ramique teretes, foliosi. Folia iterato-ternatisecta, petiolo brevi amplexicauli vaginato margine hyalino-membraceo suffulta; laciniis lineari-filiformibus. Umbellae 5-12-radiatae. Involucrum 4-5-phyllum; phyllis lineari-lanceolatis, initio radios subaequantibus, demum iis duplo brevioribus, albido-membranaceis. Umbellulae multiflorae involucellum pleiophyllum; phyllis lineari-lanceolatis, albo-membranaceis, ciliolatis, flores fructusque subaequantibus. Calycis dentes e basi latiore cuspidati. Petala e basi unguiculata obverse oblonga, obtusa, rosea. Stylopodium conicum. Styli erecti, elongati, ovarium et demum fructum circiter aequantes. Fructus oblongus, a latere paullo compressus. Ilericarpia jugis primariis 5, pilis ramosis brevibus canescentibus, secundariis valleculas occupantibus setis aculeiformibus dense vestitis, aculeis diametrum seminis duplo usque pluries superantibus non glochidiatis. Commissura bivittata.

Species pulcherrima affinis T. heterotrichae Trautv., posterior differt autem, «umbellis $2-3$-radiatis, involucro $2-3$-phyllo, umbellulis 2-6-fluris, involucelli pliyllis lineari-subulatis basi tantum anguste hyalino-marginatis nervo excurrente viridi subulato longissimo terminatis, jugis fructus primariis glabris, jugis secundariis pilis brevioribus et praeterea setis longissimis dense hispidis, stylis brevibus ovario fructuque pluries brevioribus».

In deserto aralo-caspico Ust-Ürt (Borszczow), in deserto inter Taschkent et fluvium Syr-Darja (0. Fedtschenko). 


\section{Cuchrys Herderi Rgl. ")}

Folia tripinnatisecta, laciniis linearibus sublente hirtulis. Involucra involucellaque pleiophylla. Calycis margo obsoletus. Stylopodium planum, disciforme. Petala glabra. Fructus ellipsoidei, teretes, ad suturam non constricti, glabri, laeves, ecostati.

C. macrocarpa Ledb., cui planta nostra proxima, «foliorum laciniis glabris, fructibus costatis» dignoscitur.

C. macrocorpa IIerder pl. Semenov. n. 466.

In Turkestaniae orientalis montibus alatavicis cisilicnsibus Rara T'schek. (Semenow).

33. Cachrys didyma Rgl.

Caulis erectus, teres, minute hirtulus, apice verticillato-paniculatus, 20-50 Cm. altus. Folia dense hirtula; radicalia petiolata, trisecta;

\section{*) Cachrys L.}

Specierum imperium rossicum incolentium conspectus.

Sectio I. Eucachrys D. C. Fructus costati v. ecostati laeves glabri.

* Foliorum laciniae oblongae v. obverse oblongae v. sublincarcs.

1. C. odontalgica Pall., fructibus oblongo-cylindricis, apice truncatis, ad commissuram non constrictis, ecostatis.

2. C. macrocarpa Ledb., fructibus ellipticis, ad commissuram non constrictis, costatis.

3. C. Herderi $R g l$., fructibus ellipticis, ad commissuram non constrictis, ecostatis.

4. C. didyma $R g l$., fructibus ellipticis v. ovato-subrotundis, ecostatis, ad commissuram constrictis et igitur didymis.

** Foliorum laciniae elongato-lineari-filiformes.

5. C. alpina $M I B$.

Sectio II. Aegomarathrum D. C. (ex parte).

Fructus costis crassis papilloso-undulatis glabris.

6. C. crispa Pall., foliorum laciniis lineari-filiformibus, involucri phyllis lanceolato-linearibus.

7. C. amplifolia Ledb., foliorum laciniis rigidis subulatis pungentibns, involucri phyllis lanceolatis.

Sectio III. Dasycarpae.

Fructus tomentosi.

8. C. Korolkowi Rgl. et Schmalh., foliorum laciniis lanccolatis.

9. C. eriantha D. C., foliorum laciniis lineari-subulatis. 
segmenta 2 - 3 plicato-pinnatisecta; laciniae obverse oblongae, obtusae; folia caulinabi-v. tripinnatisecta, breviter petiolata. Umbella $3-5$-radiatae; radiis subaequilongis, glabris v. parce hirtulis, involucrum pleiophyllum demum caducum multoties superantibus. Umbellulae 3-8-florae; pedicelli glabri v. hirtuli involucellum pleiophyllum hirtum superantes, quam fructus breviores v. longiores. Calycis dentes obsoleti. Stylopodium explanatum, planum, margine undulato-crenatum. Petala lutea, ovata, dorso minute hirtula, acumine inflexo. Styli recurvati, stylopodium superantes, 2 v. abortu 1 . Fructus elliptici v. ovato-subrotundi, ad commissuram constricti et igitur didymi. Mlericarpia ecostata, laevia, abortu subinde solitaria.

Cachrys odontalgica Herder pl. Semenov. n. 465.

Dschus-agatsch ad ostia fluvii Bukon in regione fluvii Irtysch in desertis arenosis (Potanin), in montibus karatavicis Mogol-tau (Severzow), in deserto prope Keles, Liarak et Tschardara (0. Fedtschenk 0 ).

ß. glabra; foliis glabris.

In deserto aralensi in regione fluvii Syr-Darja. (Borszczow).

\section{Cachrys Korolkowi Rgl. et Schmalh.}

Caulis erectus, teres, apice paniculato-ramosus, subglaber. Folia plus minus papilloso-hirtula v. glabriuscula, radicalia petiolata, bipinnatisecta; laciniis inferioribus plus minus laciniatis, superioribus integris lobisque anguste lanceolatis, petiolo a basi supra medium vaginatis; foliis caulinis petiolo brevi vaginato suffultis, inferioribus bipinnatisectis, superioribus pinnatisectis v. subsimplicibus, omnibus dense papillosohirtulis. Umbella 3-6-radiata; radiis subaequalibus, glabris, inv0lucrum pluries superantibus. Involucra involucellaque polyphylla; phyllis linearibus, hirtis. Umbellulae multiflorae; pedicellis quam involucelli phylla brevioribus, sub lente minute glandulosis. Flores monoici. Calycis margo obsoletus. Petala lutea, subrotunda acumine brevi inflex0, dorso minute hirtula. Stylopodium explanatum, disciforme, florum masculorum margine subintegerrimum, florum foemineorum margine crenato-undulatum. Styli recurvi, stylopodium superantes. Fructus immaturi dense tomentoso-hirsuti. 
Planta 30-70 Cm. alta, parce ramosa. Radii umbellarum mascularum abbreviati, $1 / 2-1 \mathrm{Cm}$. lougi, umbellarum foeminearum nsque $3 \mathrm{Cm}$. longi. Pedicelli $1^{1 / 2}-2 \mathrm{Mm}$. longi.

In expeditione ad Chiwam inter Chala-ati et Adam Kir-Ullan in solo arenoso legit $\mathrm{Cl}$. Korolkow.

\section{Hippomarathrum crispum Koch.}

Cachrys crispa Ledb. fl. ross. II. 357.

In Turkestaniae montibus karatavicis legit A. Regel. *)

\section{Albertia Rgl. et Schmalh. "*)}

Calycis margo 5-dentatus (v. nullus). Petala ovata v, obcordata, acumine inflexo. Fructus a latere compressus. Mericarpia 5 -juga; jugis

") Ledebour vereinigte die Gattung Hippomarathrum mit "achrys. Boissier stellt in seiner Flora orientalis II. p. 931, diese Gattung wieder her, indem sie sich durch den deutlichen Kelch mit verhältnissmässig grossen Zähnen von Cachrys und Prangos gut unterscheidet. Ausserdem sind bei Hippomarathrum die 5 breiten Rippen der Halbfrüchtchen mit Warzen oder mit flügelförmigen Auswüchsen dicht bedeckt oder dieselben stehen woitläufiger und nehmen mehr die Gestalt von Borsten oder Stacheln an. Boissier führt 5 Arten dieser Gattung für den Orient auf, vereinigt, wie es uns səheint unbegründet Ledebour's Cachrys amplifolia mit $H$. crispum und ausserdem treten zu diesen 2 Hippomarathrum des Russischen Asiens noch 2 neue von Fedtschenko in Turkestan gesammelte Arten, welche wir in der Aufzählung der neuen von Fedtschenko gesammelten Pflanzen beschrieben haben. Hiernach wäre die Gattung Hippomarathrum in der Flora des Russischen Asiens mit 4 Arten vertreten, die sich folgendermassen unterscheiden :

A. Folia ternation dissecta.

1. Hippomarathrum crispum Koch (Umb. p. 136.); foliorum laciniis lineari-filiformibus, erecto patentibus, plins minus elongatis, supra canaliculatis, infra carinatis.

2. Hippomarathrum amplifolium C. A. $M$. (ind. cauc. pag. 131. Cachrys amplifolia Ledb. fl. ross. II. 35.9) ; foliorum segmentis laciniisque divaricatis; laciniis linearibus, brevibus, rigidis, supra canaliculatis, tri-pentagonis.

A. Folia pinnatisecto-multificla.

3. Hippomarathrum Fedtschenkoi Rgl et Schmalh., foliorum tripinnatisectorum laciniis anguste lineari-lanceolatis planis.

4. Hippomarathrum sarauschanicum Rgl. et Schmalh., foliorum 4-5pinnatisectorum laciniis anguste linearibus, supra canaliculatis, infra convexis $\nabla$. subcarinatis.

**) Hoc genus dedicavimus Cl. viro Albert Regel, collectori diligentissimo plantarum, regionem turkestanicam incolentium. 
alatis; alis margine crenato-dentatis $v$. paleaceo-dentatis, valleculisque verrueis bullatis $\mathrm{v}$. margaritaceis $\mathrm{v}$ paleis plus minus dense vestitis, lateralibus marginantibus. Valleculae commissuraque evittatae. Semen sulco exaratum. - Affinis Pleurospermi et Aulacospermi, "fructuum jugis crenato-dentatis verrucis vestitis, vittis nullis» facile dignoscitur.

36. A. commutata Rgl. et Schmalh.

(Aulacospermum anomalum Kar. et Kir. enum. pl. song. n. 392.Herder pl. Semenov. n. 468 ex parte); perennis, foliis circuitu oblongis, involucro erecto, fructibus minute verruculosis.

Radix perennis, 1-pluricaulis. Glaber. Caules $10-25 \mathrm{Cm}$. alti, foliosi et apice ramosi, v. simplices et saepe aphylli. Folia petiolata, oblonga, bipinnatisecta; laciniis obverse oblongis v. oblongo-ellipticis, acutis, integerrimis v. apice acute dentatis v. iterato subpinnatisectis. Umbellae 5-8-radiatae, nunc in caulium v. ramulorum apice terminales, nunc sessiles et radios elongatos subradicales exserentes; radiis striato-angulatis, inaequilongis, sub lente minute hirtulis.

Involucra involucellaque saepissime 5-phylla; phyllis lineari-lanceolatis, albido-scarioso-marginatis, quam radii duplo-quadruplo brevioribus, pedicellos floriferos fructiferosque superantibus. Pedicelli numerosi, breves, $1^{1 / 2}-3 \mathrm{Mm}$. longi. Petala subrotunda cum acumine inflexo, albida v. roseo-tincta. Stylopodium planum, disciforme, atroviride, margine subintegrum. Styli initio erecti, demum recurvi stylopodio breviores v. demum id subaequantes. Fructus late ovato-subrotundus. Mericarpii juga valleculaeque verruculosa.

In montibus alatavicis cisiliensibus (Karelin), in montium alatavicorum jugo Kurmety et Keskelen (Semenow), in jugo Ketmen montium Thian-Schan (Kuschakewicz), in Kokaniae montium jugo Karakasuk et Kawuk (0. Fedtschenko).

Aulacospermum anomalum Ledb., cui habitu affinis facile dignoscitur: "caule elatiore, foliorum laciniis lineari-lanceolatis, phyllis involucelli pedicellos floriferos circiter $3 / 4$ Cm. longos aequantibus, quam 
pedicelli fructiferi usque $2 \mathrm{~cm}$. longi brevioribus, mericarpii jugis in alam integram nec verruculosam exeuntibus; valleculis univittatis, / $q 010 \mathrm{n}$ missura bivittata».

37. A. margaritifera Rigl. et Schmalh., annua, foliis circuitu deltoideis, involucro demum reflexo, fructibus dense margaritiferis.

Annua, glabra. Caulis elatus, $40-60 \mathrm{Cm}$ altus, ramosus. Folia petiolata, circuitu deltoidea, pinnatisecta; pinnis inferioribus majoribus saepe petiolatis, superioribus decurrentibus, omnibus pinnatifidis, obloug(0lanceolatis usque lineari-oblongis, integerrimis v. apice dentatis v. iteratopinnatifidis. Umbellae pauci-multiradiatae; radiis inaequalibus. Involucri 5-6-phylli phyllis anguste lanceolatis, albido-scarioso-marginatis, initio erectis radios subaequantibus v. superantibus, demum reflexis, quam radii longiores $2-3$-plo brevioribus $\mathrm{v}$. interdum in appendicem foliaceam integram $\mathrm{v}$. modo foliorum sectam excrescentibus Unbellulae multiflorae; pedicelli initio involucellum 5-phyllum circiter aequantes, demum eo duplo longiores; involucelli phyllis anguste lanceolatis albidoscarioso-marginatis, pedicellos floriferos aequantibus, fructiferis brevioribus. Calycis margo manifestus, dentibus brevibus triangularibus v. Iongioribus lanceolatis. Petala alba, obcordata, acumine oblongo apice emarginato inflexo. Stylopodium conicum. Styli plus minus recurvi, stylopodium plus duplo superantes. Fructus late-ovato-subrotundus, a

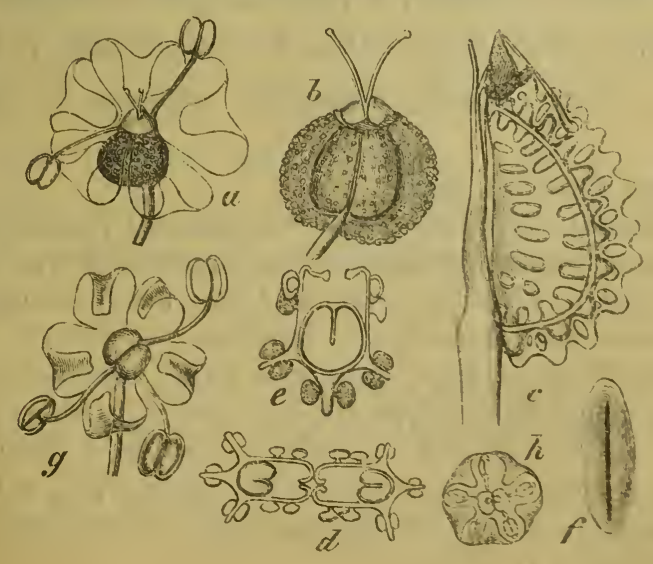


latere compressus. Mericarpii juga alata margine bullato-crenata, practerea verrucis oblongis $\mathrm{v}$. reniformibus albido-margaritaceis dense vestita.

In deserto montes karatavicos Hogol-tau adjacente (Sewerzow), prope Karnak in montibus karatavicis (A. Regel), in deserto ad fluvium Syr-Darja (Golicke), prope Taschkent (Krause), in deserto inter Taschkent et fluvium Syr-Darja, in Kokania in valle fluvii Sarawschan (0. Fedtschenko).

Explicatio figurae.
a. Flos, auctus.
b. Fructus, auctus.
c. Mericarpium cum carpophoro, auctum.
d. Fructus, in sertione transversali.
e. Mericarpium in sectione transversali.
f. Semen.
g. Flos masculus.
h. Flos junior fertilis.

38. A. paleacea Rgl. et Schmalh., annua, petiolis vaginatoinflatis, foliis ternatisectis, segmentis pinnatifidis, involuero nullo, fructibus paleis vestitis. Descriptionem cfr. in pl. Fedtschenkoanis. Fructus maturi nondum vidimus, habitu tantum Albertiae adnumeravimus.

\section{Schrenkia involucrata Rgl. et Schmalh. *)}

Padix perennis, lignosa, 1-pluriceps, collo foliorum emortuorum vaginis laceratis dense vestito. Caulis erectus, humilis v. usque $40 \mathrm{~cm}$. altus, glaber, teres, sulcato-subcostatus, simplex v. apice ramosus,

*) Schrenkia Fisch. et Meyer.

A. Hippomarathro cui Benthamus et Hookerus adnumeraverunt fructu didymo, mericarpii subglobosi jugis 5 semicircularibus vix prominentibus, vittis nullis, dignoscitnr. Herbae perennes, foliis pinnato-decompositis ; floribus umbellarum centralibus subsessilibus, lateralibus pedicellatis.

S. vaginata Fisch. et Mey., involucro nullo, pedunculis radiis fructibusque glaberrimis, calycis dentibus parvis. (Fisch. et Mey. in Schrenk enum. pl. nov. pag. 63. - Ledb. fl. ross. II. p. 366).

$S$. involucrata $R g l$. et Schmalh, involucro pleiophyllo, radiis fructibusque sub lente plus minus papillis asperulis, calycis dentibus magnis, folii laciniis acutis $\mathrm{v}$. apiculatis. 
ramis alternis v. supremis verticillatis, glabris v. asperulis//Folia caulina petiolo vaginato-inflato suffulta, glabra; inferiora tripinnatisecta; laciniis linearibus usque elliptico oblongis, acutis v. in inucronem excurrentibus. Umbellae multiradiatae; radiis inaequalibus, sub lente aculeolis minimis asperulis, involucrum pleiophyllum aequantibus v. usque pluries superantibus. Involucri involucellique phylla linearia, erecto-patentia r. demum reflexa, ea involucelli pedicellos exteriores subaequantia. Flores centrales subsessiles; laterales pedicellati, floriferi usque $4 \mathrm{Mm}$., fructiferi usque $10 \mathrm{Mm}$. longi. Calycis dentes lanceolati, acuminati, satis magni. Petala alba, ovata, acumine inflexo. Stylopodium dilatatum, depresso-conicum. Styli divaricati v. recurvi, stylopodium superantes. Fructus didymus, latior quam longus, a latere compressus. Mericarpia subglobosa, 5-juga; jugis vix prominentibus, obtusis, papillis oblongis parvis integris obtusis nune raris, nune plus minus dense vestitis. Commissura ovata, excavata. Vittae nullae. Carpophorum integrum v. bifidum.

In Songoria ad Balkasch, in vallibus fluviorum Chontau, Bektautu et Kahlasu (Schrenk), in Turkestaniae montibus karatavicis (Sewerzow), inter Taschkent et Orsk lusum foliorum laciniis anguste linearibus in mucronem tenuem excurrentibus 0 . Fedtschenko legit.

\section{Schrenkia pungens Rgl. et Schmalh.}

Glabra. Radix praecedentis. Caulis erectus, humilis, $3-5$-pollices altus, teres, sulcato-striatus, a basi ramosus. Folia petiolata, rigida; radicalia petiolo compresso, aequilato, basi vaginato, amplexicauli, adpresso; caulina petiolo vaginato-inflato: inferiora tripinnatisecta, segmentis elliptico-oblongis $\mathrm{v}$. lanceolatis integris $\mathrm{v}$. pinnatifido-laciniatis in acumen pungens transparens excurrentibus. Umbellae multiradiatae.

S. pungens Rgl. et Schmalh., involucro pleiophyllo, radiis fructibusque glabris, calycis dentibus lanceolatis acumiuatis, folii laciniis in acumen pungens transparens excurrentibus.

S. papillaris $\mathrm{Rgl}$. et Schmalh., involucro pleibphyllo, pedunculis radiisque asperis, fructibus papillis elongatis sinuato-crenatis lobatisve dense vestitis. 
Involucra et involucella praecedentis. Flores, calyx, petala, stylopodium et styli praecedentis. Fructus omnino glabri.

In Turkestaniae montibus karatavicis prope Kulotschek. (A. Regel).

\section{Schrenkia papillaris Rgl. et Schmalh.}

Laciniae foliorum omnes lineares, acutae. Calycis dentes parvi. Mericarpia papillis elongatis complanatis sinuato crenatis lobatisve dense vestitis. Cetera ut Schrenkiae involucratae.

In Turkestaniae montibus karatavicis prope Boroldai. (A. Regel).

\section{Lonicereae.}

42. Abelia corymbosa Rgl. et Schmalh.

Fruticosa, ramosissima; ramulis puberulis. Folia petiolata, ellipticolanceolata, acuta, saepissime omnia integerrima v. nonnulla crenis v. laciniis obtusis paucis lateralibus, ciliolata, utrinque laxe hirtula et demum plus minus glabrata. Flores in corymbos terminales multiflores dense congesti, bracteis foliaceis ovato-oblongis calycis tubum superantibus v. aequantibus stipitati. Calycis tubus demum elliptico-oblongus, costatus, puberulus; limbi quadripartiti laciniae lanceolatae, utrinque. attenuatae, reticulato-penninerviae, villoso-ciliatae, tubum plus duplo superantes. Flores ignoti.

Abelia triflora R. Br., cui planta nostra proxima : "foliis acuminatis calycisque 5-partiti laciniis anguste linearibus villoso-ciliatis» facile dignoscitur.

Ad ripas fluvii Mailo in Turkestania leg. Krause.

\section{Lonicera Semenovi Rgl. *)}

L. hispida $\gamma$. alpina Rgl. pl. Semenov. n. $474 \gamma$. - Frutex pygmaeus, ramosissimus, caespitosus. Folia breviter petiolata, oblonga, margine minute denticulata, denticulis in setulam rigidam porrectam

*) L. humilis Kar. et Kir. ist bis jetzt in nur einigen Bruchstücken von Exemplaren bekannt. Die von Semenow im blühenden Zustande gesammelten Exemplare, die ich in meiner Bearbeitung der Pflanzen Semenow's 
excurrentibus ot hac ex re rigide ciliata. Flores sessiles. Bracteae ovatae, ciliatae, ovaria superantes et involucrantes, baccis rubris breviores. Corolla tubo elongato, apicem versus seusim ampliato. Ovaria baccaeque omnino discreta.

Frutex vix 2--3-poll. altus. Folia 8-12 Mm. longa, 4-5 Mm. lata, subcoriacea, lacte viridia, infra pallidiora et reticulato-venosa. Flores usque $21 \% \mathrm{Cm}$. longi, ut videtur lutei. Baccae ovatae, rubrac.

In trajectu Zauku montium Thian-Schan, 8,000 ped. alt. (Semenow), in alpibus kokanicis ad,moles glaciales Schurowski. (0. Fedtschenko).

\section{Lonicera micrantha Trautv.}

L. tatarica $\beta$. micrantha Trautv. pl. Schrenk. n. 521. - Affinis L. tataricae, differt «foliis floribusque subduplo minoribus, foliis ovatis basi rotundatis (nec cordato-ovatis) ramulisque tenuiter puberulis (nec

mit L. humilis vereinigte, halte ich jetzt, wo ich die gleiche Form auch aus den Alpen Kokand's vor mir habe, für eine eigne Art. Im Folgenden gebe ich eine Uebersicht, der in Turkestan wachsenden Loniceren.

Lonicerae species in regionibus turkestanicis crescentes.

I. Ovaria baccaeque discreta

A. Pedunculi brevissimi v. nulli.

a. Bracteae minutae, lineares.

L. nummulariifolia Jaub. et Spach.

b. Bracteae lanceolatae $v$. ovatae, ovaria involucrantes.

L. Semenovi Rgl., corollae tubo apicem versus sensim ampliato; foliis oblongis, utrinque glabrescentibus, margine rigide ciliatis.

L. humilis Kar. et Kir., corollae tubo cylindrico; foliis ovatis, utrinque subhispidis $\mathrm{v}$. demum subglabrescentibus, margine rigide ciliatis.

B. Pedunculi calycem plus duplo superantes, forem subaequantes $v$. paullo superantes.

a. Bracteae cvatae $v$. ovato-lanceolatce, ovaria involucrantes

L. hispida Pall., foliis ellipticis, utrinque glabris. margine setoso-ciliatis; bracteis maximis, membranaceis; corollarum tubo a basi ad apicem sensim ampliato.

L. Olgae $\mathrm{Rgl}$. et Schmalh., foliis elliptico-oblongis, utrinque hispidis, setoso-ciliatis; bracteis herbaceis; corollarum glabrarum tubo tenui, cylindrico. 
glabris) margine ciliolatis (nec glabris), corollae tubo tenui basi aequali (nec gibboso)».

In montibus Arkat (Schrenk), - in Kokania prope Schagimardan et Ak-bura (0. Fedtschenko).

45. Lonicera humilis Kar. et Kir.

L. humilis Kar. et Kir. enum. pl. song. n. 396. - Ledb. fl. ross. Il. 388 . - Rgl. pl. Semenov. n. 477.

Frutex humilis, ramosus; ramis procumbentibus adscendentibus $\mathbf{v}$. speciminum elatiorum divaricatis v. subvirgatis, cortice griseo secedente vestitis; ramulis pilis patentibus plus ıninus hirtis. Fólia parva, ovata, acuta, in petiolum brevissinum attenuata, utrinque hirto-pilosa rigideque ciliata, demum reticulato-venosa utrinque hirta v. plus minus glabrescentia, margine semper rigide ciliata. Flores sessiles, ut videtur flavi,

L. Altmanni Rgl. et Schmalh., foliis ovatis. utrinque plus minus hirtis; bracteis herbaceis; corollarum hirsutarum tubo apicem versus ampliato.

b. Bracteae lineares.

L. Xylosteum L., foliis ellipticis, villosis; corollarum tubo basi gibboso.

L. tatarica L., foliis cordato-oblongis, glabris; corollarum tubo basi gibboso.

L. micrantha Trautv., foliis ovatis ramulisque tenuiter puberulis; corollarum tubo basi aequali.

C. Pedunculi flores duplo-triplo superantes.

L. Karelini Bnge., foliis ovato-oblongis, utrinque acutis, glabris v. subtus laxe adpresse pilosis; baccis rubris. - (L. nigra Ledb. fl. ross. II. 389)

1I. Ovaria totidem v. ad medium connata.

A. Pedunculi folium dimidium superantes.

L. microphylla Willd., baccis luteis v. fuscis. *)

B. Pedunculi folio dimidio breviores.

$L$. caerulea $L_{\text {., }}$ baccis atrocaeruleis pruina alba vestitis.

*) L. Bungeana et L. microphylla Ledb fl. ross. II. p. 391. - L. Sieversiana et L. Bungeana Kir. Lonic. p. 56 et 58 . 
extus pubescentes; tubo gracili, cylindrico, 8-9 Mm. longo, supra basin gibbo satis magno subcalcariformi. 0varia omnino distincta, glabra, calycis lobis rotundatis ciliatis coronata. Bracteac ovatue, hirtulae, ciliatae, ovaria occultantes. Baccae subglobosie, rubrae, bracteas aequantes.

In montibus alatavicis ad fluvium Sarchan (specimina fructifera) leg. Karelin et Kirilow, - in montibus alativicis cisiliensibus in alpibus prope lacum Djassyk-kul, 8,000 ped. alt., (specimina florifera) leg. Semenow, in alpibus kokauicis in angustiis Chodja Tschiburgan (specinina fructifera) leg. Fedischenko; - in montibus Alexander in trajectu Karabura, 8,000 ped. alt., leg. A. Regel.

\section{Lonicera nummularïfolia Jaub. et Spach.}

Jaub. et Spach. Ill. pl. or. I. tab. 70. - Boiss. fl or. III. p. 7.L. persica Jaub. et Spach. l. c tab. 69. - Kirilow Lonic. p. 21. L. arborea Boiss. voy esp. (quoad pl. orientalem). - L. kurdistana Schlechtd. - L. Xylosteum fl. graeca tab. 223. - L. turkomanica Fisch. in herb. - L. Xylosteum L. $\beta$. macrocalyx Rgl. pl. Semenow. n. 473 . -

Variat ramulis foliisque utrinque plus minus dense puberulis v. pubéscentibus $\mathbf{v}$. subglabris, foliis e basi rotundata v. truncata $\mathbf{v}$. subcordata ellipticis $\mathrm{v}$. late ovatis, obtusissimis $\mathrm{v}$. subacutis. - Pedunculis brevissimis, bracteis linearibus, ovariis discretis a speciebus sequentibus dignoscitur. Baccae parvae, flavescenti-fuscae.

In regionibus turkestanicis satis frequens; in montibus karatavicis in valle Bugun (Sewerzow), inter tractum Dschaman-Tasch et Balauschi-ata et prope Karagus (A. Regel); in montibus alatavicis in valle fluvii Talas et Karakol, in valle fluvii Tschirtschik prope Saylik (A. Regel); in regionibus kokanicis in tractu Torpa-bel, in valle fluvii Sarawschan in angustiis Makschewat, in montibus Aksai, in vicinitate lacus Iskander-kul et in angustiis Tschiburgan (0. Fedtschenko), inter Ak-tagtau et Ak-Sagoty (Fiorolkow). 


\section{Rubiaceae.}

47. Asperula azurea Jaub. et Spach.

Jaub. et Spach Ill. fl. or. I. pag. 151 tab. 82. a. - A. orientalis Boiss. et Hohenacker in Kotschy pl. exs. - Boiss. diagn. ser. I. fasc. III. p. 30. - Ejusd. fl or. III. p. 31. - A. arvensis Ledb. et auct. ross. quoad specimina caucasica.

In montibus karatavicis prope Boroldai (A. Regel).

48. Galium davuricum Turcz.

Turcz. cat. baic. n. 568. - Ledb. fl. ross. II. pag. 509. Caulibus retrorsum aculeolatis, foliis senis margine antrorsum ciliolatosetoso-denticulatis, pedunculis lateralibus $1-3$-floris a Galio trifido, saturejifolio et uliginoso facile dignoscitur *).

In regionibus turkestanicis et kokanicis satis frequens.

\section{Valerianeae.}

49. Valerianella cymbicarpa C. A. Meyer.

C. A. M. ind cauc. p. 49. - Ledb. fl. ross. II. 433.

Specimina omnia a nobis examinata fructibus dorso hirtis gaudent. ${ }^{* *}$ ) In regionibus turkestanicis satis frequens.

50. Valerianella hamata Bast.

Bast. in DC. fl. fr. V. 494. - DC. prodr. IV. 648. Rchb, ic. fl. germ. XII. tab. 715. fig. 1410.

*) Das ächte G. davuricum sahen wir bis jetzt nur in einigen von Turczaninow gesammelten Exemplaren und diese gemischt mit Exemplaren der üppigen breitblättrigen Form von G. uliginosum. Von diesen letzteren jrregeführt, haben C. Maximowicz (Prim. fl. amur. pag. 141) und ich selbst (Fl. ussur. p. 77) die gleiche grossblättrige Form von G. uliginosum, für G. davuricum genommen.

**) In Form des Kelches, ist diese Art der V. oxyrhyncha sehr ähnlich und ist in Folge dessen auch von Hohenacker und selbst von C. A. Meyer in den Pflanzen von Talüsch für V. oxyrhyncha genommen worden. Während aber V. oxyrhyncha 2 sehr schmale fädliche sterile Fruchtfächer besitzt, sind diese bei V. cymbicarpa noch grösser als das fruchtbare Fach der Frucht. 
Specimen unicum legit C. Sewerzow in 'Turkestiniae inontibus Mogol tau (Karatau).

Planta nostra omnino cum icone citata et cum speciminibus in herbario horti Imperialis botanici asservatis congruit, a descriptione Cl. De Candollii «fructus loculis sterilibus filiformibus fertili multo angustioribus» differt.

\section{Compositae.}

\section{Erigeron eriocephalus Rigl. et Schmalh.}

(Erigeron, Sectio IV. Heterochaeta Boiss. Il. or. III. 163. Heterochaeta D. C. prodr. Flores foeminei omnes ligulati. Pappus biserialis, serie exteriore brevissima in achaenii pilos abeunte). - Caespitosus, pluricaulis v. rarius caule solitario; caule foliisque lineari-oblongis v. linearibus, integerrimis v. paucidentatis, glabris. Canlis flexuosus v. substrictus, apicen versus paniculato-ramosus $\mathrm{v}$. apice subumbellatoramosus; ramis minute hirtulis, foliis linearibus sparsis paucis vestitis, capitula terminalia solitaria $\mathrm{v}$. capitula pauca racemoso-disposita gerentibus. Capitula multiflora; involucri albido-villosi phyllis laxe imbricatis, linearibus, attenuato-acutis, discum subaequantibus; ligulis anguste linearibus, discum pappumque paullo superantibus, albidis v. roseis; achaeniis pilosis, pappi serie externa multisetosa brevi.

Habitu _Erigero acri affinis, "caule foliisque linearibus glabris pappique constructione» diversus.

Erigeron acris var. serotina Herder pl. Semenov. n. 515.

Ad lacum Issyk-kul, Tüb, (Semenow), ad fluvium Tekes et Musart (A. Regel).

52. Linosyris punctata Rgl. et Schmalh. *)

Perennis, herbacea. Caules adscendentes, flexuosi, basi et apice ramosi, foliati, sub lente saepissime minute asperuli, $20-40 \mathrm{Cm}$. alti.

") Conspectus specierum Linosyris Imperium rossicum incolentium.

A. Folia omnia uninervia, impunctata.

1. L. vulgaris Cass., foliis anguste linearibus, acutis, glabris $\nabla$. glabriusculis; capitulis corymbosis; involucri squamis linearilanceolatis, acutis, glabris. - Ctr. Ledb. tl. ross. II. 495. 
Folia lineari-oblonga, acuta, omnia uninervia; decrescentia, sub lente saepissime minute asperula v. rarius glabra. Rami superiores caulis divaricati, 2-7, saepissimé simplices monocephali, rarius ramulos $1-3$ secundarios monocephalos gerentes, corymbum laxum 2-10-cephalum formantes. Involucrum campanulatum, floribus pappoque subduplo brevius; involucri squamis exterioribus ellipticis acutis dorso apiceque fusco-purpureis margine ciliatis, interioribus subduplo longioribus oblongis obtusis ciliatis. Flores omnes tubulosi hermaphroditi.

2. L. scoparia Kar. et Kir., foliis anguste linearibus, initio floccoso tomentosis. demum glabriusculis, acutis; ramis divaricatis, plerurnque unifloris; involucri turbinati squamis floccoso-tomentosis, inferioribus ellipticis acutis, superioribus obverse oblongis obtusis. Cfr. Ledb. l. c. II 496

3. L. villosa $D$. C., foliis oblongo-lanceolatis, obtusiusculis, v. subacutis, cinereo-tomentosis ; capitulis corymbosis; involucri turbinati squamis floccoso-tomentosis, exterioribus ovatis acutis, interioribus obovato-oblongis $\mathrm{v}$ oblongis obtusis $\mathrm{v}$. acutiusculis. Cfr. Ledb fl ross II. 495.

B. Folia omnia uninervia, punctata

4. L. glabrata Lindl., foliis (,blongo-linearibus, obtusis, glabriusculis, supra compresso-punctatis; capitulis dense corymbosis; involucri turbinati squamis inferioribus ellipticis obtusis laxe tomentellis, superioribus obverse oblongis obtusis ciliatulis caeterum glabris. - Cfr. DC. prodr. V. pag. 353. - Rossia australis (Becker), Songoria (Schrenk), - in montibus karatavicis (Kuschakewicz). - Planta perennis nec fruticosa ut Cl. De Candolle dixit.

5. L. punctata Rgl. et Schmalh, foliis linear'1-oblongis acutis, supra impresso-punctatis, glabriuscul s; caulibus adscendentibus, apice ramulis paucis monocephalis $v$. rarius $\Sigma-3$ cephalis, corymbum laxum formantibus; involucri campanulati squamis glabriusculis, exterioribus ellipticis acutis, interioribus oblongis obtusis.

C. Folia inferiora 3-5 nervia, superiora uninervia.

6. L. divaricata $D C$., foliis acutis, adpresse pubescentibus, inferoribus oblongs; caulibus simplicibus monocephalis v. parce ramosis, ramis elongatis monocephalıs; involucri campanulati squamıs elliptico-lanceolats, acuminatis, parce puberulis. - Cfr. Ledb. fl. ross II. 496.

7. L. Grimmi Rgl. et Schmalh, foliis lineari-oblongis, acutis, glabriusculis; capitulis in caule ramoso paniculatis; involucr cylindrico-turbinati squamis superioribus obovato-oblong.s, ex apicc rotundato-obtuso minute apiculatis, ciliatis, caeterum glabris. 
Linosyris glabrata Lindl., cui species nostra affinis: "foliis obtusis, involucri turbinati squamis inferioribus laxe tomentellis omnibus obtusis, corymbis polycephalis confertis, facile dignoscitur.

In valle fluvii Tekes prope Aksu et ad ostia fluvii llusart in monltibus thianschanicis. (A. Regel).

\section{Linosyris Grimmi Rgl. et Schmalh.}

Caulis e basi suffruticosa ramosissimus, glabriusculus v. sub lente minutissime hirtulus, ut rami costato-angulati, $20-40 \mathrm{Cm}$. altus. Folia lineari-oblonga, acuta, sub lente minutissime hirtula, in latere inferiore glandulis sessilibus munita; inferiora trinervia, superiora uninervia, decrescentia. Capitula in ramorum ramulorumque apice paniculata. Involucri cylindrico turbinati squamae inferiores ellipticae acutae; superiores obovato-oblongae, ex apice rotundato-obtuso apiculatae, scariosomarginatae ciliataeque, cacterum glabrae; intimae angustiores acutae. Flores omnes tubulosi, hermaphroditi, involucrum paullo usque sesqui superantes Stylus inclusus, stigmatibus breviter exsertis.

L. divaricata DC, cui species nostra foliis inferioribus trinerviis proxima, differt acaulis ramis elongatis monocephalis, involucri campa nulati squamis omnibus acuminatis».

In Turkestaniae montibus alatavicis in valle fluvii Tschirtschik prope Packrak. (A. Regel).

Specimen unicum in Kokaniae valle fluvii Sarawschan ab 0. Fedtschenko collectum stylo exserto differt, sine dubio autem hujus speciei.

Viro clarissimo Richardo Grimm, amico intimo filii mei A. Regel, dedicavimus hanc speciem.

\section{Diplopappus turkestanicus Rgl. et Schmalh.}

Minute plus minus dense cinereo-hirtulus. Radix lignosa, collo pluricipiti v. in rhizoma crassum lignosum iterato ramosum ut videtur subterraneum transiens; rhizomatis rami abbreviati, caespitosi. Cauliculi erecti v. adscendentes, simplices v. rarissime parce ramosi, monocephali, $3-4$ pollices alti. Folia inferiora (folia radicalia aemulantia) anguste lanceolato-spathulata v. lineari-lanceolata, in petiolum attenuata, saepis- 
sime integerrima, rarius parce minuteque dentata; caudiculornm sparsa, pauca, lineari-lanceolata v. linearia; folia infima ad squamas imbricatas obtusas transeuntia. Involucri triseriati phyllis lineari-lanceolatis, acutis, glanduloso-hirtulis, disco $1 / 3$ brevioribus. Flores marginales ligulati, pluriseriales; ligulis unguiculatis obovatis v. spathulato-oblongis, apice bi-tridentatis v. rarius integris, discum superantibus, in statu sicco flavis v. rarius cacrulescentibus. Flores disci hermaphroditi, tubulosi, quinquedentati, flavi. Receptaculum nudum. Achaenium erostre, oblongum, compressum, hirtum Pappus setosus, duplex, scaber, achaenium subnequans, setis exterioribus brevibus, interioribus discum circiter aequantibus.

Affinis Psychrogetoni (Diplopappi spec. efr Bnth. et Hook. gen. II. pag. 1233) cabulico Boiss. (fl. orient. III. pag. 156) diversus autem ut videtur «involucro triseriato disco pappoque breviore, ligulis discum superantibus, achaenio pappo subaequante, caudiculis 3-4 pollicaribus».

In alpibus thianschanicis $8-12000^{\prime}$ alt. (Kuschakewicz), in alpibus kokanicis $7-12000^{\prime}$ alt. ar fluvium Isphairam, in trajectu Kadschraga et Dschiptik, ad glacies Tschitschikti. (0. Fedtschenko).

\section{Conyza Krausseana Rogl. et Schmalh.}

Biennis v. perennis. Caulis elatus, erectus, breviter glandulosohirtulus v. asperulus, in paniculam elongatam abiens. Folia radicalia oblongo-lanceolata, in petiolum longum attenuata, minute hirtulo-asperula, acuta, integerrima v. apicem versus dentata; folia caulina multo 'minora, sessilia v. in petiolum brevem attenuata, acuta, dentata v. integerrima. Paniculae valde elongatae rami abbreviati, nunc brevissimi cyma 3 -pluriflora terminati, nunc praecipue superiores racemoso-cymosi. Involucri phylla triseriata, lineari-lanceolata, acuta, dorso glandulosohirtula, pappo subduplo breviora. Flores disci tubulosi hermaphroditi, radii filiformes ueutri v. foeminei. Receptaculum convexum, subalveolatum. Achaenia lineari-oblonga, compressa, minute pubescentia. Pappi setae biseriales, scabrae; serie exteriore quam interior pluries breviore.

Bi-tripedalis. Folia radicalia cum petiolo usque 5 pollices longa. Capitula parva. Involucri phylla circiter $3 \mathrm{Mm}$. longa. 
Species proxime affinis C. (Erigeron) khorassanica Boiss., secundum descriptionem C. Boissieri dignoscere videtur «indunento pubescenti-canescenti-puberulo, foliis inferioribus incluso petiolo $31 / 2$ poll. longis, capitulis majusculis magnitudine Erigeronis acris, involucri phyllis biseriatis dorso dense spinuloso-scabris longeque acuminatis, achaeniis dense hirsutis».

Prope Taschkent (Krause), in montibus alatavicis ad fluvium

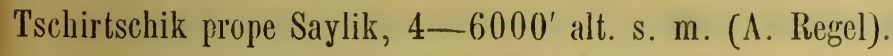

\section{Trichanthemis Rgl. et Schmalh.}

Capitula homogama, discoidea. Involucrum late campanulatun; phyllis 3-4-seriatis, imbricatis, adpressis, margine apiceque scariosis, exterioribus gradatim brevioribus. Receptaculum convexum, alveolatun; alveolis margine dense setoso-pilosis; setis quam achaenia brevioribus. Flores omnes tubulosi, hermapiroditi, ilvolucrum circiter aequantes; - tubo tereti-cylindrico; limbo vix ampliato, 5-fido. Antherae basi obtusae. Styli apice truncati, papillosi. Achaenia oblonga, teretia, subcostata, dense strigoso-hirsuta, pappo paleaceo coronata; paleis elliptico-oblongis, obtusis, achaeniorum exteriorum achaenium dimidium subaequantibus, achaeniorum centralium achaenio pluries brevioribus.

Fruticulus pygmaeus, ramosissimus; ramis ramulisque brevibus, erectis v. procumbentibus, caespitem densum formantibus, foliosis; ramulis apice pedunculum elongatum erectun nudum monocephalum edentibus. Folia alterna, pinnatisecta, lobis linearibus. Capitula mediocria. Genus novum Anthemi affine, «receptaculo alveolato-fimbrillifero, floribus lomogamis, achaeniis strigoso-hirsutis» satis diversum.

\section{Trichanthemis karataviensis Rgl. et Schmalh.}

Cauliculi ramuli foliaque hirsuta. Folia breviter petiolata, dense congesta, circuitu oblonga, $1 \frac{1}{2}-2 \mathrm{Cm}$. longa, pinnatisecta; segmentis arrectis, imbricatis, saepissime tripartitis; lobis linearibus, integerrimis, mucronato-acutis, medio viridibus, hyalino-marginatis. Pedunculi 10-15 Cm. alti, hirtuli, canaliculato-subangulati. Involucri phylla lineari-lanceolata, dor'so dense pubescentia, interiora usque $8 \mathrm{Mm}$. longa.

In montibus karatavicis ad saxa prope Bala-kschi-ata et prope Turtschi. (A. Regel). 


\section{Pyrethrum transiliense.}

Tanacetum transiliense Herd. pl. Semenow. n. 543. - Richteria pyrethroides Kar et Kir. in Bull. Soc. Mlosc. 1842 p. 126. - Ledb. fl. ross. III. 518. - Herder pl. Semenow. n. 527. - Variat:

a. tomentosum; tomentoso-lanatum, caule humili usque spithamaeo, basi dense foliato, foliis $2-3$-pinnatisectis, capitulo pedunculato.

Richteria pyrethroides Herder 1. c.

$\beta$. subsessile; capitulis sessilibus v. subsessilibus, caule humili. Cetera ut praecedentis.

\%. subvillosum; laxe villosum v. canescenti-villosum v. demum glabrescens; caulibus spithamaeis et ultra, foliosis; foliis bi-tripinnatisectis; capitulis pedunculatis.

P. transiliense Herd. 1. c.

Habitat in alpibus alatavicis cis- et transiliensibus, in alpibus kokanicis et in alpibus thianschanicis. - (Schrenk, Karelin et Kirilow, Korolkow, Kuschakewicz, 0. Fedtschenko, A. Regel).

Bentham und Hooker haben Pyrethrum nebst vielen andern Gattungen, als Untergattung mit Chrysanthemum vereinigt. Der aus kurzen Spreublättchen bestehende Pappus unterscheidet Pyrethrum, wenn auch hier Abänderungen vorkommen, doch im Allgemeinen als gute, allerdings künstliche, - aber doch allgemein angenommene Gattung, von Chrysanthemum. Nachdem Schultz bip. alle Pyrethra und viele andere Gattungen mit Tanacetum vereinigt hat, - so würden durch Vereinigung (nach Bentham und Hookers jedenfalls richtiger begründeten Ansicht) von Pyrethrum etc. mit Chrysanthemum, wieder eine Masse neuer Synonyme entstehen, so dass wir es um so mehr für richtiger halten, die Gattung Pyrethrum beizubehalten, da ja auch Bentham und Hooker dieselbe als eine gute Untergattung oder Abtheilung betrachten.

Die Formen des P. transiliense, die wir hier aufführten, sehen in ihren von einander entferntesten Gestaltungen, so verschieden aus, dass man solche für verschiedene Arten hält, so z. B. diè dicht wcisswollige Form mit lang gestielten Blüthenköpfen und am Grunde des Stengels zusaınmengedrängten Blättern und die hohe lose beharte oder später ganz 
kahle höher am Stengel hinauf beblätterte Form. Die von den mannigfaltigsten Standorten uns vorliegenden Exemplare, führen aber die 3 angenommenen Formen so allınälig in einander über, dass man die Mittelformen ebenso gut zu der einen, wie zu der anderen Form stellen kann.

\section{Pyrethrum mucronatum Rigl. et Schmalh.}

Virescens, minute laxeque patenter hirtulum v. glabrescens. Folia tripinnatisecta; lobis oblongo-linearibus, in apiculum mucroniformem acuminatis Capitula longe pedunculata, in racemum laxum v. basi sinpliciter ramosum disposita. Involucri subhemisphacrici glabriusculi phyllis imbricatis; exterioribus brevioribus; interioribus longioribus, oblongis, hyalino sublaceroque marginatis, discum circiter aequantibus. Flores omnes tubulosi. Achaenia glabra. satis conspicue angulata, pappo coroniformi dentato-lobato corollae tubum dimidium subaequante coronata.

Valde affine Pyrethri millefoliati W. varietatibus, constanter ut videtur diversum «indumento, inflorescentia, pappi paleis corollae tubum dimidium subaequantibus et foliorum lobis in mucronem acuminatis».

In Turkestaniae montibus karatavicis prope Karagus et Dschie, in montibus alatavicis ad fluvia Tschirtschik et 'schotkal, 4600-6000' alt. (A. Regel), prope Taschkent (Korolkow); in Kokania ad fluvium Sarawschan inter Varsaminor et Peti (0. Fedtschenko).

\section{Tanacetum Herderi R.gl. et Schmalh.}

Humile usque spithamaeum, cinereo-tomentosum, suffruticosum, caespitosum. Caules floriferi simplices, adscendentes v. erecti, apice dense $v$. rarius laxe corymbosi, $2-6$ cephali. Folia ad ramulorum basin dense conferta, petiolata; lamina deltoideo-ovata usque elliptico-oblonga, biternati- v. bipinnatisecta v. rarius pinnatisecta, lobis obverse oblongis obtusis v. acutis, integris v. 2-3-dentatis: folia caulina pauca, decrescentia, suprema linearia integra. Corymbi pedunculi capitulo hemisphaerico saepissime brevior'es $v$. rarius longiores. Involucri pluriserialis discum aequantis phylla imbricata, cinereo-tomentella, nigro-marginata, exteriora breviora lanceolata acuta, interiora cuneato-obovata v. cuneatooblonga rotundato-obtusa. Flores homogami, omnes tubulosi, herma- 
phroditi, 5-dentati. Achaenia lineari-oblonga, compressa, dorso 1-2costata, apice omnino calva

Caules florifori $5-18 \mathrm{Cm}$. longi Involucri phylla $6-8 \mathrm{Mm}$. longa. Flores luteoli.

Tanacetum tomentosum Herder in pl. Semenow. n. 539. T. tomentosum DC. differt «capitulis subtriplo minoribus, involucri phyllis biserialibus disco brevioribus, foliorum lobis linearibus».

In montium alatavicorum cisiliensium jugo Alaman, $8000^{\prime}$ alt., (Semenow.), in Kokaniae alpibus ad fluvium Isphairam in jugo KtschiAlai, $10-13000^{\prime}$ alt. (0. Fedtschenko).

60. Tanacetum Scharnhorsti Rgl. et Schmalh.

Fruticulus pygmaeus, e basi ramosus, albo-tomentosus. Rami brevissimi, $1 / 2-2 \mathrm{Cm}$. longi, dense foliosi. Folia brevipetiolata, deltoideoobovata, flabellatim tripartita V. trifida; lobi obverse oblongi, obtusi, integerrimi. Capitula breve pedunculata, in ramorum apice solitaria, pedunculo quam capitulum breviore Involucri campanulati phylla imbricata, ovata, obtusa, late fusco-scarioso-inarginata. Flores omnes homogami, hermophroditi, tubulosi, 4- v. rarius 5-dentati, involucrum aequantes. Receptaculum convex0-conicum, nudum. Achaenia angulata, epapposa.

Fruticulus $1 \frac{1}{12}-3 \mathrm{Cm}$. altus, imbricato-foliatus. Folia $3-7 \mathrm{Mm}$. longa. Involucri phylla $4-5 \mathrm{Mm}$. longa, exteriora interioribus paullo breviora.

In alpibus thianschanicis occidentalibus Jack-tascha, Sujok, Sart et Baskaun (Scharnhorst).

«Indumento albo-lanato, foliis flabellato-trifidis, lobis integerrimis, ramis monocephalis, statura pygmaea» ab omnibus adhuc cognitis speciebus generis Tanaceti facile dignoscitur. 


\section{B. PLANTAE TURKESTANICAE \\ A REGELIO ET SMIRNOWIO DETERMINATAE \\ auctore E. Regel.}

\section{Borragineae.}

61. Nonnea picta $M$. $B$.

Fl. taur. cauc. I. pag. 127. sub Anchusa. - Boiss. fl. orient.

IV. 166.

\section{Variat:}

a. typica; corollis calycem paullo superantibus rubro-violaceis. N picta Fisch. Mley. ind. sem. h. Petrop. II. pag. 43. Ledb. fl. ross. III. 110.

ß. caspica; corollis calycem subduplo superantibus violascentibus. N. caspica G. Don gen. syst. IV. p. 336. - Ledb. fl. ross. III. p. 110.

$\%$ sordida; corolla flavescente, calycem paullo usque sesqui superante. N. sordida Fisch. et Mey. ind. sem. h. Petrop. II p. 43. - Ledb. fl. ross. III. p. 110.

In regionibus turkestanicis et kokanicis satis communis.

62. Nonnea melanocarpa Boiss.

Boiss. diagn. ser. I, fasc. 11. pag. 96. - Ejusd. fl. or. IV. p. 165. - N. philistaea Boiss. diagn. ser. I. fasc. 11. pag. 96. Ejusd. fl. or. IV. pag. 166.

Differt solummodo a $\mathrm{N}$. picta «calycis ad tertiam partem quinquefidi dentibus triangularibus acutis (nec calycis ad medium quinquefidi dentibus acuminatis), foliis floralibus oblongis acutis (nec attenuatoacuminatis)" .

Habitat in regionibus turkestanicis et kokanicis satis frequens.

63. Lithospermum arvense L. - L. spec. 190.

a. album; floribus albis. L. arvense L. 
ß. caeruleum; floribus caeruleis. L. Sibthorpianum Griseb. L. incrassatum Guss. - L. tenuiflorum L. - Cfr. Boiss. fl. orient. IV. fasc. 1. pag 216. 217.

Nuculac variant dense v. laxe tuberculatae v. scrobiculatae tuberculis subnullis.

Forma floribus caeruleis in regionibus turkestanicis frequentior quam forma typica floribus albis.

64. Arnebia cornuta $F$. et $M$.

Ind. sem. h. Petrop. I. p. 22. - Ledb. fl. ross. III. 139. Trautv. pl. Schrenk. n. 787. - Boiss. fl. or. IV. 213.

Species valde variabilis, variat caule humili v. pedali et ultra, a basi ramoso v. subsimplici, setis rigidis patulis laxe usque densissime vestito; corolla tubo calyce sesqui-triplo longiore, limbo quam tubus duplo-5-plo latiore; antheris ad faucem insertis $v$. in tubo dispersis; tubi squamis basilaribus brevibus $\mathrm{v}$ magis elongatis, glabris $\mathrm{v}$. ciliatis v. subhirsutis.

A Clarissimo Trautvettero varietates subsequentes dignoscuntur:

a. parviflora; corollae limbo tubo vix duplo ampliore (Trautv. l. c.)

ß. grandiflora; corollae limbo tubo $3-5$-plo ampliore. (Trautv. l. c.).

In regionibus turkestanicis satis frequens.

65. Echinospermum rupestre Schrenk.

Schrenk in Bull. Ac. Petr. II. 194. - Ledb. fl. ross. IIl. 161. E. microcarpum $\beta$. rupestre Rgl. pl. Semenov. n. 753.

Variat calycis laciniis quam caryopses longioribus v. brevioribus, caryopsium marginibus saepissime serie simplici aculeorum brevissimorum armatis v. rarius omnino laevibus.

a. typicum; caryopsibus margine serie aculeorum brevissimorum armatis.

E. rupestre Schrenk. l. c.

Hab. in regionibus turkestanicis orientalibus. 
3. laeve Rgl. et Smirnow.; caryopsibus margine omnino laevibus.

In regionibus turkestanicis, Alatau (Schrenk) (lusus calycis laciniis quam caryopses brevioribus $r$. aequilongis), in valle Talas montium Alatau (A. Regel) (lusus calycis laciniis caryopses superantibus).

66. Heterocaryum minimum A. DC.

H. minimum et H. rigidum A. DC. prodr. X. p. 144 et 145 . Ledb. fl. ross. III, pag. 163. - Echinospermum minimum Lehm. Asp. p. 126. - Rochelia echinophora Röm. et Schult. syst. IV. 110. Myosotis echinophora Pall. it I!I. app. 717.

Variat caryopsium disco varie tuberculato (H. minimum A. DC.) $\mathbf{v}$. in uno eodem specimine tuberculis disci praecipue in mediano in aculeos breves v. longiores transeuntibus. Caulis nunc pygmaeus pollicaris, nunc elatior pedalis et ultra.

In regionibus turkestanicis satis frequens.

\section{Cynoglossum macranihum Rgl. et Smirnow. ")}

Caulis erectus, ramosus, patente-hispidus. Folia oblongo-lanceolata, acuta, utrinque strigilloso-hispida, omnia basin versus attenuata,

\section{*) Cynoglossum L.}

SECTIO II. Corollae tubus calycem sesqui-duplo superans. Stamina fauce v. sub fauce inserta, plus minus e tubo exserta. (Lindelofia Lehm. in Hambrg. Grtztg. 1850. p. 352. - Benth. et Hook. gen. plant. II. p. 848)

Dispositio specierum.

a. Nuculae margine serie simplici aculeorum glochidiatorum basin versus valde dilatatorum armatae, disco parce tuberculatae.

C. longiflorum Lehm., foliis superioribus basi cordato-amplexicaulibus. - C. longiflorum Lehm. in bot. reg. XXVI. tab. 50. - Lindelofia spectabilis Lehm. 1. c. - Hab. in montibus elatioribus Indiae orientalis.

b. Nuculae margine seriebus pluribus aculeorum glochidiatorum majorum basin versus valde dilatatorum, disco aculcolis brevibus glochidiatis sparsis armatcie. 
inferiora petiolata, superiora breviter petiolata v. sessilia. Florum racemi in apice ramulorum divaricato-geminati, secundi, laxiflori, ebracteolati, albido hirtulo-villosi, fructiferi erecti. Pedicelli calycem aequantes usque eo duplo longiores. Calycis lobi oblongi, obtusiusculi, corollae tubo sesqui usque duplo breviores, latere exteriore albido-lanati. Corollae limbus campanulatus, tubum aequans v. superans, quinquelobus. lobis rotundatis; fornices fauci inserti, oblongi, antherae superantes; stami cum fornicibus alternantia, sub tubi apice inserta; filamenta brevissim. antherae e basi sagittata lineares, e tubo exsertae. Stylus longissimus, florem superans.

In T'urkestania prope Taschkent floribus caeruleis (A. Regel), ad fluvium Syr. Darja floribus ut videtur albis (Golicke).

\section{Macrotomia onosnvides Rgl. et Smirnow.}

Pilis setosis patulis tuberculo insidentibus hispida. Collum pluricaule, squamis fuscis oblongo-lanceolatis vestitum. Caules erecti v. adscendentes, folia radicalia circiter duplo superantes pedales et ultra. Folia oblongo-linearia, obtusiuscula; radicalia caulinis 3-4-plo longiora, in petiolum angustata; caulina sessilia, basin versus paullo angustata. Panicula terminalis, contracta, e racemis $4-5$ composita; racemis brevibus, paucifloris, fructiferis vix elongatis, bracteatis. Bracteae foliaceae, calycibus longiores. Calycis 5-partiti laciniae lineares, longissimae, acutae, dense hirsutae, corollam (demum) superantes, calyris fructiferi $2 \mathrm{Cm}$. et ultra longae. Corolla tubulosa, intus inter lobos plicata; tubo glabro circiter $1 \mathrm{Cm}$. longo, limbo extus strigoso-piloso circiter $\breve{\mathrm{Mm}}$. longo; limbi erecti 5 -lobi lobis ovato-oblongis obtusis concavis. Stamina

C. macrostylum Bnge., foliis omnibus in petiolum attenuatis, racemis paucifloris bracteolatis, pedicellis calycem duplo-usque triplo-superantibus. - C. macrostylum Bnge. reliq. Lehm. n. 942. - Habitat inter Buchara et Samarkand et in valle superiore fluvii Sarawschan (Lehmann).

c. Nuculae margine seriebus pluribus aculeorum glochidiatorum basin versus vix dilatatorum, disco aculeis similibus satis dense dispositis armatae.

C macranthum Rgl. et Snirnow. 
5, tubo sub fauce inserta; filamenta brevissima; antherae linearioblongae, obtusae, erectae, medio dorsi affixae, limbi lobis alternae, e tubo breviter exsertae. Ovarium 4-lobum. Stylus filiformis, simplex, stigmate capitato bilamellato terminatus. Nucula abortu solitaria, ad styli basin lateralis, erecta, areola basilari plana, rugulosa, ovata, in apicem brevem ancipitem excurrens.

Taldi-usen in inontibus alatavicis legit $\mathrm{Cl}$. Kuschakewicz.

Affinis M. perenni Boiss. (fl. or. IV. p. 212 in adn. - Arnebia perennis A. DC. prodr. X. p. 95. - Ledb. fl. ross. III. p. 139. Stenoselenium perenne Schrenk enum. pl. nov. p. 34. - Lithospermum euchromum Royle et Benth. ill. p. 305. - DC. prodr. X. p. 82. Royle pl. exsicc.) et M. cyanochroae Boiss. (Boiss. fl. or. IV. p. 212). Una «corolla calycem superante limbo explanato, antheris in medio $\mathbf{v}$. infra medium tubi insertis» - altera «caulibus pumilis folia radicalia vix superantibus, foliis caulinis e basi latiore oblongo-lanceolatis, corolla calycem superante, nuculis cristato-tuberculatis dignoscuntur.

Die Wurzel dieser Art wird von dem Kirghisen, ganz wie die Wurzel von M. perennis zum Färben von Baumwolle, zum Schminken u. s. f. verwendet.

\section{Kuschakewiczia Rgl. et Smirnow.}

Calyx profunde quinquefidus, segmentis oblungis, fructifer vix auctus. Corolla tubulosa, sub fauci 5 -squamata, limbi lobis 5 erectis parvis obtusis. Stamina fauce inserta, longe exserta, filamentis filiformibus; antherae parvae, ovatae, obtusae, dorso insertae, versatiles. 0varii lobi 4, distincti; stylus filiformis, stigmate parvo. Nuculae juniores abortu binae v. solitariae, maturae semper solitariae, compressoglobosae, erectae, aculeis glochidiatis omnino armatae, monospermae. Semina immatura obovata, plano-compressa.

Solenanthus, cui genus nostrum habitu proximum, differt «staminibus medio tubi $v$. inferius affixis, nuculis 4 depressis facie antice areola concava saepe marginata praeditis». 
69. K. turkestanica. Jerennis, radice crassa perpendiculari, collo multicipite. Herba tota pilis adpressis v. vix patulis hirtulo-incana. Caules erecti v. adscendentes, pedales et ultra, foliati. Folia oblongolanceolata, integerrima v. rarius obsolete paucidenticulata. Florum corymbus terminalis, pedunculatus, initio subcapitatus, demum subumbellato-ramosus, racemis sub anthesi capitato-scorpioideis, demuin magis elongatis. Calycis segmentis obtusis, tubum corollae circiter aequantibur circiter ' $\mathrm{Mm}$. longis.

In Turkestania prope urbem Taschkent (Kuschakewicz), in montibus karatavicis prope Ak-su (Sewerzow).

70. Rochelia leiocarpa Ledl. fl. alt. 172.

a. typica; setis adpressis hirta, pedicellis calycem circiter aequantibus, calycis laciniis fructu vix longioribus.

In Turkestaniae regionibus satis frequens.

3. major; setis erecto patulis patentissimisque hirta, pedicellis calycem duplo majorem paullo usque duplo superantibus, calycis laciniis fructu subduplo longioribus.

Ad fluvium Koldjir in regione Saissan (Potanin), prope Wernoje (Kuschakewicz).

C. PLANTAE TURKESTANICAE A REGELIO ET SCHMALHAUSENIO DETERMINATAE auctore E. Regel.

\section{Scrophulariaceae.}

71. Veronica argute serrata Rgl. et Schmalh.

Prostrata, hirsuta. Folia breviter petiolata; inferiora opposita, cuneato-lanceolata usque cuneato-ovata, acuta, argute subinciso-serrata ; floralia subconformia. Pedunculi filiformes, axillares, folium sub- 
aequantes v. paullo superantes, post anthesin plus minus recurvati. Calycis fructiferi 4-partiti segmenta divaricata, elliptica, acuminata, integerrima, capsulam superantia. Corolla calycem circiter aequans. Capsula compressa, hirsutissima, profunde (usque ad 2/3) biloba, sinu acuto; loculis ovatis, erecto-patentibus, stylum duplo superantibus, saepissime 3 -spermis. Semina ovato-oblonga, facie concava, dorso pnvexa, laevia.

Proxima species Veronica Buxbaumii Ten. facile dignoscitur "pilositate laxióre, foliis basi rotundatis v. subcordatis grosse crenato-serratis (dentibus obtusis nec acutis), pedunculis folium usque duplo superantibus, capsulae lobis subhorizontaliter patentibus pilis brevioribus hirtis, stylo emarginaturam capsulae superante, seminibus tuberculatis, corolla calycem duplo superante». Calyce capsulaque V. bilobae L., habitu foliisque V. Buxbaumii et $\mathrm{V}$. agresti affinis.

In Turkestaniae montibus alatavicis in valle fluvii Karokol leg. A. Regel.

\section{Selaginaceae.}

72. Gymnandra Korolkowi Rgl. et Schmalh.

Glabra, estolonifera. Folia omnia radicalia, lineari-lanceolata, utrinque attenuata, usque $31 / 2 \mathrm{Cm}$. longa et $1 / 2 \mathrm{Cm}$. lata, superne irregulariter dentata, apice et a basi ad medium integra. Spica densa subcapitata, incluso caule florifero brevissimo foliis brevior. Bracteae anguste lineari-lanceolatae, corollis breviores. Corollae tubus calyce spathaceo triplo longior. Stamina 2, antherae maximae subexsertae. Stylus limbo paullo brevior. - Flores rubri, tubo $8 \mathrm{Mm}$. longo.

G. stolonifera C. Koch, cui species nostra valde affinis, differt: - stolonibus foliatis, foliis oblongis, bracteis oblongis flores subaequantibus, corollae tubo $5 \mathrm{Mm}$. longo limbum vix duplo superante, stylo limbum superante» .

In Turkestaniae montibus alatavicis Aktag-tau $8-11,000$ ped. alt. leg. Korolkow. 
Die Verwandtschaft obiger Art mit G. stolonifera C. Koch ist so bedeutend, dass wenn nicht bei allen uns vorliegenden Exemplaren auch jede Andeutung der Bildung von Stolonen fehlen würde, wir unsere Pflanze als Form mit schmaleren Blättern und Brakteen und längerer Blumenkrone zu G. stolonifera genommen haben würden. Die fernere Beobachtung der bis jetzt uns in wenigen Exemplaren bekannten G. stolonifera und unserer neuen Art, kann da erst später entscheiden.

\section{PLANTAE REGIONES TURKESTANICAS INCOLENTES SECUNUUM SPECIMINA VIVA}

IN HORTO IMPERIALI BOTANICO CULTA DESCRIPŢA.

\section{Auctore E. Regel.}

1. Allium talassicum Rgl.

Bulbis oblongo-cylindricis, rhizomati oblique descendenti insidentibus, aggregatis: tunicis fuscis, nervis parallelis demum prominentibus instructis, integris v. apice plus minus laciniatis; caule erecto, tenui, tereti, laevi, supra medium foliato; foliis semitereti-filiformibus, margine sub lente tenuissime serrulato-scabris, caeterum vaginisque glabris, caulem subaequantibus $\mathbf{v}$. superantibus; spatha umbellam aequante usque triplo superante; umbella capsulifera, multiflora, hemisphaerica; pedicellis subaequalibus, perigonium paullo superantibus, omnibus rectis, basi bracteolatis; sepalis elliptico-lanceolatis, acutis; filamentis simplicibus, e basi paullo latiore subulatis, sepala aequantibus, basi inter se breviter connatis; ovario subgloboso; stylo stamina vix superante.

Bulborum tunicae exteriores saturate fuscae, nervis parallelis prominentibus pallidioribus notatae, interiores fusco-stramineae. Caules $15-25 \mathrm{Cm}$. alti. Folia supra canaliculata. Spatha univalvis, e basi latiore menbranacea integra v. vix bifida in rostrun subulatum attenuata. 
Pedicelli $4-5 \mathrm{Mm}$. longi. Sepala $3{ }^{1} / 2-4 \mathrm{Mm}$. Ionga, alba, nerro medio viridi instructa. 0varium ovato-subglobosum (nee angulatum).

Affine A. subgloboso, facile autem diguoscitur "staninibus perigonium aequantibus (nec sesqui-duplo superantibus), caule supra mediun (nec, infra mediun) foliato, spatha univalvi (nec bivalvi), sepalis albis nervo viridi notatis, ovario ovato-subgloboso (nec acute trigono)".

In Turkestaniae montibus alatavicis Kara-T'schok in valle fluvii alas legit A. Regel.

\section{Allium teretifolium Rgl.}

Bulbo rhizomati descendenti insidente, oblong0; tunicis exterioribus caulis basin alte illvolucrantibus, fuscescentibus, demum reticulatofibrosis; caule tereti, glabro, sub ad medium foliato, folia subulata teretia glaberrima superante v. subaequante; spatha univalvi v. rarius bivalvi pedicellos superante, quam flores breviore; umbella capsulifera, pluriflora, fastigiata; pedicellis perigonio subduplo brevioribus, basi bracteolatis; sepalis oblongis, in tubum subcampanulatum conniventibus, in apicem obtusum sensim attenuatis, stamina paullo superantibus; filamentis simplicibus, subulatis, ima basi inter se et cum sepalis brevissime connatis, alternis basi latioribus.

Caulis erectus v. adscendens, flexuosus, $20-30 \mathrm{~cm}$. altus. Folia glaberrima, teretia, latere superiore non sulcata. Spatha saepissime univalvis, scariosa, e basi lata ovata in apicem linearem acuminata. Pedicelli erecti, $4-5 \mathbf{M m}$. longi. Sepala albida, nervo intermedio viridi percursa, 8-9 $\mathrm{Mm}$. longa et vix $3 \mathrm{Mm}$. lata. Ovarium conicum, subhexagonum, album et ad angulos stria fusca notatum, stylo subulato quam stamina breviore coronatum.

A. moschatum L., cui species nostra satis affinis, differt «bulbi tunicis exterioribus brevioribus, foliis supra canaliculatis margine saepissime ciliolato-scabris, spatha bivalvi pedicellis breviore, pedicellis perigonium plus minus superantibus, staminibus basi inter se aequalibus».

Habitat in Turkestania austro-orientali in jugo Altigimel ad lluvium 1li. Bulbos legit A. Regel. 


\section{Allium schönoprasoides Rgl.}

Omnino glabrum. Bulbi globosi tunicis albo-membranaceis; caule elatiore, infra medium foliato, foliis tereti-filiformibus fistulosis breviore; spatha quam umbella breviore, scariosa, initio univalvi, breviter acuminata; umbella capsulifera, subglobosa; pedicellis flore evoluto paullo usque duplo brevioribus, basi nudis; sepalis ovato-oblongis, nitentibus, pallide roseis, obtusiusculis; filamentis perigonio $1 / 3$ brevioribus, ba tantum connatis; exterioribus e basi latiore sensim in apicem subulatul, attenuatis; interioribus valde dilatatis, rectangulis, sub apice utrinque unidentatis et subito in filamentum breve subulatum excurrentibus; ovario globoso, apice minute 6-dentato, stylo brevi inter dentes immerso coronatum.

Sepala $6-7$ Min. longa. Habitu A. Schönopraso, characteribus A. caesio affine, unum "staminum ovariique configuratione», alterum «foliis semiteretibus, floribus albidis plus duplo minoribus, ovario apice stylo terminato» facile dignoscuntur.

Prope Wernoje. (Fetisow).

4. Allium semiretschenskianum Rgl.

(Allium, sect. Schönoprasum, subdivisio 2. B. b. a. cfr. Rgl. Allium).

Glabrum. Bulbi globosi tunicis membranaceis, integris; caule erectn, tereti, ad medium foliato, folia linearia supra canaliculata infra convexa subaequante; umbella capsulifera, multiflora, hemisphaerica; pedicellis filiformibus, flores pluries superantibus, basi minute bracteolatis; sepalis lineari-oblongis $\mathrm{v}$. lanceolato-oblongis, obtusiusculis, carneis, subconcoloribus; filamentis perigonium subduplo superantibus, ima basi tantum coalitis, exterioribus filiformibus initio brevioribus demum aequilongis, interioribus e basi dilatata ovata v. ovato-oblonga integra v. obscure dentata filiformibus.

Bulbi tunicae hyalino-scariosac. Caulis $40-45 \mathrm{Cm}$. altus, ut folia subfistulosa glaucescentia. Spatha hyalino-scariosa, quam umbella plus 
duplo brevior, biluba, lobis suborbicularibus in acumen breve productis. Pedicelli usque $2 \mathrm{Cm}$. longi. Sepala $4 \mathrm{Cm}$. longa, concolora v. nervo medio paullo intensiore notata. Ovariun subglobosum, stylo filiformi initio brevi demum sepala subaequante coronatum, stigmate minuto acuto.

Allium Pallasi Murr. cui valde simile, "bulbo ovato, floribus basi nudis minoribus, sepalis latioribus nervo pupureo notatis, filamentis inter e subaequalibus edentulis omnibus e basi dilatata in filum attenuatis petala paullo-sesqui superantibus, stigmate subcapitato» differt.

Prope Wernoje (A. Regel).

\section{Allium Fetisowi Rgl.} Allium).

(Allium, sect V. Molium. B. Umbella capsulifera, cfr. Rgl.

Bulbi depresso-globosi tunicis albo-membranaceis, integris; caule erecto, tereti, laevi, basi $2-3$ folio, folia superante; foliis oblongo- vel lineari-lanceolatis, planis; umbella capsulifera, multiflora, initio hemisphaerica, demum subglobosa; pedicellis subaequalibus, 2-3-plo perigonium superantibus, basi nudis; sepalis lineari-subulatis, acutis, nervo concolore parum conspicuo percursis, initio erecto-patentibus, demum reflexis, ima basi coalitis, initio stamina superantibus, demum ea subaequantibus v. paullo superantibus; filamentis ima basi coalitis, interioribus basi utrinque dentatis, dentibus subulatis elongatis simplicibus v. bifidis; ovario subgloboso, obtuse trigono, loculis apice rotundatis; stylo stamina subaequante, stigmate indiviso non incrassato, acuto. Glabrun. Caulis laete viridis, circiter $60 \mathrm{Cm}$. altus. Folia ${ }^{3 / 4}-2 \mathrm{~cm}$. lata, 25-40 Cm. longa, plana v. leviter concava, flaccida, striata, sensim attenuata, margine glabra v. sub lente tenuissime serrulatoscabriuscula. Spatha scariosa, albida, bifida; valvis ovato-subrotundis, quam pedicelli brevioribus.

Pedicelli $1 \frac{1}{2}-2$ Cin. longi. Sepala $6-7$ Mm longa, circiter $1 \mathrm{Nm}$. lata, e roseo lilacina, concolora. Stamina roseo lilacina; antherae cinereo-caerulescentes.

Bulbos misit cl. Fetisow e Wernoje in Turkestania orientali. 
Affine A. sarawschanico Rgl. (All. mon. n. 243), dignoscitur autem "sepalis angustioribus concoloribus nervo medio parum conspicuo instructis (nec lineari-lanceolatis nervo purpureo instructis), filamentis interioribus basi utrinque dentatis, dentibus subulatis elongatis simplicibus v. bifidis (nec filamentis interioribus utrinque brevissime unidentatis), ovarii trigoni loculis apice rotundatis (nec ovarii hexagoni loculis apice obtuse bidentatis)».

\section{Allium Alberti Rigl.}

(Sectio II. Schönoprasum. Subdivisio II. Folia teretia v. semiteretia. B. Bulbi tunicae demum reticulato-fibrosae. Cfr. Rgl. All. monogr.).

Bulbi ovati tunicis exterioribus tenuibus totis reticulato-fibrosis; caule tereti, laevi, glabro, ad tertiam partem foliato, folia filiformi-semiteretia supra canaliculata superante. Spathae albido-scariosae bifidae valvis ovato-subrotundis, breviter acuminatis, quam pedicelli triploquadruplo brevioribus; umbella capsulifera, subhemisphaerica, multiflora; pedicellis subaequilongis, basi nudis, florum abortivorum rudimentis minimis intermixtis; sepalis lineari-lanceolatis, obtusiusculis, erectopatentibus, quam stamina sesqui brevioribus ; filamentis subulatis, liberis, interioribus basi paullo dilatatis.

Bulbi tunicae interiores membranaceae, albidae, integrae. Caulis flexuosus, $20-30 \mathrm{Cm}$. altus. Folia glabra. Pedicelli filiformes, teretes, 12-17 Mm. longi, rosei. Sepala pallide rosea, dorso nervo medio intensiore roseo, circiter $4 \mathrm{Mm}$. longa et $1 \mathrm{Mm}$. lata. Ovarium depressoglobosum, stylo brevi quam filamenta pluries breviore terminatum, stigmate indiviso acuto.

Affine A. sindjarensi Boiss. et Hauskn. et A. moschato. Unum "sepalis ovato-lanceolatis acuminatis filamenta paullo - $1 / 3$ superantibus» - alterum «sepalis stamina $1 / 3$ superantibus, spathae valvis in mucronem setaceum saepe elongatum acuminatis, pedicellis saepissime valde inaequalibus» dignoscuntur.

In collibus arenosis prope Suiduu ad fluvium Ili (A. Regel). 


\section{Corydalis Kolpakowslitana Rigl.}

Bulbosa, glauca, glaberrima. Caulis basi unisquamatus, ramusus; ramis basi 1-pleiophyllis, infra medium monophyllis. Folia trisecta, segmentis petiolatis subternato-pinnatisectis, so.gmentulis cumeato-obovatis antice bi-5-lobatis, lobis oblongis obtusis. Bracteae oblongac, integrae, pedicello breviores. Flores in racemum elongatum laxum dispositi, biliiati, labio superiore et inferiore ovatis explanatis apice emarginatis. Calcar subrectum, pedicellum subsesqui superans, apice gibbo obtuso subrecurvo. Siliquae pendulae, subelliptico-oblongae.

Species proxime affinis C. longiflorae, dignoscitur autem « caule subsimplici, bracteis pedicellum aequantibus v. superantibus, corollae labio utroque naviculari (nec explanato), calcari subulato acuto pedicellum $2-3$-plo superante, leguminibus lineari-oblongis » .

Habitat in Turkestaniae locis urbem Wernoje ambientibus, ad fluvium Alnatinka, in jugo Altigimel, (A. Regel).

Variat floribus pallide roseis v. albidis purpureo-variegatis v. purpureis fauce albidis.

\section{Iris Eulefeldi Rgl.}

Foliis ensiformibus scapo, basi subfoliato caeterum aphyllo bifloro sub anthesi brevioribus, post anthesin eum superantibu circiter $1^{1 / 2} \mathrm{Cm}$. latis, glaucis, rectis v. leviter falcatis; spathis herbaceis, margine membranaceis obtusis $v$. acutis (nec acuminatis) perigonii tubun subaequantibus; floribus breviter pedunculatis; perigonii tubo ovario subduplo longiore; limbi laciniis obtusissimis, emarginatis; exterioribus cuneatoobovatis, eximie recurvis, pallide violaceis, intus a basi supra medium barbatis, sensim in unguem fusco-venosum attenuatis, - interioribus spathulato-oblongis, erectis, basi flarescentibus fusco-renosis, medio fuscescentibus, apice pallide violaceis; stigmatibus oblongis quam petala subduplo brevioribus, apice bifidis, lobis acutis grosse serratis; antheris quam filamenta paullo brevioribus.

Affinis species J. Bludovii Ledb. "spathis acuminatis $\mathbf{v}$. subacumi- 
natis, perigorii tubo ovarium subaequante, limbi laciniis latioribus obovatis flavis purpure0-renosis» dignoscitur.

Habitat in montibus thianschanicis in angustiis fluvii Talki (A. Regel).

9. Iris (Xiphion) Kolpakou'skiana Rgl.

Tunica bulborum fibroso-reticulata, fibris satis crassis irregularite anastomosantibus (nec ut in I. reticulata pinnato-anastomosantibus) Scapus brevissimus, humilis, uniflorus; vagina basilari solitaria aphylla scapum foliorumque basin involucrante (nec ut in I. reticulata vaginis nonuullis aphyllis patulis). Folia circiter 4 , glauca, linearia, erecta v. recurva, subtus carinata, sub anthesi floris tubum circiter aequantia, post anthesin magis elongata. Flos vaginis duabus oppositis ovarium florisque tubum supra medium involucrantibus. Perigonii tubus limbum aequans v. superans; phylla exteriora, e basi late lineari-unguiformi in apicem ellipticum acutum v. acuminatum v. obtusiusculum excurrentia, ungue margine caeruleo, in mediano croceo, lamina caerulea; phylla interiora exterioribus longiora, caerulea, erecta, cuneato-oblong0-elliptica, acuta v. subobtusa, integra v. monstrositate ad tertiam partem bifida.

In Turkestania prope Wernoje in pratis frequentissima. (Fetisow, A Regel). *)

Kolpakowskia Rgl.

(Amaryllidearum genus novum).

Perigonium superum, corollaceum, persistens; tubo angusto, cylindrico, apice paullo tantum ampliato; limbo sexpartito; laciniis $2-3$ nerviis, angustis, erecto-patulis v. demum patulis recurvis, aequilongis. Stamina 6 , tubo adnata; tribus brevioribus e tubo vix exsertis, tribus

") Die früher von uns gegebene Beschreibung (Cfr. acta h. Petrop. V. fasc. I. p. 263) war nach einem im Topfe im Gewächshause blïhenden monströsen Exemplar gemacht worden. Zweitheilige innere Blumenblätter sahen wir dieses Jahr an keinem der zahlreichen Exemplare die im freien Lande zur Blüthe kanen. 
longioribus exsertis quam laciniae perigonii duplo-triplo brevioribus; filamentis staninum breviorum filiformibus, staminum longiorum daplo latioribus compresso-planis. Antherae biloculares, oblongac, erectue, latere interiore rimis duabus longitudinalibus dehiscentes, dorso in incisura basali fixae. Ovarium inferum, oblongum, obtuse trigolum. Ovula in loculis crebra, angulo interno per duas series inserta. Stylus filiformis, tamina longiora circiter aequans, stigmatibus tribus subulatis.

Planta perennis bulbosa habitu Ixiolirionis, snbsequentibus characteribus autem dignoscitur: "Caulis simplex, foliatus, apice racemososubumbellato-pauciflorus. Folia linearia, inferne vaginantia, decrescentia, superiora bracteiformia flores stipantia. Perigonii gamopliylli tubus cylindricus, gracilis; filamentis tribus longioribus latioribus compresso-planis ; antheris latere interiore rimis duabus longitudinalibus dehiscentibus».

In itinere ad lacum Sairam legit A. Regel Viro Clarissimo Kiolpakowskio, protectore scientarum ıaturalium, hoc genus dedicavimus.

\section{Kolpakonskia ixiolivioides Rggl.}

Bulbus oblongus, basi bulbillos solitarios breviter petiolatos exserens; tunicis membranaceis, fuscis, arcte imbricatis. Caulis glaber, teres, 20-25 Cin. altus, foliatus. Folia glabra, anguste linearia, latere superiore canaliculata, latere inferiore convexa, caule breviora; inferiora in verticillum 3-4-phyllum disposita; folium intermedium solitarium; folia superiora bracteiformia, flores stipantia, plus minus hyalino-marginata. Flores erecto-patentes, pedunculati; pedunculo glabro, flore breviore, inferior solitarius remotus, superiores subumbellati. Perigonium pallide violascens, circiter $3 \mathrm{Cm}$. longum; laciniis tubum subaequantibus, lineari-oblongis, in mucronem acuminatis, in mediano $2-3$-nerviis, initio erecto-patentibus, demum patenti-recurvis.

\section{Scorzonera tragonogonoides Ryl. et Schmalh.}

Radix perennis, fusiformis. Caulis solitarius, erectns, $20-60 \mathrm{Cm}$. altus, plus minus dense floccoso-lanatus, foliatus. Folia plurinervia, 
late linearia v. anguste lineari-lanceolata; radicalia et caulina inferiora in petiolum attenuata; superiora basi semiamplexicauli sessilia; omnia apicem versus attenuata, margine scaberula. Capitula plura, racemosa v. corymbosa, lateralia axillaria. Pedunculi breves v. magis elongati, foliis paucis brevibus v. elongatis instructi. Involucri cylindrici imbricati tenuiter floccoso-tomentosi phylla ovata, abbreviata, acuminata; interna anguste lineari-lanceolata, floribus carneis purpureo striatis paullo breviora. Rece ptaculum planum, nudum. Achaenia elongata, rostrata, incluso papp involucrum aequantia, costato-striata, praecipue apicem versus scaberula.

Pappus achaenium subaequans, setis conformibus plumosis, plumulis intricatis.

Folia decrescentia, inferiora $15-25 \mathrm{~cm}$. longa. Involucri phylla interiora usque $5 \mathrm{~cm}$. longa.

Affinis S. macrospermae Turcz. et S. cilicicae Boiss. Una «caule foliis involucris glabris, pedunculis subnudis (squamulis paucis parvis instructis), involucro breviore» - altera «indumento serice o-canescente, pedunculis nudis v. squamula lineari instructis, capitulis brevibus, achaenio cum pappo pollicari, floribus luteis» dignoscuntur.

Semina misit Cl. Korolkow e regionibus turkestanicis.

\section{Tulipa triphylla $R g l$.}

Bulbi ovato-oblongi tunicae atrofuscae, latere interiore apice tantum strigoso-pilosae v. totidem glabrae. Caulis 6-10 pollices altus (pars subterranea $1-2 \mathrm{Cm}$. longa), uniflorus, a basi ad apicem nudus, apice triphyllus, glaber. Folia subverticillata, canaliculata, late linearia, florem superantia, immarginata, $15-20 \mathrm{Cm}$. longa, 5-7 Mm. lata, margine ciliolata v. totidem glabra. Pedunculus glaber, suberectus. Sepala ovato-oblonga, erecto-patentia, glaberrima, flava; interiora ex apice rotundata apiculata; exteriora subacuta, dorso virescentia; omnia circiter $3 \mathrm{Cm}$. longa et $1 \frac{1}{4} \mathrm{Cm}$. lata. Stamina quam corolla triplo breviora; filamenta medio latiora, utrinque attenuata, glaberrima, antherain lineari-oblongam subaequantia. Pistillum filamenta paullo superans, stigmate trigono terminatum. 
Glabritate sepalorum filamentorumque a varietatibus T. sylvestris diversa. Proxime affinis T. soogdianae Bunge, T. armenas Boiss. et T. tetraphyllac Rgl. (acta horti P'etr. III. 1. 296). Una et altera bulbi tunicis intus dense pilosis dignoscuntur; posterioris bulbus ignotus, differt tamen «caule terra sepulto tetraphyllo, foliis cartilagineo-Inarginatis, floribus dimidio minoribus, sepalis exterioribus violaceo-variegatis».

Bulbos legit $\Lambda$. Regel in collibus arenosis inter Kuldscha et lacum Sairam.

\section{Tulipa Kesselringi Rgl.}

Tulipa, sectio $\mathrm{P},{ }^{* *},+$, cc. (cfr. Rgl. Tulipa).

Bulbi tunicae intus apicem versus strigoso-pilosae, coriaceae. Folia 4, supra terram ad caulis basin conferta, erecto-patentia, anguste linearilanceolata, pedunculo glabro nudo breviora, usque $18 \mathrm{~cm}$. longa, $3 / 4-11 / 4 \mathrm{Cm}$ lata, canaliculata, subundulata, glaberrima, immarginata. Perigonium erectum; sepala erecta, patentia, oblongo-lanceolata, subaequalia, basi et apice glabra. Stamina glabra, inclusa anthera pistillo breviora. Filamenta ovata, antheris linearibus paullo breviora. Pistillum trigonum, stigmate trilobo quam diameter pistilli angustiore coronatum.

Perigonium flavum; sepala usque $4 \frac{1}{2} \mathrm{Cm}$. longa, $14 \mathrm{Mm}$. lata, exteriora ante marginem stria purpurea notata, interiora apice albida, omnia basi immaculata.

Affinis T. Kolpakowskianae et Gesnerianae, una et altera «foliis sparsis, filamentis linearibus» dignoscuntur, praeterea T. Kolpakowskiana "pistillo filamenta subaequante» et T. Gesneriana «foliis latioribus stigmateque parro» diversae.

Bulbos misit A. Regel e regionibus turkestanicis. Dedicavi cultivatori eruditissimo J. Kesselring. 


\section{E. PLANTARUM DIVERSARUM IN HORTO BOTANICO}

\section{IMPERIALI PETROPOLITANO CULTARUM DESCRIPTIONES}

\section{auctore R. Regel.}

\section{Bulbocodium Eichleri Rgl.}

Bulbus oblongo-ovatus, triphyllus, biflorus, flore altero hermaphrodito, altero masculo. Folia lineari-ligulata, canaliculata, sub anthesin flores triplo superantia, acutiuscula. Perigonii hexaphylli foliola longissime unguiculata, in tubum conniventia, omnia ad basin laminae ungue plus triplo brevioris sagittata. Stamina 6 , perigonii foliolis supra ungues inserta. Filamenta filiformia, quam lamina breviora. Antherae sagittatae, biloculares, erectae; loculis rima longitudinali marginali dehiscentibus. 0varium triloculare, superum. Styli 3 , ad basin liberi, stigmatibus parvis terminati, perigonii foliolorum unguem subsuperantes. - Flores albi, leviter carneo tincti. Perigonii foliolorum lamina plurinervia, recurvato-patens.

Bulbocodium trigynum Adam, cui planta nostra proxima, differt: «foliis sub anthesi flore lilacino brevioribus, perigonii foliolorum exteriorum lamina basi in unguem attenuata (nec sagittata)».

In Caucaso orientali prope Baku legit $\mathrm{Cl}$. Eichler.

\section{Calathea Lietzi E. Morr.}

Glaberrima. Caules circiter $40 \mathrm{Cm}$. alti, teretes, violascentes, basi foliorum vaginis involuti, apice articulo florifero foliiferoque instructi. Folia basilaria longe petiolata, terminalia brevius petiolata; omnia oblongo-lanceolata v. elliptico-oblonga, undulata, supra laete viridia metallice nitentia fasciis penniformibus saturate viridibus picta, subtus violaceo-purpurascentia, $10-14 \mathrm{Cm}$. longa, $3-5 \mathrm{Cm}$. lata. Florum spica in articulo terminali caulis solitaria, axillaris, breviter pedunculata, compressiuscula, e bracteis 3 distichis herbaceis amplectentibus in 
apicem patente-subrecurvum breviter acuminatis composita. Flores in bractearum axillis gemini. Sepala 3, anguste lanceolata, merlio virescentia, margine transparente-albida, corollae tubum subaequantia. Corolla alba, bracteam superans, tubo gracili, limbi triparti lobis lanceolatis acutis. Staminodinm externum unicum. Ovarium triloculare, loculis omuibus fertilibus.

C. Lietzi E. Morr. in Belg hort. 1875. p. 273. tab. XV-XVII. fig. 8. (folium tantum sine descriptione).

\section{Calathea medio-picta.}

Acaulis. Folia omnia radicalia. Petiolus 8-16 poll. longus, sub lente pilis brevissimis vix conspicuis bifidis v. stellatis adpressis munitus, inferne in 'vaginam compresso-teretem ampliatus, apice articulo $1-1 \frac{1}{2}$ pollicari terminatus. Lamina oblongo-elliptica, breviter acuminata, basi acuta glaberrima, $8-12$ poll. longa, $31 / 2-5$ poll. lata; supra laete viridis, nitida, nervis lateralibus numerosis prominentibus subplicata, stria albida utrinque secundum costam mediam ornata; subtus pallide viridis. Pedunculus radicalis, aphyllus, glaber, 5-6 pollices longus, spica densa subglobosa subpollicari terminatus. Bracteae albidae violaceo suffusae, late orbiculatae, in apicem squarroso-patentem acuminatae, glabrae. Flores violacei, bracteas superantes. - Maranta medio-picta h. Makoy. - Crescit in Brasilia.

\section{Keitia Rgl.}

(Iridearum genus novum). Tribus Galaxideae Baker. (Perianthium regulare, segmentis interioribus exterioribus consimilibus. Herbae bulbosae staminibus aequilateris basi connatis).

Perianthium regulare, supra basin sexpartitum; phyllis patentibus obovatis, interioribus paullo minoribus caeterum consimilibus. Stamina 3, ima basi corollae inserta; filamenta e basi latiore sensim attenuata, plano-compressa, basi tantum connata, sursum libera; antherae linearioblongae, biloculares, basi bifidae, erectae, basifixae; loculis rima lon- 
gitudinali dehiscentibus. - 0varium inferum, triloculare; loculis multiovulatis. Styli supra basin trifidi rami lineares, plani, glabri, integri v. rarius ramulus unicus ad medium bifidus. - Herba bulbosa glabra natalensis, caulescens. Caulis vix spithamaeus, 4-5-phyllus; folia ensiformia, decrescentia, inferius v. dua inferiora solitaria, superiora tria in apice caulis ronferta alterna subspathiformia, supremum minimum. Flores dense spicati. Spicae pedunculatae, axillares, ovatae, spath bivalvi suffultae. Spathae phylla herbacea, ovata, amplexicaulia, spicam involventia. Bracteae ovato-lanceolatae, membranaceo-hyalinae, pedicellos paullo superantes. Pedicelli uniflori, in bractearum axilla solitarii.

4. Keitia natalensis $R g l$.

Folium inferius $16-20 \mathrm{Cm}$. longum, circiter $1 \frac{1}{2} \mathrm{Cm}$. latum, basi in vaginam amplexicaulem attenuatın, apice attenuato-acutum. Folia superiora valde inter se approximata, subopposita, spathiformia, inferioribus pluries minora, supremuin minimum $1 / 2-3 / 4 \mathrm{Cm}$. longum. Spathae phylla circiter $1 \frac{1}{2} \mathrm{Cm}$. longa Bracteae arcte imbricatae, spatham paullo superantes. Flores exserti; sepalis albis, tenuissimis, obovatis, circiter $1 \mathrm{Cm}$. longis et $1 / 2 \mathrm{Cm}$. latis.

Ex Africae provincia Natal a Haage et Schmidt introducta.

\section{Spathiphyllum Walisi Rgl.}

Petiolo vaginato, apice tantum tereti; lamina oblongo-lanceolata, basi rotundata $v$. cuneata in geniculum longiusculum decurrente, apice sensim cuspidata, margine plus minus crispulo-crenulata; venis arcuatoadscendentibus, intervenio univenuloso; spatha oblongo-elliptica, basi rotundata in pedunculum decurrente, apice longe acuminato-cuspidata; spadice cylindrico, brevi, quam spatha triplo breviore, stipite subpollicari sub ad apicem spathae adnato suffulto, parte florigera stipitem circiter aequante; ovario conico sepala inter se libera apice truncata longe superante.

Petioli $12-20 \mathrm{Cm}$. longi. Lamina $1 \ddot{z-24}$ ('m. longa, $4-6 \mathrm{Cm}$. 
lata, laete viridis. Pedunculus teres, foliis paullo brevior. Spatha $14 \mathrm{Cm}$. longa, $4 \frac{1}{2} \mathrm{Cm}$. lata, laete viridis. Pars florigera spadicis vix $3 \mathrm{Cm}$. longa.

Affinis species S. lanceaefolium Schott, differt: "foliis angustioribus margine crispule crenulatis, intervenio univenuloso (nunquam trivenuloso), spadice quam spatha triplo breviore».

Plantam vivam $\mathrm{Cl}$. Wallis e Venezuelae regionibus inontanis attulit. 
F. SALSOLACEARUM NOVARUM IN TURKESTANIA INDIGENARUM DESCRIPTIONES, auctore A. Bunge.

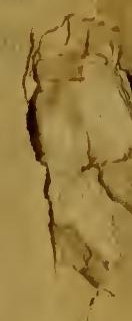

1. Atriplex serpyllifolium, n. sp

A. annuum, canescens, a basi ramosum, ramis gracilibus erectis adscendentibus, foliis subsessilibus integerrimis, inferioribus minutis orbiculato-obovatis cartilagineo marginatis cuspidatis, superioribus majoribus oblongis cuspidatis, summis linearibus muticis saepe complicatis, floribus femineis axillaribus paucis minutis, sepalis herbaceis laevibus integris utriculum aequantibus, masculis in spicas basi interruptas glomeratis, rostello adscendente

Hab. in deserto Kirghisorum ad litora salsuginosa fl. Tschu (Schrenk!), in deserto aralo-caspico Ust-urt in argillosis ad fl. Tschegon (Borsczow. no. 506!).

Herba 8-12 pollices alta, basi in ramos plures interdum oppositos divisa, ramis superne parce ramulosis. Folia inferiora circiter $2^{\prime \prime \prime}$ longa, $1^{3} / 4^{\prime \prime \prime}$ lata, circumcirca margine tenui cartilagineo cincta, basi breviter attenuata subsessilia, intermediis ramis sensim majora 5-6"' longa medio $3^{\prime \prime \prime}$ lata utrinque angustata, summa et ramulorum linearia usque ad 7'" longa et vix lineam lata. In speciminibus Schrenkianis flores femineos frustra quaesivi; in Borsczowiano sub finem mensis Septembris collecto perpaucos calyces fructiferos vidi in axillis foliorum sub spiculis masculis solitarios minimos, sepalis ut videtur integerrimis fere ad medium connatis olitusis et vix utriculum superantibus. Styli breviter exserti. De 
rostelli situ in unico fructu maturo certiorem me facere haud contigit. Florum masculorum glomeruli in spicas semipollicares vel parum longiores dispositi, globosi, linea in diametro paulo majores, $2-3$ infimi remotiusculi, caeteri arcte congesti

\section{Borsczowia. Il. gen Suedearum.}

Flores abortu monoici; masculi parcissini, quinquepartiti, sepalis ${ }_{0}^{1}$ btusis vix cucullatis. Stamina perigyna 5 . Antherae subglobosac didymae; ovarium abortivun liberum elongato-lagenaeforme, apice dilatatum; stigmata duo rudimentaria. Flores feminei numerosissimi, heteromorphi. Calyx florum minorum subpyriformis, minutissime obtuse $3-5$-dentatus, ovario adnatus, plus minusve increscens obovoideo - subpyriformis compressissimus. Staminum vestigia nulla. 0varium fere ex toto calyci adnatunn. Styli tres, breves, exserti. Pericarpium cum calyce coalescens, tenuissinuin. Semen florum minorum erectum, verticale, obovatum, margine acutum, tumidum, integumento crustaceo vix conspicue areolato. Embryon flavescenti-albidum, albumine parcissimo utrinque lateribus applicato. Semen florum majorum valde compressum, verticale, integumento membranaceo duplici opaco. Embryon spirale viridulum, vix albuminosum, rostello cotyledonibus duplo longiore.

2. B. aralo-caspica Bnge. Hab. in deserto aralensi. (Borsczow!).

Glaberrima, annua. Caulis albescens, lucidus, fragilis a basi ramosus, ramis inferioribus oppositis, caeteris sparsis, omnibus apice florigeris. Folia crassa semiteretia, inferiora pollicaria, vix lineam crassa, basi parum attenuata obtusa. Glomeruli axillares, omnino sessiles. Bracteolae minutae, hyalinae. Flores in glomerulo $3-5$ vel plures, masculi et feminei minores erecti, feminei majores nutantes; rarissime occurrunt flores intermedii inter has duas formas, at semen in his omnino ut in floribus minoribus, testa crustacea lucida.

3. Halimocnemis longifolia Buge. H. macranthecae affinis, sed antherae loculi lineam tantum longi, appendicula arcuata $1 / \mathbf{4}^{\prime \prime \prime}$ longa. 
Hab. prope Taschkent. (Kuschakewicz).

Scheint mir eine neue Art zu sein, ist aber noch viel zu jung, um genau bestimmt zu werden, passt aber zu keiner der bekannten Arten. Wegen des jugendlichen Zustandes kann aber keine Diagnose und keine genügende Beschreibung gegeben werden.

\section{Halimocnemis Smirnowii Bnge.}

Breviter villoso-canescens, bracteolis flore 4-mero (?) multo longioribus a calyce fructifero basi profunde impresso-truncato liberis, calycis parte indurata glaberrima, antheris ....?

Hab. ad fl Amu-Darja cum Alhagi camelorum. 30 Julii fructifera. (Smirnow).

Frustula collecta pauca, fructifera, sine antheris haud rite determinanda. Affinis Halim. macrantherae, sed distincta floribus ut videtur tetrameris multo brevioribus, et parte calycis indurata glaberrima.

5. Piptoptera. nov. gen.

Anabaseae, Halimocnemideae, Halarchontes, Physandreae (Bunge. Anabasearum revisio p. 19 in Mlém. Acad. Pétersb. VII. ser. IV. № 11). Clavis generum dichotoma l. c. data, ad novum genus recipiendum ita disponenda :

9. Rostellum suprum. 10.

10. Sepala calycis fructiferi basi indurato-connata 11.

11 a. Duo exteriora appendiculata. $11 \mathrm{~b}$.

11 b. Sepala 2 latissime alata, alis articulatim deciduis. Piptoptera. Sepala 2 auriculato-gibba, gibbis cartilagineis persistentibus. Halotis.

Character essentialis: Sepala 5, anticum et posticum trinervia, interiora tria enervia, omnia basi tunc indurata connata, in fructu duo exteriora latissime membranace0-alata, alis tunc demum articulatim secedentibus, thecam relinquentibus a latere subcompressam 6-costatam 
supra medium biauriculatam sepalorum apicibus conniventibus coronatam, diutius persistentem. Staminodia nulla. Antherae membranaceo-appendiculatae. Stylus bicruris, cruribus subulatis conniventibus. Rostelli apex superus.

Char. naturalis: Flores omnes hermaphroditi, bibracteolati, solitarii, sparsi. Sepala 5, parum increscentia et duo exterio:a valde indurata, basi connata, in alas duas latissimas supra medium excrescentia, alis articulatim solutis, parte basilari cum fructu diutius persistente Staminodia nulla, discus vix ullus Stamina 5, filamenta linearia. Antherae minutae loculis basi discretis, connectivo producto in vesiculam conicam acutiusculam loculos subarquantem. Frutex habitu Salsolae, ramosissimus, pube brevi hispidulus, foliis ramisque sparsis.

Species unica: P.turkestana Bnge.

Hab. in argilloso-salsis Schurachan, prope fortalitium Petro-Alexandrowsk (horolkuw et lirause!) Aug. 1873 fructifera.

Prostant specimina pauca ut videtur rami unius fruticuli $1 / 2-1$ pedales fructibus maturis et maturescentibus onusti. Rami basi $2-3^{\prime \prime \prime}$ in diametro crassi, ligno durissimo, medulla conspicua, hispiduli, parum flexuosi, ramosissimi. Ramuli tripollicares vel summi breviores, a basi florigeri, divaricato-patentes, saepe iterum ramulosi. Folia superiora subtrigona, carnosa, ad summum $3^{\prime \prime \prime}$ longa, reversa, subpungenti-acuminata ; subfloralia breviora, e basi late ovata, late membranaceo-marginata, acutata et pungentia, tunc demum saepius hebetata. Bracteolae illis longiores, caeterum similes, e basi late ovata concava acuminato-trigonae, apice intus sulcatae, extus carinatae, pungenti-acutatae, arcte calyci applicitae nec cum illo connatae persistentes. Calyx peracta anthesi $3^{\prime \prime \prime}$ longus, a lateribus parum compressus, parce praesertim apice sericeo-pubescens, basi fere glabratus. Sepala anticum et posticum subnavicularia, tenuissime trinervia, tria interiora multo angustiora plana, omnia acuta. In dorso sepalorum exteriorum vix peracta anthesi oriuntur alae, in planta exsiccata atrofuscae, initio profunde bilobae cum nervo medio formam literae $\mathrm{r}$ ostendunt, tunc valde excrescentes tenue membranaceae subhyalinae $6-7^{\prime \prime \prime}$ in diametro, 
fructu maturo deciduae, nempe a basi cartilaginea auriculam circulares in calyce fructifero formante articulatim semi circulo solutae nec disrupta€ Pars sepalorum inferior basi coalescens in thecam clausam, basi trun catam obscure 5-foveolatam, longitudinaliter acute sexcostatam, sepa lorum apicibus liberis in conum conniventibus superatam. Filament tenue linearia, ad basin usque libera, disco saltem in flore deflorato vis. ullo. Antherae (e rudimentis tantum notae) cum appendicula vix ultra $3 / 4^{\prime \prime \prime}$ longae, anthera ipsa oblique cordata basi breviter oblique biloba 0,4 '!' longa, appendicula anthera angustior sublanceolata obtusiuscula $0,3^{\prime \prime \prime}$ 1. 0varium a latere compressum, orbiculari-ovatum, sensim in stylum ad basin usque bipartitum attenuatum. Styli rami stricti, subulati invicem appliciti. Utriculus cum stylis persistentibus $3^{\prime \prime \prime}$ longus, $\mathbf{1}^{1} \mathbf{2}^{\prime \prime \prime}$ latus, fusco-violaceus, succo violaceo parco repletus. Rostellum duplicen fere gyrum absolvens apice adpresso basi styli approximato. Cotyledones breves. Plumula minuta diphylla. 
s 

